\title{
ANÁLISE TOMOGRÁFICA QUANTITATIVA LINEAR DE ESPESSURAS ÓSSEAS ALVEOLARES COM VISTAS AO DIAGNÓSTICO EM ORTODONTIA
}

- PROPOSTA DE MÉTODO -

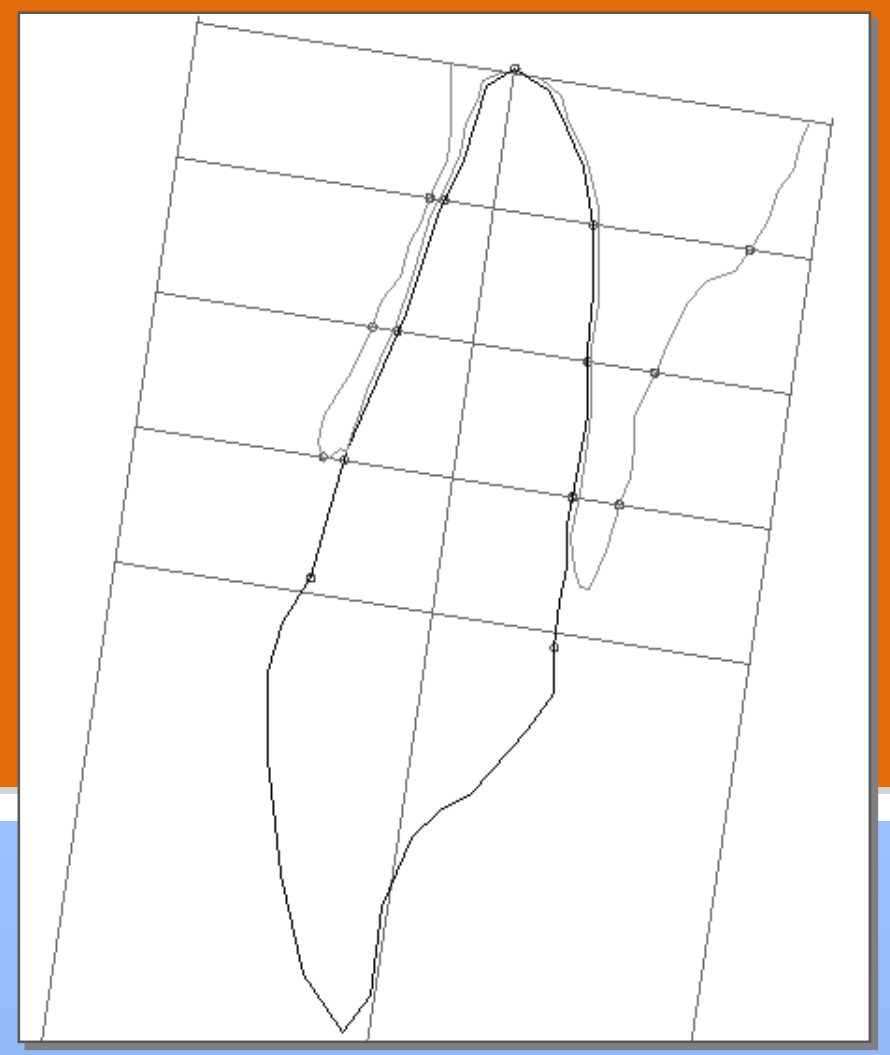




\section{SIDDHARTHA UHRIGSHARDT SILVA}

Análise tomográfica quantitativa linear de espessuras ósseas alveolares com vistas ao diagnóstico em Ortodontia - proposta de método

\section{Versão Corrigida}

Tese apresentada ao Departamento de Ortodontia e Odontopediatria da Faculdade de Odontologia da Universidade de São Paulo, para obtenção do título de Doutor em Ciências Odontológicas.

Área de Concentração: Ortodontia Orientador: Prof. Dr. Jorge Abrão

São Paulo 
Autorizo a reprodução e divulgação total ou parcial deste trabalho, por qualquer meio convencional ou eletrônico, para fins de estudo e pesquisa, desde que citada a fonte.

Silva, Siddhartha Uhrigshardt

Análise tomográfica quantitativa linear de espessuras ósseas alveolares com vistas ao diagnóstico em ortodontia : proposta de método / Siddhartha Uhrigshardt Silva; orientador Jorge Abrão. -- São Paulo, 2012.

269 p. : fig., tab.; $30 \mathrm{~cm}$.

Tese (Doutorado) -- Programa de Pós-Graduação em Ciências Odontológicas. Área de Concentração: Ortodontia. -- Faculdade de Odontologia da Universidade de São Paulo.

Versão corrigida.

1. Osso e ossos - Avaliação. 2. Processo alveolar - Diagnóstico. 3. Tomografia - Análise quantitativa. 4. AutoCAD. 5. Metrologia. I. Abrão, Jorge. II. Título. 
Silva SU. Análise tomográfica quantitativa linear de espessuras ósseas alveolares com vistas ao diagnóstico em Ortodontia - proposta de método. Tese apresentada à Faculdade de Odontologia da Universidade de São Paulo para obtenção do título de Doutor em Ciências Odontológicas.

Aprovado em: 01, $06,2012$.
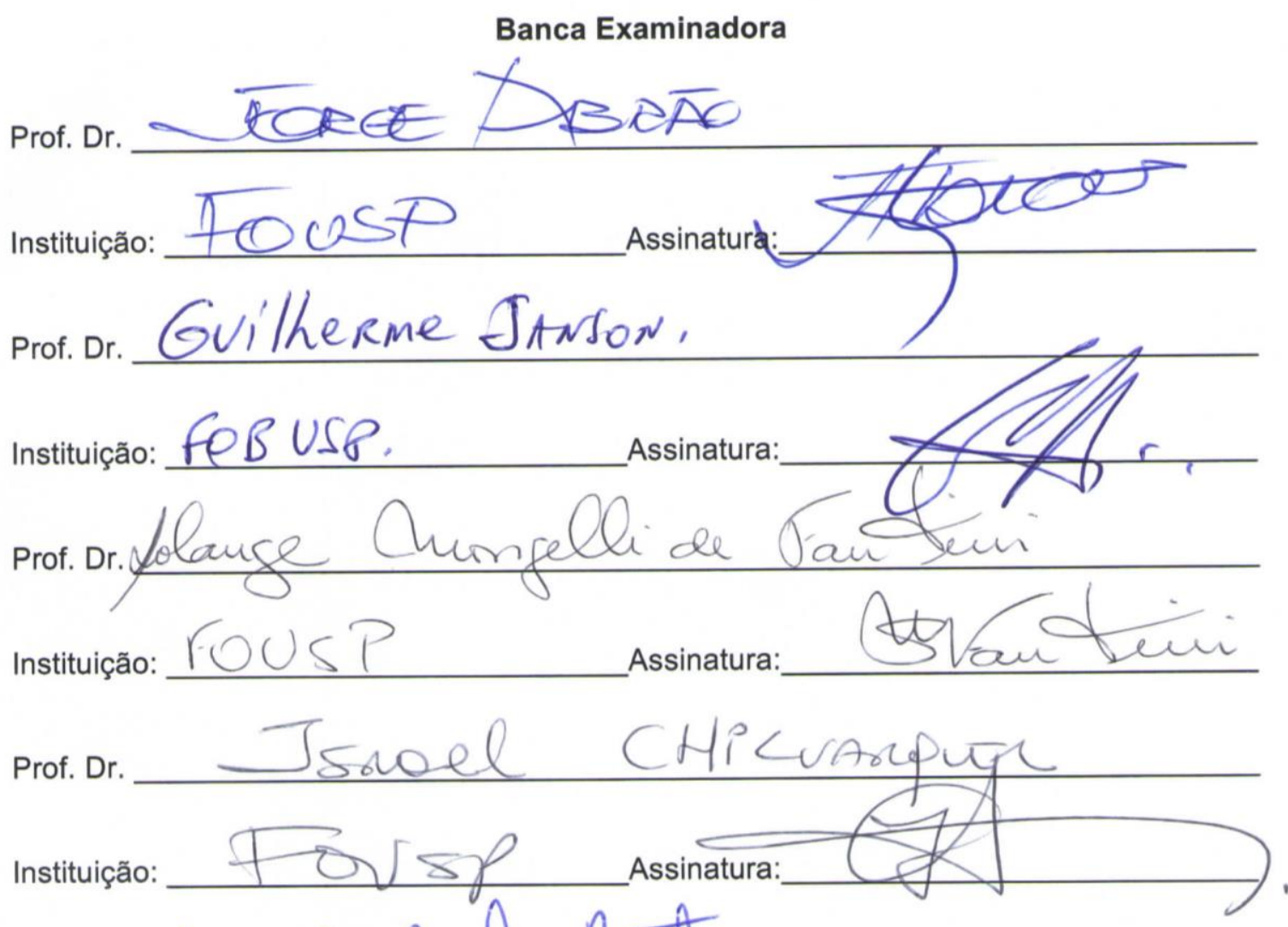

Prot. Dr. Any dos Sarten Pute

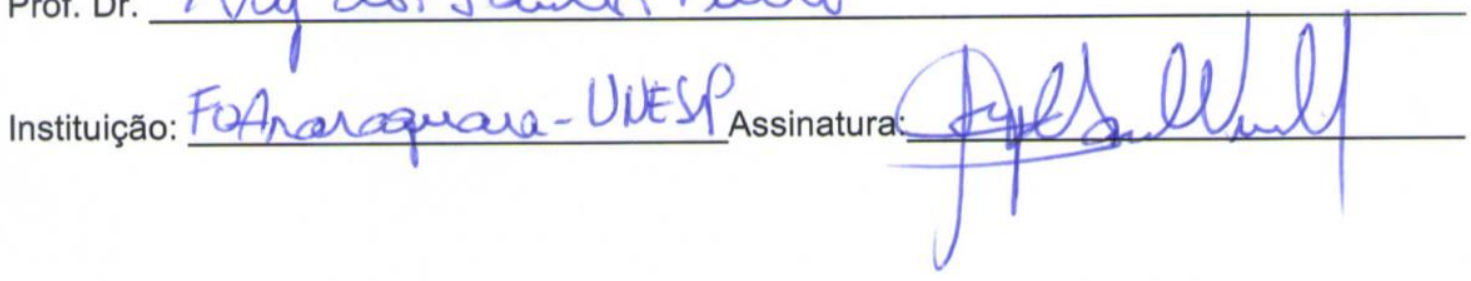


Dedico esta obra aos meus pais, Francisco Miguel Roberto Moraes Silva e Glenda Mara Uhrigshardt Silva, pelo exemplo único de ser, da essência de todos os valores às lições de companheirismo, dedicação, respeito, família e, é claro, infindável amor!

Todo agradecimento ainda será pouco.

Seu exemplo é singular, perene e repleto de força, integridade e doação!

seu filho. 


\section{AGRADECIMENTO ESPECIAL}

Ao meu orientador e amigo, Jorge Abrão, Professor Doutor, Livre-Docente do Departamento de Ortodontia e Odontopediatria da FOUSP, pelo agradável convívio nestes anos de muito empenho e esforço, mesmo em épocas difíceis, e pela incomensurável paciência dedicada aos meus deveres, projetos, saberes, dúvidas, soluções e direções.

Sua solidariedade e incentivo foram essenciais ao desenvolvimento desta obra.

Muito obrigado por acreditar e agregar sabedoria. 


\section{AGRADECIMENTOS}

A todos os meus familiares, especialmente: à minha tia, Marília Ulrike Reydams, pela paciência, solidariedade e constante interesse pelos acertos conquistados a partir do esforço empreendido, bem como aos meus tios Carlos Eduardo Moraes Silva e Cecília Moraes Silva, pela elevada paciência, tolerância e calorosa acolhida na "Terra da Garoa". Muito obrigado!

À minha irmã, Samantha B. Uhrigshardt Silva, bem como à Srta. Patricia Soria, pelo valioso auxílio durante a operacionalização e busca de soluções referentes ao programa AutoCAD ${ }^{\circledR}$.

À Dra. Márcia Olandoski (PUC-PR), bem como ao Prof. Ary Elias Sabbag Junior (UFPR), pelo empenho e eficiência profissional dedicados à análise estatística, em seus ajustes técnicos e sugestões interpretativas, requisitos estes considerados essenciais diante da natureza desta obra.

A todos os meus amigos do curso de Pós-Graduação, tanto àqueles em que a amizade já venceu o tempo, como também aos novos, ainda em fase de teste, obrigado pela amizade, respeito e solidariedade!

Aos amigos e colegas Professores dos Cursos de Pós-Graduação, UTP/ILAPEO e ABO/SJP, Augusto Ricardo Andrighetto, Ana Cláudia Melo, Isabela Almeida Shimizu, Marcos André Duarte da Silva, Ricarda Duarte da Silva, Roberto Hideo Shimizu que, mesmo não sabendo e influenciando diretamente os efeitos desse trabalho de pesquisa, colaboraram, e muito, com incentivo, amizade, respeito e solidariedade. Obrigado a todos!

Aos meus colegas (da 5 $5^{\underline{a}}$ Turma de Doutorado), Ana Cristina Soares, Fábio Vigorito, Fernando Penteado, Soo Kim, Priscilla Chibebe, Tarcila Trivino, pela 
amizade, companheirismo, respeito e pelas vitórias, pessoais e profissionais, durante essa longa etapa. Muito obrigado. Meu privilégio!

Aos amigos Milton Missaka e Maurício Accorsi pela disposição e paciência com parte dos testes preliminares da Fase II desta pesquisa ("incertezas de software").

Aos meus colegas (da 19a Turma de Mestrado), Annelise Cunha, Luiz Vicente de Moura Lopes, Edson Illipronti e, em especial, à Carolina Pedrinha, pelo interesse, doação, solidariedade e auxílio valioso em diversas situações durante a busca pelos melhores resultados associados à qualidade tomográfica. Seu auxílio e comprometimento foram indispensáveis.

Aos amigos André Abrão, Miguel Ferragut, Gustavo Watanabe e Hiroshi Miasiro pela amizade e companheirismo, sempre presentes.

Ao Sr. Marcos Alipio Dantas Ramos do Serviço de Edição e Impressão pela amizade, competência e disponibilidade.

Aos amigos e colegas Annelise Cunha, Carolina Pedrinha, Priscilla Chibebe, Fernando Penteado, Luiz Vicente Lopes e Tiago Zanet pela paciência, disponibilidade e interesse durante os testes da Fase III da pesquisa.

Ao amigo Luiz Vicente de Moura Lopes, pelo agradável, respeitoso e sempre solícito convívio!

Aos funcionários da FOUSP, sempre presentes diante dos desafios da rotina do Departamento, especialmente às amigas Viviane T. Passiano, Edina Brito, Marinalva de Jesus ("Nalvinha" e seu indispensável café), Ronaldo, Edilson e, ainda, Marize de Paiva, Fátima e Julio.

À Srtas. Glauci E. Fidelis, Vânia Funaro e Maria Claudia Pestana, do Serviço de Documentação da Biblioteca, pela atenção e eficiência durante a revisão normativa deste trabalho. 
À Coordenação de Aperfeiçoamento de Pessoal de Nível Superior (CAPES) pelo auxílio-bolsa durante o Doutoramento;

Aos Professores de Odontopediatria deste Departamento, especialmente ao Prof. Dr. Marcelo J.S. Bönecker (Titular), pelo incentivo e solidariedade;

Ao Professor Doutor João Batista de Paiva, Professor Titular do Departamento de Ortodontia e Odontopediatria da FOUSP, pela amizade pessoal, incentivo e oportunidade;

Ao Professor Doutor (Titular) Julio Wilson Vigorito, pela forte amizade, respeito e, por uma vez mais e com toda a equipe de Professores, terem decidido pela minha participação no Programa de Pós-Graduação deste respeitável Departamento. Muito obrigado!

Aos Drs. Marcos Leal Brioschi, Lin Tchia Yeng e Francisco M. R. M. Silva por terem acreditado e referendado minha participação ao Programa de Pós-Graduação do Departamento de Ortodontia e Odontopediatria da FOUSP. Muito obrigado!

Aos Professores do Departamento de Ortodontia e Odontopediatria da FOUSP, André Tortamano, Gladys Cristina Dominguez-Morea, João Batista de Paiva, Jorge Abrão, José Rino Neto, Julio Wilson Vigorito, Lylian Kanashiro e Solange Mongelli de Fantini, pela valiosa oportunidade de aprendizado e contribuição, evolução humana, respeito, carinho e amizade. As lições estão sendo aprendidas! Muito obrigado!

À Professora Doutora Solange Mongelli de Fantini, pela oportunidade primeira de orientação, aconselhamento e valioso respeito; pela paciência e atenção aos detalhes que fazem, sempre, a diferença. Obrigado!

Ao Professor Emérito Sebastião Interlandi, pelas agradáveis conversas, quase sempre curtas em duração, mas plenas de experiência e significado. Sua dedicação, doação, perseverança e influência ajudaram a formar o impulso inspirador desta obra. Muito obrigado! 
Em especial:

Ao amigo Tiago Gorgulho Zanet, pela paciência, amizade, comprometimento e doação incondicional durante à realização das sequências tomográficas (teste e definitiva) relativas à etapa radiológica (Fase $I$ ) deste trabalho, bem como pela sua singular participação, especializada e didática, durante a realização dos testes de medida preliminares e, finalmente, dos testes finais de reprodutibilidade das medidas (Fase III). Sua participação foi por demais valiosa, essencial! Muito obrigado!

Ao Professor José Rino Neto, pela amizade, respeito e solidariedade diante da crítica tarefa de decidir pela direção da presente investigação, bem como por ter prontamente aceitado o convite de co-orientação a esta Linha de Pesquisa, oferecendo apoio irrestrito à utilização do Acervo Tomográfico dos grupos de pacientes da Disciplina de Cirurgia Ortognática do Departamento de Ortodontia e Odontopediatria desta Faculdade. Muito obrigado!

Ao amigo Israel Chilvarquer, Professor Associado do Departamento de Radiologia da FOUSP, pela inestimável ajuda com a concessão de uso tanto do espaço físico, quanto do tempo e da assistência profissional dos funcionários do INDOR/FUNDECTO, possibilitando o uso imediato e irrestrito das documentações, arquivos e equipamentos, incluindo o tomógrafo iCAT ${ }^{\circledR}$ e estação de trabalho utilizados nesta pesquisa. Sua solidariedade, amizade, incentivo, respeito e participação, tecnicamente perfeita, oportuna e didática, propiciaram as boas oportunidades e, principalmente, a possibilidade de livre escolha dos melhores caminhos neste projeto. Muito obrigado!

...e, ainda mais que especial,

À querida Patricia Fabris Ferreira da Costa, companheira inestimável, pela imensa paciência e respeito durante esses anos quando, mesmo sem entender sequer uma medida realizada, uma letra impressa ou mesmo um desabafo, procurou, sempre, entender o valor desse intenso esforço, tomando pra si, em 
contido silêncio, o ônus de toda a distância e ausência. Com verdadeiro e sincero amor Ihe agradeço, e muito! 
Persons of the Dialogue: Socrates, who is the narrator; Glaucon; Adeimantus; Polemarchus; Cephalus; Thrasymachus; Cleitophon; And others who are mute auditors. The scene is laid in the house of Cephalus at the Piraeus; and the whole dialogue is narrated by Socrates the day after it actually took place to Timaeus, Hermocrates, Critias, and a nameless person, who are introduced in the Timaeus

" ...I will explain: the body which is large when seen near, appears small when seen at a distance? True.

And the same object appears straight when looked at out of the water, and crooked when in the water; and the concave becomes convex, owing to the illusion about colours to which the sight is liable. Thus every sort of confusion is revealed within us; and this is that weakness of the human mind on which the art of conjuring and of deceiving by light and shadow and other ingenous devices imposes, having an effect upon us like magic.

True.

And the arts of measuring and numbering and wheighing come to the rescue of the human understanding - there is the beauty of them - and the apparent greater or less, or more or heavier, no longer have the mastery over us, but give way before calculation and measure and wheight?

Most true.

And this, surely, must be the work of the calculating and rational principle in the soul?

To be sure.

And when this principle measures and certifies that some things are equal, or that some are greater or less than others, there occurs an apparent contradiction?

True.

But were we not saying that such a contradiction is impossible - the same faculty cannot have contrary opinions at the same time [603] about the same thing?

Very true.

Then the part of the soul which has an opinion contrary to measure is not the same with that which has an opinion in accordance with measure?

True.

And the better part of the soul is likely to be that which trusts to measure and calculation?

Certainly.

And that which is opposed to them is one of the inferior principles of the soul?

No doubt.

The Dialogues of Plato

The Republic [X],- Book X p.431

Translated by Benjamin Jowett ENCYCLOPÆDIA BRITANNICA, INC. 1993 


\section{RESUMO}

Silva SU. Análise tomográfica quantitativa linear de espessuras ósseas alveolares com vistas ao diagnóstico em Ortodontia - proposta de método [tese]. São Paulo: Universidade de São Paulo, Faculdade de Odontologia; 2012. Versão Corrigida.

O objetivo principal nesta pesquisa foi justificar a proposta de utilização de um novo método tomográfico (cone beam) de avaliação das espessuras ósseas alveolares, maxilares e mandibulares, por meio de testes objetivos das Condições de Repetitividade e de Precisão Intermediária associadas à variação intra e interoperadores, e conforme a utilização de programa computacional independente $\left(A u t o C A D^{\circledR}\right)$ para a realização das medições, aplicadas à sequência do Procedimento Operacional Padrão (POP) definido para este experimento. A Fase I da pesquisa registrou os critérios de obtenção da qualidade final das imagens tomográficas definitivas, a partir de equipamento iCAT ${ }^{\circledR}$ (Imaging Sciences International, Hatfield, $\mathrm{Pa}$ ), com parâmetros de aquisição de $120 \mathrm{kVp}, 37,7 \mathrm{~mA}$ e 26,9s, e considerando FOV cilíndrico de $13 \mathrm{~cm}$ e matriz de $512 \times 512$ pixels. A resolução do voxel foi de 0,25mm; A Fase /l registrou os critérios exploratórios relativos às condições operacionais do software de visualização, registro (inspeção e identificação) e medição das grandezas selecionadas. A Fase III registrou a realização dos testes de repetitividade e de reprodutibilidade das medidas. Um total de 72 grandezas lineares foram previamente definidas e metodologicamente testadas em sua qualidade de inspeção, identificação e medição, a partir da avaliação de sete (7) operadores independentes, cinco dos quais eram especialistas e com Mestrado Acadêmico em Ortodontia pela FOUSP e, o outro, especialista em Radiologia Odontológica e Doutor em Diagnóstico Bucal (FOUSP). Os examinadores foram previamente instruídos e treinados considerando os requerimentos necessários à execução dos testes propostos. O protocolo de pesquisa foi aprovado pelo Comitê de Ética em Pesquisa da Faculdade de Odontologia da Universidade de São Paulo (Parecer 102/11-CAAE 0120.0.017.000-11). A análise estatística dependeu da utilização de Modelo de Componentes de Variância (hierárquico), e foram consideradas como fontes de variação: as medidas, efetuadas por um mesmo 
operador ou por diferentes operadores; a face considerada, vestibular ou lingual/palatina; os locais (três níveis de espessura óssea alveolar) em cada uma das faces e, ainda, os diferentes dentes. Esta análise foi realizada de forma separada para mandíbula e maxila. Valores de $p<0,05$ indicaram significância estatística. Os resultados indicaram significativa confiabilidade geral no método proposto, considerando a Condição de Repetitividade, com apenas $0,24 \%$ da variabilidade maxilar total atribuível a um único operador, e mandibular de 0,53\%; e com valores expressivos relativos às incertezas de medida maxilares $(0,156 \mathrm{~mm}) \mathrm{e}$ mandibulares $(0,091 \mathrm{~mm})$, desse modo atestando significativa consistência interna ("repetibilidade") do método. Os testes da Condição de Precisão Intermediária também indicaram significativa confiabilidade geral no método proposto, com apenas $1,52 \%$ da variabilidade total mandibular atribuível à participação de diversos operadores, e maxilar de $0,25 \%$; e com valores também expressivos relativos às incertezas de medida mandibulares $(0,149 \mathrm{~mm})$ e maxilares $(0,158 \mathrm{~mm})$, desse modo atestando significativa condição final de "reprodutibilidade". Conclui-se que a utilização de imagens provenientes de tomógrafo $i C A T^{\circledR}$, conforme indicação de resolução de imagem com voxel de $0,25 \mathrm{~mm}$, em humanos vivos e a partir de cortes trans-axiais sistematicamente operacionalizados com auxílio de Software AutoCAD ${ }^{\circledR}$, propicia a geração de condições metodológicas suficientemente favoráveis à obtenção de mapeamento quantitativo linear de espessuras ósseas alveolares, vestibulares e palatinas/linguais, tanto para a maxila quanto para a mandíbula.

Palavras-chave: Osteologia. Espessuras ósseas alveolares. Ortodontia. Método tomográfico. Tomografia computadorizada de feixe-cônico (TCFC/cone-beam). Software AutoCAD ${ }^{\circledR}$. Confiabilidade Científica. Metrologia aplicada. 


\begin{abstract}
Silva SU. A quantitative linear tomographic analisys of the alveolar bone thicknesses and its implications to diagnosis in Orthodontics - A method proposal [thesis]. São Paulo: Universidade de São Paulo, Faculdade de Odontologia; 2012. Versão Corrigida.
\end{abstract}

This research aimed to justify the proposed use of a new tomography method (cone beam) in the clinical assessment of alveolar, maxillary and mandibular bone width, through objective tests of the Conditions of Repetitiveness and Intermediate Precision associated with intra- and inter-operator variation, using the independent computer program (AutoCAD ${ }^{\circledR}$ ) for the execution of the measurements according to the Standard Operating Procedure (SOP) sequence defined for this experiment. Phase I of the research recorded the criteria for obtaining the final quality of the tomography images, using $\mathrm{iCAT}^{\circledR}$ (Imaging Sciences International, Hatfield, Pa, USA) equipment with acquisition parameters $120 \mathrm{kVp}, 37.7 \mathrm{~mA}$, and $26.9 \mathrm{~s}$, and considering cilindric field-of-view (FOV) of $13 \mathrm{~cm}$ and $512 \times 512$ pixels matrix. The voxel resolution was $0.25 \mathrm{~mm}$. Phase // recorded the exploratory criteria relative to the operational conditions of the visualization software, registry (visual inspection and landmark identification) and measurement of the selected magnitudes. Phase III recorded the tests of repeatability and reproducibility of the measurements. A total of 72 linear magnitudes were previously defined and methodologically tested for their quality of inspection, identification and measurement, based on assessment by seven (7) independent examiners, five of whom were specialists, with masters' degrees in Orthodontics; and the other, a specialist in Dental Radiology and Doctor of Oral Diagnosis. The examiners were previously instructed, calibrated and trained according to the requirements for performing the proposed tests. The research protocol was approved by the Committee for Ethics in Research of the Faculty of Dentistry at the University of São Paulo (Protocol \# 102/11-CAAE 0120.0.017.00011). Statistical analysis used the (hierarchical) Components of Variation Model, and the sources of variation were considered to be: the measurements, made by the same operator or by different operators; the face considered, whether vestibular or 
lingual/palatal; the locations (three levels of alveolar bone thickness) in each of the faces and, also, the different teeth. This analysis was carried out separately for the mandible and the maxilla. Values of $p<0.05$ indicated statistical significance. The results indicated overall significant reliability in the proposed method considering the Condition of Repetitiveness, with only $0.24 \%$ of total maxillary, and $0.53 \%$ of mandibular, variability attributable to a single operator; and with expressive values relative to measurement uncertainties of maxillary $(0.156 \mathrm{~mm})$ and mandibular $(0.091 \mathrm{~mm})$ averages, thereby attesting to significant internal consistency ("repeatability") of the method. Tests for the Condition of Intermediate Precision also indicated overall significant reliability of the proposed method, with only $1.52 \%$ total mandibular, and $0.25 \%$ maxillary, variability attributable to the participation of the various operators; and, also, with expressive values relative to measurement uncertainties of mandibular $(0.149 \mathrm{~mm})$ and maxillary $(0.158 \mathrm{~mm})$ averages, thereby attesting to the significant final condition of reproducibility. It is concluded that the use of images from iCAT ${ }^{\circledR}$ tomography, as indicated by image resolution with voxels of $0.25 \mathrm{~mm}$, in live humans and from trans-axial cuts performed systematically with the help of AutoCAD ${ }^{\circledR}$ Software, provides methodological conditions sufficiently favorable for obtaining linear quantitative mapping of alveolar, vestibular and palatal/lingual bone thicknesses, for both the maxillary and mandibular dental arches.

Keywords: Osteology. Alveolar bone thickness. Orthodontics. Tomographic method. Cone-Beam Computed Tomography (CBCT). AutoCAD ${ }^{\circledR}$ Software. Scientific Reliability. Applied Metrology. 


\section{LISTA DE ILUSTRAÇÕES}

Figura 2.1 - a) exemplificação esquemática de defeitos ósseos; b) defeitos ósseos in loco - exemplo; c) classificação de Goldman e Cohen para bolsas periodontais infra-ósseas (Goldman; Cohen, 1958) 36

Figura 2.2 a) menor medida sub milimétrica obtida das espessuras ósseas articulares; b) maior medida sub milimétrica obtida das espessuras ósseas articulares (Honda et al., 2004)

Figura 2.3 - Representação esquemática do modo convencional de direcionamento dos feixes para determinados FOV e flat panel (A), e deslocamento do detector (flat pane), colimando lateralmente os feixes, a fim de permitir otimização da amplitude de diâmetro do FOV (B). (Scarfe; Farman, 2008). 53

Figura 2.4 - Representação esquemática da diferença associada ao elemento de volume (voxel) entre TCFC (isotrópico) e TC (anisotrópico) (Scarfe; Farman, 2008) 55

Figura 2.5 - Representação esquemática do método de obtenção de medidas lineares dentárias (Sherrard et al., 2010) 75

Figura 2.6 - (a) orientação espacial axial conforme guias auxiliares ortogonais do software Dolphin $3 D^{\circledR}$; (b) orientação espacial coronal e respectivas guias auxiliares; (c) orientação espacial sagital conforme guias geométricos auxiliares.) (Sherrard et al., 2010) 76

Figura 2.7 - Identificação dos pontos de análise maxilar: (a) corte coronal - molares; (b) corte axial - molares e pré-molares (Almeida, 2011) 78 
Figura 2.8 - Níveis de avaliação das quantidades ósseas e respectivos locais interdentários de corte trans-axial (setas vermelhas). (vista sagital) (Baumgaertel, 2011) 79

Figura 2.9 - a) Níveis (03) de avaliação vertical das espessuras ósseas (totais); b) indicação trans-axial de dois parâmetros de medição tomográfica. (corte coronal, oblíquo ou trans-axial) (Baumgaertel, 2011) 80

Figura 2.10 - a) e b) cortes tomográficos (TCFC) coronais ilustrando a presença de condições esqueléticas críticas ao posicionamento vestíbulo-lingual dos dentes, em indivíduo dolicofacial (Kapila et al., 2011) 84

Figura 2.11 - Representação esquemática das dimensões lineares consideradas para o procedimento operacional de medição (Timock et al., 2011) 95

Figura 2.12 - a) indicação, no corte axial, do local de incidência do corte para obtenção das imagens trans-axiais; b) imagem trans-axial com indicação do modo vertical de medição, definido de modo análogo às medições realizadas diretamente (c). (Patcas et al., 2012) 103

Figura 2.13 - a) indicação, sob vista panorâmica, do local de incidência do corte para obtenção das imagens trans-axiais; B1, B2 e B3) sequência de imagens tomográficas trans-axiais dos dentes de interesse; c) visa vestibular após remoção da gengiva, e d) vista vestibular após remoção de parte do osso alveolar vestibular. As setas azuis correspondem à imagem tomográfica do dente mostrado em B1. Note-se que não há osso cobrindo a raiz nas imagens B1 e B3. (Patcas et al., 2012) ..... 104

Figura 2.14 - Cortes tomográficos axiais (TCFC) ilustrando a presença de defeitos ósseos combinados (seta branca) na superfície mesial do dente 14, a) sem evidência de defeito, b) defeito com três paredes remanescentes e c) evolução do defeito em sentido cervical com apenas uma parede remanescente (Vasconcelos et al., 2012) 107 
Figura 4.1 - Tomógrafo iCAT ${ }^{\circledR}$ e estação de trabalho (workstation)

Figura 4.2 - Programa Adobe Photoshop ${ }^{\circledR}$ CS5 - Extended

Figura 4.3 - Programa AutoCAD ${ }^{\circledR}$ e Viewer WS, versões 2011 para Machintosh ${ }^{\circledR}$

Figura 4.4 - Indicação do corte axial utilizado como referência à obtenção dos cortes trans-axiais finais do experimento. 120

Figura 4.5 - Imagem gerada por corte trans-axial, correspondente a um dos setores (dentes) de avaliação - dente 16 122

Figura 4.6 - Imagem gerada por corte trans-axial, correspondente a um dos setores (dentes) de avaliação - dente 13 122

Figura 4.7 - Imagem gerada por corte trans-axial, correspondente a um dos setores (dentes) de avaliação - dente 11 123

Figura 4.8 - Imagem gerada por corte trans-axial, correspondente a um dos setores (dentes) de avaliação - dente 21 123

Figura 4.9 - Imagem gerada por corte trans-axial, correspondente a um dos setores (dentes) de avaliação - dente 23 124

Figura 4.10 - Imagem gerada por corte trans-axial, correspondente a um dos setores (dentes) de avaliação - dente 26 124

Figura 4.11 - Imagem gerada por corte trans-axial, correspondente a um dos setores (dentes) de avaliação - dente 36 125

Figura 4.12 - Imagem gerada por corte trans-axial, correspondente a um dos setores (dentes) de avaliação - dente 33 125 
Figura 4.13 - Imagem gerada por corte trans-axial, correspondente a um dos setores (dentes) de avaliação - dente 31 126

Figura 4.14- Imagem gerada por corte trans-axial, correspondente a um dos setores (dentes) de avaliação - dente 41 126

Figura 4.15 - Imagem gerada por corte trans-axial, correspondente a um dos setores (dentes) de avaliação - dente 43 127

Figura 4.16 - Imagem gerada por corte trans-axial, correspondente a um dos setores (dentes) de avaliação - dente 46 127

Figura 4.17 - Janelas de Opções - Setores ou campos de ajuste/configuração individualizada dos parâmetros funcionais requeridos à operacionalização dos desenhos (sequência de a a $h$ ) 132-135

Figura 4.18 - Janela Lista de Edição de Escala - opções de configuração de escalas operacionais 135

Figura 4.19 - Janela Unidades do Desenho - Opções de configuração do Sistema de Unidades, do tipo (decimal) e da precisão (centesimal) da escala operacional 136

Figura 4.20 - Macros (AutoCAD ${ }^{\circledR}$ ) de comandos operacionais de acesso rápido....137

Figura 4.21 - Janela de inserção da imagem tomográfica - seleção do arquivo de imagem, padrões posicionais de inserção e escala 139

Figura 4.22 - Solicitação de informações de entrada da figura inserida. a) especificação do ponto de inserção na tela - model space; b) especificação da escala de inserção. Setas em cor verde 139 
Figura 4.23 - "Régua tomográfica" ("travessões verticais de cor branca"), linhas-teste (linhas horizontais em cor vermelha) de correspondência dimensional e as cotas de medida, e mm, correspondentes (números)

Figura 4.24 - Janela de edição de layers (camadas) de trabalho - opções de configuração: ordem, cor e condição 145

Figura 4.25 - Imagem (ampliada) das características geométricas do ponto de referência (círculo) utilizado para as definições. Cor e dimensões meramente ilustrativas. 147

Figura 4.26 - Obtenção do ponto JACv. (seta vermelha) 148

Figura 4.27 - Obtenção do ponto JAC I/p. (seta vermelha). 148

Figura 4.28 - Obtenção do ponto Limite Apical (LA). (seta vermelha) 149

Figura 4.29 - Obtenção do ponto Limite Apical Geométrico (LAG). (seta vermelha) 149

Figura 4.30 - Pontos anatômicos de referência: JACv, JACp/l e LA 150

Figura 4.31 - Configuração da espessura das linhas geométricas do MGA 150

Figura 4.32 - Obtenção da linha cervical (LC) (seta verde) e do ponto LC/2 (em cor azul) 151

Figura 4.33 - Obtenção da Linha Eixo Radicular Longitudinal (ERL). (cor azul) ....152

Figura 4.34 - Obtenção das Linhas Laterais de Auxílio (LLA)..... 153

Figura 4.35 - Obtenção da Linha-Base Cervical (LBC). (seta verde). 153 
Figura 4.36 - Representação esquemática das linhas funcionais principais (L1, L2 e L3). (setas azuis)

Figura 4.37 - Representação esquemática dos pontos funcionais, ósseos e dentários, preconizados a partir do MGA proposto (esferas verdes) 158

Figura 4.38 - Representação esquemática das linhas funcionais derivadas (linhas verdes) 159

Figura 4.39 - Representação esquemática das espessuras ósseas preconizadas 160

Figura 4.40 - Exemplo de visualização (dente 23) e aplicação real do MGA (linhas escuras) e das espessuras ósseas alveolares medidas por um dos operadores. (linhas e números em cor vermelha)... 162

Figura 4.41 - Função de automação - precisão (absoluta) durante a identificação de referenciais geométricos 163

Figura 4.42 - a) visualização da função AutoSnap ${ }^{\circledR}$ para um comando "ímã" de precisão de identificação da intersecção; b) solicitação padrão para o posicionamento do cursor 163

Figura 4.43 - a) dente 41 - visualização referencial ; b) visualização conforme ampliação (zoom) padrão de 0.23. Setas identificadas indicam alguns dos locais associados à inspeção e identificação tomográficas 165

Figura 4.44 - a) dente 16 - visualização referencial; b) visualização conforme ampliação (zoom) padrão de 0.23. Setas identificadas indicam alguns dos locais associados à inspeção e identificação tomográficas 168

Figura 4.45 - a) exemplo função de medida dimension aligned b) visualização de opções de apresentação na tela de trabalho (model space) 
Figura 4.46 - Representação esquemática (ampliada) da espessura óssea vestibular cervical (V1) e a medida linear (cota), em $\mathrm{mm}$, associada

Figura 4.47 - a) visualização, conforme ampliação referencial, da sequência de MGAs aplicados individualmente às unidades de observação/medição (dentes) selecionadas para os testes no arco mandibular, com as respectivas cotas de medição, de um dos operadores.. 172

Figura 4.48 - a) visualização, conforme ampliação referencial, da sequência de MGAs aplicados individualmente às unidades de observação/medição (dentes) selecionadas para os testes no arco maxilar, com as respetivas cotas de medição, de um dos operadores 172 


\section{LISTA DE TABELAS}

Tabela 4.1 - Valores das quatro medições lineares (T1,T2,T3 e T4), em mm e de "mesmas" quantidades $(M)$, para o teste de equivalência dimensional 142

Tabela 5.1 - Medidas absolutas, sem aproximações e em milímetros, correspondentes à participação do Operador Principal (Op.0), em tempo I. Também relacionados estão: unidades de observação (dentes) e os três (03) níveis de avaliação (variáveis) das espessuras ósseas alveolares, vestibulares e palatinas, maxilares 173

Tabela 5.2 - Medidas absolutas, sem aproximações e em milímetros, correspondentes à participação do Operador Principal (Op.0), em tempo II. Também relacionados estão: unidades de observação (dentes) e os três (03) níveis de avaliação (variáveis) das espessuras ósseas alveolares, vestibulares e palatinas, maxilares 173

Tabela 5.3 - Medidas absolutas, sem aproximações e em milímetros, correspondentes à participação do Operador Principal (Op.0), em tempo III. Também relacionados estão: unidades de observação (dentes) e os três (03) níveis de avaliação (variáveis) das espessuras ósseas alveolares, vestibulares e palatinas, maxilares 173

Tabela 5.4 - Medidas absolutas, sem aproximações e em milímetros, correspondentes à participação do Operador Principal (Op.0), em tempo I. Também relacionados estão: unidades de observação (dentes) e os três (03) níveis de avaliação (variáveis) das espessuras ósseas alveolares, vestibulares e linguais, mandibulares 174

Tabela 5.5 - Medidas absolutas, sem aproximações e em milímetros, correspondentes à participação do Operador Principal (Op.0), em tempo II. Também relacionados estão: unidades de observação 
(dentes) e os três (03) níveis de avaliação (variáveis) das espessuras ósseas alveolares, vestibulares e linguais, mandibulares

Tabela 5.6 - Medidas absolutas, sem aproximações e em milímetros, correspondentes à participação do Operador Principal (Op.0), em tempo III. Também relacionados estão: unidades de observação (dentes) e os três (03) níveis de avaliação (variáveis) das espessuras ósseas alveolares, vestibulares e linguais, mandibulares 174

Tabela 5.7 - Medidas absolutas, sem aproximações e em milímetros, correspondentes à participação do Operador 1 (Op.1). Também relacionados estão: unidades de observação (dentes) e os três (03) níveis de avaliação (variáveis) das espessuras ósseas alveolares, vestibulares e palatinas, maxilares 174

Tabela 5.8 - Medidas absolutas, sem aproximações e em milímetros, correspondentes à participação do Operador 1 (Op.1). Também relacionados estão: unidades de observação (dentes) e os três (03) níveis de avaliação (variáveis) das espessuras ósseas alveolares, vestibulares e linguais, mandibulares. 175

Tabela 5.9 - Medidas absolutas, sem aproximações e em milímetros, correspondentes à participação do Operador 2 (Op.2). Também relacionados estão: unidades de observação (dentes) e os três (03) níveis de avaliação (variáveis) das espessuras ósseas alveolares, vestibulares e palatinas, maxilares. 175

Tabela 5.10 - Medidas absolutas, sem aproximações e em milímetros, correspondentes à participação do Operador 2 (Op.2). Também relacionados estão: unidades de observação (dentes) e os três (03) níveis de avaliação (variáveis) das espessuras ósseas alveolares, vestibulares e linguais, mandibulares 175 
Tabela 5.11 - Medidas absolutas, sem aproximações e em milímetros, correspondentes à participação do Operador 3 (Op.3). Também relacionados estão: unidades de observação (dentes) e os três (03) níveis de avaliação (variáveis) das espessuras ósseas alveolares, vestibulares e palatinas, maxilares 175

Tabela 5.12 - Medidas absolutas, sem aproximações e em milímetros, correspondentes à participação do Operador 3 (Op.3). Também relacionados estão: unidades de observação (dentes) e os três (03) níveis de avaliação (variáveis) das espessuras ósseas alveolares, vestibulares e linguais, mandibulares 175

Tabela 5.13 - Medidas absolutas, sem aproximações e em milímetros, correspondentes à participação do Operador 4 (Op.4). Também relacionados estão: unidades de observação (dentes) e os três (03) níveis de avaliação (variáveis) das espessuras ósseas alveolares, vestibulares e palatinas, maxilares 176

Tabela 5.14 - Medidas absolutas, sem aproximações e em milímetros, correspondentes à participação do Operador 4 (Op.4). Também relacionados estão: unidades de observação (dentes) e os três (03) níveis de avaliação (variáveis) das espessuras ósseas alveolares, vestibulares e linguais, mandibulares 176

Tabela 5.15 - Medidas absolutas, sem aproximações e em milímetros, correspondentes à participação do Operador 5 (Op.5). Também relacionados estão: unidades de observação (dentes) e os três (03) níveis de avaliação (variáveis) das espessuras ósseas alveolares, vestibulares e palatinas, maxilares 176

Tabela 5.16 - Medidas absolutas, sem aproximações e em milímetros, correspondentes à participação do Operador 5 (Op.5). Também relacionados estão: unidades de observação (dentes) e os três (03) 
níveis de avaliação (variáveis) das espessuras ósseas alveolares, vestibulares e linguais, mandibulares

Tabela 5.17 - Medidas absolutas, sem aproximações e em milímetros, correspondentes à participação do Operador 6 (Op.6). Também relacionados estão: unidades de observação (dentes) e os três (03) níveis de avaliação (variáveis) das espessuras ósseas alveolares, vestibulares e palatinas, maxilares 176

Tabela 5.18 - Medidas absolutas, sem aproximações e em milímetros, correspondentes à participação do Operador 6 (Op.6). Também relacionados estão: unidades de observação (dentes) e os três (03) níveis de avaliação (variáveis) das espessuras ósseas alveolares, vestibulares e linguais, mandibulares 177

Tabela 5.19 - Repetitividade de medidas - Médias e desvios-padrões das três (03) repetições para os três (03) níveis de espessura óssea alveolar, vestibulares e palatinas/linguais, e para os seis (06) dentes mandibulares 179

Tabela 5.20 - Repetitividade de medidas - Médias e desvios-padrões das três (03) repetições para os três (03) níveis de espessura óssea alveolar, vestibulares e palatinas/linguais, e para os seis (06) dentes maxilares

Tabela 5.21 - Reprodutibilidade de medidas - médias e desvios-padrões das sete (07) repetições para os três (03) níveis de espessura óssea alveolar, vestibulares e palatinas/linguais, e para os seis (06) dentes mandibulares 184

Tabela 5.22 - Reprodutibilidade de medidas - Médias e desvios-padrões das sete (07) repetições para os três níveis (03) de espessura óssea alveolar, vestibulares e palatinas/linguais, e para os seis (06) dentes maxilares 


\section{LISTA DE ABREVIATURAS E SIGLAS}

ABNT - Associação Brasileira de Normas Técnicas

ALARA - Princípio de indicação ponderada de exames complementares dependentes da emissão de radiação ionizante (ALARA - "As Low As Reasonably Achievable").

ANOVA - Análise de Variância

ATM - Articulação Temporomandibular

CBCT - Cone Beam Computed Tomography (Tomografia Computadorizada de Feixe Cônico - TCFC)

CCD - Charge-Coupled Device (tipo de detector tomográfico - intensificador)

$\mathrm{Cl}$ - Confidence Interval (Intervalo de Confiança - IC)

[CO] - comando operacional (computacional)

CT - Computed Tomography (tomografia computadorizada)

DICOM - Digital Imaging and Communications in Medicine (comunicação de imagens digitais em Medicina)

DP - Desvio Padrão

EA - Erro Absoluto

EOA - Espessuras Ósseas Alveolares

EP - Erro Padrão 
EPA - Error Pixel Amount (quantidade de erro associado ao pixel)

ER - Erro Relativo

flat panel - tipo de detector para o sistema de TCFC (silicone amorfo hidrogenado)

FOUSP - Faculdade de Odontologia da Universidade de São Paulo

FOV - Field of View (campo de visão: tomográfico)

FUNDECTO - Fundação para o Desenvolvimento Científico e Tecnológico da Odontologia

$\mathrm{iCAT}^{\circledR}$ - tomógrafo iCAT ${ }^{\circledR}$ (Computer Axial Tomography)

ICC - Intraclass Correlation Coefficient (Coeficiente de Correlação Intraclasse -CCI)

INDOR - Instituto de Documentação Ortodôntica e Radiodiagnóstico

INMETRO - Instituto Nacional de Metrologia, Normalização e Qualidade Industrial

ISO - International Standardization Organization (Organização Internacional para Padronização)

JPEG - Joint Photographic Experts Group (tipo de arquivo de imagem - bitmap)

LCD - Liquid Crystal Display (monitor/mostrador de cristal líquido)

ME - Method Error (Erro do Método - EM)

MGA - Modelo Geométrico Auxiliar

mouse - dispositivo computacional auxiliar - "periférico" 
pixel (pel) - picture element (elemento de imagem, unidade fundamental de imagem digital bidimensional, de área)

POP - Procedimento Operacional Padrão

PPO - Protocolo de Participação do Operador

RAM - Random Access Memory (memória de acesso aleatório)

SEM - Standard Error of Measurement (Erro Padrão de Medida - EPM)

SDD - Smallest Detectable Difference (Menor Diferença Detectável - MMD)

SI - Sistema Internacional de Unidades

TC - Tomografia Computadorizada (convencional)

TCFC - Tomografia Computadorizada de Feixe Cônico

TCMC - Tomografia Computadorizada de Múltiplos Cortes (TC)

TCV - Tomografia Computadorizada Volumétrica (de feixe-cônico -TCFC)

TIFF - Tagged Image File Format (formato de arquivo bitmap)

VIM - Vocabulário Internacional de Metrologia

voxel - volume element (elemento de volume, unidade fundamental de imagem digital tridimensional, de volume)

CCT - Micro Tomografia Computadorizada (volumétrica) 


\section{LISTA DE SÍMBOLOS}

HU - Unidade Hounsfield

$\mu \mathrm{Sv}$ - microsievert (sexto sub múltiplo, um milionésimo, do sievert)

mGy - miligray (terceiro sub múltiplo, um milésimo, do gray)

mA - miliampere (terceiro sub múltiplo, um milésimo, do ampere - miliamperagem)

kVp - quilovolt (terceiro múltiplo do volt - quilovoltagem-pico)

$\mu \mathrm{m}$ - micrômetro (sexto sub múltiplo, um milionésimo, do metro - SI)

mm - milímetro (terceiro sub múltiplo, um milésimo, do metro - SI)

cm - centímetro (segundo sub múltiplo, um centésimo, do metro - SI)

a- alpha. Nível de significância estatística, expresso em porcentagem.

$p$ - valor P. Probabilidade de que seja obtido, pela ação pura do acaso, resultado tão ou mais extremo que aquele observado a partir da amostra utilizada, assumindo a hipótese nula (da nulidade ou da não diferença) como verdadeira.

bit - dígito binário, "Blnary digiT" - corresponde à menor unidade de informação que pode ser armazenada ou transmitida. Usada na Computação e na Teoria da Informação. Um bit pode assumir somente dois (02) valores, por exemplo: 0 ou 1, verdadeiro ou falso.

byte (B) - "Binary Term" (baite ou octeto), é um tipo de dado integral em computação, usado com frequência para especificar o tamanho ou quantidade da memória ou da capacidade de armazenamento de um certo dispositivo, 
independentemente do tipo de dados armazenados. A codificação padronizada de byte foi definida como sendo de 8 bits. O byte de oito (08) bits (octeto).

MB - megabyte (sexto múltiplo, um milhão, do byte)

$\mathrm{K}$ - constante estatística

n - número ou tamanho amostral

Z - constante estatística

s - segundo (unidade padrão para medição do tempo - SI)

GHz - gigahertz (nono múltiplo, um bilhão, do hertz)

$\hookleftarrow$ - enter, comando computacional de ativação de função

“ - símbolo para a unidade da polegada (pol.) 


\section{SUMÁRIO}

1 INTRODUÇÃO

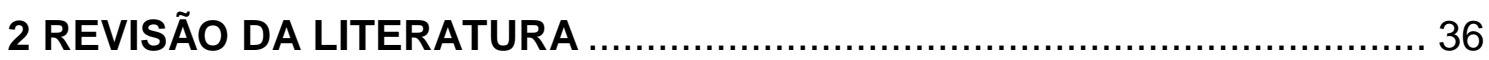

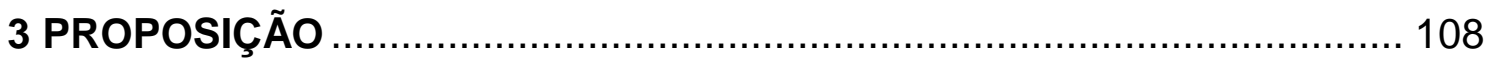

4 CASUÍSTICA - MATERIAL E MÉTODO

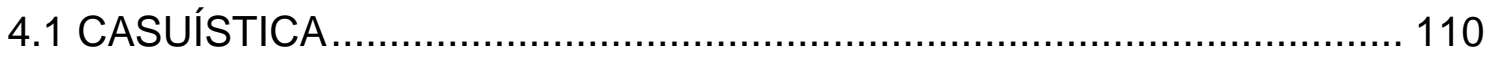

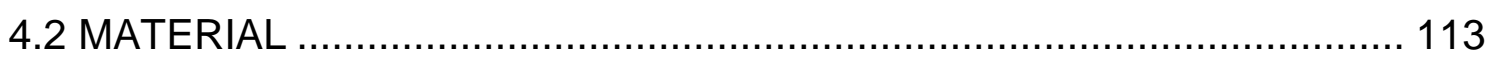

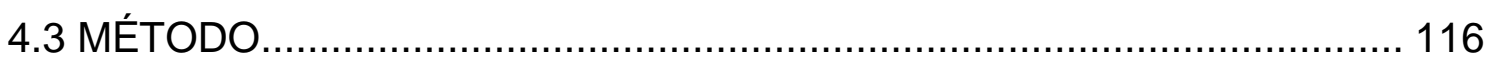

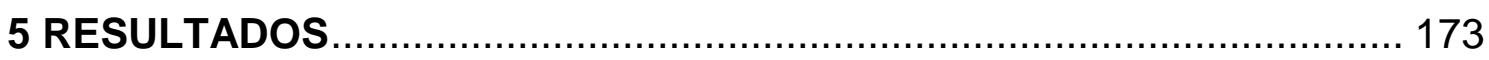

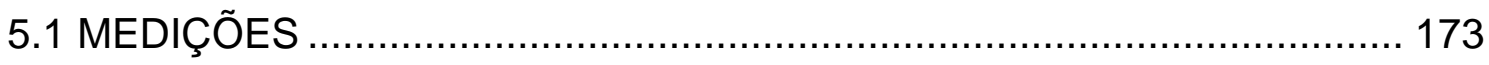

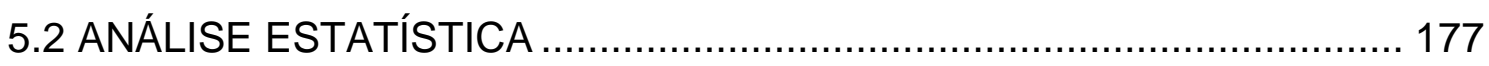

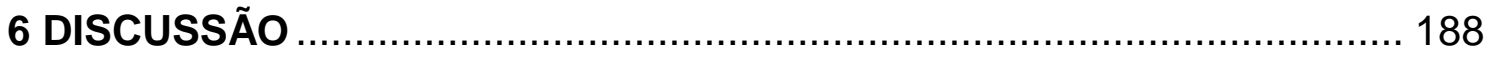

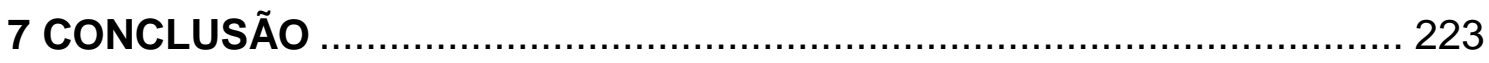

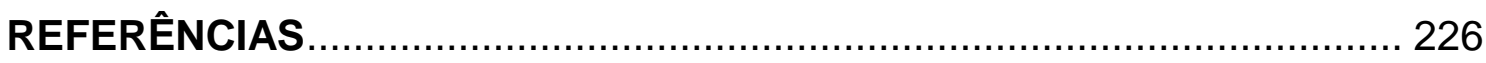

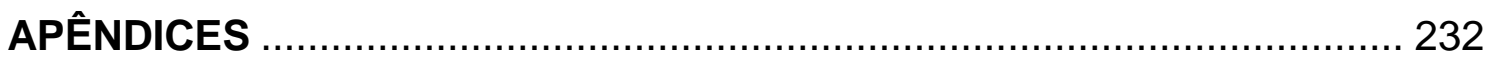

ANEXOS 


\title{
1 INTRODUÇÃO
}

\begin{abstract}
"O avanço da ciência não se deve ao fato de se acumularem ao longo do tempo mais e mais experiências perceptuais. Nem se deve ao fato de estarmos fazendo uso cada vez melhor de nossos sentidos. A ciência não pode ser destilada de experiências sensoriais não interpretadas, independentemente de todo o engenho usado para recolhê-las e ordená-las. Idéias arriscadas, antecipações injustificadas, pensamento especulativo, são os únicos meios de que podemos lançar mão para interpretar a natureza: nosso único "organon", nosso único instrumento para apreendê-la. E devemos arriscar-nos, com esses meios, para alcançar o prêmio. Os que não se disponham a expor suas idéias à eventualidade de refutação não participarão do jogo científico".
\end{abstract}

KARL POPPER

A Lógica da Pesquisa Científica 1972

A decisão profissional de proceder com ajustes, ou mesmo com correções ortodônticas das posições dentárias em relação às respectivas bases ósseas, depende essencialmente da correta elaboração do diagnóstico.

Para que essa condição seja observada, é necessário que sejam reconhecidos e conhecidos os meios técnicos proporcionalmente mais indicados à obtenção das informações pretendidas (Mileman; van den Hout, 2009) e, outrossim, o modo pelo qual estas poderiam contribuir com as melhores probabilidades de acerto terapêutico, especialmente quando a condição periodontal exigir maior atenção, haja vista a possibilidade de que alguns dos procedimentos ortodônticos poderão, sob certas condições, influenciar de modo desfavorável a saúde tecidual deste importante local (Palomo et al., 2008).

Portanto, a formulação do diagnóstico representa importante etapa no processo de gerenciamento das informações associadas tanto ao problema individualmente identificado, como também aos efeitos terapêuticos necessários aos esforços de sua solução.

Fontes de informação provenientes de exames complementares de imagens tem agregado valor substancial aos efeitos qualitativos das decisões clínicas inerentes aos problemas ortodônticos e periodontais (Goldman; Cohen, 1958; Mol, 2004; Mileman; van den Hout, 2009). Entretanto, também é fundamental que sejam conhecidas e corretamente entendidas as inúmeras características e possibilidades associadas aos recursos tecnológicos disponíveis (Mol, 2004; Scarfe; Farman, 2008; 
Kapila et al., 2011), para que estes possam, com efeito, contribuir com a obtenção de resultados clínicos mais consistentes e efetivos em suas propostas.

Com isso, o ato de reconhecer a real necessidade destas informações tornase essencial à evolução do aprendizado clínico.

A partir do advento da tomografia computadorizada de feixe cônico (TCFC/CBCT), em meados de 1997 (Dr. Yoshinori Arai - Universidade de Nihon, Japão) (Chilvarquer et al., 2008), considerando os inúmeros modos sistemáticos de interpretação das imagens em formato Digital Imaging and Communications in Medicine (DICOM), bem como suas aplicações (Kapila et al, 2011), pode-se verificar significativo avanço no processo de identificação dos fatores relevantes ao diagnóstico em Odontologia, especialmente no que se refere à possibilidade de condições mais favoráveis ao controle operacional com vistas à produção de pesquisa e experimentação (Chilvarquer et al., 2008; Shiratori et al., 2011; Timock et al., 2011; Tsutsumi et al., 2011)

A validação do método de análise tomográfica depende, considerando as finalidades específicas de identificação das condições atípicas e/ou patológicas, da utilização de referências e padrões confiáveis, sejam estes "absolutos ou mesmo relativos, definidos circunstancialmente como sendo representativos das melhores estimativas, qualitativas e/ou quantitativas, da(s) grandeza(s) considerada(s) (mensurando) durante a aplicação do(s) método(s) de medição, haja vista a importância de serem estabelecidos os padrões-ouro mais adequados a cada proposta experimental (Mileman; van den Hout, 2009).

Entretanto, análises e decisões clínicas estão invariavelmente associadas aos modos e critérios pessoais de avaliação do "espectro de abrangência" do problema observado. Portanto, pode-se intuir que sejam dependentes da experiência profissional individual, a qual deve ser considerada, também, pela frequência e qualidade das ações do tipo "tentativa - erro - correção".

Estudos tomográficos (imaginológicos) foram realizados com vistas a oferecer informações descritivas, qualitativas e quantitativas, dos locais de interesse às avaliações e para as mais diversas intenções de aplicação, variando métodos, equipamentos e instrumentos, com ajustes tais que fosse favorecida a amplitude de aplicabilidade dos resultados (Brezniak et al., 2004; Mol, 2004; Loubele et al., 2006; Noujeim et al., 2009; Damstra et al., 2010; Nowzari et al., 2010). No entanto, a própria natureza do exame, diante de algumas de suas indicações mais específicas, 
pode ser questionada quando consideradas as qualidades de precisão e exatidão (acurácia) dos equipamentos dela constituintes e, sobretudo, considerando a real utilidade das decisões clínicas obtidas a partir das informações geradas a partir destes equipamentos (Ballrick et al., 2008; Hulley et al., 2008; Strateman et al., 2008; Mileman; van den Hout, 2009; Leung et al., 2010; Özer, 2011; Schulze et al., 2011).

Embora sejam conhecidas as características técnicas de obtenção, indicações, limitações e importantes qualidades em termos de benefícios associados às imagens obtidas por meio de tomografia médica (TC) (Chilvarquer et al, 2008; Saddy, 2006; Suomalainen et al., 2009), a exatidão (acurácia) propiciada pelo exame de tomografia volumétrica (TCFC) também foi investigada e cientificamente discutida a partir da utilização de inúmeras propostas metodológicas (Kamburoglu et al., 2010; Sherrard et al., 2010; Kapila et al., 2011; Özer, 2011; Timock et al., 2011; Sun et al., 2011), quando então foram conhecidos os valores de aplicação relativos às estimativas de medidas e, ainda, as possibilidades de aplicação para a o desenvolvimento de pesquisa dessa modalidade particular de exame.

As Imagens tomográficas computadorizadas produzidas a partir de aquisição com sistema de feixe cônico (TCFC), com quantidade de radiação proporcionalmente menor, de aproximadamente vinte por cento (20\%) da aquisição obtida com o sistema helicoidal (TC), ou ainda equivalente a uma sequência completa de registros radiográficos periapicais (Suomalainen et al. 2009; Kapila et al, 2011), são suficientemente adequadas às aplicações em pesquisa pois satisfazem a necessidade de exatidão (acurácia "1:1") para muitas das aplicações de interesse, tanto para a avaliação de defeitos ósseos específicos (Kamburoglu et al., 2010; Leung et al., 2010; Tsutsumi et al., 2011; Vasconcelos et al., 2012; Patcas et al., 2012), quanto para o conhecimento, ainda que limitado, das espessuras ósseas alveolares estimadas (Loubele et al, 2006; Razavi et al., 2010; Januário et al., 2011; Naitoh et al., 2011; Swasty et al., 2011; Timock et al., 2011; Tomasi et al., 2011), desde que observada a combinação entre precisão de aquisição dos dados, bem como a qualidade do programa computacional e método de inspeção, identificação, medição e registro das dimensões de interesse.

Algumas quantidades biológicas específicas como tamanho, volume e posição dentária, além de espessuras e densidades ósseas alveolares, podem ser interpretadas e aplicadas terapeuticamente como parâmetros de grandezas 
biológicas quantitativas, considerando cada indivíduo em sua particularidade anatômica e funcional.

Para tanto, é de suma importância a obtenção de informações confiáveis relativas à exatidão e precisão dos meios (técnicas) e métodos disponíveis, haja vista a diversa gama de possibilidades considerando equipamentos, análises computacionais e, sobretudo, as finalidades de aplicação. 


\section{REVISÃO DA LITERATURA}

"As análises críticas que revelam a relatividade do discurso científico podem abalar, em alguns, a confiança e a crença que depositam na ciência. Existem várias maneiras de acreditar nelas mas, em cada uma delas, a expressão "crer" aproxima-se da noção de uma certa fé, de uma certa confiança".

GÉRARD FOUREZ

A Construção das Ciências - Introdução à Filosofia e à Ética das Ciências 1995

Goldman e Cohen (1958) descreveram as características anatômicas normais e patogênicas associadas a certos tipos e classes de defeitos ósseos. Propuseram classificação biológica de qualidade morfológica, para a qual consideraram a prevalência observada subjetivamente dos referidos defeitos (figura 2.1).
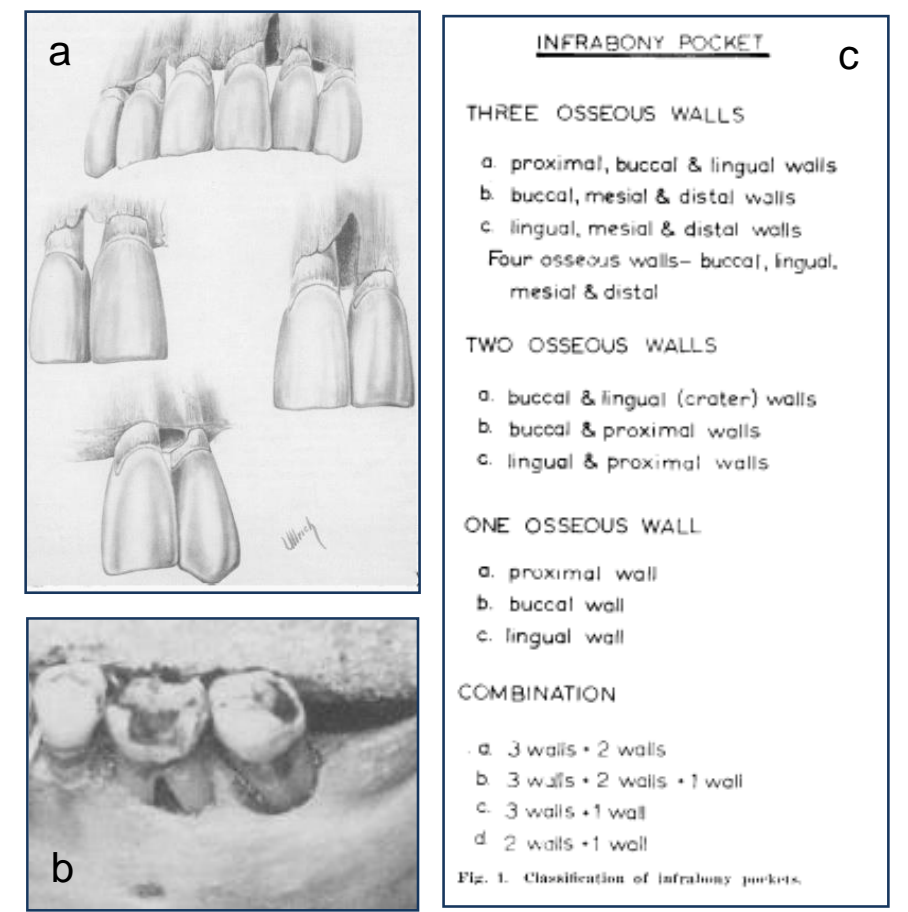

Figura 2.1 - a) exemplificação esquemática de defeitos ósseos; b) defeitos ósseos in loco - exemplo; c) classificação de Goldman e Cohen para bolsas periodontais infra-ósseas

A amostra utilizada foi derivada de casos clínicos em tratamento, bem como de material ex vivo. Não foi oferecida descrição detalhada do delineamento metodológico utilizado. Enfatizaram a importância do exame radiográfico para a determinação da qualidade das paredes alveolares circundantes, e, ainda, que esta 
avaliação, em particular, constitui-se em uma de extrema relevância à clínica odontológica. Destacaram a utilidade diagnóstica e terapêutica da classificação proposta, no sentido de serem propiciadas melhores comunicação e padronização das avaliações locais dos defeitos ósseos. Assim, a visualização topográfica deveria ser cuidadosamente observada a fim de que as informações radiográficas pudessem ser representativas daquelas condições anatômicas clinicamente avaliadas.

Wagner (1973) considerou o conceituação e caracterização de aplicação do método estatístico com ênfase à análise e correção dos dados gerados no âmbito da literatura odontológica, bem como a proposta de explicação das razões e aplicabilidade de funções como: média, desvio padrão, erro padrão da média, teste $t$, teste $F$, análise de variância, teste do qui-quadrado, coeficiente de correlação, valores de probabilidade e níveis de significância estatística. Os resultados, após terem sido definidos os padrões de amostragem, possuem sempre um dado padrão de distribuição estatística, médias podem ser obtidas, desvios padrões podem ser calculados em termos de variância e distribuição em torno das médias. Quanto ao padrão de distribuição dos dados, normalidade e não-normalidade são condições matemáticas as quais determinam a direção dos testes estatísticos pretendidos. Um resultado de análise atestando diferença estatística significante representa uma diferença real e importante. Uma diferença estatística detecta uma grande diferença a qual é provavelmente causada por uma verdadeira diferença entre variáveis das unidades de observação testadas, ou seja, as diferenças entre variáveis provavelmente não ocorrem simplesmente por ação do acaso (coincidência). Lembrou o autor que análises estatísticas são empreendidas com o auxílio de vários métodos a fim de que sejam calculados os valores $P$ e intervalos de confiança (IC), determinando, via de regra, se os dados são ou não diferentes. O tipo de teste depende do amanho da amostra, do número de amostras, do tipo de dados, se os dados são pareados ou não, e ainda de outros fatores adicionais. Concluiu relatando que os testes $t$ e $F$, de análise da variância, do qui-quadrado e do coeficiente de correlação são os métodos estatísticos mais utilizados na literatura odontológica. 
Freitas et al. (1988) descreveram os principais fatores associados à interpretação radiográfica diante da presença de fenômenos físicos e químicos de geração de imagens, bem como das características de visualização inerentes. Destacaram que camuflagem, superposição, contraste, figura e fundo, organização sensorial e, ainda, ilusões de ótica, são fatores clássicos associados aos padrões radiológicos interpretativos. As imagens radiográficas são constituídas de inúmeros tons intermediários de cinza, entre o preto absoluto e o branco absoluto. Assim, a interpretação deve ser conduzida sem o recurso de presença das cores (monocromatismo). É uma avaliação caracterizada pela identificação das qualidades das sombras e, conforme salientado por Thomas e Landsdown (1963, apud Freitas et al., 1988):

[...] As sombras numa radiografia não são áreas vazias, mas ausências de continuidade que parecem atrair o olhar.

A definição ou identificação do estudo patológico ou anatômico está baseada na diferença existente entre as sombras mais claras e as mais escuras. Segundo Hueller \& Rudolph (1968, apud Freitas et al., 1988):

[...] Não há duas pessoas que assumam mesmas conclusões a partir de imagens radiográficas repletas de sinais visuais, os quais são constantemente interpretados pelo cérebro. O processo varia de pessoa a pessoa, de acordo com o que os psicólogos chamam de estilo perceptual.

Vuolo (1996) descreveu os principais conceitos associados ao valor de interpretação normativa da participação dos erros relativos aos experimentos técnico-científicos. Erros sistemáticos, vieses e erros aleatórios (estatísticos) foram explicados e relacionados às etapas de realização das sequências operacionais usuais ao processo de investigação, ou de reconhecimento da incidência de erros e, por conseguinte, da validade científica ou grau de universalidade dos resultados obtidos. Incerteza residual do tipo B e incerteza do tipo A, bem como os tipos de distribuição estatística associadas à participação do erro total, sua análise e influência na qualidade final dos resultados, foram consideradas diante das 
possibilidades de registro, medição, classificação e interpretação, em cada sistema particular de experimentação científica.

Brezniak et al. (2004) estudaram a validade em termos de exatidão (acurácia) e precisão da utilização de referenciais anatômicos correspondentes às junções amelo-cementárias (JACs) e limites apicais radiculares com vistas à identificação de reabsorções radiculares externas e sua quantificação vertical. Utilizaram método radiográfico tradicional, e a partir da utilização de um incisivo central extraído por motivos periodontais, analisaram a influência da variação posicional associada à incidência dos raios $X$ e sua influência na qualidade de identificação daqueles pontos de referência. Medições indiretas foram realizadas a partir da identificação de imagens das projeções de esferas metálicas posicionadas nos locais dos limites avaliados, as quais foram consideradas como referências-padrão à comparação com os resultados da participação dos seis (06) examinadores (ortodontistas) selecionados para a realização do experimento. Consideraram as dificuldades inerentes à variação anatômica dos locais estudados, bem como das técnicas de obtenção de imagens tomográficas. Os examinadores não receberam instruções, nem tampouco treinamento prévio relativos à qualidade de inspeção tomográfica dos reparos anatômicos, que ocorreu mediante utilização de cursor controlado por mouse. Foi dada a oportunidade para que os operadores ajustassem, caso julgassem necessário, a intensidade de brilho e contraste das imagens selecionadas. Não foi estabelecido limite de tempo para a obtenção dos resultados. As imagens foram ampliadas em proporção de sete (07) vezes para a inspeção, e operacionalizadas a a partir de Programa Adobe Photoshop ${ }^{\circledast} 5$ (Adobe, San Jose, CA, E.U.A.). A qualidade da técnica radiográfica, afirmaram, constitui-se em fator de acentuada relevância quando considerado o efeito final, em termos de resolução espacial de imagem. Os resultados indicaram pobre reprodutibilidade, porém suficiente repetitividade, assim favorecendo a noção de que, eventualmente, instrução, treinamento e experiência operacional prévias possam influenciar positivamente a qualidade de inspeção radiográfica. Concluíram que mudanças angulares entre dentes e filme influenciam, em radiografias periapicais, a identificação dos pontos das JACs, obtidas com a técnica do paralelismo; e que as 
características associadas às limitações do exame utilizado na pesquisa podem explicar, ao menos em parte, as limitações dos resultados finais obtidos.

Honda et al. (2004) testaram a utilidade de um sistema de tomografia volumétrica com feixes cônicos limitados $\left(3 D X^{\circledR} \mathrm{J}\right.$. Morita Co., Japão) para 0 conhecimento da exatidão de espessuras ósseas associadas à articulação temporomandibular. Utilizaram vinte e uma (21) unidades (ex vivo), colhidas pósautópsia, de articulações temporomandibulares (ATM), sendo oito (8) do gênero masculino (média de idade, no momento da morte, de 70,4 anos) e treze (13) do feminino (média de idade, no momento da morte, de 76,8 anos), as quais foram investigadas tanto microscopicamente, por meio de imagens $3 D X^{\circledR}$, como macroscopicamente (padrão-ouro), por meio de micrômetro Mitutoyo ${ }^{\circledR}$ Digimatic Outside (Mitutoyo Co., Japão), com exatidão 0,001 mm ( \pm 1$)$. O voxe/ resultante foi de 0,125mm, após parâmetros de exposição de $80 \mathrm{kVp}, 7 \mathrm{~mA}$ e 17s., com tela de avaliação apresentando 240 pixels em altura, por 320 pixels de largura, e cada pixel contendo 8 bits de informação. Para as medições das espessuras ósseas tomográficas, todas realizadas por um mesmo operador (o próprio autor), foram utilizados os recursos do software nativo do equipamento, o 3DX-Image ${ }^{\circledR}$, porém não foram descritos quaisquer detalhamentos associados à sequência operacional de medição selecionada aos locais de inspeção e identificação de medidas sub milimétricas, e nem eventuais limitações dela decorrentes. Devido à significância dos valores de exatidão obtidos $(r=0,93$. $P<0,001)$, verificaram que as medidas das espessuras ósseas articulares (figura 2.2) podem ser estimadas diretamente das imagens tomográficas obtidas com equipamento $3 D X^{\circledR}$.
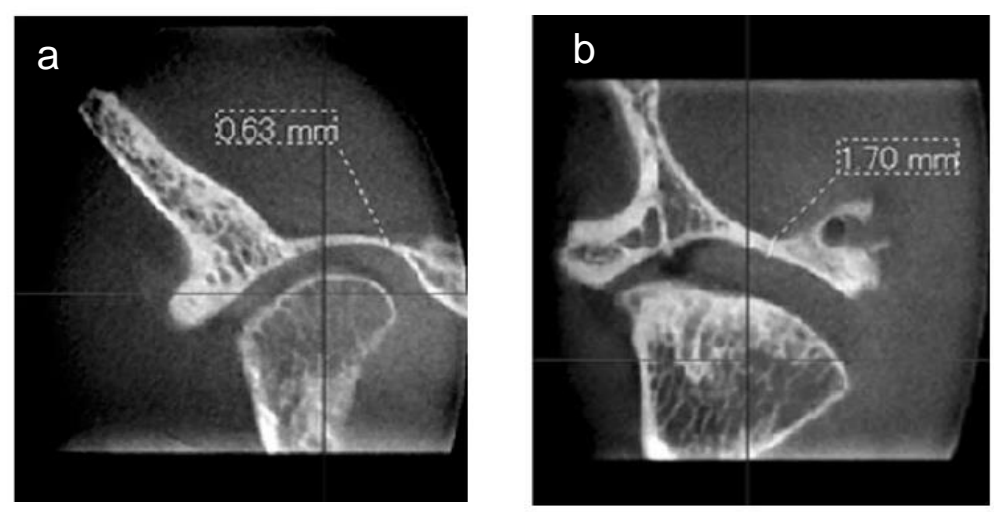

Figura 2.2 - a) menor medida sub milimétrica obtida das espessuras ósseas articulares; b) maior medida sub milimétrica obtida das espessuras ósseas articulares 
Concluíram que o recurso tomográfico $3 D X^{\circledR}$ é útil às aplicações clínicas devido à exatidão verificada, além de favorecer a redução de doses de radiação ionizante, quando comparadas à tomografia médica (TC).

Lascala et al. (2004) investigaram a exatidão (acurácia) de medidas lineares provenientes de sistema TCFC. Tomógrafo NewTom ${ }^{\circledR}($ QR-DVT 9000 - Verona, Itália). Utilizaram oito (08) crânios secos (ex vivo), sem identificação de gênero, idade ou grupo étnico, onde foram selecionados dezenove (19) locais para observação. Esferas metálicas foram fixadas com godiva. Treze (13) distâncias lineares foram identificadas e medidas. Os valores reais de medida, (padrão-ouro) foram obtidos por meio de paquímetro digital de alta precisão diretamente nos crânios secos. Para a obtenção dos registros tomográficos, cada crânio seco fora imerso em recipiente contendo água e, então, posicionados para cumprir com os requerimentos do exame. Os parâmetros de exposição foram: $7 \mathrm{~mA}, 85 \mathrm{kVp}$, com escaneamento único de $70 \mathrm{~s}$ e com espessura de corte de $2 \mathrm{~mm}$. As imagens foram processadas a partir de recursos do próprio software do sistema NewTom ${ }^{\circledR}$. Testes $t$ foram aplicados para o conhecimento estatístico das diferenças entre os métodos (medidas diretas e tomográficas). As medidas realizadas diretamente $\mathrm{e}$ correspondentes à base craniana foram, em média, sempre maiores que as tomográficas (subestimação tomográfica). Os autores salientaram a variedade de propostas tomográficas e métodos de TCFC disponíveis. Contudo, a exatidão foi suficientemente satisfatória para a maioria das aplicações odontológicas.

Mol (2004), a partir de revisão compreensiva da literatura, discutiu os conceitos e possibilidades de uso clínico, acadêmico e para pesquisa relativas às inúmeras modalidades de obtenção de imagens radiográficas para o diagnóstico, tratamento e prognóstico das condições periodontais indesejáveis. Salientou que embora os avanços tecnológicos tenham sido bastante representativos em termos de novas possibilidades práticas de observação, os estudos e conhecimento necessários à utilização mais controlada das técnicas e protocolos não tem ocorrido com a mesma proporção de avanço. Há muito que as limitações relativas aos atuais 
métodos radiográficos tem sido observadas e consideradas, a saber: o fator de representação bidimensional das estruturas de interesse, ausência de validação e também de conteúdos realmente informativos associados à acurácia e precisão das medidas quantitativas. Lembrou que o uso de imagem radiográfica como cuidado complementar à elaboração do diagnóstico e tratamento da doença periodontal é amplamente aceito. Sua principal utilização ocorre com a necessidade de serem mensurados os níveis presentes de osso alveolar, bem como a quantificação estimada de sua perda ou reabsorção. Medidas lineares da junção amelocementária até a crista alveolar, bem como da junção amelo-cementária até a base do defeito ósseo são comumente executadas a fim quantificar o grau de perda óssea alveolar local. Imagens radiográficas também servem para mostrar a qualidade em termos de contorno da lâmina dura, bem como situação do espaço periodontal e, ainda, presença de cálculo e/ou de outros fatores de relevância crítica ao diagnóstico periodontal. $\mathrm{O}$ autor relacionou os principais conceitos associados à correta indicação e utilização dos registros radiográficos. Assim, quando houver a presença de condição(ões) crítica(s), a(s) qual(is) seja(m) capaz(es) de modificar a linha prévia de pensamento diagnóstico, e a partir dos padrões de análise radiográfica obtidos, então a indicação dessa modalidade de exames, baseada nessa sugestão de análise de custo-benefício, poderá ser clinicamente justificada. Custos biológico, ou a dose de radiação ionizante absorvida pelo indivíduo, e financeiros devem ser ponderados durante a análise e diante dos possíveis e prováveis benefícios decorrentes da interpretação e utilização do conhecimento para benefício do paciente. Como em qualquer teste de diagnóstico, os problemas envolvendo exatidão (acurácia) e precisão devem ser considerados para a decisão de solicitação dos exames radiográficos, então sempre haverá um fator de probabilidade tanto para o falso-positivo quanto para o falso-negativo. É de conhecimento geral que, se uma imagem radiográfica não possibilita a identificação de perda óssea em um local de furca, dificilmente seria possível afirmar que não há realmente qualquer grau de perda óssea naquele local, fazendo com que o valor de predição negativa seja consideravelmente crítico; No entanto, quando a imagem propiciar a decisão de que foi identificada lesão de perda óssea no local de furca, então pode-se, com efeito e de modo virtualmente afirmativo, garantir que algum grau de lesão esteja de fato presente, fazendo com que o valor de predição positiva dessa modalidade de exame seja significativo. Destarte, afirma o autor, as 
informações provenientes do exame clínico são de essencial importância diante da necessidade de se estabelecer comparações entre resultados, com vistas à obtenção da melhor decisão relativa tanto à presença de uma dada condição patológica/desfavorável, como ao grau ou fator de influência dos resultados confirmados para a saúde periodontal local/regional. A hipótese de que as informações acerca das perdas ósseas alveolares, bem como dos níveis ósseos locais acabam por determinar mudança significativa nas linhas terapêuticas, tem sido bastante testada. Segundo o autor, é consensual que a solicitação de exame(s) radiográfico(s) complementar(es) depende da circunstância em que se encontram profissional e paciente, e não pode ser resumida ou ainda classificada em um dado guia para indicações. A possiblidade de obtenção rotineira de imagens tomográficas, sejam elas provenientes de Tomografia Computadorizada médica (TC) ou de FeixeCônico (TCFC), veio como alternativa singular à utilização no contexto clínico. Imagens de qualidade superior quanto à nitidez de detalhes, contraste $e$ possibilidade reais quanto à precisão e acurácia (exatidão), especialmente para observações do tecido ósseo, regional e local (alveolar), tornaram-se realidade com o advento da Tomografia Computadorizada. Contudo, e para avaliações destinadas ao diagnóstico periodontal, existe significativa desvantagem na indicação de TC médica em decorrência da alta dose de radiação absorvida, conforme mostraram outros estudos. A TCFC, porém, veio suplantar essa limitação, propiciando, com maiores possibilidades de aplicação ao diagnóstico e tratamento periodontal, menor efeito proveniente da acumulação de radiação, favorecendo ainda a observação específica de tecidos mineralizados, uma vez que a radiação dispersante determina a redução de contraste e nitidez de contornos para os tecidos não mineralizados. Portanto, conclui o autor, a TCFC representa qualidade em termos de imagem radiográfica, com exatidão e favorável à precisão, propiciando sobremaneira a obtenção de vários locais de avaliação, com um único registro geral.

Sim e Wright (2005) discutiram a importância do entendimento, interpretação e aplicabilidade da estatística Kappa em situações distintas de análise associadas à condição biológica. Usualmente a indicação de aplicação desta modalidade estatística depende da necessidade de análise de concordância inter-examinadores, e, fundamentalmente, considerando a escala nominal, com ênfase ao diagnóstico a 
partir de decisões categoriais. Observaram que é possível, para esse modo particular de análise estatística, transformar, ou converter, dados quantitativos em ordinais categoriais, mas que, nesses casos, maior atenção deve ser conferida à interpretação dos limites entre as categorias classificadas, bem como ao poder final almejado. A estatística Kappa pode ser ponderada ("pesada") a fim de propiciar seletividade quanto à detecção de diferenças maiores em relação às menores, provendo, deste modo, um grau teoricamente maior de sensibilidade diante da necessidade de interpretação das discordâncias, mas a severidade das diferenças podem ser ofuscadas com essa decisão. A ocorrência de vieses de não independência entre resultados $\mathrm{a}$, ainda, de prevalência são os fatores principais os quais poderiam interferir significativamente no efeito final da análise. Considerando os padrões de execução dos testes de repetibilidade, é importante, salientaram, observar o critério relativo à manutenção de intervalos regulares entre as avaliaçõesteste, sendo esta uma condição relevante à qualidade final dos resultados, uma vez que intervalos reduzidos favoreceriam a participação de um tipo específico de viés, o efeito memória. Enquanto que intervalos estendidos poderiam favorecer outra tendência (viés) associada à modificação do contexto sob avaliação. Assim, enfatizaram, intervalos de dois (2) a quatorze (14) dias seriam os mais usuais, sendo importante, para a definição destes, tanto conhecer o padrão de estabilidade dos fatores participantes das avaliações, quanto estabelecer critério de aleatoriedade para as condições de seleção durante o processo de registro e medição. Ao citar a classificação proposta por Landis e Koch como referência usual para interpretações da força de concordância a partir de Coeficientes Kappa: $\leq 0=$ pobre; 0,01-0,20 = leve; $0,21-0,40=$ boa (justa/satisfatória); $0,41-0,60=$ moderada; $0,61-0,80=$ substancial, e 0,81-1 = quase perfeita, salientaram que as classificações são, em última análise, de origem arbitrária. Explicaram que o Coeficiente Kappa não reflete o erro de amostragem e, se a intenção for a de generalizar os resultados da condição de confiabilidade a uma dada população, então o Coeficiente Kappa frequentemente é testado em sua significância estatística por meio de testes de hipóteses. Se a hipótese da nulidade (não diferença - Ho) for de $\mathrm{K}=0$, então teste uni-caudal estaria indicado, já que $K<0$ geralmente não representa conteúdo informativo. Contudo, enfatizaram que o valor de Ho deveria ser considerado para um dado valor-referência de $K$ (ex. $K=0,40)$, com a justificativa de que quaisquer valores abaixo desta referência assumida deveriam ser considerados clinicamente 
inaceitáveis. Concluíram que o mínimo valor aceitável para o Coeficiente Kappa dependerá do contexto clínico presente. Uma abordagem mais informativa quanto aos valores de $K$ seria aquela em que são calculados Intervalos de Confiança (IC), usando o Erro Padrão de Kappa e o Escore $Z$ correspondente para o desejado nível de confiança $(\alpha)$.

Loubele et al. (2006) avaliaram quantitativamente a qualidade de modelos ósseos gerados a partir de dois sistemas tomográficos, o volumétrico (TCFC) e o de Múltiplos Cortes/TCMC (TC). Os equipamentos utilizados para o sistema de TCFC foram: NewTom ${ }^{\circledR} 9000$ DVT (Quantitative Radiology, Verona, Itália); 3D Accuitomo $^{\oplus}$ (J. Morita, Kyoto, Japão) e $i C A T^{\circledR}\left(i-C A T^{\circledast}\right.$, Imaging Sciences International, Hatfield, $\mathrm{Pa}$, EUA). Os equipamentos para TC foram: Somatom Volume Zoom ${ }^{\circledR}$ (Siemens, Erlangen, Germany) e Light Speed ${ }^{\circledR}$ PX/I (GE Medical Systems, Milwaukee, WI, E.U.A.). Salientaram a importância de serem conhecidas as exatidões geométricas dos modelos ósseos para efetivas contribuições durante o planejamento cirúrgico e simulações. Enquanto que a exatidão da segmentação óssea já teria sido extensivamente avaliada para o sistema de TCMC (TC), ainda não o foi de modo suficiente significativo para o sistema de TCFC. Conforme destacaram, existem quatro (04) métodos usualmente utilizados para a obtenção deste conhecimento: a utilização de manequins (fantomas) reais e próprios à reprodução de aproximação dos padrões de atenuação; de manequins virtuais; de estudos em cadáveres e, anda, de estudos in vivo. Cada método, lembraram, possui critérios próprios de estabelecimento dos valores de padrões-ouro (verdadeiros ou a melhor aproximação destes). Comparativamente, foram selecionadas as informações dos exames de TCMC (TC) como representativas do padrão-ouro (convencionado) clínico, já que o procedimento de validação proposto não exigia a utilização de um padrão-ouro absoluto (verdadeiro). A avaliação realizada foi completamente automatizada (segmentação óssea derivada de análise de histograma e abordagem global de limiares) e, sendo assim, foi considerada como sendo uma do tipo observadorindependente. As imagens, equiparadas em formato DICOM, foram associadas por interpolação à qualidade das imagens de TCMC (TC), e alguns locais previamente selecionados de interesse foram finalmente analisados. Obtiveram resultado de diferença significante entre espessuras avaliadas com TCMC e TCFC para todos os 
experimentos, variando entre 0,05 $\pm 0,47 \mathrm{~mm}\left(\right.$ iCA $\left.^{\circledR}\right)$ e 1,2 $\pm 1,00 \mathrm{~mm}\left(\right.$ Accuitomo $\left.^{\circledR}\right)$, o que correspondeu a uma diferença de até 1 a 1,5 voxels de TCMC. Para os sistemas ${ }^{2} C A T^{\circledR}$ e Accuitomo ${ }^{\circledR}$ (TCFC), menores valores de espessura óssea foram comparados à TCMC, enquanto que o $\mathrm{NewTom}^{\circledR}$, foi empregado para comparações de maiores valores desta grandeza. Embora tenham constatado a possibilidade de inconsistências técnicas de inexatidão associadas à TCMC, fato este que poderia ter causado interferência na análise dos resultados para os equipamentos de TCFC, haja vista que não se trata de padrão-ouro estabelecido, mas sim convencionado (clínico), os autores confirmaram a adoção da TCMC como referência para os parâmetros de comparação. Destacaram que o método utilizado no estudo não pode ser aplicado de igual sorte aos sistemas de TCFC devido aos diferentes padrões de atenuação entre os mesmos. Para todos os grupos de dados, a diferença média entre espessuras foi menor que $1 \mathrm{~mm}$, registrando assim variação mínima (limiar) sub milimétrica e que esta, para muitas das aplicações clínicas, seria insignificante. O desvio padrão da diferença entre espessuras TCFC e TCMC (TC) foi menor que $0,7 \mathrm{~mm}$ para a maioria dos dados comparados. Explicaram que desvios padrões (DP) reduzidos representam, na prática, contornos ósseos de superfície mais regulares, aproximando-se comparativamente dos valores proporcionais obtidos do sistema de TCMC.

Saddy (2006) comparou a qualidade de modelos de prototipagem obtidos por meio de tomografias volumétrica (TCFC) e médica (TC). A avaliação específica foi de precisão e de exatidão (acurácia) durante a capacidade de reprodução física de parâmetros tomográficos (imaginológicos). Para tanto, foi utilizado material ex-vivo correspondente a uma mandíbula, a qual foi submetida aos exames de TCFC (NewTom ${ }^{\circledR} 9000$ QR, Itália) e TC (Select ${ }^{\circledR}$ SP-Elscint, Israel). Foram utilizados dois sistemas de tratamento de imagens, o 3D-Analyze ${ }^{\circledR}$ (Mayo Clinic, EUA) e o InVesalius $^{\Theta}$ (CenPRA, Brasil), a partir dos quais foram obtidos os protótipos conforme dois recursos distintos - SLS (Sinterização Seletiva à Laser) e 3DP (Impressão Tridimensional). A mandíbula seca foi utilizada como fonte do padrãoouro, bem como os oito (8) conjuntos de protótipos gerados (I-TC-Analyze 3DP; IITC-Invesalius-3DP; III-TC-Analyze-SLS; IV-TC-Invesalius-SLS) foram submetidos a processos de engenharia reversa com a finalidade de digitalizar as superfícies dos 
objetos, propiciando assim a comparação de cada resultado gerado da prototipagem com o padrão-ouro estabelecido, com precisão de $0,0001 \mathrm{~mm}$. Os desvios de até $1 \mathrm{~mm}$ e até $2 \mathrm{~mm}$ foram calculados, comparados e analisados estatisticamente os erros percentuais. Concluiu que os modelos de prototipagem rápida originados por meio da obtenção de informações (dados) de exames de tomografia médica (TC) foram mais precisos comparativamente àqueles obtidos da tomografia volumétrica (TCFC).

Suomalainen et al. (2007) avaliaram a utilidade do tomógrafo 3DX micro-CT $T^{\circledR}$ para a produção de micro tomografias computadorizadas. Cento e noventa e oito (198) imagens foram retrospectivamente selecionadas e examinadas ao longo de seis (06) anos e em consultório particular, com a finalidade de que fossem estabelecidos parâmetros de comparabilidade com informações obtidas de radiografias panorâmicas e ainda intra-bucais. O tomógrafo 3DX® (Accuitomo, J. Morita, MFG, Corp., Kyoto, Japão) é um equipamento tomográfico de ação limitada à região maxilo-facial e temporomandibular. Permite a visualização em três dimensões (3D) e reconstruções volumétricas derivadas. Favorece, ainda, a visualização de estruturas mineralizadas. O campo de visão é de $30 \mathrm{~mm}$ de altura por $10 \mathrm{~mm}$ de largura no centro de rotação. Os cortes tomográficos podem ser conforme espessuras de 0,125 e $2 \mathrm{~mm}$. Para o estudo, os autores selecionaram corte de $1 \mathrm{~mm}$. A função do $\operatorname{Ortho} T^{\circledR}$ (protótipo do $3 D X^{\circledR}$ micro-CT) foi utilizada. Dois (02) operadores participaram do estudo (ambos especialistas em Radiologia Oral), e suas participações foram independentes e a partir de leitura consensual dos padrões de resultado. Para a determinação da variação inter-operadores e a "reprodutibilidade intra-operador" das medidas das dimensões ósseas, Percentis de Concordância e Índices Kappa foram calculados com tolerância de 0,5mm. A média de idade dos indivíduos da amostra foi de 50,3 anos ( $\mathrm{DP}=15,4$ anos). A presença de alguns artefatos, relataram, prejudicou a precisão de medição de locais e torno do ápice radicular. Obtiveram concordância de variação inter e intra operador de 91,7\% e índice Kappa para a variação inter-operadores de 0,9. O Índice Kappa foi de 0.89 para ambos os radiologistas. Constataram não haver padrões-ouro de comparabilidade para as condições qualitativas avaliadas no estudo. Concluíram que o tomógrafo $3 D X^{\circledR}$ micro-CT é capaz de oferecer padrões precisos de 
visualização das características ósseas anatômicas e, ainda, complementaram, constitui-se em recurso bastante confiável para o planejamento de implantes.

Ballrick et al. (2008) avaliaram comparativamente tanto a qualidade de resolução espacial (capacidade técnica, associada ao equipamento, de distinção entre objetos posicionados em situação de limite de proximidade espacial), quanto a de obtenção de medidas a partir de imagens provenientes de tomográfo $i C A T^{\circledast}(i$ CAT ${ }^{\circledast}$ model 9140-0035-000C, Imaging Sciences International, Hatfield, Pa, E.U.A.). Cortes nos três planos de referência, e considerando todos os doze (12) ajustes comercialmente disponíveis pelo fabricante, foram selecionados de um fantoma convencional com marcadores metálicos de cromo (diâmetro de $0,3 \mathrm{~mm}$ ). As distâncias foram medidas três (03) vezes, tanto nas imagens tridimensionais, com auxílio do Programa de Visualização de imagens DICOM (Viewer), quanto diretamente no manequim com auxílio de paquímetro digital de pontas finas, a fim de favorecer a minimização de incidência de erros. Todas as imagens foram padronizadas em seus contrastes e brilhos, e a ampliação foi padrão. Trinta (30) avaliadores voluntários participaram dos testes de identificação dos intervalos de resolução qualitativa das imagens, quando então foram instruídos acerca dos critérios de inspeção. Análise de Regressão Multivariada foi aplicada para conhecer a qualidade das associações entre as variáveis ajustadas. Coeficientes de Determinação $\left(R^{2}\right)$ foram calculados para cada parâmetro e para a combinação dos dois parâmetros mais influentes. Coeficientes de Correlação Intraclasse (CCI) foram considerados para avaliar as medidas em tempos diferentes e, com isso, avaliar a confiabilidade inter-operador. Não foi oferecida descrição detalhada do procedimento de medição especificamente empregado, e nem de eventuais limitações dele decorrentes. Não obtiveram diferenças estatisticamente significantes associadas às imagens tridimensionais em termos de precisão de medida. Relataram excelente confiabilidade intra-operador $(\mathrm{CCl}=0.892)$, e também inter-operador para as concordâncias qualitativas ( 0.78 para a qualidade em distinguir entre duas linhas do fantoma; e 0.91 para a identificação de uma linha na imagem dele proveniente) Comparativamente aos valores da medição direta, ou exatidão, verificaram diferenças estatisticamente significantes $(p<0,01)$. Contudo, destacaram, esse valor de diferença provavelmente não seja clinicamente significante para a maioria das 
aplicações já que a diferença absoluta foi de $<0,1 \mathrm{~mm}$. Com vistas a minimizar vieses, indicaram ser útil a instrução ao operador de inspecionar o local mais denso em uma imagem a qual seja pouco definida (detalhe). As diferenças comparadas com outros autores, relataram, foram bastante reduzidas $(<0,1 \mathrm{~mm})$ e devem ter ocorrido devido ao efeito de volume parcial. Os autores destacaram a importância da resolução espacial no processo de inspeção tomográfica, lembrando que a resolução espacial pode ser melhorada com diminuição do tamanho do voxel e aumento do tempo de exposição. A diminuição do voxel, registraram, pode, de fato, influenciar diretamente a qualidade do detalhe de imagem. Obtiveram, a partir do cálculo do coeficiente de determinação (R2), que mais de cinquenta por cento $(50 \%)$ da variação total de resolução espacial da imagem pode ser explicada pelo tamanho do voxel. Diminuir ao extremo o tamanho do voxel pode, eventualmente e dependendo da qualidade do detector em aumentar a razão sinal-ruído proporcionalmente, gerar a presença de ruídos de imagem. Maior tempo de aquisição resulta em mais informação adquirida e, por conseguinte, melhor resolução espacial. Os resultados indicaram a qualidade do sistema $i C A T^{\circledR}$ para a obtenção de medidas lineares em todas as direções de aplicação, e que a resolução espacial pode ser otimizada a partir de ajustes de FOV, da utilização de voxel de menor tamanho e ainda com maior tempo de aquisição, desde que seja considerada a condição de maior dose proporcional de radiação. Concluíram que a resolução espacial foi menor (pior) para as aquisições (tempo de escaneamento) mais rápidas e com maiores tamanhos de voxel.

Chilvarquer et al. (2008), a partir de revisão compreensiva da literatura, descreveram particularidades técnicas associadas à evolução dos recursos de imagem radiológica, suas origens, indicações, características e limitações. Ênfase foi conferida às características e diferenças entre os sistemas geração tomográfica computadorizada. Breve análise comparativa foi oferecida entre os sistemas de TCMC e TCFC, destacando as inúmeras possibilidades e vantagens de aplicação clínica e experimental deste último. O sistema de TCFC, ainda, registraram: 
todas as afecções de tecidos duros do complexo maxilo-mandibular, avaliações sistemáticas da dinâmica das articulações temporomandibulares, planejamento de cirurgias ortopédicas e ortognáticas, planejamento da análise topográfica quantitativa dos remanescentes do rebordo alveolar tanto para o planejamento cirúrgico de reabilitações com o uso de implantes osseointegrados, bem como cirurgias periodontais. Mais recentemente, com 0 desenvolvimento de softwares específicos para análises cefalométricas tridimensionais, é possível a obtenção de reconstruções detalhadas da anatomia topográfica materializadas por meio de biomodelos e cirurgias virtuais guiadas (2008, Chilvarquer et al., p. 5).

Lembraram os autores que a TC é uma técnica que incorpora princípios de digitalização direta de imagem, ou seja, são imagens eletrônicas obtidas por meio de radiografias seccionais de uma determinada parte do corpo humano. Concluíram que tanto a TCMC (TC), quanto a TCFC (TCV) podem oferecer reformatações exatas do complexo maxilo-mandibular, com melhores resoluções de contraste (proporcionalmente) para tecidos mineralizados com o sistema de TCFC, mas que, para tecidos não mineralizados, o sistema de TCMC ainda representava uma opção superior. A menor liberação de radiação ionizante pelo sistema de TCFC traduz-se em vantagem geral, embora, salientaram, o risco radiobiológico seja uma função da dose estocástica, ou seja, cumulativa.

Hulley et al. (2008) salientaram a importância do critério durante 0 delineamento metodológico dos experimentos clínicos. As aferições descrevem fenômenos em termos que podem ser analisados estatisticamente e a validade de um estudo depende da capacidade que as variáveis delineadas possuem de representar os fenômenos de interesse. Os autores expuseram problemática inerente às decisões metodológicas ou escolhas relativas à necessidade de agregar qualidade aos resultados. Entre os fatores de relevância destacados estão a seleção da escala de medida, o reconhecimento da fontes de erro sistemático e aleatório e a interpretação dos conceitos de acurácia e precisão derivados dos resultados com vistas à ação preferencial. Enfatizaram que variáveis contínuas são preferíveis pois a informação nelas contida aumenta a eficiência estatística. Recomendaram a adoção de condições relevantes durante o processo de delineamento experimental, 
como a padronização dos métodos de aferição, treinamento e certificação dos operadores; a otimização de aplicação dos instrumentos e técnicas, incluindo possibilidades de automação no processo experimental. Descreveram a conceituação de dois termos fundamentais ao entendimento das qualidades de valoração da pesquisa clínica, a saber: Exatidão (acurácia) - de uma variável é a capacidade desta de representar realmente o que deveria representar (mensurando real). Esta qualidade influencia direta e significativamente a validade dos estudo, já que estabelece o grau de confiança associada à correta aplicação inferencial relativa a fenômenos que ocorrem tanto na amostra quanto no universo de onde proveio a referida amostra. Exatidão e precisão são conceitos distintos, porém interdependentes, de modo que muitas das estratégias empreendidas para aumentar a precisão, acabam também por aumentar a exatidão. A exatidão é função do erro sistemático, e a precisão, do aleatório ou causal. As principais fontes de erro sistemático são: viés de observação, viés de seleção e viés de instrumentação; Precisão - uma medida de alta precisão é aquela que é reprodutível, isto é, cujos valores são semelhantes em cada aferição. A precisão tem influencia relevante no poder estatístico de um estudo. Quanto mais precisa for a medida, maior o poder que um determinado tamanho amostral ( $n$ ) possui em estimar os valores médios na população de origem e, com isso, obter maior representatividade para os testes de hipótese. A precisão também é denominada de reprodutibilidade, confiabilidade e consistência. É influenciada diretamente pelo erro aleatório (variabilidade devido ao acaso). Quanto maior for o erro, menor será a precisão da aferição. Há três fontes principais de erro nas aferições: variabilidade do observador, variabilidade do instrumento e variabilidade do sujeito.

Palomo et al. (2008) apresentaram descrição pormenorizada de alguns fatores de influência associados ao diagnóstico e tratamento das principais condições periodontais indesejáveis associadas à prática ortodôntica, bem como discutiram o modo de participação destas em relação às informações diagnósticas disponíveis. Mecanismos de dano tecidual, Tratamento do paciente acometido por infecção, Opções de tratamento e justificativas, Hiperplasia gengival, Intervenções para o paciente de risco, Procedimentos gengivais reconstrutivos, Dentes 
impactados e Solução ortodôntica para problemas periodontais, foram os temas abordados nesta revisão crítica.

[...] o termo sinergia refere-se à interação entre diversos fatores agindo organizadamente a fim de que seja criado um efeito maior do que das partes separadas; em outras palavras, o todo é maior que as partes. Ortodontistas deveriam reconhecer os possíveis riscos periodontais aos pacientes submetidos ao tratamento ortodôntico (Palomo et al., 2008 p. 229).

Além de referendar a utilização de fontes digitais oficiais para a obtenção de informação técnica especializada, como um dos recursos circunstancialmente importantes ao conhecimento das atualidades e inovações tecnológicas, concluíram que a obtenção de desfechos clínicos ótimos depende da experiência durante a avaliação interdisciplinar, a qual requer coordenação, comunicação e compromisso profissional.

Scarfe e Farman (2008), a partir de revisão da literatura, descreveram as características técnicas e principais aplicações dos efeitos de imagens geradas por sistemas de TCFC, desde sua preconização para avaliações angiográficas, sendo também utilizada para guiar os procedimentos médicos de radioterapia e mamografia, até a presente condição de aplicabilidade. Exploraram, a partir do conhecimento dos equipamentos e técnicas disponíveis, questões relevantes e associações importantes entre exatidão (acurácia) e precisão de medida, bem como dosagens de radiação, tempo de exposição e as diversas modalidades de utilização deste exame complementar. Salientaram ser fato conhecido que os procedimentos radiográficos convencionais, intra e extra-bucais, produzem limitações inerentes às projeções bidimensionais (planares em 2D), tais como magnificação, distorção, superposição e interpretação equivocada da imagem dos limites entre estruturas anatômicas associadas. Campos de visão maiores teriam a desvantagem de produzir menor resolução final associada à presença de ruído de imagem e ainda baixa resolução de contraste, em decorrência da detecção acentuada de radiação dispersante. Os detectores tomográficos inicialmente desenvolvidos eram constituídos de intensificadores de imagem (CCD), os quais determinavam maior incidência de prejuízos associados à qualidade final das imagens geradas, vindo a 
ser posteriormente substituídos pelos detectores flat panel, os quais são detectores indiretos de feixes, possuindo maior área de detecção de pixels, com diminutos sensores de silicone amorfo hidrogenado associados. Os detectores flat panel propiciam a geração de imagens com maior exatidão (acurácia). A obtenção de registros tomográficos volumétricos depende de quatro estágios: a) configuração de aquisição; b) detecção da imagem; c) reconstrução da imagem, e d) apresentação (visualização) da imagem. Os autores explicaram que a partir da geração inicial de vários cortes bidimensionais (quantidade fixa, entre 150 e 600 cortes para os tomógrafos disponíveis, à exceção do $i C A T^{\circledR}$, onde a quantidade é variável), as imagens são então reformatadas (recombinação) em um volume total (dados de projeção), o qual passa a estar virtualmente/digitalmente disponível às várias possibilidades de corte oferecidas pelos sistemas tomográficos em suas particularidades técnicas, e considerando cortes proporcionais e precisos nos três planos do espaço. As possibilidades associadas aos campos de visão (FOV), ou dos volumes de escaneamento capazes de serem incluídos no registro volumétrico, irão depender da área e formato do detector, da geometria de projeção dos feixes e, ainda, da capacidade de colimação do mesmo (figura 2.3).
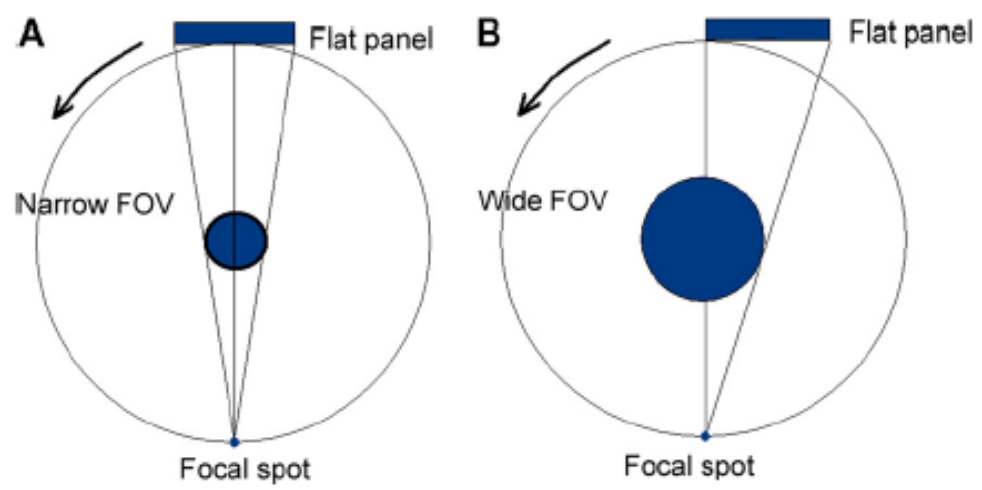

Figura 2.3 - Representação esquemática do modo convencional de direcionamento dos feixes para determinados FOV e flat panel (A), e deslocamento do detector (flat panel), colimando lateralmente os feixes, a fim de permitir otimização da amplitude de diâmetro do FOV (B)

Existem modos padronizados de FOV, mas que são nominados variavelmente conforme a predefinição industrial de aquisição volumétrica dos diâmetros pretendidos, sendo: local - aquele com aproximadamente $5 \mathrm{~cm}$ ou menos; simples arco - de 5 a 7cm; inter-arcos - de 7 a 10cm; maxilo-facial - de 10 a 15cm, e 
craniofacial - acima de $15 \mathrm{~cm}$. Salientaram os autores que quanto maior for a quantidade de projeções, considerando fixos os outros ajustes, maior será a capacidade de reconstrução das imagens e, desse modo, propiciando maior qualidade em termos de resolução espacial e contraste das mesmas, aumentando a razão sinal-ruído, produzindo contornos curvos mais regulares e, ainda, reduzindo a incidência geral de artefatos. Contudo, essa possibilidade exigiria maior dose de radiação ionizante e maiores tempos de aquisição e reconstrução primária, o que poderia influenciar diretamente a indicação do exame tomográfico a partir da observância dos critérios de interpretação constituídos pelo Princípio ALARA ("as low as reasonably achievable"). Devido a uma limitação inerente aos sistemas tomográficos, há a possibilidade de ser verificado o efeito de volume parcial, onde dois pixels vizinhos são ponderados, em média monocromática (cinza), em um só elemento de área de imagem devido à ocorrência de objetos, ou alvos de observação, muito próximos e apresentando densidades similares (padrão de atenuação) entre seus limites, com isso fazendo da observação um evento tecnicamente improdutivo, já que se faz presente o aspecto de "degrau" em relação ao limite de contorno tecidual, e/ou, ainda, de homogeneidade de imagens em um mesmo setor (pixel), quando esta não deveria estar presente. Alguns programas computacionais, operando com algoritmos complexos, podem minimizar o efeito desta condição, atenuando o prejuízo de acuidade visual durante a inspeção visual tomográfica. A resolução, e portanto o detalhe da imagem de TCFC, lembraram, são determinados pelos elementos individuais de volume (voxels) produzidos da aquisição volumétrica dos dados. Diferentemente da TC, onde as dimensões dos voxels dependem da espessura do corte tomográfico, no sistema de TCFC as dimensões daqueles elementos dependem primariamente do tamanho dos pixels presentes na área do detector. A resolução da área do detector é de exatidão sub milimétrica (variando de 0,07 a $0,4 \mathrm{~mm}$ ), condição esta que acaba por determinar primariamente a dimensão final do voxel. Com isso, e após a determinação dos cortes de interesse (coronais: oblíquos/trans-axiais, sagitais e/ou axiais) às análises bidimensionais (2D), são gerados os níveis conhecidos e satisfatórios de exatidão, aplicáveis às necessidades impostas pelas diversas especialidades odontológicas. Assim, e usualmente, o sistema de TCFC gera resoluções de voxel ditas isotrópicas, ou seja, padrão de resolução semelhante nas três dimensões consideradas do espaço (figura 2.4). 


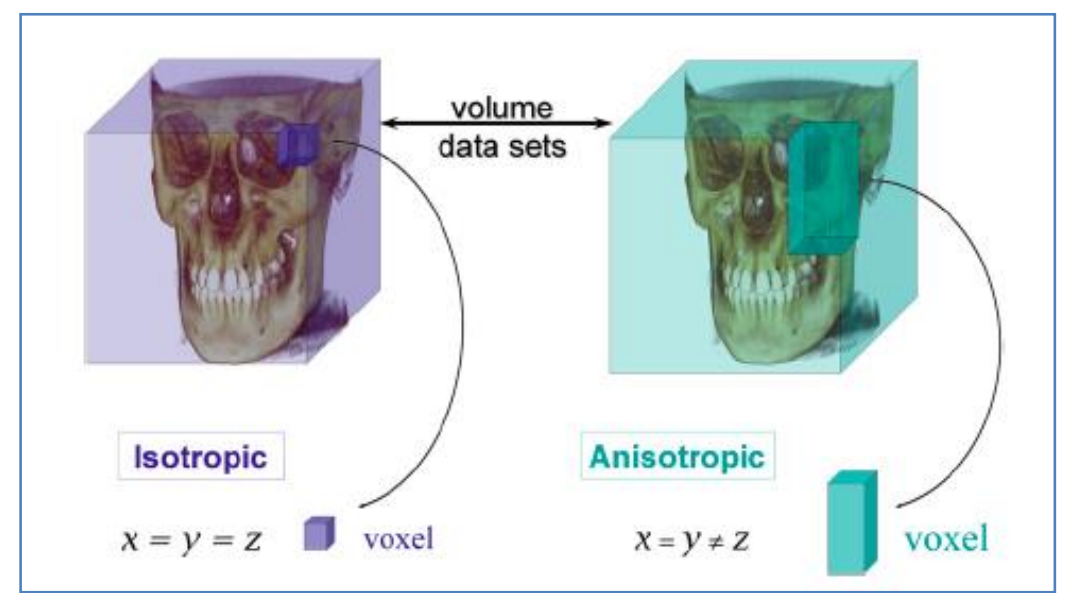

Figura 2.4 - Representação esquemática da diferença, associada ao elemento de volume (voxel), entre TCFC (isotrópico) (a) e TC (anisotrópico) (b)

Considera-se que o efeito de média ponderada entre densidades de uma dada quantidade, a qual seja menor que o tamanho do pixel/voxel e na sua área incluída, seja visualmente indistinguível em decorrência do efeito de mistura das densidades, interferindo assim na acuidade de identificação dos seus limites anatômicos.

Stratemann et al. (2008) testaram a exatidão (acurácia) de distâncias lineares medidas à partir de aquisições volumétricas (TCFC) de dois (02) sistemas distintos, - NewTom QR DVT 9000 (Aperio Inc., Sarasota, FL, E.U.A.) e o CB MercuRay ${ }^{\circledR}$ (Hitachi Medico Technology, Tokyo, Japão), com os respectivos softwares CB Works $^{\circledR} 1.0$ (CyberMed, Inc., Seoul, Korea) e Amira ${ }^{\circledR}$ (Amira 3.1, Mercury Computer Systems, GmbH, Berlin, Germany). Os parâmetros NewTom ${ }^{\circledR}$ foram: tempo de aquisição de 75s, gerando 360 imagens brutas, FOV cilíndrico de $13 \mathrm{~cm}$ e voxel de $0,29 \mathrm{~mm}$, com 8 bits por voxel $\left(2^{8}=256\right.$ tons de cinza). As medições diretas foram realizadas com paquímetro digital Mitutoyo ${ }^{\circledR}(C D-6$ "C Mitutoyo America Corp., Aurora, IL, E.U.A.), e todas pelo mesmo operador, em cinco (05) ocasiões distintas, separadas pelo tempo de uma (01) semana e com precisão de leitura de $0,01 \mathrm{~mm}$. Utilizaram um crânio seco e nele fixaram pequenas esferas metálicas, de modo que um total de sessenta e cinco (65) locais craniométricos foram registrados como referenciais à análise. Destacaram que o sistema de TCFC pode ser alternativa 
viável ao uso da TC, haja vista o menor tempo de aquisição e proporcional menor dose de radiação, o menor custo associado e, ainda, a exatidão bastante satisfatória e similar àquela obtida com os sistemas de TC. Salientaram que nas radiografias digitais, a cor do pixel é cinza, assim que as intensidades, do preto ao branco, são divididas entre o espectro de valores, com $2^{8}$ (256) tipos para dados com oito (8) bits, ou com $2^{12}$ (4.096) tipos de cinza para dados com doze (12) bits. Ultimamente, afirmaram, a resolução de imagem tem sido associada ao tamanho do pixel e ao número de tipos (tons) de cinza. Assim, o Erro Relativo (ER) aos dados volumétricos depende do tamanho de voxel e da escala de cinzas disponibilizada, já que o valor de intensidade aplicado à cada voxel depende, por sua vez, da intensidade média (ou atenuação dos feixes em unidades HU do material contido no volume). Com um tamanho menor de voxel, explicaram, menos material é mediado, resultando em uma participação mais exata (acurácia) de um dado valor de atenuação. Foi aplicada Análise de Variância (ANOVA - $\alpha=0.05$ ), bem como estimados os Erros Absolutos e Relativos associados. Concluíram que a distorção gerada pelos dois sistemas testados foi reduzida (NewTom ${ }^{\circledR}=0,07 \pm 0,41 \mathrm{~mm} /$ CB MercuRay ${ }^{\circledR}=0,00 \pm 0,22 \mathrm{~mm}$ ), com erro relativo (ER) menor que um por cento (1\%), corroborando estudos anteriores similares e, com isso, também aceitando a hipótese de que utilização de recursos de TCFC é capaz de gerar modelos com exatidão (acurácia) quando utilizados os padrões-ouro como referências. Embora tenham relatado limitações técnicas com os sistemas de TCFC, afirmaram que o avanço tecnológico dos equipamentos e softwares é bastante promissor para suplantar as dificuldades operacionais observadas.

Suomalainen et al. (2008), por meio de estudo comparativo tomográfico (TCFC e TC) observacional, e a partir de material ex vivo, avaliaram a exatidão (acurácia) de medidas lineares na região posterior da mandíbula. Os tomógrafos, softwares (nativos) e parâmetros selecionados foram: TCFC - 3D Accuitomo ${ }^{\circledR}$ (J. Morita Corp., kyoto, Japão), com programa Ortho $C T^{\circledR}, 80 \mathrm{kVp}, 3 \mathrm{~mA}, 17 \mathrm{~s}$, com voxel de $0,25 \mathrm{~mm}$ e corte reconstruído de $1 \mathrm{~mm}$; TC - Light Speed Plus ${ }^{\circledR}$ (GE Medical Systems), com programa DentaScan ${ }^{\circledR}$, protocolos SE 759 e 905 respectivamente: 140/80KVp, 80/100mA, 0,8/1,0s. A posição da mandíbula (imersa em solução de sacarose), durante a aquisição volumétrica, foi mantida constante. As avaliações 
radiográficas foram conduzidas de modo independente, a partir da participação de dois (02) operadores (especialistas em Radiologia Oral), os quais avaliaram duas (02) vezes cada registro com a sequência de doze (12) locais de inspeção, com intervalo de duas (02) semanas. As imagens de qualidade duvidosa foram, por eles e previamente, descartadas. Imagens de cortes adjacentes foram utilizadas como recurso auxiliar às inspeções. Para a avaliação da variação intra e inter-operadores, Coeficientes de Correlação Intraclasse para medida simples (CCl) foram calculados. Exploraram os parâmetros técnicos a partir de ajustes das variáveis independentes consideradas (miliamperagem, quilovoltagem e tempo de aquisição) para os testes de regressão, com efeitos mútuos, enquanto que o Erro do Método (EM) foi a variável dependente (desfecho). Concluíram que o volume ósseo pré-operatório pode ser avaliado com suficiente exatidão por meio de TCFC, a qual é capaz de gerar menor dose de radiação ionizante e, ainda, oferecer medidas lineares bastante confiáveis às finalidades clínicas, com menor custo agregado. Também constataram que foi possível obter medidas confiáveis e exatas com protocolo de TCMC com dose reduzida.

O Vocabulário Internacional de Metrologia (VIM), por meio da descrição oficial do Instituto Nacional de Metrologia, Normalização e Qualidade Industrial (INMETRO, 2009) (grifos do autor), estabelece regras, parâmetros e diretrizes técnicooperacionais à realização de experimentos com processos de medição, valorizando o entendimento da Metrologia, bem como da importância do reconhecimento e das possibilidades de aplicações-padrões das convenções para a normalização de quantidades. Conceitos de: grandezas e unidades, sistemas de unidades, unidades de medida, medição, mensurando, princípio de medição, método de medição, procedimento de medição, resultado de medição, valor medido, valor verdadeiro. $\mathrm{E}$ ainda: de exatidão de medição (acurácia), erro sistemático, precisão de medição, erro aleatório, erro sistemático, condição de repetitividade, condição de precisão intermediária e condição de reprodutibilidade, foram descritos em sua classificação convencional, importância e aplicação geral (Anexo A - VIM, p. 254). 
médicos - assim como professores e técnicos envolvidos no planejamento e na realização de medições, independentemente do nível de incerteza de medição e do campo de aplicação. Ele também se propõe a ser uma referência para Organismos Governamentais e Intergovernamentais, Associações Comerciais, Organismos de Acreditação, Agências Reguladores e Associações Profissionais (Inmetro, 2009).

Condições de experimentação associadas à confiabilidade dos resultados são atualmente descritas:

Condição de Repetitividade: a condição de medição num conjunto de condições, as quais compreendem o mesmo procedimento de medição, os mesmos operadores, o mesmo sistema de medição, as mesmas condições de operação e o mesmo local, assim como medições repetidas no mesmo objeto ou em objetos similares durante um curto período de tempo.

Condição de Precisão Intermediária: a condição de medição num conjunto de condições, as quais compreendem o mesmo procedimento de medição, os mesmos operadores, o mesmo sistema de medição, o mesmo local e medições repetidas no mesmo objeto ou em objetos similares, ao longo de um período extenso de tempo, mas pode incluir outras condições que envolvam mudanças.

Condiçãa de Reprodutibilidade: a condição de medição num conjunto de condições, as quais compreendem diferentes locais, diferentes operadores, diferentes sistemas de medição e medições repetidas no mesmo objeto ou em objetos similares.

Repetitividade de medição: é a precisão de medição sob um conjunto de condições de repetitividade.

Precisão Intermediária de medição: é a precisão de medição sob um conjunto de condições de precisão intermediária.

Reprodutibilidade de medição: é a precisão de medição sob um conjunto de condições de reprodutibilidade.

Baumgaertel e Hans (2009) estudaram a espessura óssea cortical vestibular de todos os locais interdentários com vistas a favorecer o entendimento analítico das possibilidades de aplicação de mini implantes de ancoragem ortodôntica (esquelética). Enfatizaram que mais importante que a avaliação da densidade óssea, 
para a estabilidade primária destes dispositivos, é a espessura do osso cortical. Utilizaram trinta (30) crânios secos de adultos. A aquisição tomográfica foi conduzida com os dentes intercuspidados, e a partir de tomógrafo CB MercuRay ${ }^{\circledR}$ (Hitachi Medical, Tokyo), com FOV de 9 pol., $100 \mathrm{kVp}$ e $10 \mathrm{~mA}$. Cortes trans-axiais de espessura de $0,28 \mathrm{~mm}$, correspondentes a cada uma das áreas de contato, foram obtidos de modo que atravessassem as raízes de todos os dentes. O software de operacionalização e visualização foi o Accurex $^{\circledR}$ (CyberMed, Seoul, Korea). A demarcação enter tipos de ossos foi obtida manualmente por meio de discriminação visual de cinza-branco, onde cinza correspondia ao tecido ósseo, e branco ao osso cortical. A medidas foram codificadas e agrupadas em sextantes. Em cada uma das áreas interdentárias avaliadas, níveis de medição em 2, 4 e 6mm, a partir da crista óssea alveolar, foram considerados. As medidas foram realizadas perpendicularmente à superfície óssea utilizando a "função régua" do programa Accure $x^{\circledast}$. Assim, os referenciais de medição foram fixos em direção vertical, e as espessuras ósseas foram definidas de modo não ortogonal e dependente das condições de obtenção dos registros (variável). Apenas um (01) operador foi considerado para este estudo e, como parâmetro de teste de confiabilidade intraoperador, todas as medidas foram realizadas duas vezes para dez (10) dos crânios secos (ex vivo) disponíveis, os quais foram aleatoriamente selecionados e as sessões mantiveram o intervalo de duas semanas. Porém, não foram detalhadas as características funcionais do processo de registro e de medição tomográfica (padronização das imagens, posicionamento das mesmas, ampliação de visualização, critérios de inspeção e identificação, e precisão de medição). Os dados foram tabulados e analisados conforme Análise de Variância (ANOVA) para as diferenças entre espessuras, e a confiabilidade intra-operador foi avaliada por meio de cálculo de Coeficientes de Correlação Intraclasse (CCI). Nível de significância ( $\alpha$ ) de $5 \%$ foi selecionado. Relataram confiabilidade intra-operador significativa (0.90), e as medidas, declararam, provaram ser reprodutíveis. A análise estatística indicou que as espessuras ósseas corticais vestibulares, em média, foram mais espessas na mandíbula que na maxila. Concluíram que as espessuras ósseas corticais vestibulares maxilares, definidas no experimento, parecem variar de acordo com padrões distintos. Conforme destacaram, o conhecimento destes padrões pode servir como auxiliar aos clínicos à seleção dos melhores locais de instalação dos mini implantes. 
Brown et al. (2009) investigaram comparativamente os efeitos da variação do número de projeções de dados, propiciado pelo sistema de aquisição tomográfica iCAT ${ }^{\circledR}$ (Imaging Sciences International, Hatfield, Pa, CA, E.U.A.), na qualidade da precisão e exatidão (acurácia) relativas à identificação de medidas lineares, representadas por grandezas cefalométricas específicas e com visualização do volume a partir da reconstrução. A amostra foi constituída de dezenove (19) crânios secos (ex vivo) humanos, dentados (dentadura permanente completa), com oclusão estável e reproduzível, e presença de e tamanhos cranianos similares. Quinze (15) referenciais craniométricos, dos quais nove (9) eram bilaterais, foram identificados em cada crânio utilizando marcadores metálicos. Os referenciais foram selecionados de modo que pudessem constituir dimensões lineares representativas nos três planos do espaço. $O$ valor anatômico verdadeiro fora determinado a partir de médias das repetições intervalares do mesmo operador, e, ainda, de um operador adicional. Foi utilizado paquímetro digital eletrônico (27-500-90 GAC, Bohemia, NY, E.U.A.). A fim de fossem propiciadas as condições de simulação de atenuação dos tecidos não mineralizados, dois balões de látex, preenchidos com água, foram posicionados dentro dos crânios. Os registros tomográficos foram obtidos a partir de tomógrafo $i C A T^{\circledast}\left(i-C A T^{\circledR}\right.$, Imaging Sciences International, Hatfield, Pa, E.U.A.), conforme FOV de $17 \mathrm{~cm}$ (diâmetro) $\times 13 \mathrm{~cm}$ (altura), e resolução espacial de voxel de $0,4 \mathrm{~mm}$. Três pré-ajustes de escaneamento foram definidos com vistas a gerar três padrões distintos de projeção de dados: a) TCFC 10s/153projeções; b) TCFC 20s/306 projeções, e c) TCFC 40s/612 projeções. Os dados foram exportados em extensão DICOM, para o programa computacional Dolphin $3 D^{\circledR}$ (v.10, Dolphin Imaging Chatsworth, CA, E.U.A.). Utilizaram método da segmentação (ajuste manual dos limites visíveis entre pixe/s) para ajuste da imagem. A imagem da posição da cabeça foi orientada por meio do próprio recurso computacional e a partir do Plano Horizontal de Frankfurt. Foram utilizados os recursos de medida próprios do programa de operacionalização das imagens (Dolphin $\left.{ }^{\circledR}\right)$, embora não tenham sido apresentadas as características do procedimento de medição empregado, e nem de eventuais limitações dele decorrentes. As medidas foram repetidas três vezes pelo operador principal. Médias de medida, considerando os tipos de grupo, foram comparadas com o modelo linear geral de medida repetida usando o Teste 
Multivariado de Wilks lambda $(p \leq 0,05)$ e Ajuste de Sidak para as comparações múltiplas. Observaram a probabilidade de ter existido incidência de maior variação inerente ao processo de inspeção e identificação dos referenciais tomográficos craniométricos, e afirmaram, ainda, que o resultado clinicamente mais relevante encontrado foi o de não haver diferença estatisticamente significante relativa à exatidão das medidas obtidas a partir das imagens 3D melhoradas (renderizadas), não importando quantas projeções tenham sido utilizadas para a reconstrução volumétrica. Esta condição, lembraram, pode ser particular e clinicamente interessante àqueles equipamentos que operam em regime de pulsos, como é o caso do $i C A T^{\circledR}$, pois a exposição do paciente à radiação ionizante poderá ser reduzida. Verificaram que algumas áreas com menos voxels resultaram em maior dificuldade de inspeção visual e identificação (demarcação). Os autores concluíram que mais projeções (612) tiveram efeito equiparável, em termos de exatidão de imagem, a menos projeções (153), aumentando assim o potencial de redução da radiação em até $75 \%$ do valor total esperado. Enfatizaram que as medidas lineares analisadas, considerando o modo 3D de visualização cefalométrica do software utilizado, apresentaram-se com exatidão (acurácia) variável.

Kameoka et al. (2009) investigaram quantitativamente a exatidão (acurácia) produzida por micro tomografia computadorizada aplicada a lesões quimicamente induzidas. Simularam quimicamente um modelo de artrite por meio de injeção de coquetel (CFA) em um dos lados articulares. Os defeitos foram macroscópica e qualitativamente avaliados para a constatação ou não de concordância intra e interoperadores em relação às classes de defeitos incluídas. Os resultados desta avaliação serviram como referência padrão-ouro às comparações subsequentes. $O$ protocolo de aquisição tomográfica foi de acordo com tomógrafo $R \_\mu C T^{\circledast}$ (Rigaku CO., Tokyo, Japão), o qual dispõe de detector flat panel com matriz efetiva de

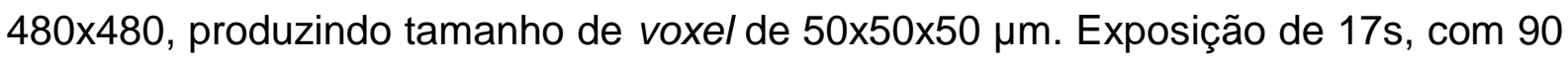
$k \bigvee p$ e $177 \mu \mathrm{A}$ foi utilizada, gerando um total de 512 projeções disponíveis à reconstrução volumétrica. O processamento das imagens foi a partir do software IView- $R^{\circledR}$ (Rigaku Co., Tokyo, Japão). Os operadores não foram informados dos resultados tomográficos quando da avaliação macroscópica qualitativa, e se a concordância entre os cinco examinadores diferia, então eram repetidas as 
avaliações até que no mínimo três examinadores concordassem com os padrões dos defeitos. Registraram sensibilidade, especificidade e exatidão de 0.96, 1.0 e 0.98 respectivamente, confirmando a boa concordância entre os modos de avaliação selecionados para a identificação de osso cortical normal, osteófitos condilares e ainda erosão óssea. Concluíram que a técnica de micro tomografia computadorizada $(\mu \mathrm{CT})$ é efetiva para a detecção de anormalidades ósseas em escala bastante diminuta, sugerindo alto rendimento diagnóstico.

Mileman e van den Hout (2009) estudaram algumas das inúmeras propostas metodológicas aplicadas corriqueiramente na prática clínica e científica experimental, com a finalidade de esclarecer acerca dos graus de concordância destas (em sua variação apresentada) com a conceituação atual de diagnóstico elaborado à luz da "prática baseada em evidências". Destacaram que a prática de combinar as informações clínicas, com aquelas obtidas a partir de exames complementares, especificamente as dos exames de imagem radiológica, constituise em uma das mais frequentes realizadas pelo clínico geral, e que a correta identificação das condições patológicas e/ou desfavoráveis depende de inúmeros fatores relevantes, tais como a experiência do operador, a qualidade dos testes de diagnóstico selecionados (considerados os equipamentos utilizados, as técnicas e as relativas precisão e exatidão registradas), o tipo de doença ou problema e, ainda, o padrão epidemiológico de distribuição destas condições desfavoráveis. Enfatizaram que o teste ideal de diagnóstico deve oferecer informação confiável, sem que, para isso, seja modificada a condição da saúde do paciente, e que esta informação seja obtida rapidamente e, preferencialmente, com baixo custo. Os procedimentos de obtenção radiológica de imagem geralmente dependem da capacidade interpretativa dos examinadores. Assim, declararam, o examinador acaba por fazer parte do sistema de diagnóstico. A seleção do(s) padrão(ões)-ouro deve ser cuidadosamente estabelecida e, preferencialmente, com técnica diferente daquela que está sendo utilizada para os testes. Conforme salientaram, recomendase, para testes de exatidão (acurácia), que uma imagem seja comparada com resultados obtidos de técnicas de preparo histológico e/ou de biópsias. Contudo, também há risco de serem inferidas condições diversas daquelas constatadas clinicamente. Geralmente os trabalhos de avaliação da qualidade diagnóstica estão 
associados à análise do amplo espectro de abrangência do rendimento dos sistemas de diagnóstico. A sensibilidade de um teste representa a porcentagem de casos da doença para a qual o teste é, de fato, positivo. A especificidade de um teste representa a porcentagem de casos sem a doença para a qual o teste é, de fato, negativo. Essas qualidades de teste, lembraram, são geralmente entendidas como sendo independentes das informações de prevalência da doença avaliada, mas que podem variar dependendo da severidade da doença em um dado estudo populacional. Um dos problemas associados aos testes de se sensibilidade e especificidade, destacaram, é que estas qualidades são inversamente relacionadas. Com isso, muitos estudos médicos acabam por depender de valores de limiar numérico para a distinção entre resultados de normalidade e anormalidade gerados por estes referidos testes. Curvas de Características de Operação do Receptor (ROC) graficamente representam a natureza da dependência entre sensibilidade e especificidade. A área sob a curva ROC (denominada $A z$ ) provê uma medida da capacidade do teste em distinguir pacientes com doença daqueles sem doença, sem especificar o ponto de corte usado para o teste, e ainda sem distinguir a diferença de importância ao paciente dos erros de falso-positivo e falso-negativo. A área sob a curva ROC pode variar de 0.5 (um teste não informativo) a 1.0 (um teste o qual discrimina perfeitamente as condições de saúde e doença). Os autores enfatizaram a observância aos critérios Internacionais padronizados de obtenção de evidências para o diagnóstico, a partir da inciativa STARD, a fim de que sejam compreendidas as variações metodológicas entre os estudos, as quais são capazes de estagnar o avanço científico para a geração de conteúdos técnicos específicos, os quais deveriam ser realmente informativos, fazendo da decisão clínica uma ação verdadeiramente acertada, menos sujeita a erro, e baseada em evidências sistematizadas.

Noujeim et al. (2009) propuseram avaliação comparativa entre imagens tomográficas volumétricas (TCFC) e radiografias periapicais digitalizadas. Em revisão, ponderaram acerca dos fatores responsáveis pela incidência de erros durante a inspeção de lesões periodontais associadas à perda óssea local. Entre estes, estão erros devido ao equipamento e técnica, método e, ainda, conhecimento prévio do(s) operador(es). Foram simuladas cento e sessenta e três (163) lesões 
periodontais em crânios secos, e sessenta e cinco (65) locais sem interferência simulada serviram como grupo controle. As lesões simuladas foram conforme profundidades distintas, sendo que cinquenta (50) locais apresentavam lesões diminutas (de 01 a $03 \mathrm{~mm}$ ) e quarenta e oito (48) apresentavam lesões extensas (de 3 a $6 \mathrm{~mm}$ ). Todos os locais estiveram em região de molares e pré-molares. $\mathrm{O}$ tomógrafo utilizado foi Accuitomo $^{\circledR}$ (J. Morita, Tokyo, Japão), e conforme os parâmetros de aquisição: $60 \mathrm{kVp}, 5 \mathrm{~mA}, 180^{\circ}$ de rotação, matriz de $312 \times 312$ pixels, voxel de $0,125 \mathrm{~mm}$ e com volume específico de $3 \mathrm{~cm}$ de altura por $4 \mathrm{~cm}$ de diâmetro. A espessura de corte tomográfico, a partir do volume reformatado, foi de $1 \mathrm{~mm}$, e então foi exportada para outro software (para a subsequente operacionalização. Dez (10) operadores participaram das observações (oito tinham treinamento avançado em Radiologia MaxiloFacial - quatro residentes e quatro graduandos de Odontologia; e dois com treinamento avançado e Periodontia). As imagens foram aleatorizadas com vistas a serem evitados vieses de seleção do operador, diminuindo a chance de acerto por reconhecimento prévio dos padrões inerentes às imagens. Os testes foram realizados em sala escura e os operadores tinham controle da intensidade de iluminação. Computador pessoal Sony Vaio ${ }^{\circledR}$ P4 (Sony Corp., Tokyo) e software i-Dixe ${ }^{\oplus}$ (nativo Accuitomo $3 D X^{\circledR}$ ), foram utilizados. A avaliação (observação) foi categorial (qualitativa) para as classes definidas de defeitos. Curvas ROC foram analisadas para a informação de estimativa de exatidão diagnóstica considerando as duas modalidades de obtenção de imagem. A hipótese da nulidade (Ho) foi rejeitada e a técnica associada ao sistema de TCFC provou ser mais efetiva que à radiografia periapical para a detecção de defeitos ósseos periodontais interradiculares, e conforme várias as várias extensões simuladas. Os autores salientaram ainda a importância de ser realizado treinamento prévio instrucional aos operadores a fim de que fossem favorecidas as chances de aumentar a eficiência dos registros. Registraram que o tempo de registro, com as imagens tomográficas, foi discretamente maior que aquele utilizado com as imagens radiográficas periapicais, revelando, conforme afirmaram, a importância da "curva de aprendizado" do operador. Concluíram em favor do sistema de TCFC, enfatizando que, em estudos clínicos, os padrões de resultado podem ser diferentes. 
Suomalainen et al. (2009) compararam as doses de radiação decorrentes da utilização de quatro sistemas de aquisição tomográfica volumétrica (TCFC), e dois de tomografia convencional (TC). Os sistemas de TCFC utilizados foram: dois (02) tomógrafos 3D Accuitomo ${ }^{\circledast}$ (J. Morita MFG Corp., Kyoto, Japão), Promax 3D ${ }^{\circledR}$ (Planmeca, Helsinki, Finlândia) e Scanora $3 D^{\circledR}$ (Soredex, Tunsula, Finlândia). Os sistemas de TCMC foram: GE 4-slice Light Speed Plus ${ }^{\circledR}$ (General Electric Medical Systems, Milwaukee, WI) e GE-64 slice Light Speed VCT ${ }^{\circledR}$ (General Electric Medical Systems). Utilizaram fantoma RANDO ${ }^{\circledR}$ (Radiation Analogue Dosimetry System, Nuclear Associates, Hicksvilee, NY, E.U.A.), preparado com cortes de 2,5cm de espessura e orifícios contendo os dosímetros, os quais permitiram a mensuração da dose de radiação absorvida em sua distribuição considerando os tecidos críticos dose efetiva. Concluíram que os sistemas de aquisição volumétrica (TCFC) proporcionam adequados padrões de qualidade de imagem para avaliações dentofaciais, enquanto liberam quantidades consideravelmente menores de radiação ionizante efetiva ao paciente, quando comparados aos protocolos de TCMC.

Zanet (2009) propôs a elaboração de um programa computacional específico, o qual pudesse auxiliar no processo de interpretação do diagnóstico radiográfico e pedagógico das alterações ósseas do complexo maxilo-mandibular. Utilizou software Delphi $7^{\circledR}$ na formulação da interface de avaliação, o programa $M S$ Access ${ }^{\circledR}$ na construção do banco de dados e o programa MS SQL Server ${ }^{\circledast}$ para o gerenciamento do referido banco de dados. As informações contidas no banco de dados seguiu a classificação WHO-CTPG/2003. Para validação do software, foram selecionadas 20 radiografias panorâmicas que possuíam o laudo anátomo-patológico e que apresentavam características de lesões ósseas radiolúcidas, uni ou multiloculares. Doze (12) cirurgiões-dentistas (6 especialistas e 6 generalistas) participaram do processo metodológico, o qual se constituiu de 3 fases: I - Interpretação da imagem da radiografia panorâmica e fornecimento de hipóteses diagnósticas pelos C.D., II Utilização do software para interpretação das radiografias, e III - Comparação das respostas das Fases I e II. Após as avaliações, os participantes responderam a um questionário de opinião referente ao software. Os resultados foram submetidos à análise discriminante e aos testes Wilcoxon e Mann-Whitney. $O$ autor concluiu que 0 nível de conhecimento entre especialistas e clínicos generalistas não interferiu no 
resultado final da utilização do software. O software possui aplicabilidade no processo de decisão clínica por meio de recursos de identificação das características radiográficas e aplicabilidade pedagógica como meio colaborativo na construção de hipóteses diagnósticas. Somado todos os resultados, obteve a validação do Programa Computacional (software) proposto.

Damstra et al. (2010) determinaram a exatidão (acurácia) linear da superfície de modelos 3-D derivados de um sistema de TCFC disponível comercialmente a partir de softwares combinados: a) $3 D$ eXam $^{\circledR}$ Scanner (Kavo Dental GmBH, Bismarckring, Germany); b) eXam Vision ${ }^{\circledR} Q$ (Imaging Sciences International, Hatfield, Pa, CA. E.U.A.), e Sim Plant Ortho $\operatorname{Pro}^{\circledR}$ (v. 2.00, Materialise Dental, Leuven, Bélgica). As imagens foram processadas em formato DICOM, e avaliadas em computador pessoal (laptop). Utilizaram dez (10) mandíbulas secas (ex vivo) parcialmente dentadas de adultos selecionadas de Acervo de Material Humano ex vivo do Centro Médico Universitário de Gröningen. Foram descartadas mandíbulas, as quais continham dentes com restaurações metálicas a fim de controlar a incidência de artefatos de imagem. Utilizaram, como medida de confiabilidade, o cálculo dos Coeficientes de Correlação Intraclasse (CCl) para o conhecimento da qualidade de concordância absoluta a partir da variação calculada com análise de variância (ANOVA), e para os três métodos de medida: paquímetro digital, voxel de $0,4 \mathrm{~mm}$ e voxel de $0,25 \mathrm{~mm}$. Para a determinação da exatidão (acurácia) linear dos procedimentos de medida entre imagens tomográficas e medições diretas com paquímetro digital, o Erro Padrão de Medida (EPM/SEM) foi utilizado, a partir de dados gerados de três (03) sessões de consecutivas de análise tomográfica, como sendo a variância do erro aleatório. As medidas obtidas da análise tomográfica e da medição direta mostraram excelente confiabilidade intra e inter-operador, com valores de $\mathrm{CCl}$ de 1.00 (perfeita concordância). A menor diferença detectável (SDD/MDD), calculada para determinar a exatidão (acurácia) das medidas tomográficas, foi de $0,03 \mathrm{~mm}$ para o tamanho de voxel de 0,40 , e de $0,02 \mathrm{~mm}$ para a resolução de voxel de $0,25 \mathrm{~mm}$. A MDD para as medições diretas (paquímetro digital) foi de $0,03 \mathrm{~mm}$. Os autores salientaram as dificuldades e limitações relativas à extrapolação de resultados ex vivo para a realidade clínica, e encontraram maior tendência à subestimação do que à superestimação linear e, ainda, e detalhando, 
que a subestimação foi menor com o voxel de $0,25 \mathrm{~mm}$, comparativamente ao de $0,40 \mathrm{~mm}$; e que a superestimação foi maior com o voxel de $0,25 \mathrm{~mm}$, comparativamente ao de $0,40 \mathrm{~mm}$, confirmado, deste modo, a participação do erro sistemático quanto à direção de poder de detecção dos tamanhos de resolução dos voxels avaliados $(0,25 \mathrm{~mm}$ e $0,40 \mathrm{~mm})$, tanto para a estimativa de inexatidão de subestimação, quanto para a de superestimação.

Kamburoglu et al. (2010) avaliaram a exatidão (acurácia) e precisão (reprodutibilidade) de medidas de defeitos periapicias quimicamente criados e avaliados tomograficamente por meio de TCFC. Utilizaram dezoito (18) cortes de dentes mandibulares (ex-vivo). As mandíbulas foram dissecadas com auxílio de brocas para osso, resultando assim na obtenção de cortes trans-axiais similares àqueles obtidos tomograficamente. Os cortes foram medidos diretamente em sua profundidade e diâmetro com paquímetro digital (Shinua ${ }^{\circledR}$, Co. Osaka, Japão) de exatidão equivalente a $0,01 \mathrm{~mm}$. Cada distância foi medida duas vezes, e a média dos valores foi utilizada como padrão-ouro para a avaliação tomográfica comparativa. A fim de que fosse evitado viés de observação, as medidas in loco foram realizadas por anatomista, enquanto que as tomográficas foram executadas por dois especialistas em Radiologia Bucal. Os dezoito (18) cortes foram então embebidos em cera e divididos em quatro grupos para o registro tomográfico. Cada grupo foi imerso em recipiente com água destilada, feito de Pexiglas $^{\circledR}$, com a finalidade de simular o efeito dos tecidos não mineralizados. $O$ registro tomográfico foi realizado com scanner NewTom ${ }^{\circledR}$ G Plus (Quantitative Radiology, Verona, Itália). Campos de visão (FOV) de 6 e 9 polegadas (15,24 e 22,86cm), com parâmetros de aquisição de $110 \mathrm{kVp}$ e 36 segundos de escaneamento (3,6s de exposição) foram selecionados. As especificações de observação foram, para os FOVs selecionados: FOV de 6": tamanho de pixel de 0,11m x 0,11 mm, diâmetro máximo de $100 \mathrm{~mm}$, voxel de $0,19 \mathrm{~mm}^{3}$; FOV de 9": tamanho de pixel de $0,15 \mathrm{~mm} \times 0,15 \mathrm{~mm}$, diâmetro máximo de $140 \mathrm{~mm}$, voxel de $0,29 \mathrm{~mm}^{3}$. A variação de miliamperagem para os respectivos FOVs foi de 1,5 a 5,8 mAs, e 4,96 a $21,07 \mathrm{mAs}$, com variação de radiação de 1,77 a $3,21 \mathrm{mGy}$. Cortes axiais de $0,2 \mathrm{~mm}$ de espessura, com intervalos de $0,5 \mathrm{~mm}$, e para um total de 30 a 48 imagens para cada dente avaliado, foram obtidos. As avaliações foram realizadas separadamente, em sala escura e por dois 
especialistas que possuíam experiência prévia com o software selecionado (NewTom ${ }^{\circledR} 3 G$ Software). As medidas tomográficas foram determinadas por meio de recursos do próprio software do equipamento e não foi descrito, em detalhe, o procedimento de medição utilizado, e nem de eventuais limitações dele decorrentes. Os operadores foram orientados a ajustar, caso julgassem necessário, a qualidade de contraste e brilho das imagens selecionadas às avaliações. As medidas fora realizadas duas (02) vezes e com intervalos de uma (01) semana. Os autores afirmaram que o rendimento técnico dos examinadores, a seleção dos pontos de referência, a sensibilidade do mouse e as possibilidades em termos de recursos do software são todos fatores importantes para o processo de medição das dimensões das lesões simuladas. Após conduzida Análise de Variância (ANOVA) para a avaliação da reprodutibilidade entre operadores; e análise de regressão para a qualidade de associação entre as medidas físicas diretas (paquímetro digital) e as tomográficas, obtiveram resultados de significativa confiabilidade intra e interoperadores, além de valores relevantes relativos aos coeficientes de regressão, quanto da análise da associação linear entre variáveis estudadas, de diâmetro (FOV de 6": $r^{2}=94,6 \%$; FOV de 9": $r^{2}=94,8 ; p<0,001$ ) e profundidade (FOV de 6": $r^{2}=99,3 \%$; FOV de 9": $\left.r^{2}=99,3 ; p<0,001\right)$ ósseas. Para o diâmetro, o desvios médios das medidas diretas foram de $0,0625 \mathrm{~mm}$ e $0,0895 \mathrm{~mm}$ para os FOVs de 6"e 9" respectivamente. Para a profundidade, os desvios médios foram de -0,100mm e 0,098mm respectivamente. Enfatizaram que as diferentes relações de exatidão (acurácia) obtidas, em comparação com aquelas de outros estudos, provavelmente ocorreram em decorrência da condição de difícil visualização provocada pelo tipo de bordas dos defeitos estudados (lesões), fossem eles simulados ou não. A decisão de se usar um ou mais observadores pode ser determinante para a qualidade dos resultados. Concluíram que as imagens tomográficas volumétricas são proporcionalmente mais adequadas, comparativamente àquelas produzidas por TC, para avaliações exatas e precisas de defeitos ósseos periapicais em escala do milímetro.

Leung et al. (2010) investigaram a exatidão e precisão da TCFC para o diagnóstico de fenestrações e deiscências ósseas naturalmente provocadas. Destacaram a considerável variabilidade metodológica quanto às propostas de 
estudos e experimentos, e que muitos dos delineamentos analisados não foram capazes de oferecer meios diretos de comparabilidade relativos à realidade clínica. Afirmaram também que o avanço dos recursos computacionais, concomitante às novas propostas de equipamentos de geração de tomografia volumétrica, propiciou a significativa e crescente utilização destes sistemas (TCFC) na prática clínica. Segundo Carranza et al. (2002, apud Leung et al., 2010):

[...] as fenestrações representam aquelas áreas isoladas onde a raiz dentária não possui cobertura óssea, mas apenas periósteo e gengiva sobre o referido defeito; e as deiscências, os defeitos ósseos onde áreas sem osso circundante incluem a margem coronária do osso alveolar, e, ainda, que estes defeitos diminuem a área de suporte para os dentes.

Os autores complementaram que, sob determinadas condições, os referidos defeitos podem comprometer a estabilidade dos resultados ortodônticos, além de promover efeitos irreversíveis ao periodonto (proteção e sustentação). Além destes defeitos ósseos, os autores também avaliaram a exatidão e precisão de medidas de altura óssea alveolar. Utilizaram amostra constituída de treze (13) crânios secos, contendo, no total, trezentos e trinta e quatro (334) dentes. Foi selecionado tomógrafo CB MercuRay ${ }^{\circledR}$ (Hitachi Medical Systems, American, Twinsburg, Ohio, E.U.A.) com o seguinte parâmetro de aquisição: $110 \mathrm{kVp}, 2 \mathrm{~mA}, 9$,6s e FOV de 12 pol. (30,48cm), com voxel resultante de $0,38 \mathrm{~mm}$. Imagens DICOM foram importadas ao software $\operatorname{Accurex}^{\circledR}$ (v. 1.1, CyberMed, Seoul, Korea), operacionalizado o em estação de trabalho para a transformação tridimensional dos cortes bidimensionais brutos (rendering). Os autores ilustraram parte do método de visualização e medição, o qual dependeu de adequação das imagens (em 3D) aos recursos métricos geométricos do software utilizado. Medidas de altura (linear) foram definidas da junção amelo-cementária (JAC) até a borda dos defeitos ósseos (final ou inicial). Além da avaliação quantitativa, realizaram avaliação qualitativa (dados categoriais) de sensibilidade e especificidade, bem como de valores preditivos. Deiscências foram classificadas como defeitos em forma de "V" que incluem as bordas ósseas marginais, e sendo maiores ou iguais a três $3 \mathrm{~mm}$. Todas as medidas realizadas foram ajustadas para um conhecido erro sistemático de medição do software, o qual subestima a distância entre dois pontos, à metade do voxe/ de cada ponto. Deste modo, $0,38 \mathrm{~mm}$ foram adicionados a cada medida a fim de fossem 
corrigidos os referidos erros sistemáticos do software. Consideraram apenas a avaliação da variação intra-operador como parâmetro integral de confiabilidade, a partir de noventa e um (91) locais de medição, os quais foram medidos duas vezes, com intervalo de duas (02) semanas a partir da primeira medição. Cálculos de Coeficientes de Correlação Intraclasse $(\mathrm{CCl})$ foram realizados. O padrão-ouro considerado foi aquele de média das medidas obtidas diretamente a partir de paquímetro digital (Code $n^{\circ} 500-171-20$, modelo $n^{\circ}$ CD-6 pol., CX Digimatic Caliper, Mitutoyo, American, Plymouth, MI, E.U.A.), com precisão de leitura de 0,01mm. Relataram que a altura linear da JAC até a borda do defeito ósseo foi mais exata que a medida até a borda óssea marginal. Justificaram este resultado em decorrência da diferença de resultado de densidades dos tecidos associados, e que esta característica seria uma função da resolução do voxel selecionado. Assim, as estimativas de altura a partir da JAC só poderiam ocorrer até o limite dimensional do voxel $(0,38 \mathrm{~mm})$. Em contraste, a identificação das bordas ósseas marginais está associada à detecção de tecidos com resolução de baixo contraste, e não do tamanho do voxel. Informaram que o limite de resolução espacial, considerando o sistema selecionado, foi de $0,668 \mathrm{~mm}$. Assim, o limite de resolução possível para as medidas das bordas ósseas seria de $0,6 \mathrm{~mm}$. Correntes reduzidas de miliamperagem piorariam ainda mais esta condição. Associando este fenômeno à qualidade dos tecidos locais, e ainda com Carranza et al. (2002, apud Leung et al., 2010), as densidades do cemento e osso são similares pois possuem conteúdos aproximadamente equivalentes de cristais de hidroxiapatita. $\mathrm{O}$ cemento tendo de 45 a $50 \%$ destes cristais; o osso em torno de $65 \%$ e, o esmalte, cerca de $97 \%$. Conforme indicaram, as limitações associadas à resolução espacial determinam que áreas ósseas com menos de 0,6mm de espessura são vistas tomograficamente como áreas sem osso circundante e, ainda, que a menor espessura óssea detectável (medível) foi de $0,6 \mathrm{~mm}$, sugerindo que esta seria a quantidade mínima detectável de osso em torno da raiz dentária. Concluíram que há limitações sistemáticas entre os delineamentos compulsados, os quais possivelmente poderiam interferir em algum aspecto dos resultados, e que as medidas em TCFC não são tão exatas quanto aquelas obtidas diretamente. As principais diferenças dever-se-iam às limitações de resolução espacial das imagens TCFC. As localizações das JACs foram exatas o suficiente em intervalos de 0,4mm. A localização das bordas ósseas marginais foi exata em intervalos de $0,6 \mathrm{~mm}$. A confiabilidade do método foi alta $(\mathrm{CCl}$ 
de 0.95). Finalmente, enfatizaram que quando um defeito ósseo é encontrado em imagens de TCFC, em metade das vezes haverá a constatação de deiscências verdadeiras. Quando um defeito não é encontrado tomograficamente (TCFC), quase que sempre não haverá, de fato, a constatação real do mesmo. Contudo, a confiabilidade técnica de obtenção de medidas em tomografia volumétrica foi garantida, e a baixa capacidade preditiva para fenestrações e/ou deiscências parece não ter relevância clínica dada à baixa prevalência destes defeitos na população.

Nowzari et al. (2010), em estudo descritivo clínico, investigaram a prevalência de larguras (espessuras) ósseas alveolares vestibulares, maiores ou iguais a $2 \mathrm{~mm}$, em torno dos incisivos centrais maxilares de cento e um (101) pacientes, com vistas a favorecer a avaliação tomográfica preliminar à aplicação de implantes dentários nos locais das extrações. Dois (02) observadores independentes avaliaram as imagens, as quais foram aleatoriamente obtidas de um Acervo Clínico de Documentações. As medidas foram obtidas a partir de locais diversos de avaliação vertical das espessuras ósseas, de 1 a $10 \mathrm{~mm}$ a partir das cristas ósseas alveolares. As imagens trans-axiais utilizadas foram selecionadas de dois sistemas distintos (TCFC) de aquisição, o NewTom $3 G^{\circledR}$ (QR s.r.l., Verona, Itália) e o Galileos Comfort ${ }^{\circledR}$ (Sirona, Long Island, E.U.A.). Foram descartados o registros que possuíam artefatos de imagem decorrentes da presença de aparelho ortodôntico, bem como aqueles em que as imagens dos locais correspondentes às junções amelo-cementárias (JAC) apresentavam-se distorcidas. A média de idade dos pacientes incluídos foi de 48,5 anos. Os parâmetros de aquisição foram: NewTom $3 G^{\circledR}-110 \mathrm{kVp}$, de 1 a $15 \mathrm{~mA}$, dose efetiva de $65 \mu \mathrm{Sv}$, tempo de escaneamento de $36 \mathrm{~s}$ (exposição de $5 \mathrm{~s}$ ), voxel de $0,3 \mathrm{~mm}$, escala de cinza de 12 bits, FOV de 7,9cm; Galileos ${ }^{\circledR}$ (Sirona, Long Island, E.U.A.), com $85 \mathrm{kVp}$, de 5 a $7 \mathrm{~mA}$, dose efetiva de $68 \mu \mathrm{Sv}$, tempo de escaneamento de $14 \mathrm{~s}$ (exposição de 2 a $6 \mathrm{~s}$ ), FOV de $15 \mathrm{~cm}$ e voxel de 0,3mm/0,15mm. As imagens foram convertidas em DICOM e operacionalizadas a partir de computador pessoal (Laptop Dell, Round Rock, Texas, EUA). Os modos de visualização utilizados pelos dois sistemas foram: axial, panorâmico (com navegação 3D) e trans-axial (perpendicular aos arcos maxilar e mandibular). Os cortes tiveram orientação de incidência aproximadamente no centro das coroas dos dentes de interesse. Os softwares utilizados à operacionalização das imagens foram: Easy Guide ${ }^{\circledR}$ (Keystone 
Dental, Inc. - Burlington, MA, E.U.A.), para o sistema NewTom $3 G^{\circledR}$, e Sidexis $X G^{\circledR}$ (Sirona Dental X-Ray Imaging System - Next Generation), para o sistema Galileos ${ }^{\circledR}$. Ambos os programas, relataram, ofereciam função régua de medida de precisão milimétrica decimal. Os dois (02) operadores foram previamente calibrados a partir de dez (10) imagens selecionadas aleatoriamente do sistema Galileos ${ }^{\circledR}$, e quatorze (14) do sistema NewTom $3 G^{\circledR}$. Os examinadores avaliaram de modo independente as imagens de mesmos cortes e com as mesmas ampliações (zoom). Cada operador, após calibração, avaliou cento e uma (101) imagens. As medidas realizadas foram: a) distância da crista óssea alveolar até a junção amelocementária; e b) largura óssea (espessura): distância entre contorno ósseo alveolar externo e a superfície radicular, medidas em níveis de $1 \mathrm{~mm}$ a $10 \mathrm{~mm}$ a partir da crista óssea alveolar vestibular. Embora os autores tenham descrito resumidamente o modo operacional de utilização de duas referências geométricas lineares de orientação (em forma de cruz e abrangendo toda a tela) disponibilizadas e automatizadas por um dos dois softwares selecionados, não foi detalhado o critério de operacionalização para a obtenção das medidas lineares produzidas individualmente por estes softwares, nem qual foi o modo de controle de zoom e, ainda, os recursos de medida por eles utilizados. Os resultados da "reprodutibilidade" das medidas (dois operadores), obtida da análise de variação inter-operadores, para mesmas quantidades, não foi descrita nem discutida, além da informação de que os valores seriam somados e divididos a fim de serem utilizadas as médias aritméticas com vistas ao cálculo das médias dos dois sistemas tomográficos. Encontraram limitação de aplicação da Análise de Variância (ANOVA) devido à escassez de medidas de espessura a partir do "nível de avaliação de 8 mm", justificando que além desse nível $(9 \mathrm{~mm}$ e $10 \mathrm{~mm})$, e em decorrência da inclinação radicular vestibular, as espessuras pareciam não existir. Utilizaram teste $t$ para a comparação entre os dois métodos. A espessura óssea alveolar total média registrada foi de $1,0 \mathrm{~mm} \pm 0,52 \mathrm{~mm}$ (incisivos direitos) e $1,1 \mathrm{~mm} \pm 0,56 \mathrm{~mm}$ (incisivos esquerdos). A variação de medida, para todos os níveis avaliados, esteve localizada entre 0 e $5,1 \mathrm{~mm}$. À $1 \mathrm{~mm}$ da crista óssea, nenhum paciente apresentou espessura óssea $\geq 2 \mathrm{~mm}$; à $2 \mathrm{~mm}$ da crista, osso $\geq 2 \mathrm{~mm}$ foi detectado apenas em três locais; à 3 , 4 e $5 \mathrm{~mm}$ da crista, osso $\geq 2 \mathrm{~mm}$ foi detectado em quatro, seis e cinco locais respectivamente. Aparentes fenestrações foram detectadas (medida de osso igual a 0mm) nos níveis 6, 7, 8, 9 e 10mm de avaliação em 12\% dos casos. Enfatizaram a 
importância de serem conhecidos os limites anatômicos locais com vistas ao posicionamento controlado e seguro de implantes dentários. Concluíram haver significativa variabilidade metodológica entre os estudos disponíveis onde foram realizadas medições de espessuras ósseas alveolares.

Razavi et al. (2010) avaliaram a exatidão (acurácia) de medição da espessura óssea cortical adjacente a implantes dentários a partir de dois sistemas de TCFC. Foram utilizados dez (10) implantes (Astra Tech ${ }^{\circledast}$ - Astra Tech AB, Mölndal, Suécia), de dimensões $4 \times 11 \mathrm{~mm}$, os quais foram posicionados conforme diferentes distâncias em relação às corticais ósseas de duas (02) costelas bovinas preparadas previamente. Registraram os resultados da participação de dez (10) examinadores, os quais possuíam graus variados de experiência com operacionalização de imagens TCFC e foram instruídos e medir quatro distâncias em relação aos dez (10) implantes posicionados. O processo de medição foi aleatorizado. Distâncias verticais, do limite cervical do implante até a crista óssea alveolar; e de espessura óssea cortical até a superfície externa do implante, seguindo níveis de avaliação (profundidade) de 3, 6 e 9mm a partir do limite cervical do implante. O padrão-ouro foi obtido a por meio de cortes observados (e medidas) com o auxílio e microscopia ótica. Os resultados indicaram diferenças estatisticamente significantes $(p<0,001)$ entre as direções de avaliação, de espessura óssea e distâncias verticais considerando os dois sistemas de TCFC (i-CAT NG ${ }^{\circledR}$, Imaging Sciences International, Hatfield, Pa, E.U.A. e Accuitomo $3 D^{\circledR}-F P D$, Kyoto, Japão) e quando as espessuras estavam contidas no intervalo entre 0,3 e $3,7 \mathrm{~mm}$. Verificaram, para este intervalo dimensional, que as medidas obtidas com o sistema ${ }^{2} C A T^{\circledR}$ consistentemente subestimaram aquelas do padrão-ouro, bem como as do sistema Accuitomo $^{\circledR}$, só que em menor grau. O protocolo de aquisição para o iCAT $N G^{\circledR}$ foi: $120 \mathrm{kVp}, 18,54 \mathrm{~mA}$, voxel de 0,3mm, tempo de exposição de 8,9s, FOV de $16 \mathrm{~cm}$ e espessura de corte de $0,3 \mathrm{~mm}$. Para o sistema Accuitomo $^{\circledR}$, foi: $80 \mathrm{kVp}, 4 \mathrm{~mA}$, voxel de $0,125 \mathrm{~mm}$ e $18 \mathrm{~s}$ de duração, com FOV de $6 \mathrm{~cm}$ e espessura de corte de $1 \mathrm{~mm}$. Foram discutidas as condições associadas à incidência dos erros sistemáticos, entre resolução de voxel, FOVs e artefatos, os quais influenciam direta e indiretamente a qualidade final dos detalhes produzidos pelos referidos sistemas selecionados. $O$ endurecimento do feixe, salientaram, promoveu discrepâncias de avaliação de 
imagens eventualmente comprometendo a exatidão final para os dois sistemas considerados de TCFC, devido à influência da elevada densidade da liga metálica dos implantes, produzindo faixas escuras em torno das imagens das superfícies externas dos implantes. As medidas foram realizadas a partir dos softwares (nativos) dos dois sistemas, ICAT NG ${ }^{\oplus}$ (iCAT Vision ${ }^{\circledR}$ - Imaging Sciences International, Hatfield, Pa, E.U.A.) e Accuitomo ${ }^{\circledR}$ (One Data Viewer Plus ${ }^{\circledR}$ - J. Morita, Japão). Procederam com tentativa de redução de vieses importando as imagens DICOM para um software genérico $C A S C O^{\circledR}$ (Erik Gotfredsen, Faculdade de Odontologia da Universidade de Aarhus, Dinamarca). Se e quando fosse necessário, o operador, ainda, poderia utilizar um tipo de template auxiliar à medição (o qual foi desenvolvido em folha de acetato transparente e necessitava ser fixado diretamente à tela do laptop utilizado para as medições). Enfatizaram que diferença entre equipamentos, por si só, já é capaz de gerar padrões de resolução de imagem distintos. O voxel de $0,3 \mathrm{~mm}$, do sistema $i C A T^{\circledR}$, comparativamente ao de $0,125 \mathrm{~mm}$ do sistema Accuitomo $^{\circledR}$, já deveria oferecer, por esse motivo, condições menos favoráveis de resolução espacial. A maior quilovoltagem associada ao sistema iCAT ${ }^{\circledR}(120 \mathrm{kVp}$ vs. $80 \mathrm{kVp}$, do Accuitomo $^{\circledR}$ ) e ainda o maior FOV empregado acabariam por gerar piores (proporcionalmente) qualidade de contraste associado e detalhamento específico, porém com maior área sendo atenuada. A dose de radiação, verificaram, foi maior com o Accuitomo $^{\circledR}$. Assim, os autores ponderaram ser melhor a indicação final do sistema Accuitomo $^{\circledast}$, com voxel $0,125 \mathrm{~mm}$, para que seja possível a detecção de finas corticais ósseas. Análise de Variância Fatorial foi utilizada à avaliação das diferenças entre os sistemas, examinadores e implantes, bem como para os diferentes níveis de avaliação. Testes $\mathrm{t}$ foram aplicados para avaliar as diferenças entre espessuras padrão-ouro e tomográficas. A reprodutibilidade foi avaliada por meio do Coeficiente de Correlação Intraclasse $(\mathrm{CCl})$. Concluíram que os dois sistemas subestimaram as medidas reais (padrão-ouro), entre 0,3 e 3mm, mas com exatidão melhor para identificação de finas corticais com o sistema Accuitomo $^{\circledR}$ quando as corticais eram maiores que $0,8 \mathrm{~mm}$. Ambos os sistemas superestimaram as distâncias verticais medidas da crista óssea até o limite cervical dos implantes. Com espessuras maiores, a porcentagem média de erro diminuiu. Para os três níveis avaliados, e respectivamente para o ICAT NG ${ }^{\circledR}$ e o Accuitomo ${ }^{\circledR} 3 D 60$ FPD, os percentuais de erro foram: $68 \%, 28 \%$ e $18 \%$ e $23 \%, 5 \%$ e $6 \%$, embora, salientaram, 
não serem estes erros aleatórios, mas sim sistemáticos e influenciadores da exatidão.

Sherrard et al. (2010) analisaram a exatidão (acurácia) e confiabilidade de medições lineares de comprimentos dentários e radiculares derivados de tomografia volumétrica (TCFC). Neste estudo ex vivo (sete cabeças frescas de porcos - Sus domestica), os autores consideraram a comparação entre medidas obtidas a partir de método considerado como sendo o padrão-ouro clínico (radiografia periapical) para as avaliações de reabsorções radiculares apicais a partir dos comprimentos radiculares calculados (figura 2.5 ).

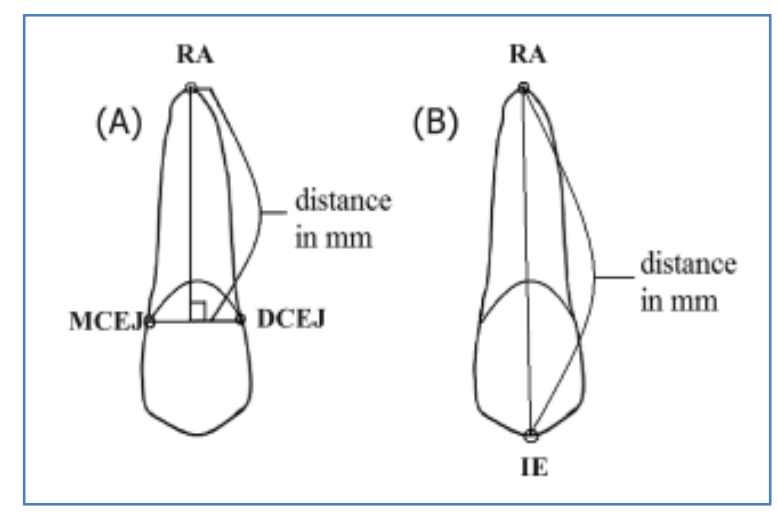

Figura 2.5 - (A) medida linear do comprimento radicular, medida do ponto mais apical da raiz e, de modo perpendicular, até a linha que une as junções amelo-cementárias mais mesiais e distais proporcionalmente. (B) comprimento dentário total, do ponto mais apical até o mais incisal

Salientaram as médias obtidas na literatura relativas à perda vertical radicular, anual, de 1 a $2 \mathrm{~mm}$ considerando este método padrão. Destacaram as inúmeras vantagens de utilização clínica e experimental das imagens multiplanares derivadas do sistema de TCFC, especialmente aquelas determinadas às avaliações de cortes bidimensionais (2D) trans-axiais, fazendo com que o clínico possa obter mais informação diagnóstica confiável. Cinquenta e dois (52) dentes, vinte e oito (28) prémolares e vinte e quatro (24) incisivos, foram selecionados à realização das medições previstas. As imagens radiográficas foram digitalizadas e salvas em arquivo TIFF, com resolução de 600 dpi. Estas imagens foram operacionalizadas a partir de software Image Too $^{\circledR}$ (UTHSCSA, San Antonio, Texas, E.U.A.), com ampliação de sete $(07)$ vezes. Tomógrafo $\operatorname{iCAT}^{\circledR}\left(i-C A T^{\circledR}\right.$, Imaging Sciences 
International, Hatfield, Pa, E.U.A.), com parâmetros de aquisição de 120 kVp, 3-8 $\mathrm{mA}$ (modo pulso) e FOV de $16 \times 8 \mathrm{~cm}$, foram utilizados. Tamanhos de voxel de 0,2, 0,3 e $0,4 \mathrm{~mm}$ foram testados em sua qualidade de informação associada à resolução espacial. Software Dolphin3D ${ }^{\circledR}$ (Dolphin Imaging Chatsworth, CA, E.U.A.) foi empregado considerando método geométrico especificamente desenvolvido. Os cortes trans-axiais foram adequados aos referenciais geométricos oferecidos pelo programa utilizado. Um técnico certificado em Radiologia MaxiloFacial obteve as imagens, as quais foram salvas em arquivo DICOM. Filtro sharpen foi aplicado a fim de melhorar a qualidade de inspeção dos limites do ligamento periodontal (baixo contraste). A ampliação das imagens, para a identificação dos pontos tomográficos, foi de aproximadamente sete (7) vezes (figura 2.6).

(A)

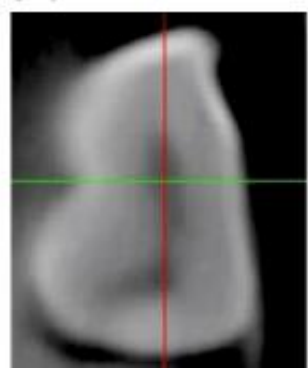

(B)

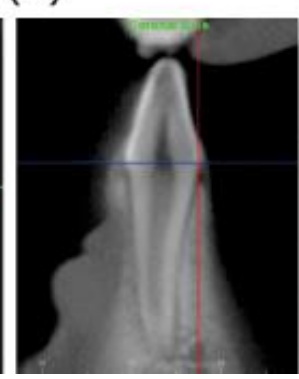

(C)

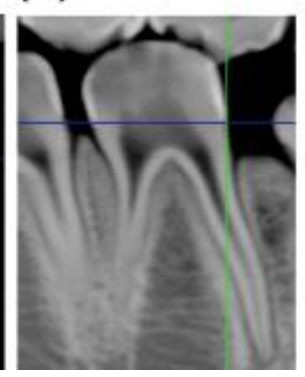

Figura 2.6 - (A) orientação espacial axial conforme guias auxiliares ortogonais do software Dolphin $3 \mathrm{D}^{\circledR} ;(\mathrm{B})$ orientação espacial coronal e respectivas guias auxiliares; (C) orientação espacial sagital conforme guias geométricos auxiliares

O processo de obtenção das orientações de medida foi replicado, remedido apenas uma (01) vez e após intervalos de três (03) a quatro (04) dias. No entanto, não foram descritos quaisquer detalhamentos associados à sequência operacional de medição selecionada aos locais de inspeção e identificação de medidas sub milimétricas, e nem eventuais limitações dela decorrentes, bem como não foi informada a participação de outros operadores durante o referido experimento e para a análise da confiabilidade metodológica anunciada. Embora o tamanho de voxel de 0,20mm devesse tecnicamente oferecer maior resolução de imagem, lembraram os autores que os resultados de variação similares (erro) obtidos comparativamente ao voxel de $0,4 \mathrm{~mm}$ podem ser explicados pela facilidade operacional promovida pelo voxel maior (de $0,4 \mathrm{~mm}$ ) em identificar repetidamente o mesmos pontos de modo consistente (devido ao seu tamanho), ou de voxels adjacentes verticalmente. Os erros, 
enfatizaram, podem ocorrer devido ao modo de aquisição, visualização, operacionalização e ainda identificação das estruturas anatômicas. O erro aleatório foi avaliado a partir da combinação entre Coeficiente de Correlação Intraclasse (CCI) e estatística do Erro do Método $\left(E M / M E=\sqrt{ }\left[\sum \mathrm{d} 2 / 2 n\right]\right)$. Concluíram que para a obtenção das distâncias estudadas (baseadas em reparos anatômicos apenas dentários), voxel de $0,40 \mathrm{~mm}$ deveria ser indicado haja vista a menor dose de radiação associada, mas todos os voxels testados $(0,20 / 0,30$ e 0,40mm) foram ou iguais ou melhores em qualidade comparativamente às imagens radiográficas periapicais.

Almeida (2011) realizou estudo descritivo tomográfico (TCFC) a fim de verificar a associação entre padrão morfogenético da base craniana e dimensões transversais da maxila e mandíbula e, ainda, se a referida associação também se estenderia à porção alveolar das bases apicais. As imagens foram obtidas de tomógrafo $i C A T^{\circledR}$ (Imaging Sciences International, Hatfield, Pa, E.U.A.), com os seguintes parâmetros de aquisição: $120 \mathrm{kVp}, 47,74 \mathrm{~mA}$, escala de cinza de 14bits, protocolo extended height e voxel de $0,4 \mathrm{~mm}$ e, a partir de recursos próprios do programa computacional Dolphin $3 D^{\circledR}$ (versão 11 - Premium Dolphin Imaging and Management Solutions, Chatsworth, CA, E.U.A.), mediu e avaliou as características associadas às inclinações vestíbulo-linguais dos dentes posteriores (figura 2.7), com o intuito de verificar se as mesmas apresentavam padrão de estabilidade independente das medidas de largura das respectivas bases ósseas alveolares, ou se seriam constatadas variações significativas. Não foram descritos quaisquer detalhamentos associados à sequência operacional de medição selecionada aos locais de inspeção e identificação de medidas sub milimétricas, e nem eventuais limitações dela decorrentes. A amostra foi constituída de trinta (30) indivíduos adultos jovens, brasileiros, leucodermas, com perfis faciais equilibrados e neutrooclusão. A referida foi dividida em dois grupos de acordo com a dimensão transversal da base anterior do crânio, definida pela distância entre os pontos esfenóide, direito e esquerdo, sendo o grupo G1 composto pelos indivíduos apresentando valores menores que a mediana, e, o grupo G2, com indivíduos apresentando valores maiores ou iguais à mediana. Foi realizada correlação intraclasse para avaliar o erro do método; média, mediana e desvio padrão para 
descrever o grupo amostral; teste t (Student) para comparar os grupos G1 e G2; teste exato de Fischer para avaliar associação entre base do crânio e gêneros e teste de correlação linear de Pearson. As medidas apresentaram significativa reprodutibilidade. Indivíduos do grupo G2 apresentaram maior largura de mandíbula e maior espessura alveolar no nível dos primeiros molares e primeiros pré-molares superiores. Não houve associação entre largura de base do crânio e gêneros. A largura basal da mandíbula apresentou correlação estatisticamente significante com a largura da base do crânio, assim como a largura alveolar maxilar, na região de prémolares e molares superiores, em relação à largura basal da maxila. Concluiu que a largura da base craniana apresentou correlação com a largura da mandíbula; que a largura da maxila variou em proporção com a largura da mandíbula; que a largura alveolar da maxila, na região dos primeiros pré-molares e molares superiores, apresentou correlação com largura basal da maxila; que a largura basal mandibular apresentou correlação com a largura alveolar da mandíbula, na região dos primeiros pré-molares, e ainda que as inclinações vestíbulo-linguais dos primeiros molares e primeiros pré-molares foram constantes, independentemente das larguras basais e alveolares de suas respectivas bases ósseas.
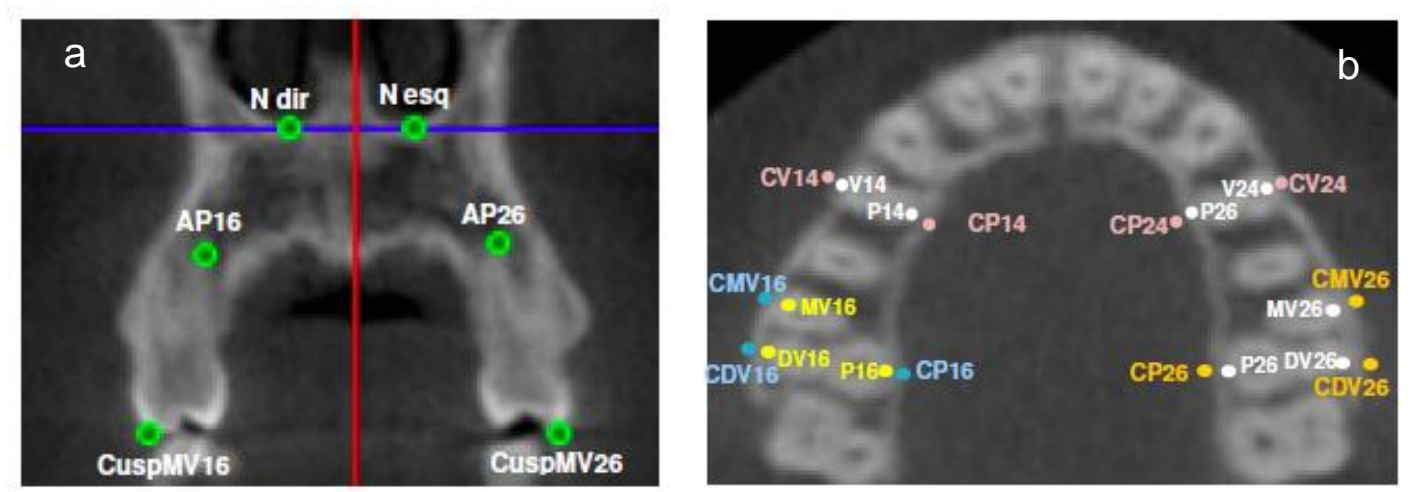

Figura 2.7 - Identificação dos pontos de análise maxilar: (a) corte coronal - molares ; (b) corte axial - molares e pré-molares

Baumgaertel (2011) discutiram, a partir de estudo descritivo tomográfico com (TCFC), as possibilidades de identificação dos locais ósseos mais favoráveis à instalação de mini implantes de ancoragem esquelética. Utilizaram trinta (30) crânios secos de adultos leucodermas, obtidos a partir da Coleção Osteológica Hamman- 
Todd, Museu de História Natural de Cleveland, Ohio, E.U.A.). A história médica foi inicialmente consultada em busca de informações capazes de determinar a exclusão de unidades para a amostra. Utilizaram tomógrafo CB MercuRay ${ }^{\circledR}$ (Hitachi Medical, Tokyo, Japão), com os seguintes parâmetros de aquisição: 100kVp, 10mA, FOV de 09 pol. E tamanho resultante de voxel de $0,28 \mathrm{~mm}$. O software utilizado foi o Accurex $^{\circledR}$ (CyberMed, Seoul, Korea). Três (03) níveis de avaliação foram definidos a partir dos cortes trans-axiais, os quais foram em número de seis (06) para cada hemi-arco e obtidos perpendicularmente aos cortes axiais, conforme as distâncias de 4, 8 e 12mm a partir das cristas ósseas interproximais (figura 2.8).

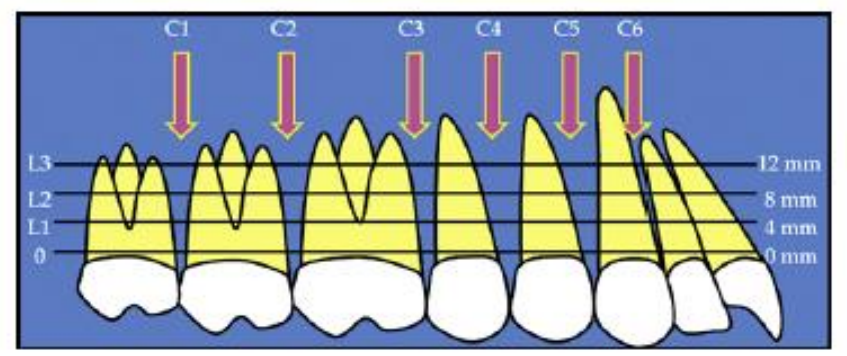

Figura 2.8 - Níveis de avaliação das quantidades ósseas e respectivos locais interdentários de corte trans-axial (setas vermelhas). (vista sagital)

Coeficientes de Correlação Intraclasse (CCl) foram utilizados para a avaliação da confiabilidade específica do método de medição. Análise da Variância (ANOVA) foi empregada para avaliar as correlações entre locais dos cortes, níveis de medição e espessuras ósseas corticais (figura 2.9). Descreveram parcialmente o método de obtenção geométrica e de registro (inspeção e identificação) das espessuras ósseas totais (vestíbulo-linguais). Afirmaram que o limite de resolução para o conhecimento da exatidão (acurácia), tecnicamente corresponde ao limite de resolução do próprio voxel que, para este estudo, foi de $0,28 \mathrm{~mm}$. Contudo, não registraram detalhamento relativo à sequência operacional de obtenção do posicionamento dos cortes transaxiais, nem tampouco da qualidade dos procedimentos de medição propriamente ditos. Concluíram ser favorável a aplicação de miniimplantes de ancoragem esquelética no processo alveolar palatino, devido a possibilidade de presença de espessuras corticais, e profundidades ósseas, estruturalmente favoráveis, porém recomendaram cuidados durante a inspeção tomográfica em relação a alguns dos locais estudados, a fim de que seja evitada penetração dos mini implantes no seio maxilar, o que poderia promover complicações terapêuticas eventuais. A estimativa 
linear média, para espessura óssea cortical, foi de 1,2mm. Afirmaram que as medidas de espessura bastante delgadas representam uma limitação do trabalho em seu delineamento, mas que a mesma não teria significância clínica.
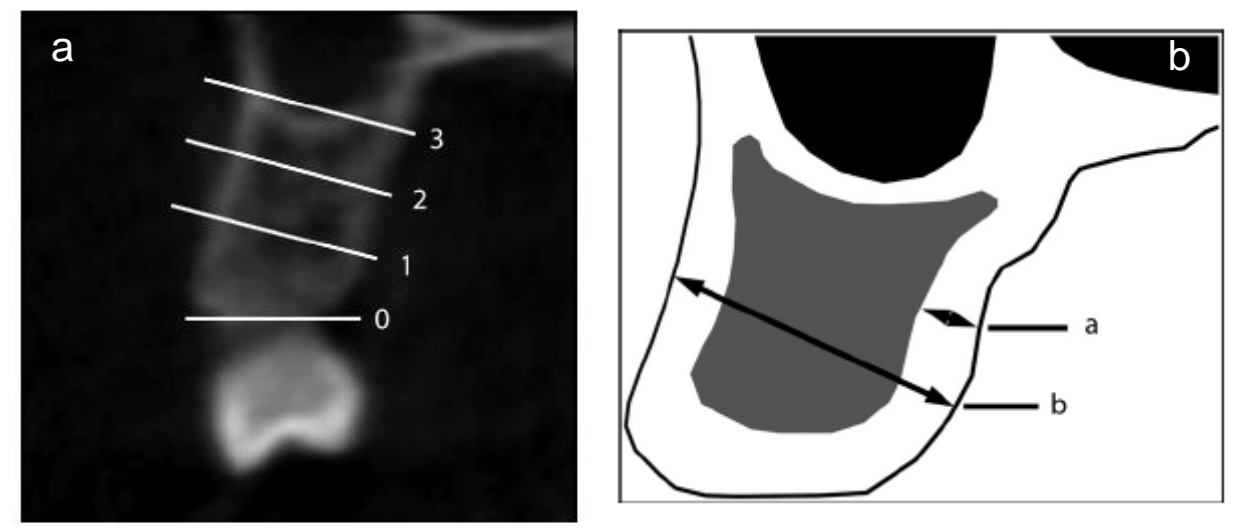

Figura 2.9 - a) Níveis (03) de avaliação vertical das espessuras ósseas (totais); b) indicação trans-axial de dois parâmetros de medição tomográfica. (corte coronal, oblíquo ou trans-axial)

Farnsworth et al. (2011), a partir de estudo descritivo tomográfico de imagens pré-tratamento, avaliaram a qualidade de associação de fatores como idade, gênero e diferenças locais, maxilares e mandibulares, com as possibilidades de locais de instalação de miniimplantes de ancoragem esquelética. Utilizaram amostra constituída de cinquenta e dois (52) pacientes, distribuídos em dois grupos: I Adolescentes $(n=26)$ e II - Adultos $(n=26)$. Os arquivos foram selecionados de arquivo próprio de documentações ortodônticas e foi considerado durante 0 experimento o dimorfismo de gênero. $O$ tomógrafo selecionado foi o $C B$ MercuRay ${ }^{\circledR}$ (Hitachi International, Tokyo, Japão). As imagens, pré-tratamento, foram selecionadas a partir do seguinte critério: voxel de $0,39 \mathrm{~mm}$, faixa etária de interesse para a composição dos grupos previstos. Pacientes possuidores de periodontopatias e/ou necessidades endodônticas não foram aceitos para o experimento, bem como aqueles com dentes permanentes não irrompidos e/ou ausentes. História médica e/ou odontológica significativa para influência local e, ainda, assimetrias dentárias e/ou faciais, também determinaram exclusão. Não informaram acerca dos parâmetros de aquisição tomográfica. As imagens (DICOM) foram importadas para o software Dolphin $3 D^{\circledR}$ (v.10.5 - Dolphin Imaging Systems, Chatsworth, CA. E.U.A.). As espessuras ósseas corticais, vestibulares e palatinas maxilares e vestibulares 
mandibulares, foram medidas a partir de cortes tomográficos obtidos dos setores inter-dentários, ao longo de todo o arco, e à distância de $4 \mathrm{~mm}$ das cristas ósseas alveolares interproximais. Os locais foram selecionados aleatoriamente para as medições. Os cortes foram computacionalmente orientados em suas posições (nos três planos do espaço virtual), de modo que, antes da definição posicional final, os longos eixos das raízes dentárias deveriam estar aproximadamente paralelos às linhas de referência vertical de operacionalização do próprio software. A distância vertical, de referência para a realização das medições, foi determinada pelo movimento da linha de referência horizontal até a marca de $4 \mathrm{~mm}$ (régua milimétrica "tomográfica" vertical fixa). Um segundo tempo de medições foi realizado aproximadamente um (01) mês depois do primeiro, em vinte (20) do total dos pacientes, selecionados aleatoriamente. Embora tenha sido descrita a sequência operacional de obtenção do posicionamento dos cortes trans-axiais, não foram descritos nem discutidos os detalhes do procedimento de inspeção e medição utilizados, e nem as eventuais limitações destes decorrentes, para os resultados de diminuta variação obtidos. Teste bicaudal Multivariado de Variância (MANOVA) foi aplicado para o conhecimento das diferenças entre os diversos grupos. Dos dezesseis (16) locais remedidos, apenas o "local de $6 \mathrm{~mm}$ palatino" apresentou erro sistemático significante. Os autores registraram que a exatidão encontrada (para o voxel de $0,39 \mathrm{~mm}$ ) foi garantida a partir de estudo prévio piloto. Contudo, as imagens do referido estudo foram obtidas a partir de tomógrafo $i C A T^{\circledR}$ (Imaging Systems International, Hatfield, Pa, E.U.A.), equipamento distinto daquele utilizado para a obtenção das imagens clínicas deste experimento (CB MercuRay ${ }^{\circledR}$ ). Obtiveram que corticais de adultos mostraram-se significativamente mais espessas em todas as áreas, enquanto que as corticais mandibulares, mais espessas da região posterior à anterior, mostraram-se ainda mais espessas que as maxilares.

Januário et al. (2011) apresentaram estudo tomográfico descritivo de três níveis de espessura óssea (1, 3 e $5 \mathrm{~mm}$ ) a partir das cristas ósseas alveolares, em duzentos e cinquenta (250) pacientes (amostra de conveniência). Os pacientes não possuíam histórico de doença periodontal, não apresentavam recessões gengivais extensas no setor maxilar anterior e tampouco perda óssea naquele local. As espessuras ósseas foram registradas verticalmente a partir das cristas ósseas, e 
também foram medidas as distâncias das junções amelo-cementárias até as cristas ósseas, todas realizadas por mesmo operador (radiologista). A estimativa do erro do método $(0,18 \mathrm{~mm})$ foi considerada a partir de duplas medições de vinte (20) imagens de dentes treze (13), e em tempos diferentes. O tomógrafo utilizado foi ${ }^{2} C A T^{\circledR}$ (Imaging Sciences International, Hatfield, Pa, E.U.A.), conforme os seguintes parâmetros de aquisição: FOV de $17 \mathrm{~cm}$, resolução de voxel de $0,20 \mathrm{~mm}$, escala de cinza de 14 bits, $40 \mathrm{~s}$ de exposição e com detector flat panel. Utilizaram software (nativo) do equipamento (iCAT ${ }^{\circledR}$ Xoran) para a realização das medidas. Contudo, não foram informadas as condições de delineamento, aleatorização, ou mesmo as definições do procedimento de medição, nem tampouco os parâmetros de confiabilidade no método utilizado. Entretanto, obtiveram resultados de estimativas de espessuras ósseas maxilares vestibulares, médias, e para níveis diferentes e ainda idades diferentes. Aproximadamente $85 \%$ dos locais apresentaram espessura $\leq 0,5 \mathrm{~mm}$. Discutiram seus resultados com estimativas de exatidão obtidas de estudos ex vivo para definição de dimensões alveolares.

Kapila et al. (2011) salientaram os fatores mais relevantes associados à indicação, aplicação e interpretação dos exames complementares de tomografia volumétrica (TCFC) par a Ortodontia. Quanto à quantidade de radiação produzida pelo sistema de feixe-cônico, destacaram que é menor comparativamente à tomografia médica (TC), variando entre 87 e $206 \mu \mathrm{Sv}$ para uma escaneamento craniofacial completo, enquanto que para uma exame radiográfico convencional completo, a dosagem total seria discretamente menor que à do sistema de TCFC

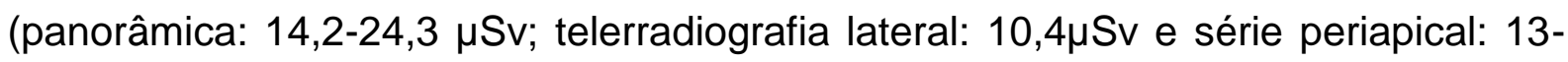
$100 \mu \mathrm{Sv}$ ). Considerando a exatidão de medida (acurácia), erro associado às representações de padrões-ouro, afirmaram que as aplicações cefalométricas tendem a ser mais precisas com o uso de TCFC, podendo ser ajustados os campos de visão (FOVs), as dosagens de radiação e, ainda, os modos ou tipos específicos de cortes tomográficos subsequentes, úteis às mais variadas finalidades complementares. Além disso, é possível também avaliar, com esse sistema em particular, a morfologia radicular e os padrões de reabsorção radicular, bem como as relações espaciais entre dentes e ossos. Embora o sistema de TCFC tenha se mostrado qualitativamente equivalente quando comparado a algumas aplicações 
específicas em radiografias periapicais, considerando comprimentos radiculares, embora aproximações aplicáveis sejam possíveis com as radiografias periapicais, somente com a TCFC é que podem ser favorecidos os requisitos associados à exatidão de medida, uma vez que a própria técnica radiográfica convencional induz a esses tipos de erro sistemático, sendo que para esse último sistema, os registros de incerteza de medida, considerando as quantidades lineares pretendidas, são de fato mais promissores em termos de inferência clínica. As ampliações de imagem com a TCFC tendem a produzir efeitos de visualização mais favoráveis que aqueles produzidos pela técnica radiográfica convencional, o que pode representar um importante fator de auxílio durante o processo de inspeção anatômica complementar. Salientaram, também, a importância da possibilidade de serem avaliadas, quantitativa e qualitativamente, as espessuras ósseas alveolares. Contudo, destacaram, devido à significativa incidência de falsos-positivos relativos à identificação de fenestrações ósseas, bem como de outros defeitos ósseos similares, essa modalidade de aplicação tomográfica deve ser conduzida com cautela. Foi igualmente apresentada e discutida a possibilidade de serem conhecidos, com melhor resolução final de imagem, os volumes ósseos locais de interesse à instalação de implantes e também de mini-implantes de ancoragem ortodôntica, fazendo, desse modo e a partir dessa nova prática de conduta, com que as rotinas de avaliação diagnóstica fossem definitivamente modificadas, ou evoluídas, em decorrência de preferências por sistemas mais eficientes em todos os sentidos de avaliação. Aplicações para avaliação tomográfica local tem mostrado as vantagens durante a necessidade de supervisão terapêutica do modo de reação do osso alveolar diante dos padrões de ação das mecânicas ortodônticas, com atenção especial a identificação, mesmo que mais qualitativa, dos limites de posicionamento dentário e sua influência no plano terapêutico inicialmente estabelecido, principalmente nos casos mais críticos. Além de ser possível a observação e avaliação anatômica considerando os três planos do espaço (3D), e de modo preciso e exato para inúmeras das aplicações propostas, os autores destacaram as vantagens de serem ainda obtidos padrões bidimensionais de imagem e conforme a versatilidade em termos de obtenção de cortes específicos, com a possibilidade de atender às mais diversas demandas de aplicação, fazendo dessa possibilidade uma de melhor condição de observação/avaliação comparativamente àquelas radiográficas tradicionais, para muitas das aplicações usuais. Concluíram que esta 
modalidade particular de exame tomográfico (TCFC) pode, de fato, contribuir confiavelmente com as avaliações das condições morfológicas individuais, sejam elas normais ou mesmo atípicas, como, por exemplo, nos casos de estreitamento ósseo devido à condição fenotípica própria do indivíduo, onde pode haver dúvidas acerca das reais possibilidades terapêuticas de serem obtidas certas posições dentárias, e eventualmente extremas dadas as imitações do suporte dento-alveolar disponível (figura 2.10).

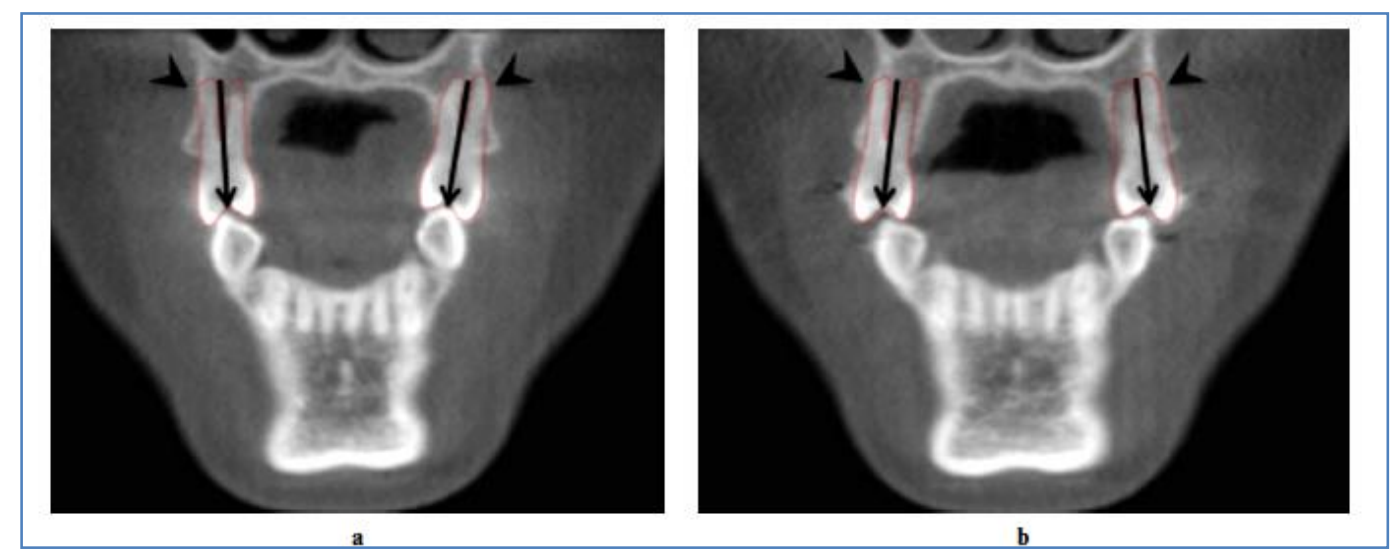

Figura 2.10 - a) e b) cortes tomográficos (TCFC) coronais ilustrando a presença de condições esqueléticas críticas ao posicionamento vestíbulo-lingual dos dentes, em indivíduo dolicofacial

Naitoh et al. (2011) avaliaram a possibilidade de ser estimada, a partir de exame de TCFC e in vitro, a mínima quantidade possível de osso alveolar vestibular em torno de implantes dentários. Enfatizaram a importância de serem obtidos cortes tomográficos trans-axiais, a fim de que se possa avaliar as espessuras ósseas alveolares, vestibulares e palatinas/linguais, associadas aos implantes dentários. Devido à produção de artefatos de imagem, ocasionada em decorrência da alta densidade da liga metálica daqueles dispositivos, afirmaram que quantidades diminutas de osso circundante não podem ser visualizadas com clareza de detalhe. Os autores selecionaram um dente (canino inferior esquerdo) extraído de mandíbula seca (ex-vivo), a partir do qual foram obtidos os locais de análise. O osso vestibular do local da exodontia foi cortado e então lâminas finas de alumínio (espessuras de 0,$2 ; 0,4 ; 0,6 ; 0,8$ e $1 \mathrm{~mm}$ ) foram sistematicamente posicionadas como modo de substituir a cobertura óssea vestibular removida. Também posicionaram um pino de alumínio preenchendo a loja óssea resultante, a fim de simular a presença metálica 
de um implante. As imagens tomográficas foram obtidas a partir de tomógrafo Alphard VEGA, com detector flat panel (Asahi Roentgen Ind. Kyoto, Japão). O volume exposto foi ajustado para três diâmetros de FOV, $51 \mathrm{~mm}$ (modo dente), $102 \mathrm{~mm}$ (modo implante) e 154mm (modo panorâmico), com voxels cúbicos de 0,1, 0,2 e 0,3mm respectivamente. Utilizaram software Osirix ${ }^{\circledR}$ (Osirix Imaging Software, versão 1.7.1, Genebra, Suíça). Contudo, não houve descrição informativa acerca do procedimento de medição utilizado, e nem de eventuais limitações dele decorrentes. Verificaram que quando a espessura óssea alveolar circunjacente ao implante era menor que $0,6 \mathrm{~mm}$, então a mesma era indistinguível a partir dos registros tomográficos definidos pelo referido experimento. Entretanto, quando a mesma era maior que $0,6 \mathrm{~mm}$, então podia ser tomograficamente distinguida, mas apenas para os FOVs de 51 e $102 \mathrm{~mm}$ de diâmetro.

Özer (2011) comparou a exatidão de diagnóstico a partir de imagens de TCFC com diferentes protocolos de aquisição, variando a qualidade de resolução dos voxels a fim de comparar a capacidade de detecção de fraturas radiculares longitudinais simuladas. Foram utilizados sessenta (60) dentes, sendo trinta (30) destes com os defeitos provocados e outros trinta (30) sem a presença dos mesmos. Todas as imagens foram avaliadas por três (3) examinadores (dois endodontistas e um radiologista) e em diferentes sessões de observação. Tomografia volumétrica (TCFC), sistema CCAT $^{\circledR}$ (Imaging Sciences International, Hatfield, Pasadena, CA, E.U.A.) foi utilizado, variando-se quatro modos ou tipos de resolução de voxel / tempo de aquisição $(0,125 \mathrm{~mm} / 4 \mathrm{~s} ; 0,2 \mathrm{~mm} / 4 \mathrm{~s} ; 0,3 \mathrm{~mm} / 7 \mathrm{~s}$ e $0,4 \mathrm{~mm} / 7 \mathrm{~s})$, com parâmetros: $120 \mathrm{kVp}, 5 \mathrm{~mA}$ e FOV de $4 \mathrm{~cm}$. A preferência pela definição de rápidas exposições baseou-se na intenção de favorecer a incidência de menores doses de radiação. Após a obtenção das diferentes aquisições, o scanner foi calibrado. Os arquivos foram registrados em formato DICOM e as imagens foram analisadas com - software próprio do equipamento (Xoran $i C A T^{\circledR}$, versão 3.1.62, Xoran Technologies, Ann Arbor, MI, E.U.A.). As imagens foram visualizadas em monitor de tela plana de 19" (EIZO Flexscan ${ }^{\circledR}$ S1901-LCD, Ishikawa, Japão). A referência ou critério de identificação das fraturas radiculares simuladas foi a presença de linha radiolúcida na superfície radicular. Não foram utilizadas ampliações de imagem. Os examinadores foram treinados em estudo piloto prévio. A observação não aconteceu 
com restrição de tempo, foram realizadas com intervalos semanais e com os quatro modos de aquisição de voxel/ tempo, e os participantes não foram informados de qual(is) dente(s) possuía(m) o defeito ou não. Para a análise estatística, em decorrência de serem dados categoriais, foram calculados Coeficientes Kappa Ponderados. Os resultados atestaram a confiabilidade à detecção de fraturas radiculares longitudinais, e o tamanho de voxel de $0,2 \mathrm{~mm}$ foi o mais efetivo em termos de protocolo de aquisição, considerando o curto tempo de exposição e a boa efetividade de diagnóstico.

Romans (2011) descreveu conceitos de técnica tomográfica associados à identificação de qualidade na geração das imagens, bem como características de interpretação associadas à presença de artefatos e sua influência na exatidão de medidas tomográficas. A fim de avaliar o quão corretamente a imagem pode representar a anatomia real, dois conceitos foram descritos: detalhe, ou seja, a resolução de alto contraste, onde o nível de detalhe visível na imagem corresponde à qualidade de serem detectados dois objetos diminutos e muito próximos entre si como objetos tomográficos realmente distintos; e detectabilidade de contraste, ou seja, a resolução de baixo contraste, a qual corresponde à capacidade de um sistema em distinguir, na imagem, objetos de com densidades similares, ou pouco diferentes. Detalhe e resolução espacial são termos equivalentes. Os fatores que influenciam a qualidade de imagem (TC) são: tamanho da matriz, tamanho do pixel, tamanho e tipo de voxel, campo de visão (FOV) e espessura de corte. A resolução espacial pode ser diretamente medida, ou ainda calculada de modo indireto a partir de análise do espectro da informação gerada internamente pelo sistema. Esta modalidade de análise denomina-se análise da Modulação da Função de Transferência (MTF), onde curvas de rendimento (gráficos) são interpretadas com o propósito de oferecer quantificação da resolução espacial. A análise de gráficos MTF envolve a verificação da qualidade de informação radiológica transmitida ao observador, onde o tamanho real do objeto é relacionado à função de qualidade da informação. Sendo que quanto menor for o objeto (maior frequência espacial), menor será a tendência de ser obtida pior qualidade de informação ao observador, embora estes efeitos não sigam um padrão linear de resposta. A escala de resposta MTF varia de 0 a 1 (perfeita exatidão $=1 /$ imperfeita exatidão $=0$ ). Salientou 0 
autor que a quantificação da qualidade de imagem também pode ser obtida de modo complementar a partir de testes de medição comparada utilizando fantomas radiológicos. Foram discutidas as chances de ocorrência de erros de resolução espacial a partir da utilização do Teorema de Nyquist, o qual resolve que o tamanho do objeto, associado à probabilidade de posicionamento espacial deste em relação à organização dos pixels da matriz, pode determinar efeito de somação do artefato de volume parcial, fazendo com que o tamanho final do voxel em questão deva ser, para a mínima possibilidade de detecção e considerando as probabilidades condicionais, pelo menos metade da dimensão absoluta do objeto pretendido à reprodução tomográfica.

Schulze et al. (2011) revisaram a condição de influência deletéria decorrente da presença de artefatos de imagem gerados durante o processo de obtenção de registros tomográficos volumétricos (TCFC), destacando que estes são estruturas visualizadas nos dados reconstruídos e que não estão presentes no objeto real; e que são fenômenos associados à técnica tomográfica muito comuns atualmente. São o efeito de discrepâncias entre a modelagem matemática e o processo atual de obtenção da imagem física. Artefatos, conforme explicaram, podem interferir com o processo de diagnóstico e sua qualidade final. Em uma dada imagem tomográfica, a distribuição da escala de cinza pode ser considerada como uma função matemática. O Algoritmo Feldkamp, em sua forma original ou derivada, é um exemplo desta função. Embora seja difundido que o sistema de TCFC produziria menos artefatos em diante da presença de estruturas metálicas, sob um ponto de vista técnico, o que ocorre é que eles de fato acontecem, mas se manifestam de modo diverso daquele dos sistemas de TCMC, provavelmente pela geometria de baixo espectro energético inerente aos sistemas de TCFC. Discutiram acerca da escassez de trabalhos científicos associados ao tema, e o consenso quanto aos tipos mais comuns de artefatos relatados na literatura: de extinção, de endurecimento do feixe (faixas escuras ao longo do objeto, próximo de áreas de hiperdensidade), de efeito de volume parcial e EEGE, de dispersão (estrias), de anel e de movimento (alinhamento mal conduzido). Além de ruídos de imagem (aspecto granulado, "grãos de sal e pimenta") e dispersão de radiação (responsáveis pela produção de artefatos adicionais, as imagens de artefatos geralmente aparecem como sombras, estrias e 
estruturas lineares. Salientaram a presença de artefatos produzidos nos casos de definição de FOV reduzido (locais), por interferência da área circundante, não incluída na reconstrução volumétrica, enquanto que necessidades de obtenção de FOVs muito mais amplos requereriam painéis detectores flat panel maiores e mais dispendiosos. Um modo de diminuir esta influência, lembraram, é a utilização de dois modos de rotação, um para o centro e o outro para a periferia do volume de interesse, mas a transição abrupta entre as duas regiões produziria artefatos em forma de anel nas imagens axiais. Os autores também descreveram a presença dos principais artefatos, e entre eles especialmente o ruído de imagem. Embora ruído não seja usualmente considerado como sendo propriamente um artefato de imagem, é um fenômeno de deterioração da imagem tomográfica. Os ruídos podem ser de dois tipos: aditivos (elétricos) e de contagem de fótons (provavelmente seguindo a distribuição de Poisson), e ainda entendidos como "detecção desfocada". Como a miliamperagem produzida pelo sistema de TCFC, a fim de reduzir a dose de radiação, é menor que a do sistema de TCMC (TC), então a razão sinal/ruído é muito menor que aquela usualmente considerada pelo sistema de TC, ou seja, maior probabilidade de incidência de ruídos de imagem para o sistema de TCFC. Ruídos, ainda, são inconsistências associadas aos valores de atenuação considerando a escala monocromática (cinza) nas projeções de imagem, isto é, amplos desvios padrões em áreas onde a constância de atenuação deveria estar presente. Concluíram o fato de que a TCFC incorpora artefatos adicionais, os quais podem ser evitados mais com o avanço tecnológico do que com a utilização de algoritmos de pós-processamento do volume, como é o caso atualmente.

Shiratori et al. (2011) estudaram a qualidade de exatidão (acurácia) tomográfica (TCFC) associada às quantidades ósseas alveolares circundantes aos implantes metálicos. Três a seis implantes foram inseridos na região anterior da maxila de oito (8) crânios secos, dependendo da disponibilidade de osso local. Os crânios foram selecionados aleatoriamente e então um total de trinta e um (31) implantes foram inseridos $\left(13 \times 3,75 \mathrm{~mm}\right.$, Master $A R$ - Morse Porous $^{\circledR}$, Conexão, São Paulo, Brasil). Foram obtidas impressões em positivo dos sítios de instalação dos implantes, nos quais foram conduzidas as medições. Critérios operacionais próprios e específicos foram desenvolvidos com a intenção de propiciar a qualidade final das 
impressões, antes da realização dos cortes pretendidos à avaliação. Gesso tipo IV foi utilizado em conformidade com as instruções do fabricante. Perfurações de $2,5 \mathrm{~cm}$ de diâmetro foram produzidas próximas aos locais de recebimento programado dos implantes e, então, foram realizados os cortes trans-axiais tomográficos de interesse. Todas as medidas, físicas e tomográficas, foram obtidas conforme intervalo semanal entre sessões, pelo mesmo operador e então repetidas três (03) vezes de modo sistemático. As imagens tomográficas foram obtidas a partir de tomógrafo iCAT ${ }^{\circledR}$ (Imaging Sciences International, Hatfield, Pasadena, CA, E.U.A.), e o software iCAT Vision ${ }^{\circledR}$ (nativo) foi utilizado para medir as quantidades ósseas pretendidas (espessuras), avaliadas sob cortes trans-axiais, embora não tenham sido apresentados os detalhes do procedimento de medição utilizado, e nem as eventuais limitações dele decorrentes. O protocolo de aquisição foi: $120 \mathrm{kVp}$, 46,72mA, 40s, resolução de voxel de $0,25 \mathrm{~mm}$, espessura de corte de $1 \mathrm{~mm}$ e reconstruções em escala de 1:1. Análise de Variância (ANOVA) foi utilizada com intervalos de confiança de $95 \%$, a fim de que fossem conhecidas as eventuais diferenças entre as técnicas de medição. Programa Microsoft Exce ${ }^{\circledR}$ foi utilizado para a análise estatística. Devido à presença de implantes metálicos, artefatos foram confirmados mesmo tendo sido realizados ajustes compensatórios para essa condição. No entanto, essa condição não foi suficiente para influenciar a qualidade das medidas. Discutiram as limitações durante o processo operacional tomográfico, principalmente aquelas em que o reconhecimento de espessuras ósseas alveolares torna-se crítico pela difícil visualização anatômica. Concluíram que a precisão volumétrica é possível com a utilização do protocolo firmado neste estudo, sendo possíveis medições do volume de espessuras ósseas alveolares vestibulares aos implantes, para finalidades clínicas, bem como para identificação e dimensionamento de cistos e reabsorções ósseas. Também é possível avaliar sítios de reparação óssea periodontal, com vistas ao planejamento terapêutico préoperatório, bucomaxilofacial e periodontal.

Slezák e Waczulíková (2011) apresentaram e discutiram conceitos técnicos e terminologia médica/científica associada ao delineamento experimental onde qualidades de reprodutibilidade e repetitividade estão envolvidas. Limitações de conceituação, entendimento e aplicação destes termos foram salientadas. Conforme 
afirmaram, "...não é incomum encontrar estudos com terminologia inconsistente associada aos termos "reprodutibilidade" e "repetitividade". Tais inconsistências de uso da terminologia tornam difícil a determinação metodológica correta, tanto a experimental, quanto a descritiva e analítica. Os termos "reprodutibilidade e repetitividade" são, ambos, estritamente definidos, cada um deles com seu próprio significado, e os cientistas deveriam respeitar as respectivas distinções de entendimento, interpretação e uso.

Sun et al. (2011) propuseram estudo de avaliação da exatidão (acurácia) de medidas ósseas alveolares verticais, sub milimétricas e a partir de imagens tomográficas volumétricas (TCFC), considerando também certas quantidades ósseas horizontais em associação com dois modos de resolução de voxel, 0,25mm e 0,4mm, ainda testando duas condições-teste: a redução óssea, de $1,5 \mathrm{~mm}$, para que o remanescente ósseo fosse menor que o tamanho de voxel de $0,4 \mathrm{~mm}$; ea remoção óssea, de $0,5 \mathrm{~mm}$, para que o remanescente ósseo fosse maior que este limite último de resolução de voxel. Utilizaram onze (11) espécimes maxilares de porcos (Sus scrofa), os quais foram preparados para receber as avaliações de medida em seis (06) locais selecionados. As distâncias foram medidas com o auxílio de paquímetro digital. Explicaram os autores que, inesperadamente, quantidades remanescentes diversas das pretendidas acabaram ocorrendo dada a imprecisão no estabelecimento daquelas reduções ósseas, ou seja, que as remoções ósseas descritas não puderam ser precisamente confirmadas. $O$ equipamento tomográfico foi iCAT $^{\circledR}$ (Imaging Sciences International, Hatfield, Pasadena, CA, E.U.A.). Utilizaram software Dolphin3 $D^{\circledR}$ (Premium Dolphin Imaging and Management Solutions, Chatsworth, CA, E.U.A.) para a avaliação das imagens, bem como para as medições. Medidas verticais (altura) e horizontais (espessura) foram realizadas por dois (02) operadores independentes, quando então a identidade dos espécimes não foi revelada aos participantes (cegamento). A seleção dos locais de medição nos cortes trans-axiais foi aleatória, constituindo um total de quarenta e oito (48) locais. Intervalos de, no máximo, duas semanas foi instituído para as avaliações. Concordância intra e inter-operadores foi avaliada por meio de Coeficiente de Correlação Intraclasse (CCl). Não foi descrito em detalhes, ou mesmo comentado o critério operacional de utilização dos cortes trans-axiais, e/ou dos recursos e 
procedimentos de medição. Testes $\mathrm{t}$ foram aplicados para comparar os resultados de utilização dos voxels de $0,4 \mathrm{~mm}$ e $0,25 \mathrm{~mm}$ em associação com as medidas diretamente obtidas, aquelas com e sem redução óssea simulada. Foi estatisticamente definido o nível de significância $(\alpha)$ de $5 \%(p=0.05)$. Para as alturas ósseas, a concordância intra-operador foi maior que 0,9 ; enquanto que para a avaliação inter-operadores, a concordância foi discretamente maior que 0,6. A avaliação das espessuras ósseas foi avaliada somente por meio da condição intraoperador. Discutiram acerca do valor de interpretação relativo aos níveis qualitativos estabelecidos e estimados de concordância Kappa, ressaltando que não há intervalo objetivamente aceito de confiabilidade para esses parâmetros, mas que são arbitrariamente sugeridos. Valores maiores que 0.6 expressariam substancial concordância, enquanto que aqueles maiores que 0.8 , uma quase que perfeita concordância. Afirmaram que boa ou excelente repetitividade pode ser obtida com a utilização de tomografias volumétricas (TCFC) para o conhecimento de medidas ósseas alveolares lineares. Em geral, e naturalmente, coeficientes de concordância intra-operadores mostram resultados melhores que os de concordância interoperadores. Embora a melhor resolução de imagem (voxel de $0,25 \mathrm{~mm}$ ) tenha possibilitado a obtenção de medidas lineares mais próximas daquelas obtidas do padrão-ouro que aquelas obtidas a partir do voxel de $0,4 \mathrm{~mm}$, constataram que tanto a avaliação intra, quanto a avaliação inter-operador não propiciaram resultados substancialmente significativos em favor da resolução de voxel de $0,25 \mathrm{~mm}$, comparativamente à de $0,4 \mathrm{~mm}$. Este resultado, discutiram, pode ter ocorrido devido à participação de fatores associados à própria qualidade das imagens, ou mesmo a partir de inconsistências de interpretação dos operadores. Obtiveram subestimação de medida significante (entre 0,9 e 1,2mm) paras as distâncias ósseas verticais com voxel de $0,4 \mathrm{~mm}$. O fenômeno de "invisibilidade óssea", observado para as cristas ósseas, explicaram, pode ter ocorrido a partir de dois fatores adicionais: o efeito de volume parcial (ponderação computacional entre médias de informação de cinza) e incapacidades quanto à resolução de contraste do próprio sistema de TCFC (resolução de baixo contraste). Estas condições, provavelmente, estiveram presentes durante o experimento dadas as médias ponderadas entre densidades de quantidades muito próximas de tecidos biologicamente distintos, ou seja, osso, cemento e ligamento periodontal (com espessura média de $0,5 \mathrm{~mm}$ ). A espessura óssea, medida no nível de $1 \mathrm{~mm}$ da crista óssea alveolar vestibular, foi registrada por 
meio de medição direta e valores médios menores que $0,4 \mathrm{~mm}$ foram obtidos. Contudo, e em razão da subestimação de 0,9 a 1,2mm, os valores de altura óssea não puderam ser tomograficamente detectados. No nível de medição (sub crestal) de $2 \mathrm{~mm}$, as médias de espessuras ósseas foram maiores que $0,6 \mathrm{~mm}$, e algum osso podia ser detectado tomograficamente para as medidas de altura óssea, já que a subestimação geral para as medidas de alturas ósseas foi menor que $2 \mathrm{~mm}$. Concluíram que espessura mínima de $0,6 \mathrm{~mm}$ deve estar presente para que a quantidade óssea possa ser distinguida do cemento, e que quando as espessura ósseas se aproximavam-se do valor do voxel $(0,4 \mathrm{~mm})$, então as medidas de altura óssea eram subestimadas (de 0,9 a $1,2 \mathrm{~mm}$ ). Diferentemente daquilo que esperavam, encontraram superestimação de medida (de 0,5 a $1,0 \mathrm{~mm}$ ) para as alturas ósseas quando espessuras ósseas "normais" estavam presentes (maior que o voxel de $0,4 \mathrm{~mm}$ ). Justificaram que esta possibilidade de efeito possa ter ocorrido tanto devido à pobre qualidade relativa à visualização dos limites entre "osso e ar", quanto às alterações de visualização promovidas pelo próprio software utilizado. Assim, sugeriram a utilização de outro software para a reprodução dos testes a fim de conhecer a origem desta limitação. Lembraram, ainda, que as limitações clínicas devem ser maiores que aquelas verificadas neste trabalho, e que a redução do voxel de $0,4 \mathrm{~mm}$ para $0,25 \mathrm{~mm}$ pode aumentar a exatidão de medidas ósseas alveolares lineares a partir de imagens de TCFC.

Swasty et al. (2011) investigaram, a partir de estudo retrospectivo tomográfico (TCFC) em humanos vivos, a relação entre características anatômicas das espessuras ósseas corticais, a partir de cortes trans-axiais da sínfise mandibular, e em três grupos de tipos faciais distintos. Utilizaram amostra (de conveniência) constituída de cento e onze (111) imagens tomográficas de pacientes com idades entre 10 e 65 anos, distribuídos em três grupos: um com faces equilibradas ( $n=43)$, e outros dois, um com faces longas $(n=34)$ e outro com faces curtas $(n=34)$. Os autores selecionaram treze (13) cortes para a realização de oito (08) medidas em cada um deles. As medidas selecionadas em cada corte incluíam uma (01) distância em altura e uma (01) em largura da sínfise, bem como cinco (05) espessuras ósseas corticais. Os tipos faciais foram determinados a partir de telerradiografias em norma lateral. Não foi informado o critério de exclusão na eventualidade de presença de 
artefatos metálicos. As imagens tomográficas foram obtidas a partir de dois tomógrafos, MercuRay ${ }^{\circledR}$ (Hitachi Medical, Tokyo) e iCAT ${ }^{\circledR}$ (Imaging Sciences International, Hatfield, Pasadena, CA, E.U.A.), e a partir de um Centro privado de Documentação Radiológica (Sacramento, AC, E.U.A.). Os parâmetros de aquisição para o CB MercuRay ${ }^{\boxplus}$ foram: $110 \mathrm{KVp}, 10 \mathrm{~mA}$ e $10 \mathrm{~s}$; e para o $i C A T^{\circledR}$ foram: $120 \mathrm{KVp}$, $8 \mathrm{~mA}$ e $20 \mathrm{~s}$. Um total de 512 cortes brutos foram obtidos com cada um dos sistemas. As imagens foram reconstruídas e também operacionalizadas com o auxílio do

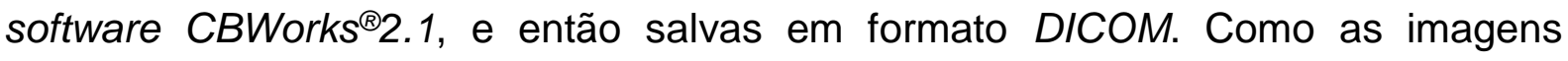
mostraram algumas dificuldades de visualização, então o "recurso histograma" foi utilizado para os ajustes de contraste e saturação. O recurso aplicativo "Z" foi utilizado a fim minimizar os efeitos de variação promovidos pela posição da cabeça. Como o programa $C B W o r k s^{\circledR} 2.1$, relataram, é incapaz de medir distâncias menores que $0,9 \mathrm{~mm}$, então, e após os ajustes da posição da cabeça, o programa $A V I A^{\circledR}$ (Hitachi, Tokyo, Japão) foi utilizado para as tarefas de medição. Os arquivos foram abertos com as dimensões originais DICOM, a partir dos quais foram definidos cortes trans-axiais entre os dentes. Cortes entre incisivos centrais e laterais não foram obtidos devido à proximidade das raízes. O plano mandibular foi selecionado como referência inicial à determinação dos demais referenciais de medida utilizados. O longo eixo da sínfise foi determinado como referência à determinação dos dois níveis de avaliação das larguras e espessuras. Três (03) operadores (um residente em Ortodontia e dois estudantes de Odontologia), incluindo o operador principal (autor-operador 1), foram associados à realização dos testes de confiabilidade a partir da variação do método. Os estudantes foram treinados pelo autor. Cento e quatro (104) distâncias foram selecionadas à avaliação do erro de medida. Os operadores mediram quantidades diferentes. $O$ operador 1 foi quem mediu a maioria das distâncias $(n=87)$. A variação intra-operador foi determinada a partir de apenas uma repetição de dez (10) medidas pelo operador principal (1). Declararam ter havido repetibilidade quase perfeita (0.997) com o software $A V I A^{\circledast}$ a partir de um único operador. A variação inter-operador foi determinada a partir de vinte (20) imagens selecionadas aleatoriamente. Oito (08) imagens foram avaliadas pelos operadores 1 e 2; cinco (05) foram avaliadas pelos operadores 1 e 3; e sete (07) foram avaliados pelos operadores 2 e 3 . Cálculo do Coeficiente de Concordância de Lin foi utilizado. A concordância média entre operadores 1 e 2 foi de 0,987 . A média para os operadores 1 e 3 foi de 0,991 . Para os operadores 2 e 3 , a média foi de 
0,983. Constataram excelente concordância entre os operadores. Concluíram haver discreta redução de espessura cortical associada aos indivíduos do grupo com face longa em comparação àqueles dos outros dois grupos. Os indivíduos do grupo com face longa também demonstraram, comparativamente àqueles dos outros dois grupos, significativa redução da largura óssea mandibular no terço superior do corte trans-axial da sínfise. A mandíbula foi mais larga e mais alta nos indivíduos do gênero masculino, mas não encontraram diferenças significantes quanto à espessura cortical entre gêneros.

Timock et al. (2011) investigaram a confiabilidade e exatidão (acurácia) de medidas de espessura e altura ósseas vestibulares, obtidas a partir de imagens de TCFC. Salientaram a importância atual de utilização do exame de TCFC para as mais diversas finalidades. As avaliações dos limites ósseos transversais, quando aplicados ao diagnóstico em Ortodontia, merecem destaque a partir de estudos histológicos prévios, e também aqueles realizados em animais, os quais tem indicado efeitos ósseos deletérios diante de certas condições associadas à aplicação de força ortodôntica. Conforme indicaram, o exame de TCFC, a partir da possibilidade única de reunir qualidade de análise em resolução sub milimétrica e ainda de versatilidade dos modos de avaliação, é capaz de ser reconhecido como recurso ideal à avaliação de efeitos ósseos terapêuticos. Enfatizaram que muitos estudos ainda devem ser conduzidos a fim de que sejam conhecidas as limitações de aplicabilidade clínica associadas à indicação da TCFC, haja vista a variabilidade metodológica presente considerando os objetivos das pesquisa, os equipamentos selecionados, os sujeitos e ainda as técnicas de obtenção das imagens, tornando difícil a inferência clínica em sentido amplo. Utilizaram doze (12) espécimes (cinco do gênero masculino e cinco do feminino) de material ex vivo, com idades variando entre 55 a 89 anos no momento da morte, de onde então foram selecionados sessenta e cinco (65) dentes (sem restaurações metálicas, coroas íntegras e periodonto sem condições capazes de gerar artefatos de imagem), os quais foram distribuídos conforme associação dente-espécime. Tomógrafo iCAT ${ }^{\circledR}$ 17-19 CBCT Unit (Imaging Sciences International, Hatfield, Pa, E.U.A.) foi utilizado para a obtenção da sequência de imagens, conforme os seguintes parâmetros de aquisição: $120 \mathrm{kVp}, 3-8 \mathrm{~mA}$ (modo pulso), 8,9s, rotação de aquisição de $360^{\circ}$, FOV 
de 13mm, 12 bits de informação, detector de silicone amorfo: flat panel e resolução de voxel de 0,3mm. Descreveram em detalhes os critérios de posicionamento do material com vistas à aproximação da orientação real da cabeça do espécime no tomógrafo. O resultado do escaneamento foi salvo em arquivos DICOM. Depois de obtida a sequência de imagens, os espécimes foram dissecados e medidos em seus locais de interesse com o auxílio de paquímetro digital Vernier (General Tools ${ }^{\circledR}$, New York, NY, E.U.A.), com precisão de aproximação de leitura de $0,01 \mathrm{~mm}$. Os autores definiram um procedimento operacional de medição para a execução das medidas lineares (figura 2.11). Assim, a altura óssea avaliada diretamente foi definida como a distância, em milímetros, da ponta da cúspide ou incisal, até o topo da crista óssea alveolar, ao longo do eixo dentário.
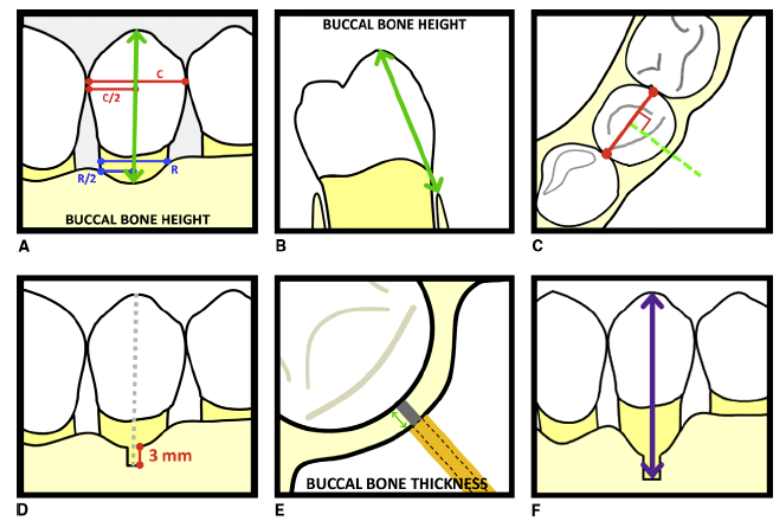

Figura 2.11 - Representação esquemática das dimensões lineares consideradas para o procedimento operacional de medição (instrução)

Dois (02) operadores participaram de modo independente, realizando, cada um, três (03) medidas de cada grandeza: espessura e altura ósseas, tanto direta quanto tomograficamente, mantendo intervalo mínimo de um (01) dia entre as medições. Conforme descreveram, repetições de medidas tomográficas realizadas por dois (02) operadores, foi suficiente para avaliar a confiabilidade intra e inter-operadores. Foi utilizado, para a visualização e medição tomográfica, o software Dolphin3 ${ }^{\circledR}$ Imaging (Dolphin Imaging Systems, Chatsworth, CA, E.U.A.). Cortes de 0,5mm foram selecionados para a realização das medições, a qual ocorreu em sala com controle de luminosidade (escura). O seguinte protocolo operacional foi definido: a) a imagem foi orientada de modo tal que o plano oclusal fosse paralelo ao plano axial, nas vistas frontal e lateral, e a linha média facial foi coincidente com o plano sagital mediano; b) O plano axial foi definido de modo que cortasse tomograficamente a coroa do dente de interesse; c) os planos sagital e coronal foram ajustados para 
passarem pela coroa e raiz dos dentes de interesse (ápices dilacerados foram ignorados), com o plano sagital perpendicular à forma do arco do indivíduo sob vista axial; d) a partir da vista sagital, a altura óssea vestibular foi medida da ponta da cúspide/incisal, até o local mais coronal da crista óssea alveolar; e) A referência vertical de medida das espessuras ósseas tomográficas foi definida por equivalência à dimensão previamente definida durante as medições diretas de altura óssea, resultando que a espessura óssea medida foi, sob vista axial, do ponto mais vestibular do osso alveolar até o ponto mais vestibular da raiz, avaliada. Não foram descritos os critérios de operacionalização métrica, então provavelmente foram utilizados os recursos do próprio software. Utilizaram Análise Estatística de Generabilidade (EduG - versão 6.0; Swiss Society for Research in Education Working Group, Neuchatel, Suíça) para avaliar as fontes de erro decorrentes das medidas de altura e espessura ósseas. Variações intra e inter-operadores foram consideradas no âmbito da referida análise. A variação inter-operadores deu-se a partir da descrição das diferenças médias absolutas (sinais ignorados), as quais foram posteriormente analisadas por meio de Coeficientes de Correlação de Concordância, bem como com o auxílio de coeficientes de correlação de Pearson (Stata Statistical Software-11.0, Stata Corp. College Station, Texas, E.U.A.). Testes $t$ foram executados para conhecer a qualidade de exatidão entre os dois métodos. $A$ concordância tomográfica foi avaliada a partir dos parâmetros do gráfico sugerido por Bland-Altman, utilizando limites de 95\% de concordância ( \pm 1,96 do DP das diferenças). Quanto à exatidão das medidas lineares verticais, obtiveram resultados de superestimação linear em $54 \%$ dos casos; e de subestimação em $43 \%$. Em $3 \%$ dos casos, as medidas foram equivalentes. Constataram aparente não associação entre direções e magnitudes das diferenças e os dois métodos considerados. Ignorando os sinais, a diferença absoluta média, para as alturas ósseas e a partir dos dois métodos estudados, foi de $0,30 \pm 0,27 \mathrm{~mm}$. O teste $t$ indicou não haver diferença significativa entre as medidas de altura óssea tomográfica e aquelas diretamente obtidas. Quanto às espessuras ósseas vestibulares, as médias e desvios-padrões para ambas as medições, direta e tomográfica, foram aproximadamente equivalentes $(0,54 \pm 0,35 \mathrm{~mm}$ e $0,52 \pm 0,33 \mathrm{~mm}$ respectivamente), com diferença média entre os métodos de 0,03 $\pm 0,18 \mathrm{~mm}$. A distribuição indicou que, em $56 \%$ dos casos, as espessuras ósseas vestibulares tomográficas foram maiores (superestimação) que aquelas medidas diretamente (padrão-ouro), e que, 
em $41 \%$ dos casos, as mesmas grandezas foram menores (subestimação), o que indica que as diferenças entre métodos, considerando medições de objetos reais e equivalentes tomográficos, mostraram exatidão bastante satisfatória, com erro mostrando tendência ao zero, resultando em equivalência em termos de sub e super estimação linear das grandezas tomográficas obtidas. Com isso, também não constataram aparente associação entre magnitude e direção das diferenças e os dois métodos considerados. A diferença absoluta média, para as espessuras ósseas alveolares e a partir dos dois métodos estudados, foi de 0,13 $\pm 0,12 \mathrm{~mm}$, quando 0 Coeficiente de Concordância e de Correlação de Pearson foi de 0.86, menor que aquele obtido para as alturas ósseas (0.98). Compararam os resultados disponíveis relativos à confiabilidade intra-operador (CCs entre 0.93 e 0.99 ), com os quais obtiveram consistência (CCs entre 0.98 - 1.00). Criticaram haver poucos estudos com a participação de diversos operadores para o conhecimento da variação de medições tomográficas e, ainda, que a adoção de protocolos mais bem definidos podem realmente oferecer parâmetros de medidas mais confiáveis. Discutiram a associação entre resolução espacial (capacidade de serem tomograficamente distinguidos dois objetos muito próximos) e exatidão (acurácia) de medidas quando distâncias diminutas são consideradas, ponderando as possibilidades inferenciais haja vista a variação dos níveis de exatidão publicados, alguns registrando que a mesma pode ser de décimos do milímetro, porém outros indicando valores muito acima do limite dos voxels selecionados, para os quais a variação metodológica, a participação de ruídos de produção e a dispersão dos feixes seriam as causas das limitações em termos de valores absolutos maiores, em até o dobro, dos tamanhos de voxel/pixe/ selecionados. Conforme relataram, as alturas ósseas avaliadas foram mais confiáveis (0.98) que as espessuras ósseas alveolares (0.86) e que esta informação poderia ser o resultado de serem, as alturas ósseas, distâncias lineares bem maiores que as espessuras alveolares, e bem maiores que os tamanhos de voxel/pixel usualmente utilizados, fazendo da identificação quantitativa das espessuras ósseas um procedimento menos favorável que a identificação das alturas ósseas para a avaliação dos efeitos da movimentação ortodôntica. Concluíram que cortes trans-axiais, por facilitarem a padronização dos protocolos de medição e reprodução, são mais favoráveis à comparabilidade considerando medidas executadas diretamente, e, ainda, que a variação comercial entre tomógrafos disponíveis, softwares de visualização e processamento das imagens, 
além dos protocolos de aquisição e de medição, constituem os fatores de maior influência final quanto à exatidão e confiabilidade do resultados.

Tomasi et al. (2011) avaliaram a influência da indicação posicional de objetos submetidos ao exame de TCFC na determinação de medições lineares de estruturas anatômicas mandibulares. Enfatizaram a importância para o planejamento de implantes da utilização de imagens bidimensionais exatas, portanto livres de distorção e artefatos, e da condição de reprodutibilidade associada às medidas lineares provenientes do exame. Relataram possíveis distorções decorrentes da condição de voxel anisotrópico da TC quando utilizadas para finalidades de planejamento pré-cirúrgico e que, para voxels isotrópicos da TCFC, a produção daquelas distorções não ocorreria. Utilizaram dez (10) diferentes distâncias lineares selecionadas a partir de pontos anatômicos definidos previamente em uma mandíbula seca humana (ex vivo). Três (03) examinadores (dois estudantes de Odontologia e um já formado) participaram do estudo. Para a tarefa, os participantes utilizaram paquímetro digital (Leone, Firenze, Itália), com precisão de leitura de $0,1 \mathrm{~mm}$. Antes de iniciarem, os operadores fora treinados para o uso do paquímetro em relação às distâncias solicitadas. As medidas foram realizadas três (03) vezes por cada operador e a média das medições foi utilizada como verdade dimensional (padrão-ouro convencionado). O tomógrafo utilizado foi o Planmeca Promax $3 D^{\circledR}$ Unit (Planmeca $O Y^{\circledR}$ Helsinki, Finlândia). A mandíbula, fixada com silicone, foi posicionada tanto paralela ao solo, quanto sob ângulo de $45^{\circ}$ em relação ao plano horizontal do detector (scanner). O Planmeca dispõe de detector flat panel e o FOV utilizado foi de $80 \mathrm{~m}^{2}$. O tempo total de aquisição foi de $18 \mathrm{~s}$, com $56 \mathrm{kVp}$ e $3 \mathrm{~mA}$, produzindo 300 cortes brutos bidimensionais a partir de rotação (curta) de $194^{\circ}$ em torno do objeto. O voxel final resultante foi de $0,16 \mathrm{~mm}$. O software de operacionalização tomográfica utilizado foi 0 Romexis $^{\oplus}$ (Planmeca, Helsinki, Finlândia). A partir do respectivo recurso computacional de medida, os operadores, os quais não foram calibrados para esta etapa, realizaram, de modo independente as medições solicitadas. O responsável pela análise dos resultados não participou das sessões de registro e medição. Os examinadores não tiveram a oportunidade de acessar previamente informações tomográficas similares àquelas sob teste. A imagens foram operacionalizadas de modo que o posicionamento dos cortes fosse 
adequado às características métricas dos recursos de medição do software. Definiram protocolo de participação dos operadores e foi descrito o critério de realização das sessões. As imagens foram selecionadas aleatoriamente entre as sessões, e o total de medidas realizadas foi de duzentos e quarenta (240). Utilizaram Coeficiente de Correlação Intraclasse (CCl), para medida simples, como modo de análise da confiabilidade de medição entre os grupos de dados obtidos. Obtiveram significativas reprodutibilidade e confiabilidade de medidas, geradas a partir de imagens de TCFC. Comentaram que a utilização de apenas uma amostra poderia limitar a possibilidade de análise da variação das características anatômicas, mas que essa aparente condição foi positivamente compensada pela seleção de dez (10) diferentes distâncias lineares. Concluíram que as variações de posicionamento da cabeça não seriam clinicamente significantes haja vista que todo o volume foi incluído para a aquisição e, também, que a confiabilidade das medidas não se mostrou dependente da experiência dos operadores. Este fato, adicionaram, pode ser atribuído à alta qualidade das imagens geradas, em termos de resolução de contraste.

Tsutsumi et al. (2011) avaliaram a dependência direcional de exatidão (acurácia) linear, com a utilização de TCFC, e com o intuito de obter a mínima espessura necessária a fim de manter a quantidade de erro do pixel (EPA) restrita a um único pixel na medida. Utilizaram fantoma de alumínio, o qual fora preparado para a obtenção de cortes de espessura de 0,3 a 1,0mm. Tomógrafo $C B$ Mercury ${ }^{\circledR}$ (Hitachi Medical), com intensificador de imagem de 12 pol., e capaz de gerar dados de voxel de $512 \times 512 \times 512$, foi empregado conforme diferentes resoluções de voxel, 0,20 mm (102mm - modo implante), 0,29mm (150mm - modo panorâmico) e 0,37mm (192,5mm - modo facial), e parâmetros de $120 \mathrm{kVp}$ e $15 \mathrm{~mA}$. Afirmaram que é desconhecida a exatidão de medida, quando considerado o sistema TCFC para objetos diminutos, ou muito finos. Discutiram as dificuldades inerentes à identificação dos limites ou margens das imagens a partir de monitores de computadores pessoais, esclarecendo que a exatidão pode ser afetada pela variação intra e inter-operador. A precisão obtida do fantoma foi de $\pm 0,01 \mathrm{~mm}$. Portanto, e para a avaliação das medidas lineares no referido estudo, consideraram o valor de 0,01mm como sendo confiável para a distância absoluta. As imagens 
tomográficas foram avaliadas por meio de Método do Limiar Relativo de 50\%, o qual estabelece a possibilidade, segundo informaram, de eliminação da variabilidade operador-dependente. Com o aumento de tamanho do voxel e do FOV, e sob mesmas condições, o erro absoluto tende a aumentar. Registraram que os voxels variaram nos três FOVs selecionados, sendo necessária a utilização de um índice específico: o da Quantidade de Erro do Pixel (EPA), o qual fora também utilizado como índice de erro de medida. Verificaram que espessuras de no mínimo 3 ou 4 pixels foram necessárias para manter a exatidão dentro do padrão de um pixel de erro, e este limite, salientaram, é importante para avaliações da doença periodontal e de corticais ósseas delgadas. Os autores registraram que os resultados de exatidão, obtidos do referido experimento, podem não ser aplicáveis comparativamente considerando outros sistemas tomográficos. Justificaram que esta limitação pode ocorrer devido às várias diferenças possíveis entre os sistemas, como, por exemplo, o tipo de equipamento tomográfico, o tamanho ou resolução do voxel, os tipos de detector (utilizaram intensificador de imagem, o qual impõe algumas distorções geométricas se comparado aos sistemas com flat panel), os métodos de calibração e, ainda, os de correção das distorções geométricas pósprocessamento produzidas. Concluíram que as distâncias horizontais foram discretamente superestimadas, enquanto que as longitudinais foram de exatidão excelente, e que as imagens obtidas do sistema TCFC, para o planejamento em Implantodontia, são superiores qualitativamente àquelas produzidas pelos sistemas de TC convencional e de múltiplos cortes (TCMC), em decorrência das doses proporcionalmente menores de radiação ionizante, alta resolução no sentido longitudinal, menor incidência de artefatos de imagem e, ainda, de custo proporcionalmente reduzido.

Umetsubo (2011) propôs método tomográfico para constituição de protocolo de aquisição, o qual fosse mais favorável à detecção de lesões incipientes de furca, quimicamente simuladas. $O$ autor avaliou a reprodutibilidade, bem como sensibilidade e especificidade da TCFC para a finalidade proposta. Para tanto, foram utilizadas quinze (15) mandíbulas suínas maceradas, as quais apresentavam o segundo molar íntegro e as corticais adjacentes preservadas As simulações de lesões em região de furca foram produzidas a partir da aplicação de ácido perclórico 
a 70\%, em até quatro sítios possíveis em cada mandíbula (vestibular do lado direito, lingual do lado direito, vestibular do lado esquerdo, lingual do lado esquerdo) por um (1) examinador participante que não avaliou as imagens. Dos sessenta (60) sítios possíveis, foram aleatoriamente selecionados vinte (20) para as simulações das lesões. Posteriormente, as mandíbulas foram submetidas à TCFC (i-CAT ${ }^{\circledR} N e x t$ Generation, E.U.A.), conforme dois protocolos distintos de aquisição relativos ao tamanho de voxel, 0,2 $\mathrm{mm}$ e 0,25 mm, ambos com FOV de $6 \mathrm{~cm}$ de altura por $16 \mathrm{~cm}$ de diâmetro e com 26,9 segundos de tempo de aquisição. Dois (02) observadores (radiologistas previamente treinados) avaliaram os exames duas (02) vezes, em ordem aleatória, sob iluminação controlada. Os observadores foram orientados a direcionar a avaliação das regiões dos segundos molares, e questionados acerca da presença ou não de lesões nos sítios observados. A interpretação das imagens foi realizada em estação de trabalho independente, localizada no Laboratório de Imagem em Terceira Dimensão da Faculdade de Odontologia da Universidade de São Paulo, utilizando o software $\operatorname{Xoran}^{\circledR}$ (Xoran Technologies, E.U.A.). Não foi oferecida descrição detalhada do procedimento de medição empregado, e nem de eventuais limitações dele decorrentes. A sensibilidade, especificidade e reprodutibilidade da TCFC foram avaliadas nos dois protocolos. A TCFC apresentou especificidade alta, sensibilidade baixa e reprodutibilidade moderada na detecção de lesões incipientes de furca. A influência do tamanho do voxel não foi estatisticamente significativa na detecção destas lesões.

Kajan e Taromsari (2012) avaliaram a possibilidade de serem detectadas fraturas radiculares a partir de imagens tomográficas volumétricas (TCFC), bem como de serem comparados os resultados com amostras reais, constituídas de dentes extraídos. Dez (10) pacientes constituíram a amostra desse estudo Todos os dentes-alvo estavam comprometidos e seriam extraídos devido à presença de inflamação local e/ou fístulas e/ou sintoma de dor durante a mastigação. A análise radiográfica convencional não revelou evidência de fraturas radiculares verticais, mas sim de espessamento do ligamento periodontal, radiolucência apical em torno da superfície radicular e/ou, ainda, perda angular da crista óssea, definida ou difusa, sem limites corticalizados definidos. Conforme salientaram: 
[...] A tomografia computadorizada volumétrica (TCV ou TCFC) é um recurso tecnológico recente para uso em Endodontia. Neste tipo de imagem, um feixe cônico, ao invés de um feixe "em leque" de radiação é utilizado, propiciando a oportunidade de gerar imagens com alta resolução, e isotrópicas, o que é mais vantajoso quando comparadas às imagens geradas pelo sistema de TCMC (2012, Kajan e Taromsari, p. 05).

Utilizaram tomógrafo NewTom $V G^{\circledR}(Q R$ SRL Company, Verona, Itália) em modo de zoom de lata resolução, com $110 \mathrm{kVp}, 5,5 \mathrm{~mA}$ e 5,4s. O tempo total de aquisição tomográfica foi de 18-20s. Imagens axiais foram utilizadas com cortes de espessura de $1 \mathrm{~mm}$ e intervalo espacial de $0,15 \mathrm{~mm}$ a $0,5 \mathrm{~mm}$, obtidos perpendicularmente aos eixos mésio-distais e vestíbulo-linguais/ palatinos. Dois (02) operadores (Endodontista e Radiologista), com experiência de mais de dez (10) anos e familiarizados com TCFC participaram dos testes de detecção. Os autores confirmaram a exatidão (acurácia) de uso da TCFC para o diagnóstico de fraturas radiculares e seus padrões de visualização de modo similar a outros estudos. Entre os diferentes sistemas de TCFC, os que utilizam detector flat panel são superiores aos de outros tipos para o diagnóstico de fraturas radiculares verticais. Salientaram o critério de obtenção de planos de corte perpendiculares ao eixo radicular de modo a produzir imagens axiais as quais são de grande valor para o diagnóstico de fraturas. Concluíram que os sistemas de TCFC com recurso flat panel são, de fato, auxiliares para a obtenção de qualidade no diagnóstico de fraturas radiculares verticais, bem como de graus de perda óssea localizada.

Patcas et al. (2012), visando resolver deficiências de delineamento experimental verificadas em outros estudos, determinaram a exatidão (acurácia) de medidas derivadas da utilização de imagens de tomografia volumétrica (TCFC) a partir de diferentes resoluções de voxel, e em torno dos dentes mandibulares anteriores, considerando o arco ósseo. Discutiram acerca das limitações inerentes à utilização de modelos ex vivo na produção de referenciais numéricos de exatidão linear. Ênfase foi conferida ao planejamento terapêutico considerando a participação dos incisivos inferiores durante a movimentação ortodôntica, uma vez que foi demonstrado o efeito crítico de participação dos dentes daquele setor na produção 
de deiscências e fenestrações ósseas. Foram utilizadas oito (08) cabeças de cadáveres, sendo destas cinco (05) do gênero feminino e três (03) do masculino, e a partir de dois sistemas distintos de TCFC: KaVo 3D eXam ${ }^{\circledR}$ e KaVo Dental AG $^{\circledR}$ (Brugg, Suíca), conforme parâmetros de aquisição distintos, mas com quilovoltagem e miliamperagem similares (120 kVp e $5 \mathrm{~mA}$ ), e resolução de voxels de $0,4 \mathrm{~mm}$ e $0,125 \mathrm{~mm}$. As medidas tomográficas foram realizadas a partir de software de pósprocessamento (eXam Vision ${ }^{\circledR}, \mathrm{Pa}$, E.U.A.). Todas as imagens obtidas foram a partir de cortes reformatados conforme incidência de corte perpendicular à linha de curvatura do arco ósseo, considerando o perfil vestíbulo-lingual de cada dente incluído no estudo. As distâncias verticais medidas foram tomograficamente análogas àquelas diretamente realizadas (figura 2.12).
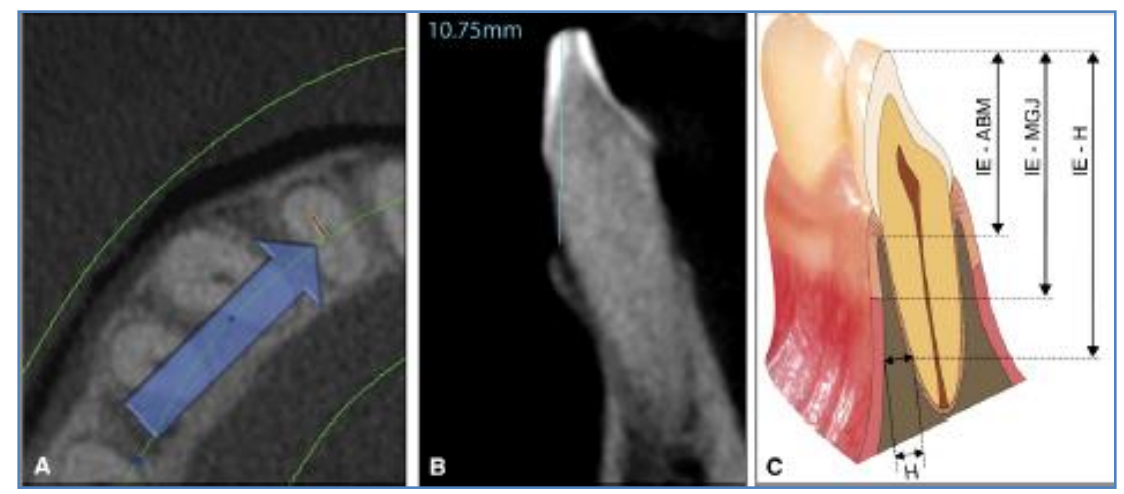

Figura 2.12 - a) indicação, no corte axial, do local de incidência do corte para obtenção das imagens trans-axiais; b) imagem trans-axial com indicação do modo vertical de medição, definido de modo análogo às medições realizadas diretamente (c)

Dois paquímetros eletrônicos foram utilizados (exatidão de 0,01mm). Todas as medidas foram executadas duas vezes pelo mesmo operador, com intervalo mínimo de uma (01) semana. A confiabilidade intra-observador foi avaliada por meio de análise do Coeficiente de Correlação Intraclasse (CCI). para a concordância absoluta, com base na Análise da Variância (ANOVA). Discutiram a utilização excessiva de análises de correlação para testar concordância entre dois métodos de medição, já que o que se pretenderia, naqueles casos, seria avaliar as dissimilaridades entre métodos de medição, e não avaliar a concordância dos operadores com os referidos métodos. Verificaram que a concordância entre medidas verticais e horizontais foi discretamente maior em direção às espessuras ósseas. Conforme enfatizaram, medidas próximas a zero também apresentam diferenças menores entre elas, fazendo incidir viés de observação relativo aos 
limites de concordância estabelecidos. Discutiram acerca do resultado de que os limites de concordância (um operador) foram maiores que as médias de espessuras ósseas indicando que os dois protocolos de aquisição, quanto aos tamanhos de voxel selecionados, não foram exatos o suficiente para medir tão delicadas estruturas na forma de espessura óssea. Para as medidas absolutas de dimensões bem maiores, no entanto, obtiveram que os dois protocolos mostraram exatidão significante. Concluíram que a resolução de voxel de $0,125 \mathrm{~mm}$ foi mais sensível para as detecções, mas, devido ao maior erro absoluto de medida, amplo limite de concordância e dispersão das diferenças, afirmaram ser este um protocolo menos confiável que aquele com voxel de 0,4mm (figura 2.13).

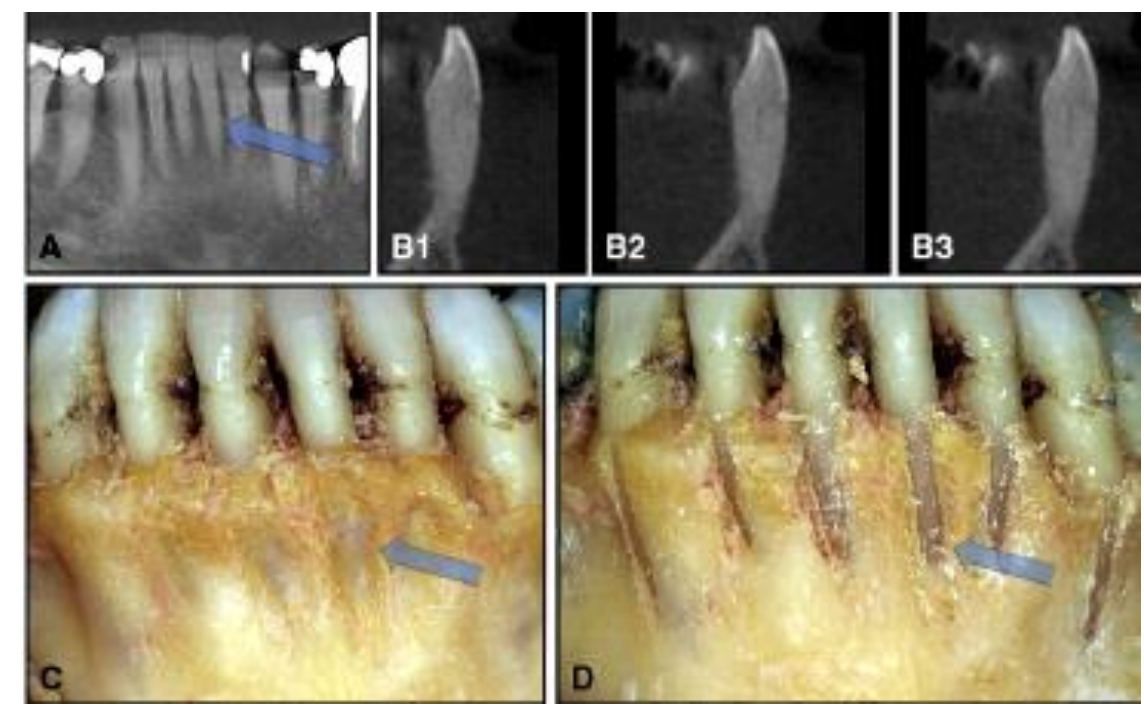

Figura 2.13 - a) indicação, sob vista panorâmica, do local de incidência do corte para obtenção das imagens trans-axiais; B1, B2 e B3) sequência de imagens tomográficas trans-axiais dos dentes de interesse; c) visa vestibular após remoção da gengiva, e d) vista vestibular após remoção de parte do osso alveolar vestibular. As setas azuis correspondem à imagem tomográfica do dente mostrado em B1. Note-se que não há osso cobrindo a raiz nas imagens B1 e B3

Enfatizaram questões associadas à diversidade metodológica entre estudos e aos limites de tolerância clínica diante das estimativas de inexatidão. Sugeriram que, na prática, limites de concordância devem ser preferíveis aos valores médios absolutos. A espessura óssea mais fina registrada (medida direta) pelos autores foi de $0,14 \mathrm{~mm}$. Ponderaram que medidas de espessura óssea com $1 \mathrm{~mm}$, devido ao amplo limite de concordância, são praticamente perdidas na avaliação tomográfica. Afirmaram que a sensibilidade tomográfica não é capaz de detectar finas camadas de osso com vistas ao diagnóstico ortodôntico e, ainda, que que seus resultados indicaram um 
risco genuíno de serem confirmadas fenestrações e/ou deiscências, a partir de imagens obtidas de tomografia volumétrica, as quais não existiriam verdadeiramente (superestimação).

Vasconcelos et al. (2012) compararam a detecção de perda óssea, em sua qualidade de identificação e localização, utilizando referenciais lineares de largura, altura e profundidade correspondentes aos defeitos observados, mediante utilização de dois métodos radiológicos: radiografias periapicais e imagens de TCFC. As imagens radiográficas foram selecionadas a partir de acervo próprio (amostra de conveniência). Protocolo de $70 \mathrm{kVp}$ e $8 \mathrm{~mA}$, bem como tempos de exposição entre 0,5 e $0,7 \mathrm{~s}$ foram utilizados para essa modalidade de exame. Os registros radiográficos foram digitalizados com auxílio de Scanner HP ${ }^{\circledR} 4890$ (Hewlett Packard, Palo Alto, CA, E.U.A.), com resolução de 300 dpi e definidos em extensão de arquivo Tagged Image File Format (TIFF). As imagens de TCFC foram obtidas com sistema ${ }^{2 C A T^{\circledR}}$ (Imaging Sciences International, Hatfield, PA, E.U.A.), com parâmetros de exposição de $120 \mathrm{kVp}$ e $36,12 \mathrm{~mA}$, campo de visão (FOV) de $6 \mathrm{~cm}$, tamanho de voxel de $0,20 \mathrm{~mm}$ e definidos os arquivos em formato DICOM, processado por Software Xoran $C A T^{\circledR}$, versão 3.1.62, em um computador pessoal Inte ${ }^{\circledR} R$ Pentium, com CPU $340 \mathrm{GHz}, 335$ GB RAM, Sistema operacional Windows $\mathrm{XP}^{\circledR}$, analisados a partir de reconstruções axiais e sagitais conforme intervalo de corte de $1 \mathrm{~mm}$. Um (01) especialista em Radiologia Odontológica, com quatorze (14) anos de experiência, selecionou as imagens conforme o seguinte critério de inclusão: boa qualidade de imagem, definida como apresentando média densidade e contraste; centralização da região avaliada e boa visualização da junção amelocementária. De um arquivo de 1.485 imagens, foram selecionadas imagens periapicais e tomográficas de vinte e um (21) pacientes adultos que haviam sido relacionados, por meio de avaliação radiográfica, à avaliação de doença periodontal, propiciando a obtenção de um total de duzentos e dezoito (218) dentes. Destes, cento e setenta e nove (179) foram excluídos da amostra por não apresentarem visualização satisfatória das junções amelo-cementárias, em decorrência de comprometimento naqueles locais. Discutiram os parâmetros de normalidade comumente encontrados na literatura relativos às distâncias verticais entre junção amelo-cementária e crista óssea alveolar, relatando desde variações aceitas entre 1 
e $3 \mathrm{~mm}$, sendo de $3 \mathrm{~mm}( \pm 1,5 \mathrm{~mm})$ para adultos acima de 45 anos, até o valor médio de $2 \mathrm{~mm}$, este último mais comum entre estudos com condições periodontais normais. Assim, e como utilizaram indivíduos com média de idade de quarenta e oito (48) anos, selecionaram, como parâmetro de normalidade à realização dos testes, distâncias lineares (da junção amelo-cementária até a crista óssea alveolar) com valores $\geq 3 \mathrm{~mm}$. Em relação aos trinta e nove (39) dentes, cinquenta e um (51) apresentavam perda óssea. A amostra resultante foi então de trinta e nove (39) dentes, de onze (11) pacientes adultos, de ambos os gêneros e com idades entre trinta e nove (39) e sessenta e seis (66) anos. As imagens foram analisadas por três (03) examinadores, dos quais um (01) era Radiologista, com dois anos de experiência e, os outros dois (02), estudantes de Pós-Graduação (Mestrado) em Radiologia Bucal. Os examinadores foram previamente treinados utilizando vinte (20) imagens não incluídas durante os testes. Antes de iniciar as medições, os operadores tiveram de converter o padrão de imagem de pixels para milímetros, a fim de que fossem mantidas as proporções reais das dimensões utilizadas. Os testes foram realizados em sala com controle de luminosidade e ruído, em monitor de 17 ", com resolução de tela de $1280 \times 1024$. O software de auxílio às medições foi - ImageToo ${ }^{\circledR}$ (University of Texas Health Science Centre, San Antonio, Texas, E.U.A.), baseado no método de Misch et al. (2006). Entretanto, não ofereceram descrição detalhada do procedimento de medição empregado, e nem das eventuais limitações dele decorrentes. Três (03) medições foram obtidas de cada local de avaliação (figura 2.14). Obtiveram resultados diversos de outros autores que utilizaram cortes trans-axiais e oblíquos para avaliação semelhante. Atribuíram as diferenças à diversidade metodológica, incluindo a utilização de protocolos tomográficos distintos. Os resultados provenientes da TCFC foram melhores quanto ao potencial de detecção da perda óssea em áreas interproximais. Concluíram que os dois (02) métodos diferiram quanto aos valores lineares de altura óssea, mas que foram correspondentes em relação às larguras e profundidades. Salientaram a justificada indicação de tomografia volumétrica para 0 planejamento de procedimentos cirúrgicos periodontais, bem como àqueles de regeneração tecidual, dada a complexidade envolvida nestas tarefas. Contudo, destacaram, a importância do exame clínico permanece essencial para a avaliação das periodontopatias, e outros estudos, também em humanos vivos, podem esclarecer melhor as limitações encontradas em termos de aproximações de aplicação clínica das medidas obtidas. 


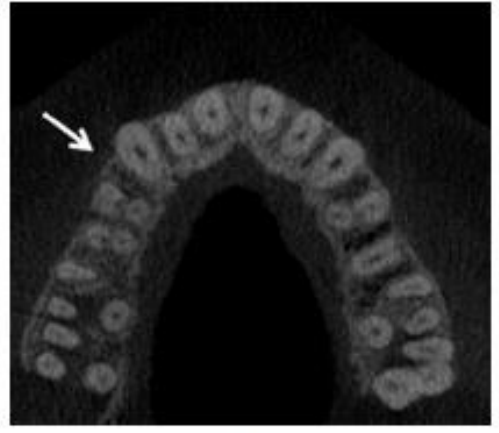

a

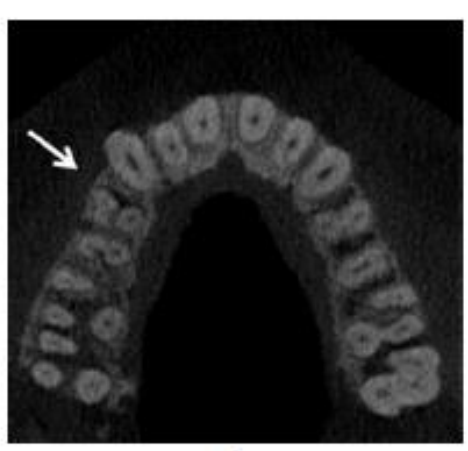

b

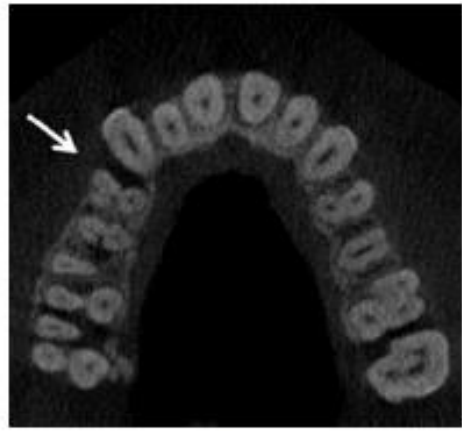

c

Figura 2.14 - Cortes tomográficos axiais (TCFC) ilustrando a presença de defeitos ósseos combinados (seta branca) na superfície mesial do dente 14, a) sem evidência de defeito, b) defeito com três paredes remanescentes e c) evolução do defeito em sentido cervical com apenas uma parede remanescente 


\section{PROPOSIÇÃO}

[...] Quando o homem do tempo prevê uma chance de 95\% de chuva para amanhã, a maioria de nós sairá de casa com guarda-chuva"

DAVID SALSBURG

Uma Senhora Toma Chá... - Como a estatística revolucionou a ciência no século XX

\subsection{GERAL - Informação descritiva}

- Conhecer melhor, a partir do método proposto de obtenção, visualização, registro (inspeção e identificação) e medição das imagens tomográficas obtidas, as condições de expressividade anatômica associadas às espessuras ósseas alveolares, vestibulares e linguais/palatinas, maxilares e mandibulares, de modo a favorecer o entendimento de como se distribuem estas quantidades lineares ao longo do perímetro dos arcos dentários, gerando, com isso, a possibilidade efetiva de realização de mapeamentos quantitativos confiáveis destas dimensões, e

- Organizar as informações quantitativas com vistas à utilização das mesmas em aplicações subsequentes com modelos geométrico-matemáticos, os quais possam favorecer outras condições de delineamento experimental e teste, principalmente àquelas associadas às possibilidades terapêuticas em Ortodontia.

\subsection{ESPECÍFICA - Informação analítica}

A partir da concretização do objetivo geral, a presente investigação intenciona:

- Testar, por meio de análise da repetitividade e reprodutibilidade das medições executadas, e com a hipótese de não diferença $(H 0)$ entre os valores de 
medida obtidos a partir da sequência operacional (POP) previamente definida, as Condições de Repetitividade e de Precisão Intermediária associadas ao método de registro (inspeção e identificação) e medição que está sendo proposto, com vistas a oferecer parâmetros cientificamente confiáveis (exatidão e precisão) e metodologicamente eficazes quando da representação tomográfica (TCFC) transaxial de setores dentários de interesse à avaliação quantitativa das espessuras ósseas alveolares, maxilares e mandibulares, vestibulares e/ou linguais/palatinas, com aplicação diagnóstica em Ortodontia, Periodontia e demais especialidades;

- Discutir as possibilidades de aplicação inferencial dos erros estimados com o presente experimento, considerando as estimativas de exatidão linear (acurácia), existentes na literatura especializada, relativas às dimensões ósseas alveolares e que tenham sido geradas a partir de padrões similares de obtenção tomográfica;

- Oferecer, se necessário for e após ter sido concluída a análise da qualidade final da informação obtida, ajustes ad hoc os quais possam favorecer a eficácia integral de aplicação do método proposto. 


\section{CASUÍSTICA / MATERIAL E MÉTODO}

A verdade sai do erro mais facilmente do que da confusão.

BACON

\subsection{CASUÍSTICA}

Utilização de um (01) registro tomográfico, sistema de feixe-cônico (TCFC) de um (01) indivíduo (voluntário).

\subsubsection{Voluntário}

Além das características gerais, descritas adiante, e considerando os requerimentos metodológicos necessários à execução dos testes de confiabilidade relativos ao método que está sendo proposto, não foram, propositadamente e com vistas a minoração da presença de vieses (erros sistemáticos), definidas sistematicamente quaisquer circunstâncias prévias específicas relativas à condição anatômica (fenotípica) do indivíduo (voluntário) que iria servir de referência à obtenção das imagens para a realização dos testes, já que foi considerada a condição de aleatoriedade durante o delineamento do experimento. Assim, as variações anatômicas de origem biológica, fossem elas intuitivamente desfavoráveis, indiferentes ou mesmo favoráveis à obtenção dos resultados, foram consideradas, todas, constantes para a identificação da estimativa geral de variação decorrente da participação dos operadores, considerando a sequência própria de registro, medição e análise das grandezas selecionadas.

As fontes de variação operacional podem estar associadas a condições específicas, relativas tanto à qualidade técnica da sequência do processo de medição proposto (função do erro sistemático), quanto à participação do fator humano no sentido probabilístico (erro aleatório). Assim sendo, estas fontes de variação foram consideradas durante a interpretação dos resultados obtidos, no 
sentido de se proceder com eventuais ajustes (ad hoc) dos fatores-problema, favorecendo assim melhores condições de entendimento e aplicação do modo pelo qual os valores associados à confiabilidade poderiam ser inferidos.

O registro tomográfico selecionado foi organizado em um conjunto de cortes trans-axiais (oblíquos), conforme descrição metodológica dos setores de interesse (p. 116) e, em seguida, armazenado em pasta-arquivo própria, seguindo o formato de arquivo JPEG e com resolução final de 600 dpi.

A fim de que fossem satisfeitas as condições tomográficas exigidas à realização da presente investigação, foram estabelecidos os seguintes critérios de seleção para o indivíduo voluntário:

\subsubsection{Critério de inclusão}

- dentadura permanente completa, com ou sem terceiros molares;

- idade entre 18 e 45 anos, e

- oclusão, tratada ortodonticamente ou não, considerada clinicamente

satisfatória (por meio de critérios morfológicos de avaliação).

\subsubsection{Critério de exclusão}

- presença de doença periodontal e/ou histórico de ocorrência dessa condição, independente do tipo;

- histórico de distúrbio hormonal recente;

- necessidades especiais associadas à restrição quanto a receber a dose de radiação ionizante prevista para o experimento, $\mathrm{e}$

- presença de restaurações metálicas extensas nos locais dos cortes transaxiais pretendidos (dentes: 16;13;11;21;23 e 26 / e dentes: 36;33;31;41;43 e 46).

- dor e/ou sensibilidade dentinária nos locais pretendidos aos cortes transaxiais (dentes: $16 ; 13 ; 11 ; 21 ; 23$ e 26 / e dentes: $36 ; 33 ; 31 ; 41 ; 43$ e 46). 


\subsubsection{Anuência (TCLE)}

A voluntária selecionada a participar da pesquisa, ou C.A.P. (gênero feminino, $29 \mathrm{a} 07 \mathrm{~m}$ ), atendeu aos requerimentos exigidos a partir dos seguintes predicados:

- ausência de restaurações metálicas;

- dentadura completa, sem os terceiros molares;

- havia sido tratada ortodonticamente há mais de dez (10) anos;

- oclusão clinicamente satisfatória;

- ausência de recessões gengivais extensas no momento do exame;

- ausência de histórico de doença periodontal;

- ausência de sintomas de dor e/ou de sensibilidade dentinária no momento do exame;

- ausência de histórico médico associado a distúrbios hormonais no momento do exame;

A voluntária foi instruída, em linguagem clara e compreensível, verbalmente e por meio do Termo de Consentimento Livre e Esclarecido (Apêndice A - TCLE, p. 232), acerca das condições gerais e específicas associadas à sua participação no experimento.

A pesquisa foi aprovada conforme parecer (Anexo B - Parecer do CEP, $p$. 269) do Comitê de Ética em Pesquisa da FOUSP.

\subsubsection{Participantes}

Para os testes da Condição de Precisão Intermediária (variação interoperadores), além do responsável pela pesquisa e também operador (principal), aqui referido como Operador Zero (Op.0), foram selecionados seis (06) operadores/examinadores, aqui referidos como Operador "um" (Op.1), Operador "dois" (Op.2), e assim por diante até o último, ou Operador "seis" (Op.6), os quais 
foram sistematicamente selecionados (ver adiante) e devidamente instruídos (Apêndice B - PPO, p. 235) a cumprir com os requerimentos do experimento.

\subsubsection{Critério de Inclusão}

A seleção dos participantes não foi casual, mas sim sistemática.

Além dos operadores possuírem formação especializada em Ortodontia e estarem habituados (sem indicações específicas) aos requerimentos computacionais necessários à operacionalização de tomografia volumétrica, não Ihes foram exigidas quaisquer capacitações técnicas prévias e específicas associadas à modalidade tomográfica em questão (TCFC), ou mesmo com o programa computacional selecionado às finalidades do experimento.

Dos sete (07) participantes, seis (06) possuem titulação de Mestrado Acadêmico em Odontologia - área de concentração em Ortodontia (FOUSP), todos Especialistas também em Ortodontia, e um (01) de Doutorado em Diagnóstico Bucal (FOUSP), especialista em Radiologia Odontológica, que foi o responsável pela operacionalização de todos os cortes e ajustes tomográficos.

À exceção do operador radiologista, que possuía ampla experiência com a referida técnica, todos os demais participantes, no momento de realização dos testes, possuíam alguma experiência prévia com a visualização e identificação de reparos anatômicos e de pontos tomográficos com o sistema de feixe-cônico. Contudo, esses predicados técnicos foram considerados como sendo de natureza variável em decorrência das diversas experiências anunciadas, entre elas: as avaliações terapêuticas qualitativas e gerais a partir dos volumes reconstruídos; a utilização para instrução acadêmica; para pesquisas associadas à análise cefalométrica; para avaliações descritivas craniofaciais gerais e, também, para avaliações locais relativas à morfologia do osso alveolar.

\subsection{MATERIAL}

Os seguintes materiais foram utilizados nesse experimento: 
- Tomógrafo iCAT ${ }^{\circledR}$ Cone Beam 3D is - Next Generation (Imaging Sciences International, Hatfield, Pasadena, E.U.A.), com painel detector flat panel, escala de cinzas de 14 bits, para obtenção dos registros tomográficos volumétricos (TCFC) (figura 4.1)

- Estação de trabalho iCAT ${ }^{\oplus}$, para operacionalização das imagens, constituída de:

a) CPU (Processador Inte ${ }^{\circledR}$ Core 2 Duo, 2,13GHz e memória RAM de 3,25);

b) Monitor (Dell) de tela plana, com 24 polegadas, e

c) Programas computacionais: iCAT ${ }^{\circledR}$ Calibration Software / Imaging Sciences International, iCAT ${ }^{\circledast}$ Vision (versão 2001-2008) e iCAT ${ }^{\circledast}$ Xoran (versão 3.1.62).

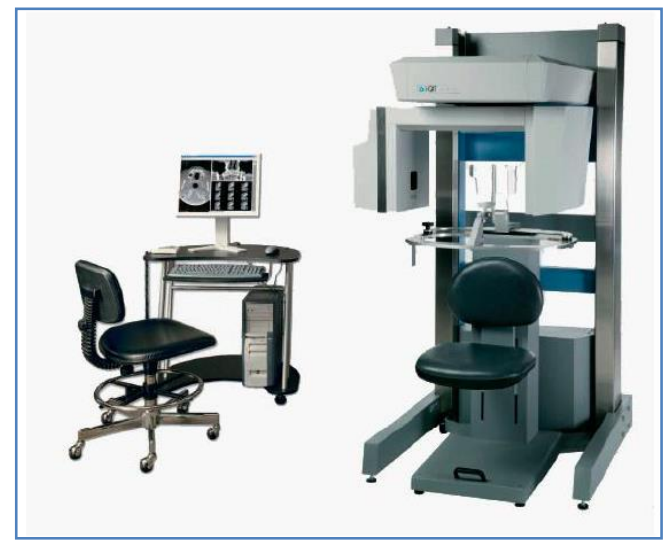

Figura 4.1 - Tomógrafo iCAT ${ }^{\circledR}$ e estação de trabalho (workstation)

- Programa computacional para acesso e ajustes das imagens - PS - Adobe ${ }^{\circledR}$ Photoshop ${ }^{\circledR}$ CS5 Extended (12.1x64 / Adobe Systems Incorporated, versão 19902011) (figura 4.2).

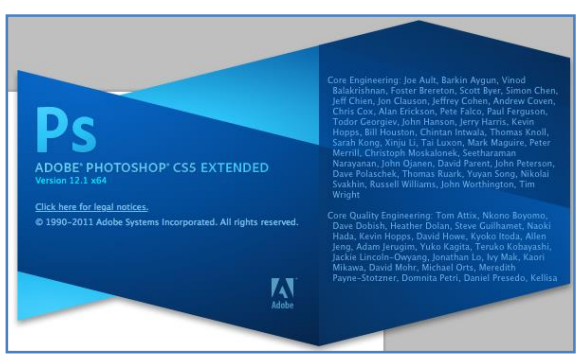

Figura 4.2 - $\begin{gathered}\text { Programa Adobe Photoshop } \\ \text { Extended }\end{gathered}$ CS5 - $^{\circledR}$ 
- Programa computacional para o desenvolvimento e aplicação do método de medição - AutoCAD ${ }^{\circledR}$ Autodesk, versões E.49.H.62 - 2011 for Mac, 2010 para PC e Viewer AutoCAD WS ${ }^{\circledR}$ - versão 1.4, 2011 AutoDesk Inc. (figura 4.3)

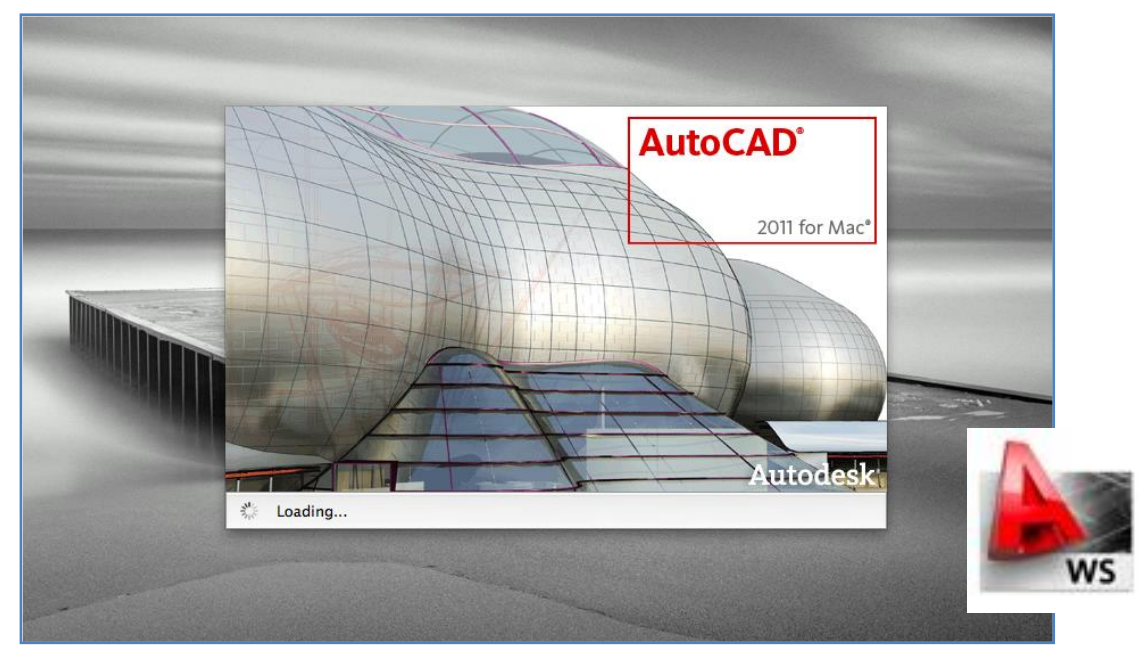

Figura 4.3 - Programa AutoCAD ${ }^{\circledR}$ e Viewer WS, versões 2011 para Macintosh $^{\circledR}$

- Computador pessoal marca: Macintosh ${ }^{\circledast}, \mathrm{n}^{\circ}$ série: C02G53QKDJWV, modelo MacBookAir, com teclado integrado, sistema operacional: Mac $\mathrm{OS}^{\circledR} \mathrm{X}$ Lion, versão 10.7.2 (11C74), Processador 1.7 GHz Inte/ ${ }^{\circledR}$ Core i5, Disco Rígido de $256 \mathrm{~GB} / 1333$ MHz DDR3, memória RAM: 4 GB, Intel HD Graphics 3000-384 MB, Monitor LCD fosco de 13 pol. / colorido / Resolução: 1440x900 / Profundidade em pixels: cor de 32 Bits (ARGB8888), n’de série: C02G53QKDJWV.

- Dispositivo iPad - aparato eletrônico em forma de tablete (tablet), marca Macintosh $^{\circledR}$, sistema iOS5, processador A5 de $1 \mathrm{GHz}$ (dual-core), tela touch de 9,7 polegadas.

- Programa (aplicativo) "Senses - What U See" de teste preliminar da acuidade visual. Sistema OS5 / Macintosh ${ }^{\circledR}$ - Baltronic ${ }^{\circledR}$ (Multimedia Systems Department - Gdänsk University of Technology).

- Mouse óptico USB Wireless 4000 D5d-00003 - Microsoft ${ }^{\circledR}$. 
- Mouse Pad, para mouse óptico (marca Clone ${ }^{\circledR}$; diâmetro: 180mm; constituído de filme termoplástico).

\subsection{MÉTODO}

A fim de que fossem viabilizadas as condições metodológicas exigidas à realização deste estudo, e a partir da análise prévia de estudos similares, considerando seus padrões, acertos e limitações; foram definidas três fases para a realização deste experimento, a saber:

Fase I - Definição de parâmetros técnico-operacionais para a obtenção do registro tomográfico base. Nesta fase foi conferida ênfase à utilização de meios eficazes ao controle de vieses durante a elaboração do Procedimento Operacional Padrão (POP). A mesma caracterizou-se pela realização de testes preliminares, subjetivos e qualitativos, a partir de registros tomográficos pertencentes ao Acervo de Documentação Ortodôntica do Departamento de Ortodontia e Odontopediatria da FOUSP, e também do INDOR/FUNDECTO. Foram então, subjetiva, preliminar e qualitativamente testados quatro softwares comercialmente disponíveis, com vistas à obtenção de informações que pudessem ou aprová-los ou reprová-los considerando a eficiência esperada durante a realização dos objetivos do presente experimento (Apêndice C - Nota Técnica- Fase I, p. 239).

Fase II - Seleção e definição final do software, ou do sistema de medição propriamente dito. Nesta fase foram realizados os ajustes de configuração necessários do programa selecionado (AutoCAD ${ }^{\circledR}$ ), com vistas a favorecer o controle de vieses durante a elaboração do método geral requerido. Assim, e por meio de um Procedimento Operacional Padrão (POP) especificamente desenvolvido para a realização dos testes, foram definidos tanto 0 método de registro (inspeção e 
identificação), quanto o de medição das quantidades tomográficas propostas (Apêndice D - Nota Técnica - Fase II, p. 244).

Fase III - Testes de incidência do erro (total). A partir da análise de influência da participação das variações intra e inter-operadores, e com a finalidade de conhecer a qualidade e intensidade dos erros associados, foi estabelecida, sob teste, interpretações das Condições de Repetitividade (qualidade das condições metodológicas associadas à repetitividadede de medida) e de Precisão Intermediária (qualidade das condições metodológicas associadas à reprodutibilidade de medida), para que fossem definidos os critérios de confiabilidade finais para o método que está sendo proposto. Nesta fase também seriam relacionados eventuais ajustes ad hoc, dada a eventual relevância de participação do erro resultante (Apêndice E Nota Técnica - Fase III, p. 247).

\subsubsection{Obtenção do Registro Tomográfico}

\subsubsection{Calibração do equipamento}

Foi realizada imediatamente antes da realização do registro tomográfico, e com a finalidade de adequar a temperatura do volume de ar presente em frente ao detector flat panel. Foi executado a partir de sequência operacional determinada pelo programa computacional de calibração: iCAT ${ }^{\circledR}$ Calibration Software (Imaging Sciences International). O operador especializado (Radiologista), e também experiente quanto ao procedimento técnico em questão, foi também o responsável pelos ajustes pré-testes, obtidos em conformidade com as indicações do fabricante e buscando regular melhor os padrões de atenuação dos feixes, com isso favorecendo a tendência de diminuição de geração de artefatos agregados à qualidade final da imagem. 


\subsubsection{Preparo prévio}

O voluntário da pesquisa foi inicialmente informado das condições técnicas, biológicas e legais associadas à realização do experimento, quando então foi obtido seu consentimento assinado (Apêndice A - TCLE, p. 232).

O voluntário foi instruído:

- a remover todos os objetos metálicos como brincos, piercing e outros, e

- a permanecer imóvel, sem movimentar a cabeça, ou mesmo a boca e os olhos durante o tempo de aquisição (escaneamento) e respirando calmamente, a fim de que fosse evitada a inclusão de artefatos de movimento como, por exemplo, embaçamento de imagem (b/ur).

Após o voluntário ter recebido as instruções, procedeu-se com:

- a acomodação do indivíduo em relação à cadeira do tomógrafo;

- a orientação espacial da cabeça - ajustes de estabilização dorso-ventral, de flexão/extensão, inclinação e, ainda, de rotação médio-lateral requeridos à obtenção dos referenciais necessários;

- as instruções de cooperação, e

- verificação final prévia à aquisição-teste.

\subsubsection{Aquisição}

A partir da sequência automática determinada pelo programa computacional iCAT ${ }^{\circledR}$ Vision (versão 2001-2008) e conforme o protocolo de aquisição descrito a 
seguir, todas as imagens foram obtidas, inspecionadas, ajustadas e registradas a partir da estação de trabalho (workstation) do próprio equipamento tomográfico (iCAT $\left.{ }^{\circledR}\right)$ pertencente ao INDOR/FUNDECTO.

A dose de radiação ionizante recebida pelo paciente situou-se no intervalo entre 50 a $130 \mu \mathrm{Sv}$, sendo, em média, equivalente a de um exame periapical completo, ou, entre 13 e $100 \mu \mathrm{Sv}$ (Kapila et al., 2011). Estes valores estão contidos em intervalos habituais de exposição considerando esta modalidade particular de exame (TCFC).

Os parâmetros de exposição utilizados foram: 120kVp, 37,7mA, 26,9s, com tamanho do volume reconstruído (FOV- campo de visão) cilíndrico de $13 \mathrm{~cm}$, escala de cinza de 14 bits, matriz de $512 \times 512$ pixels e resolução final do voxel (elemento de volume) de $0,25 \mathrm{~mm}$. Um total de 512 cortes brutos foram gerados a partir de única rotação de aquisição de $360^{\circ}$.

Após a realização da aquisição-teste, seguiu-se com a pré-visualização geral, de modo a favorecer a obtenção da área anatômica de interesse, a qual consistiu no campo de inspeção visual de limites: cefálico (superior) - próximo ao ponto násio; caudal (inferior) - próximo ao ponto pogônio, e dorsal - próximo ao ponto pório (anatômico), pontos estes, todos, de referência cefalométrica convencional (norma lateral).

Uma vez definida a área de interesse, foi realizado o escaneamento (aquisição) definitivo propriamente dito.

\subsubsection{Operacionalização do registro tomográfico}

A visualização final, registros e ajustes necessários foram realizados a partir de programa próprio de manipulação de imagens, o $\operatorname{iCAT}^{\circledR}$ Xoran. Em seguida, foram importados os arquivos xoran para o programa iCAT ${ }^{\circledR}$ Vision, quando então foi realizada, automaticamente, a reconstrução volumétrica.

Os cortes tomográficos foram conforme a espessura de $1 \mathrm{~mm}$, bem como mantendo $1 \mathrm{~mm}$ de intervalo espacial entre os mesmos, conforme o limite máximo de precisão de ação do aparelho para o campo de visão (FOV) e voxel utilizados.

Os cortes foram mantidos em proporção de (exatidão/acurácia) 1:1. 
Foi aplicado filtro de imagem sharpen mild, a fim de que fosse mantido o protocolo usual de avaliação preliminar das imagens.

Neste momento, foi então estabelecida e desenhada uma linha de arco (preliminar) de referência sobre a imagem das áreas oclusais, maxilares e mandibulares, do corte axial, a fim de que propiciassem a obtenção dos cortes transaxiais (oblíquos) definitivos e necessários à realização do experimento de medição das espessuras ósseas alveolares, vestibulares e palatinas/linguais, maxilares e mandibulares.

\subsubsection{Setores (locais) de interesse às medições}

A imagem auxiliar (corte axial, figura 4.4), localizada no canto superior direito da aquisição tomográfica-base, serviu como referência-padrão à determinação dos locais dos cortes trans-axiais (oblíquos) subsequentes.

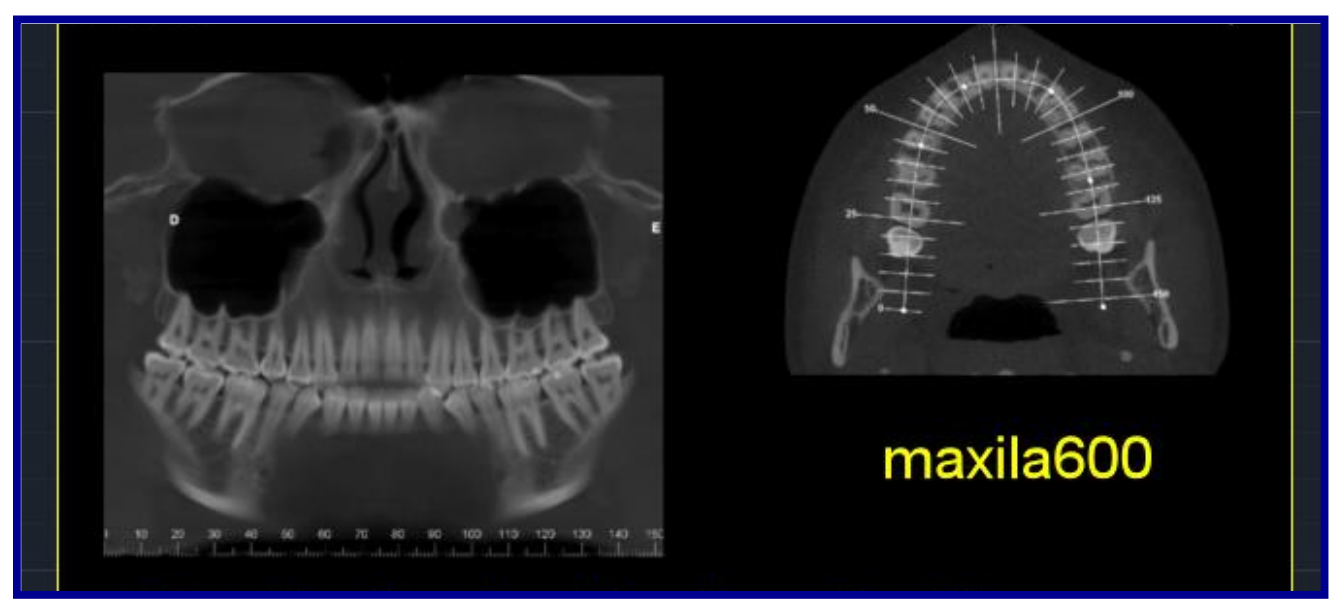

Figure 4.4 - Ilustração tomográfica do corte axial de referência (à direita) inicial à obtenção dos cortes trans-axiais subsequentes e finais - maxila

Os setores de interesse aos cortes, e consequentemente à medição indireta (tomográfica) das espessuras ósseas alveolares, corticais e trabeculares, foram aqueles relativos aos primeiros molares, caninos e incisivos centrais de ambos os arcos, maxilar e mandibular. 
Assim, os cortes tomográficos sujeitos à análise foram todos selecionados para a maxila: do quadrante 1 (dentes 1,3 e 6) ao 2 (dentes 1,3 e 6); bem como para a mandíbula, do quadrante 3 (dentes 1,3 e 6 ) ao 4 (dentes 1,3 e 6 ).

A intenção desta pré-seleção de locais foi devido à percepção de que, sob vista oclusal (axial), seriam estes alguns dos locais críticos à subsequente avaliação ortodôntica, quando ponderadas as necessidades de definição dos tamanhos e formas de arco ortodôntico terapeuticamente mais indicados a cada caso, observados em sua particularidade morfogenética.

Assim, foram então qualitativamente definidos doze (12) locais de corte tomográfico trans-axial (oblíquo), seis (06) maxilares (figuras 4.5, 4.6, 4.7, 4.8, $4.9 \mathrm{e}$ 4.10) e seis (06) mandibulares (figuras 4.11, 4.12, 4.13, 4.14, 4.15 e 4.16), de modo tal que os mesmos pudessem servir à subsequente verificação e confirmação do critério, padrão, para os dois arcos.

\subsubsection{Critério de corte trans-axial (oblíquo)}

Obtenção de imagem trans-axial a qual fosse compatível com a localização do corte tomográfico mais central (sentido mésio-distal) possível, em relação aos dentes-alvo (unidades de observação), favorecendo assim a obtenção de referências de medida as quais fossem intencionalmente proporcionais em termos de tendência à proximidade dentária (radicular) dos limites ósseos externos (laterais) alveolares de cada arco, em cada um dos dentes selecionados, à exceção dos molares, onde foram obtidos cortes tomográficos trans-axiais correspondentes às dimensões dentárias vestíbulo-linguais definidas a partir da raiz mesial (referência lateral: cúspide mésio-vestibular). Assim, o objetivo foi o de favorecer a inspeção e identificação daqueles setores, considerando a constituição anatômica local e regional própria de cada indivíduo (o arco ósseo local), maxilar e mandibular; os quais foram estabelecidos como referencias principais de locais onde a quantidade de espessura óssea alveolar possivelmente seria mais crítica, considerando a associação clínica entre fatores como volume e posição dentária, volume, distribuição e densidade óssea, e forma (e tamanho) do arco terapêutico ortodôntico. 


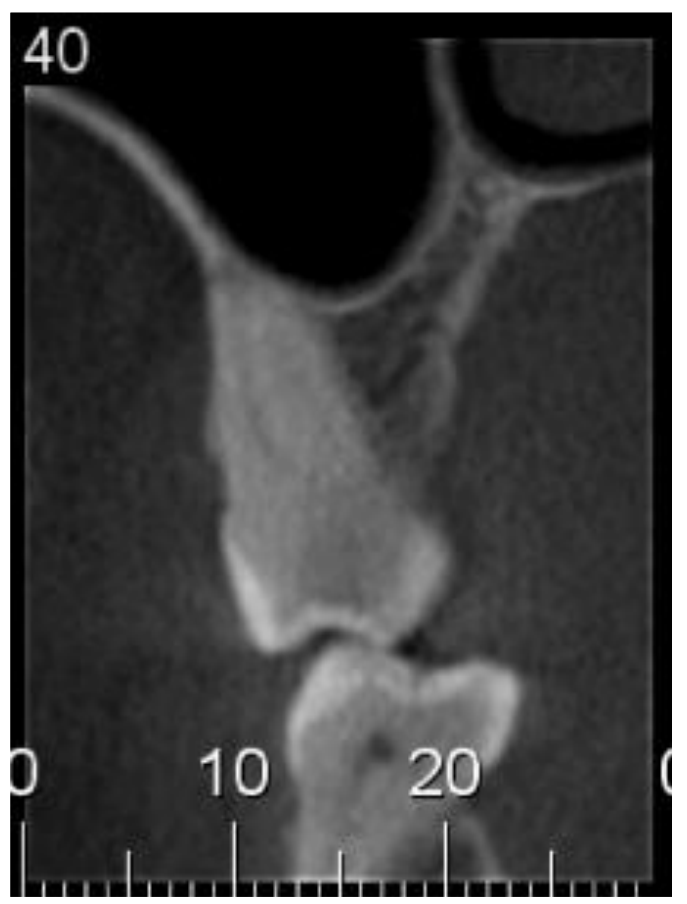

Figura 4.5 - Imagem gerada por corte trans-axial, correspondente a um dos setores (dentes) de avaliação - dente 16

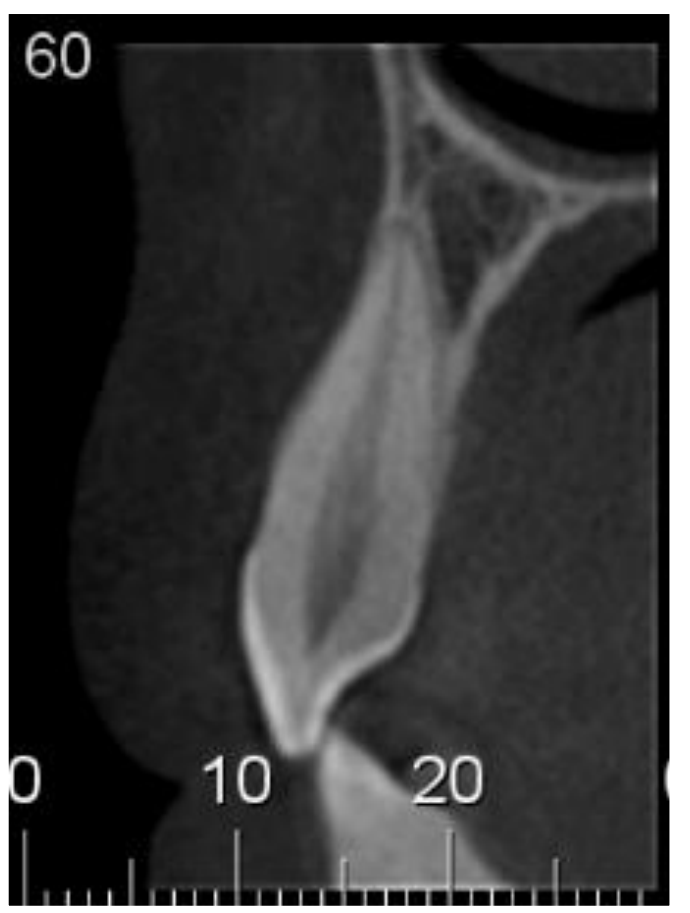

Figura 4.6 - Imagem gerada por corte trans-axial, correspondente a um dos setores (dentes) de avaliação - dente 13 


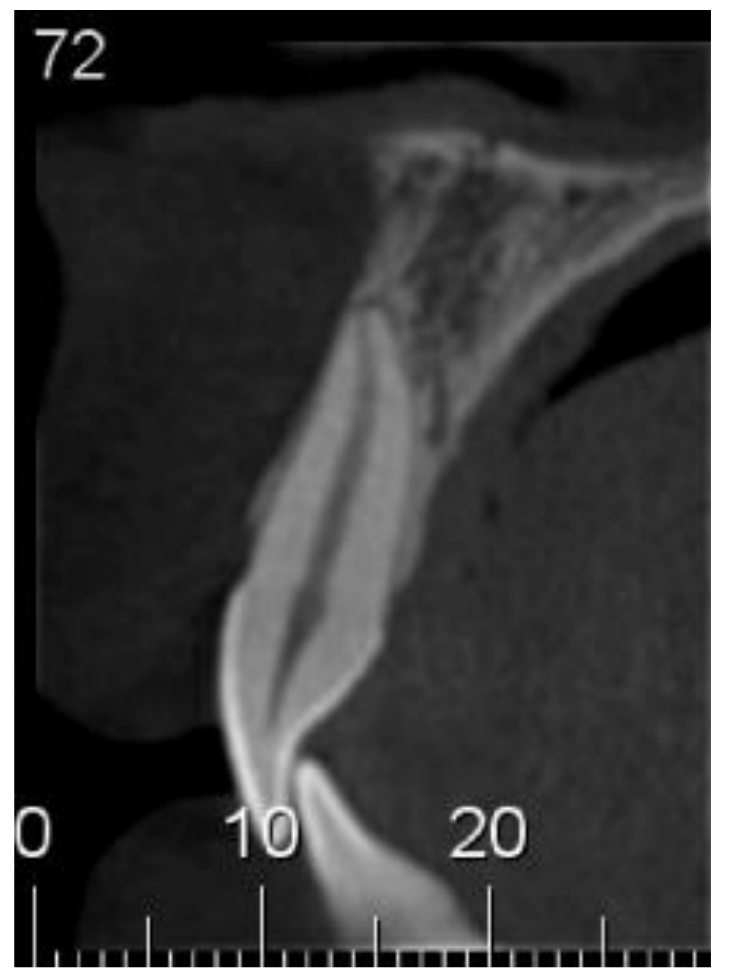

Figura 4.7 - Imagem gerada por corte trans-axial, correspondente a um dos setores (dentes) de avaliação - dente 11

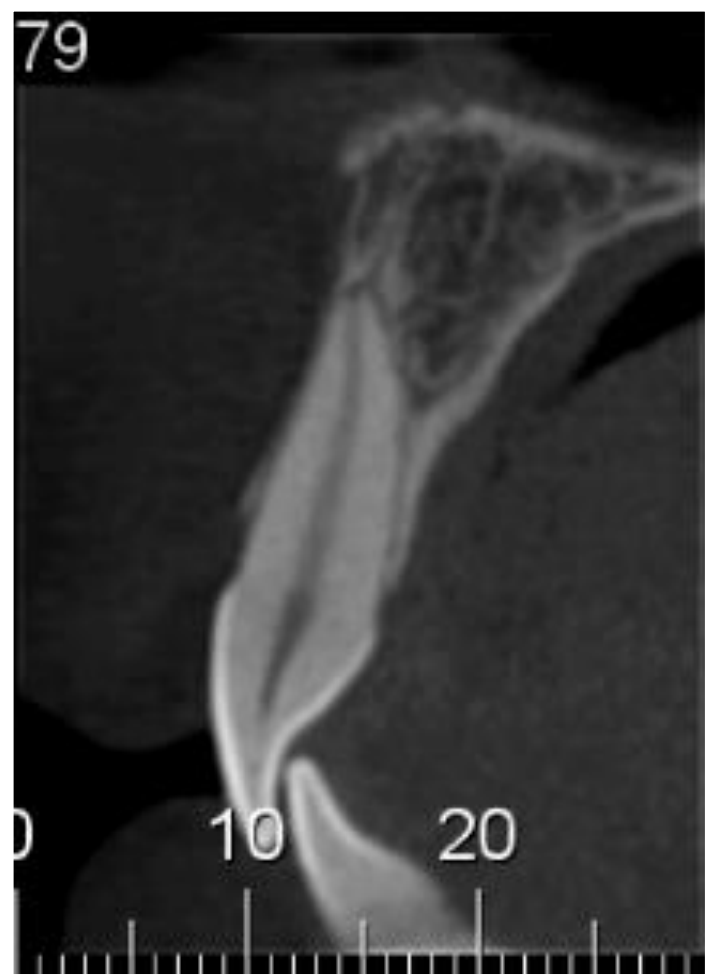

Figura 4.8 - Imagem gerada por corte trans-axial, correspondente a um dos setores (dentes) de avaliação - dente 21 


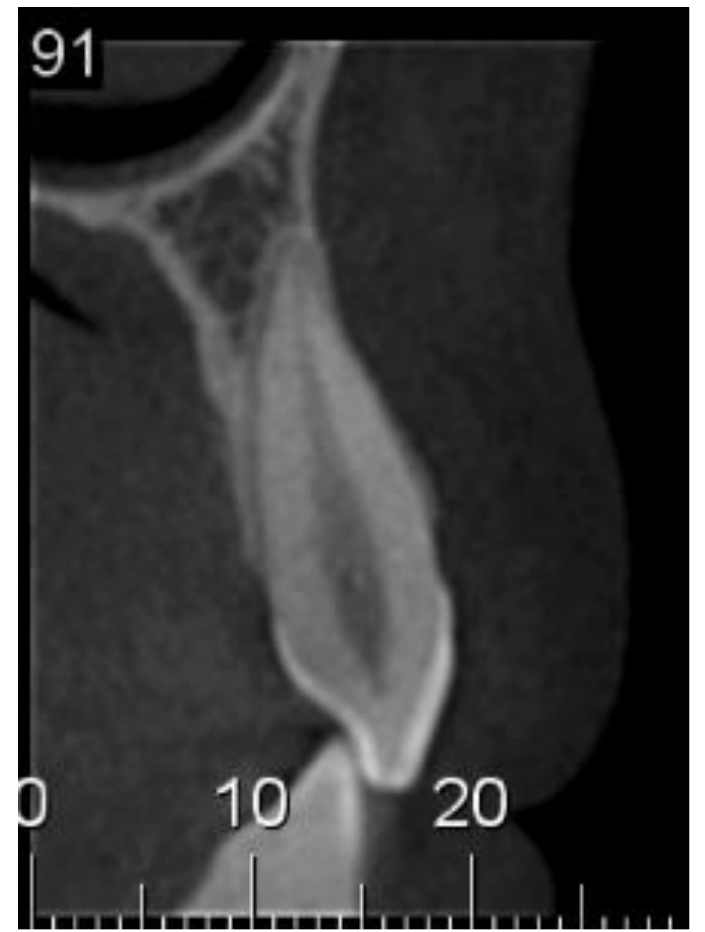

Figura 4.9 - Imagem gerada por corte trans-axial, correspondente a um dos setores (dentes) de avaliação - dente 23

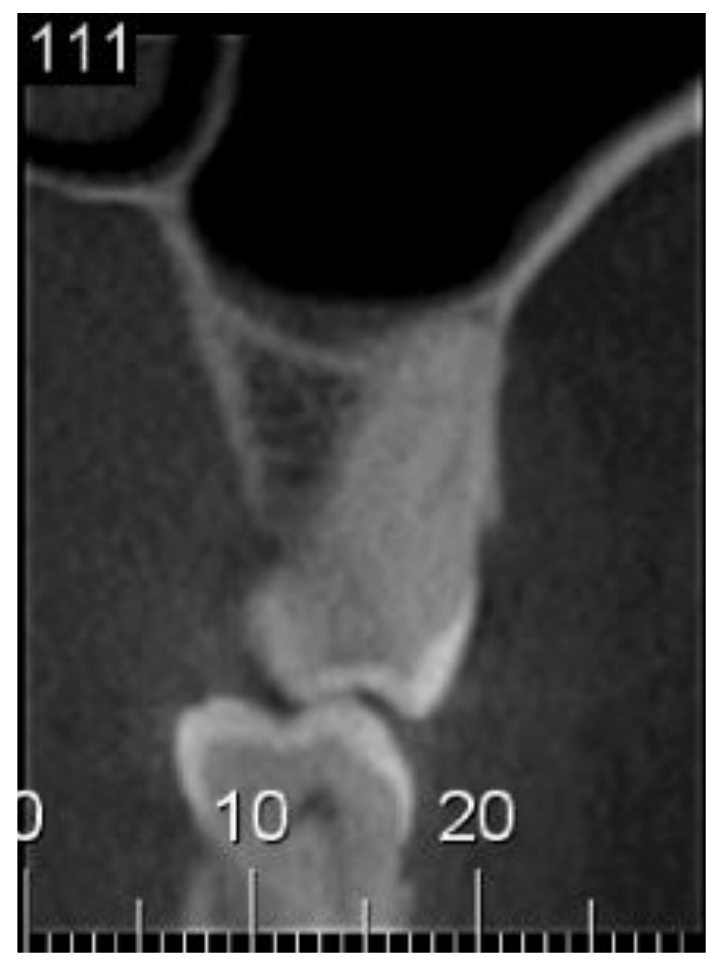

Figura 4.10 - Imagem gerada por corte trans-axial, correspondente a um dos setores (dentes) de avaliação - dente 26 


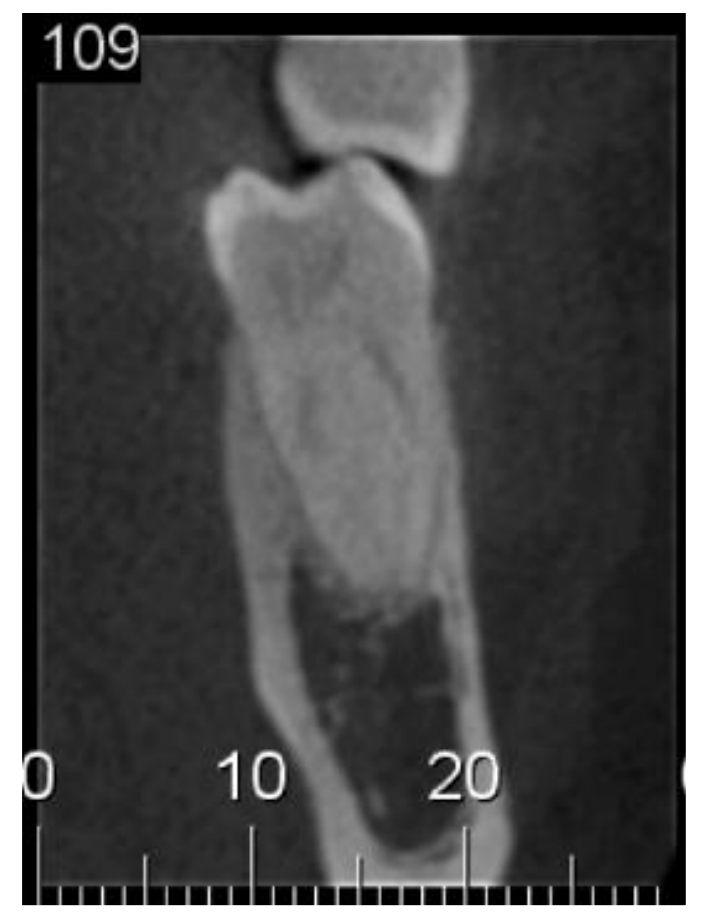

Figura 4.11- Imagem gerada por corte trans-axial, correspondente a um dos setores (dentes) de avaliação - dente 36

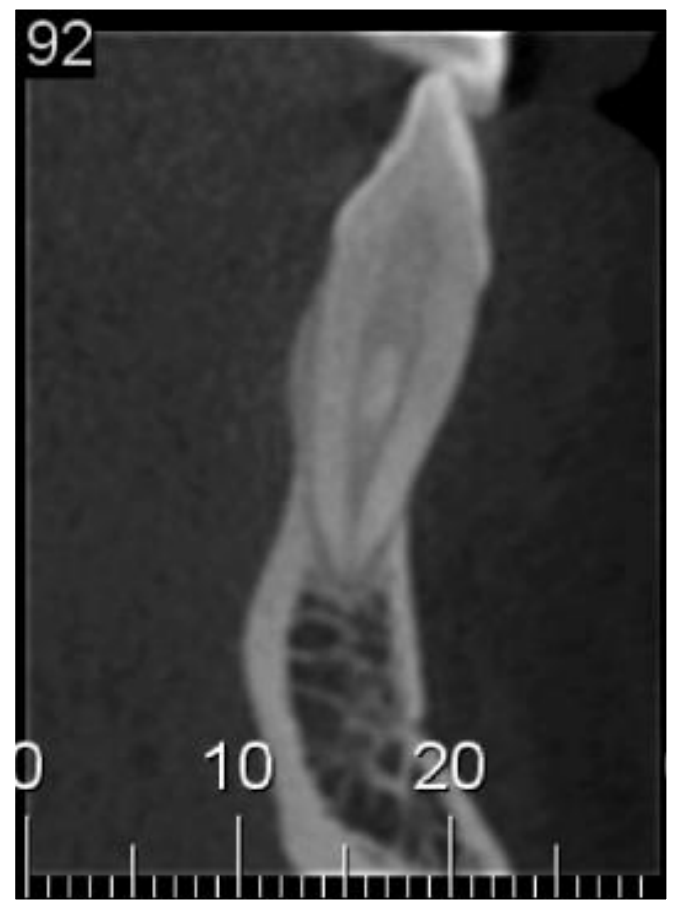

Figura 4.12- Imagem gerada por corte trans-axial, correspondente a um dos setores (dentes) de avaliação - dente 33 


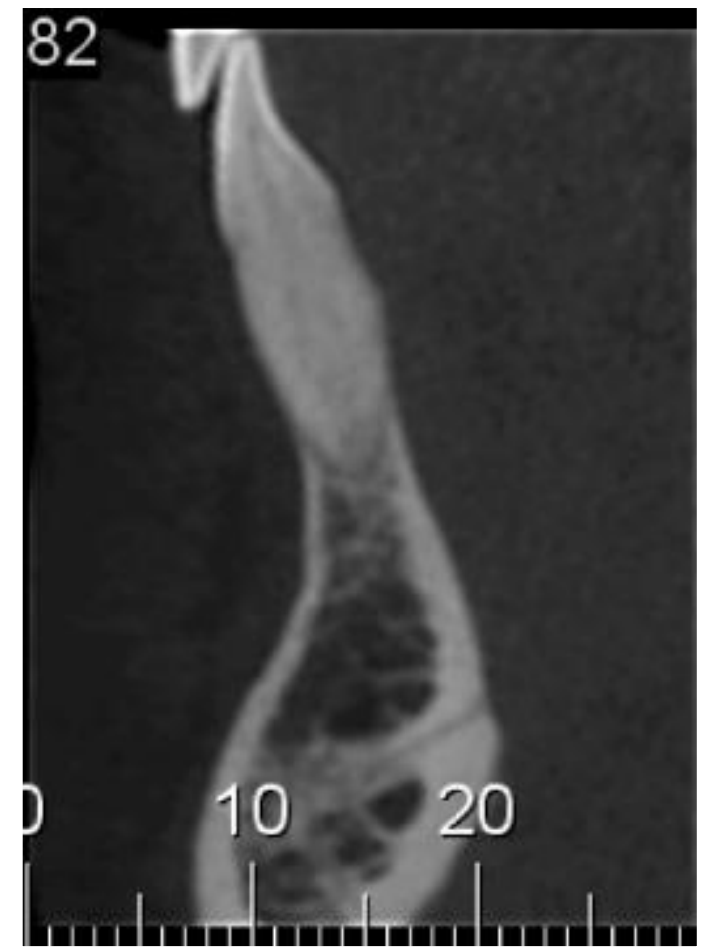

Figura 4.13 - Imagem gerada por corte trans-axial, correspondente a um dos setores (dentes) de avaliação - dente 31

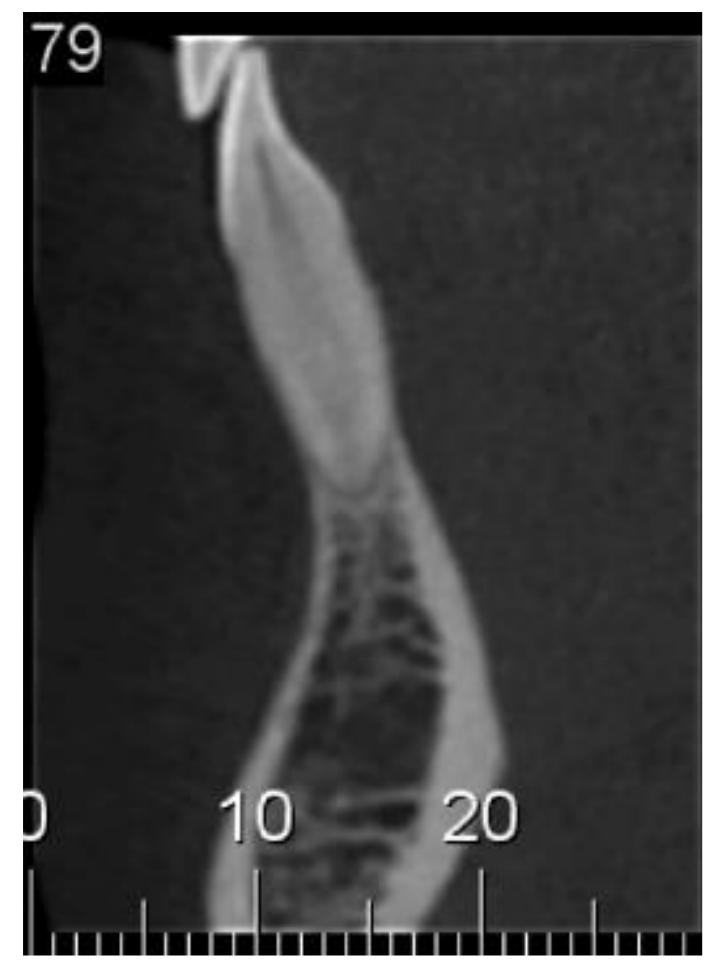

Figura 4.14 - Imagem gerada por corte trans-axial, correspondente a um dos setores (dentes) de avaliação - dente 41 


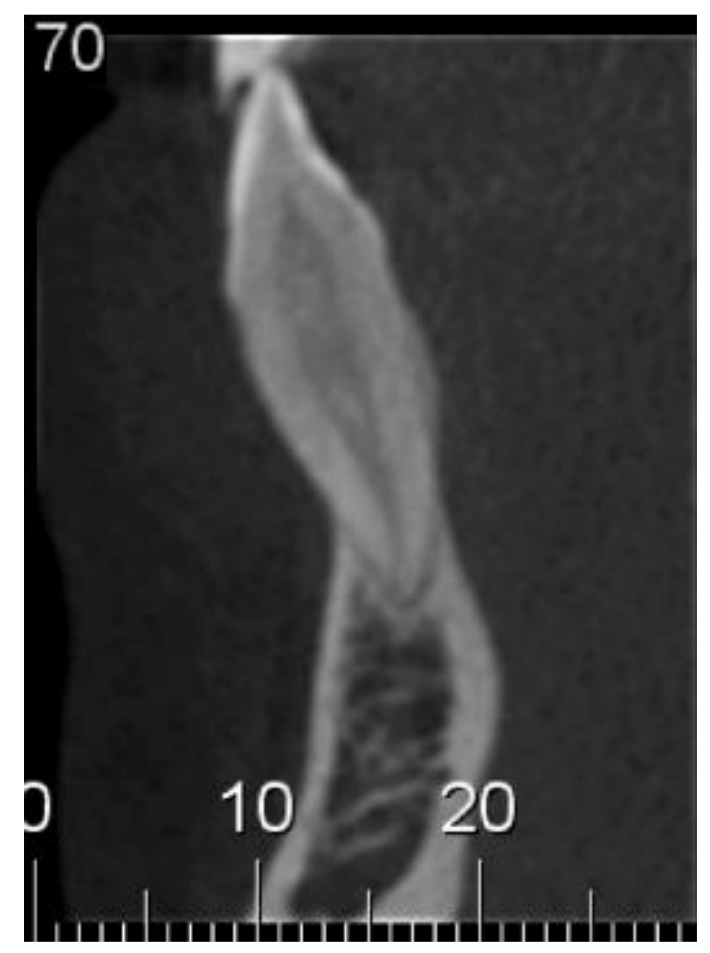

Figura 4.15 - Imagem gerada por corte trans-axial, correspondente a um dos setores (dentes) de avaliação - dente 43

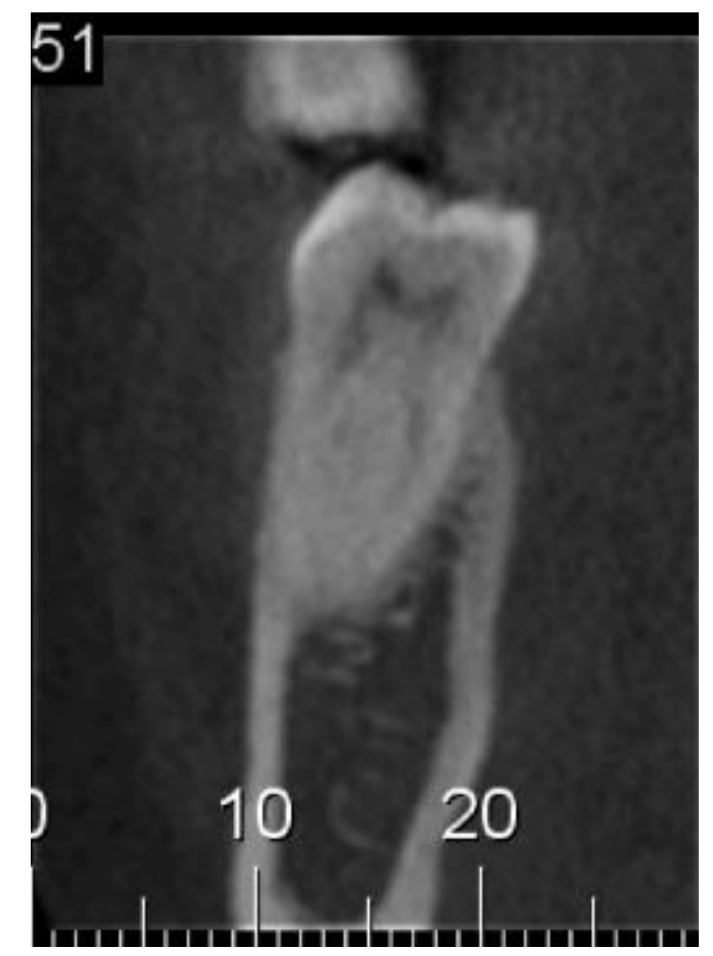

Figura 4.16 - Imagem gerada por corte trans-axial, correspondente a um dos setores (dentes) de avaliação - dente 46 
Cortes trans-axiais tomográficos (oblíquos), a partir de obtenção volumétrica inicial (TCFC), ocorrem conforme transições, ventrais e dorsais, de intervalos de corte possíveis de acordo com as especificações técnicas de cada sistema (equipamento) de aquisição tomográfica, entre os limites de padrão tomográfico coronal e sagital, obtidos perpendicularmente a um dado corte axial de referência.

Assim, por exemplo, quando o local de interesse for o de um molar, o corte trans-axial aproximar-se-ia da direção coronal de corte; enquanto que se o local for o de um incisivo central, o corte trans-axial aproximar-se-ia da direção sagital de corte.

Para estes padrões de corte (trans-axiais), a posição relativa da cabeça, no momento de obtenção dos registros tomográficos, não representou fator variável e que eventualmente viesse a influenciar (tendências-vieses) de modo desfavorável a qualidade do método de registro e medição proposto, já que havia sido determinado - após experimentação prévia (Fase II) com outros softwares disponíveis, e sem perspectivas satisfatórias quanto à qualidade associada ao controle do Procedimento Operacional Padrão (POP) definido - que os pressupostos e requerimentos metodológicos necessários não seriam atendidos (Apêndice $B$ PPO, p. 235).

O programa computacional - Software AutoCAD ${ }^{\circledR}$ - atendeu às expectativas de operacionalização dos registros tomográficos paras as finalidades da pesquisa e, por conseguinte, foi utilizado à elaboração do POP deste experimento (Apêndice $F$, p. 253).

Cortes axiais (figura 4.4, p. 120), num total de dois (02), um para a maxila e outro para a mandíbula, foram gerados durante 0 processo inicial de operacionalização tomográfica, mas utilizados tão somente para o estabelecimento preliminar das referências posicionais correspondentes aos locais dos dentes, selecionados para as avaliações-teste (unidades de observação e medição), por meio dos já citados cortes tomográficos trans-axiais (oblíquos) e finais.

A justificativa pela preferência de utilização de cortes tomográficos transaxiais pode ser resumida em três (03) fatores principais, a saber:

a) os cortes axiais, comuns em alguns estudos proponentes da avaliação qualitativa e quantitativa de locais alveolares, não oferecem, em decorrência de características técnicas próprias deste modo de corte tomográfico, imagens de profundidade vertical (sentido 
cérvico-apical e direção de orientação céfalo-caudal) para a avaliação de espessuras vestíbulo-linguais/palatinas. Portanto, como o interesse da presente proposta de método foi o de definir e testar, de modo o mais versátil e confiável possível, algumas distâncias lineares (sub milimétricas) localizadas em níveis (verticais) alveolares distintos, aqui referidos como espessuras ósseas alveolares, vestibulares e palatinas/linguais, foi então determinada a utilização de imagens tais que fossem compatíveis com as intenções da presente avaliação, preferencialmente em um mesmo corte, considerando a informação de inclinação vestíbulolingual/palatina dos dentes-alvo e, ainda, de tantas distâncias-teste quantas fossem necessárias. A intenção não foi a de avaliar espessuras ósseas alveolares distribuídas no sentido mésio-distal;

b) Devido à condição de haver, necessariamente, uma dada espessura de corte tomográfico (fatia), bem como um dado intervalo para esse corte (os quais, em seus limites de precisão, são parâmetros determinados automaticamente pelos padrões de fabricação de cada sistema de aquisição tomográfica/equipamento), as imagens axiais acabam por resumir bidimensionalmente, e no espaço da espessura do corte tomográfico nativo, todas as características anatômicas contidas naquela espessura. Se a intenção for a de avaliar, por meio de alguns cortes axiais, espessuras alveolares muito próximas verticalmente umas das outras, e bastante diminutas, então o padrão de obtenção de imagem poderá, eventualmente, e dependendo da amplitude do defeito ou condição avaliada, omitir (erro sistemático) características associadas àquele espaço (de corte) em questão. O corte trans-axial, por sua vez, determina o mesmo padrão sistemático de limitação, só que no sentido mésio-distal dos dentes-alvo, o que, por si só, não é capaz de interferir diretamente na avaliação vertical das espessuras propostas; e 
c) As imagens trans-axiais, diferentemente das axiais, podem oferecer observação dos padrões de continuidade vertical das espessuras ósseas alveolares, vestibulares e palatinas/linguais, em um mesmo corte e seus padrões, condição essa que pode ser eventualmente utilizada como referência operacional de localização de alguns reparos de difícil inspeção, seja por condições próprias da variação anatômica local individual, seja por limitações associadas ao conhecimento e preparo do operador, quer seja, ainda, em decorrência das limitações técnicas do próprio equipamento, ou mesmo pela combinação destes fatores. Essa possibilidade favorece a padronização de inspeção e minimiza possíveis tendenciosidades.

\subsubsection{Arquivos}

As imagens foram uniformemente processadas e ajustadas para a realização das medições-teste. Contudo, não foram executados quaisquer ajustes além daqueles já descritos (p. 119), mesmo que um dado corte trans-axial não apresentasse qualidade semelhante, melhor ou até pior comparativamente aos outros cortes obtidos previamente.

Após a seleção e obtenção dos registros, os mesmos foram exportados (formato JPEG) para uma pasta-arquivo própria (externa ao programa Xoran ${ }^{\circledR}$ ) e, em seguida e com o auxílio do Programa Adobe Photoshop $^{\circledR}(P S)$, foram convertidos em arquivos de imagem com resolução de 300 e 600 dpi, com manutenção da escala original, os quais foram preliminarmente testados quanto à qualidade subjetiva do padrão de detalhe sem ampliações ou mesmo ajustes de filtro e contraste pósprocessamento.

A resolução final de 600 dpi foi então confirmada para a realização dos testes associados à presente proposta metodológica, haja vista ter apresentado melhor definição de detalhe.

O tamanho médio e final de cada arquivo gerado foi de aproximadamente $6 \mathrm{MB}$. 
Também com auxílio do programa Adobe Photoshop $^{\circledR}$ PS foi realizada conversão de unidades, relativa às dimensões originais e para cada uma das doze (12) imagens de cortes trans-axiais obtidas, originalmente em polegadas (pol.), e finalmente em milímetros $(\mathrm{mm})$. Esta providência foi necessária em decorrência da necessidade de serem conhecidos e discutidos os valores de unidades do SI (submúltiplo do milímetro) com os padrões encontrados na literatura compulsada, tanto para favorecer a operacionalização e registro, quanto para facilitar as eventuais aplicações dos resultados em termos clínicos.

As dimensões de imagem foram então anotadas para posterior verificação quando fossem utilizadas no programa-destino de medição.

Todas as sequências tomográficas originais foram produzidas $e$ operacionalizadas nas dependências do INDOR/FUNDECTO, conforme a observância do Protocolo de Atendimento daquele Serviço, com a supervisão do Prof. Dr. Israel Chilvarquer (Professor Associado do Departamento de Radiologia Odontológica/FOUSP) e mediante assistência técnica/operacional direta do Dr. Tiago Zanet (Doutor em Diagnóstico Bucal-CRO/SP: 86901).

\subsubsection{Programa AutoCAD ${ }^{\circledR}$ e POP}

A seguir serão apresentadas, descritas e justificadas as etapas constituintes do Procedimento Operacional Padrão (POP) computacional definido para a realização deste experimento, com auxílio do programa $A u t o C A D{ }^{\circledR}$.

\subsubsection{Configuração padrão}

A partir da decisão de serem operacionalizadas as imagens com os recursos computacionais do programa AutoCAD ${ }^{\circledR}$ (Fase II), fez-se necessária a definição de sequência operacional específica, a qual fosse capaz de garantir a manutenção tanto dos predicados dimensionais das imagens estabelecidas (garantia de 
manutenção da escala original considerando as dimensões), quanto das características originais da imagem (garantia de resolução espacial original).

Para que as imagens pudessem ser trabalhadas a partir da versatilidade dos recursos oferecidos pelo programa, foi preciso adequar, em alguns termos, a configuração do programa para a respectiva operacionalização. Os ajustes foram todos de natureza simples e intuitiva, e, uma vez definidos, permaneceram estáveis durante e após a realização dos testes.

O programa AutoCAD ${ }^{\circledR}$ possui setores de configuração geral e específica dos parâmetros necessários às individualizações.

A figura 4.17 (de a a $h$ ) apresenta as janelas de ajuste (utilidades/opções) dos parâmetros computacionais definidos para este experimento.

a

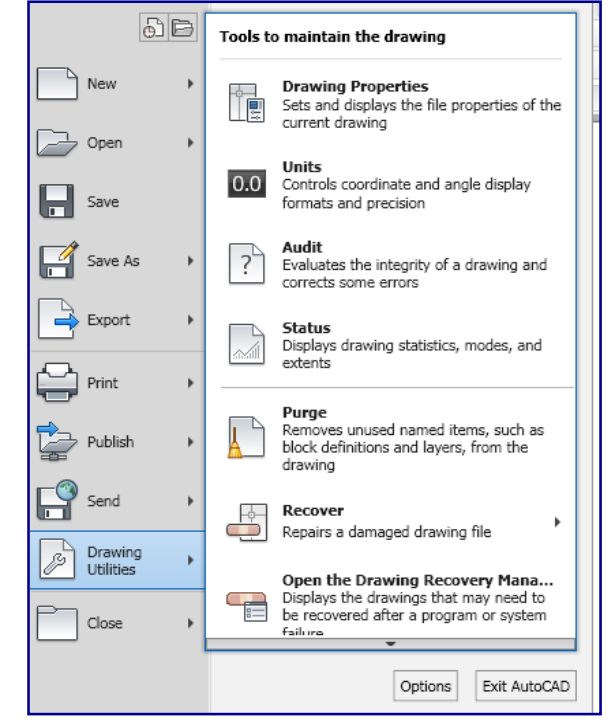




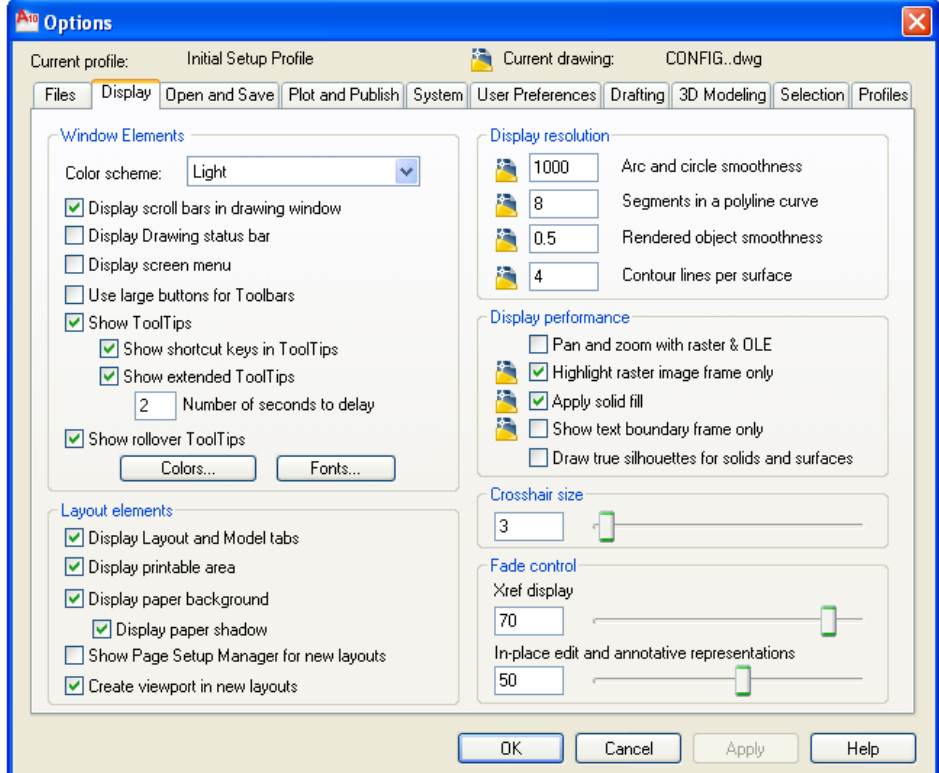

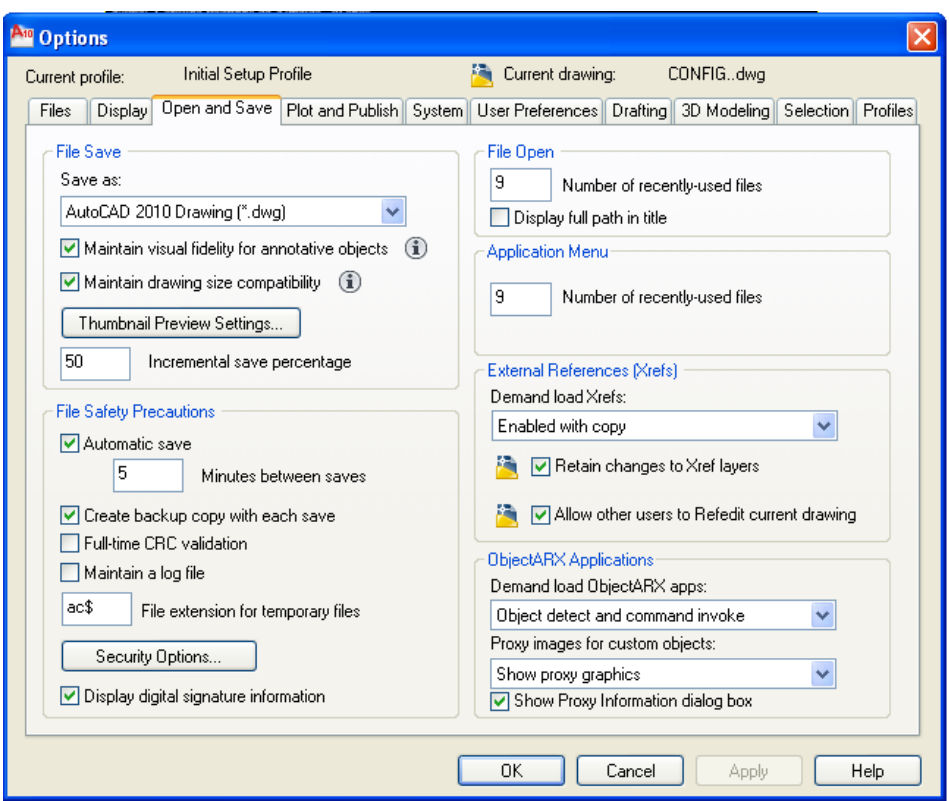

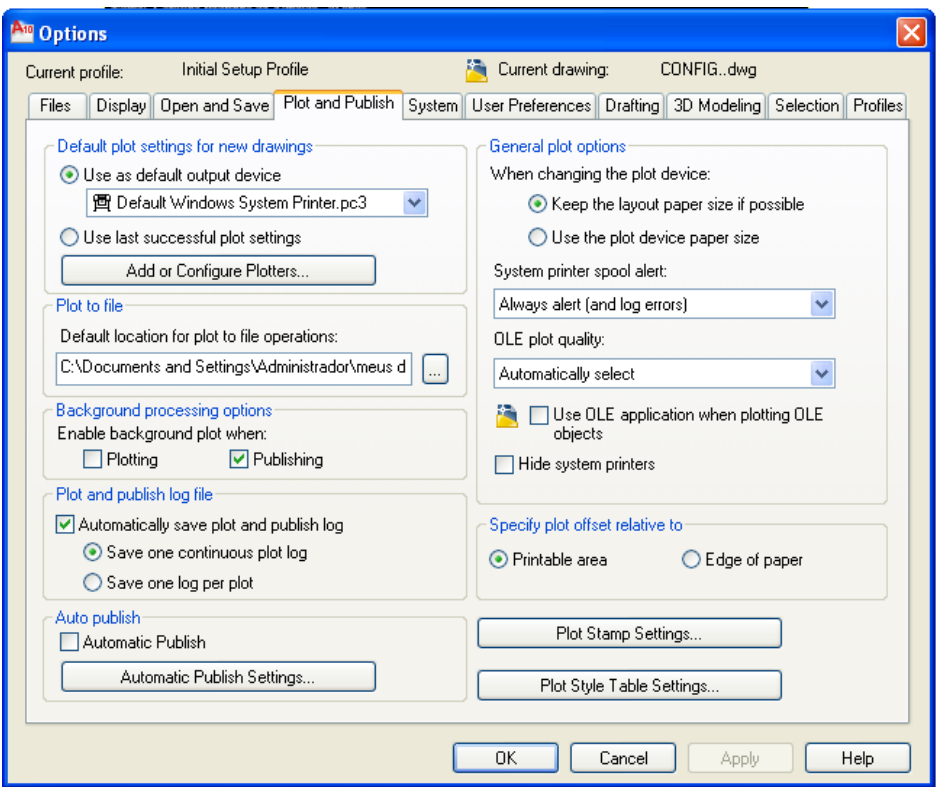




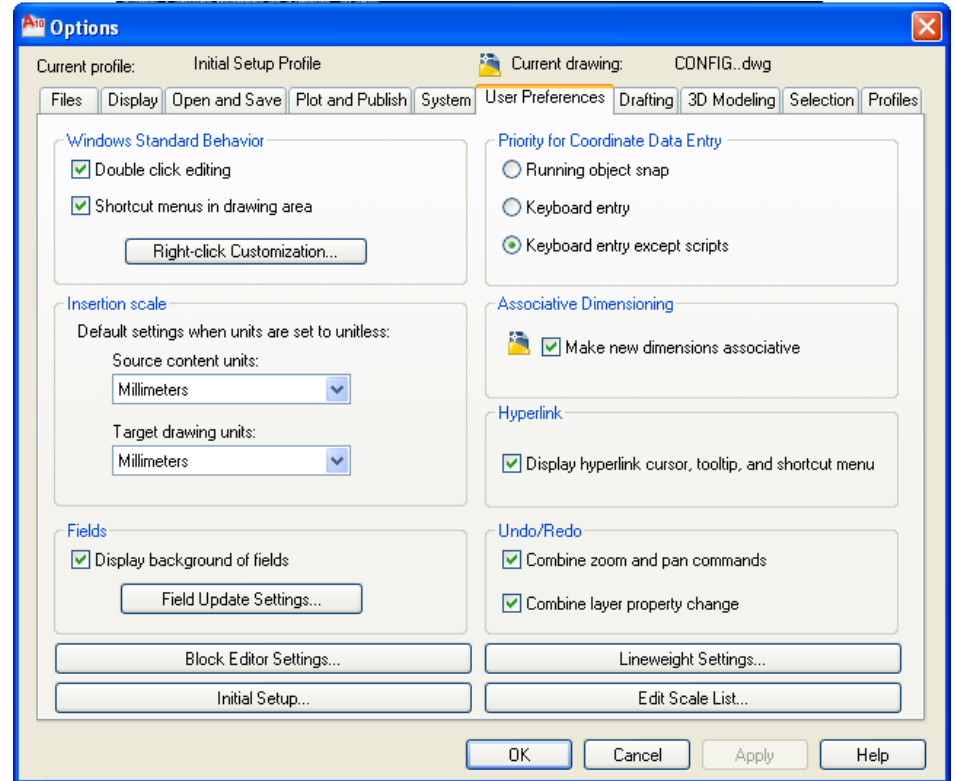

\section{A Aro Options}

\section{Initial Setup Profile Current drawing: CONFIG..dwg}

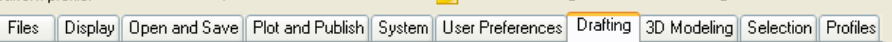

AutoSnap Settings

$\square$ Marker

ఐ Magnet

Display AutoSnap tooltip

$\square$ Display AutoSnap aperture box

\section{Colors...}

AutoSnap Marker Size

$$
\text { - - ] }
$$

Object Snap Options

$\square$ Ignore hatch objects

$\square$ Replace $Z$ value with current elevation

$\square$ Ignore negative $Z$ object snaps for Dynamic UCS

AutoTrack Seltings
$\square$ Display polar tracking vector
$\square$ Display full-screen tracking vector

$\square$ Display AutoT rack tooltip

Alignment Point Acquisition

$\odot$ Automatic

Shift to acquire

Aperture Size

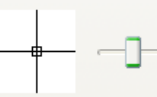

Drafting Tooltip Settings

Lights Glyph Settings.

Cameras Glyph Settings..

\section{OK Cancel Apply Help}

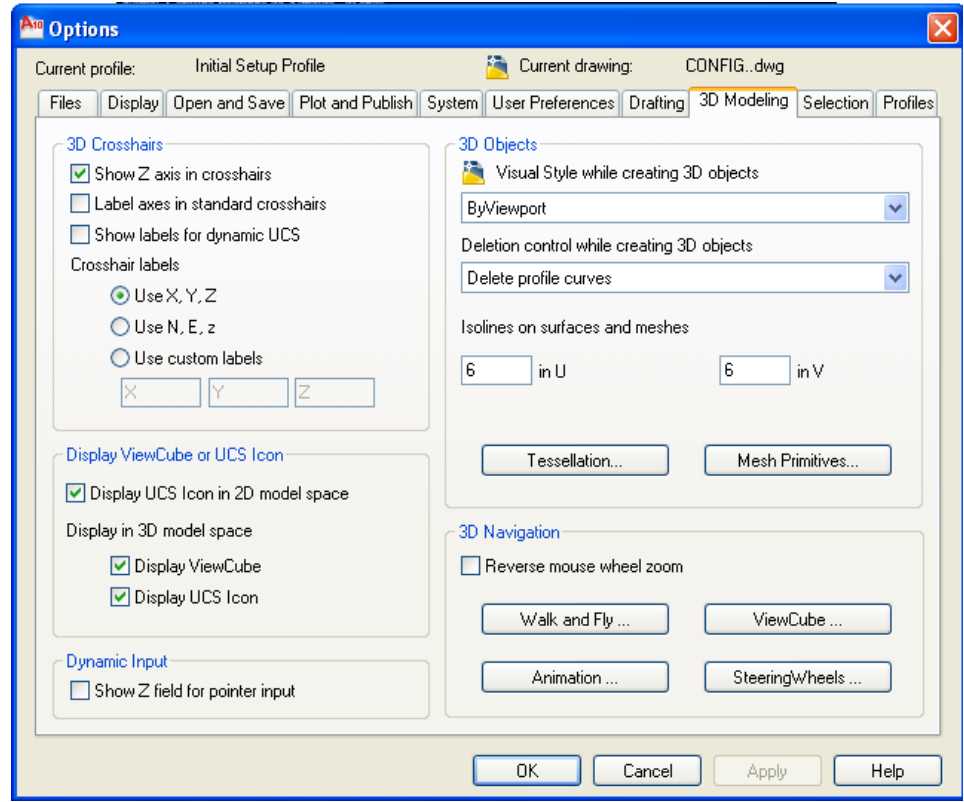




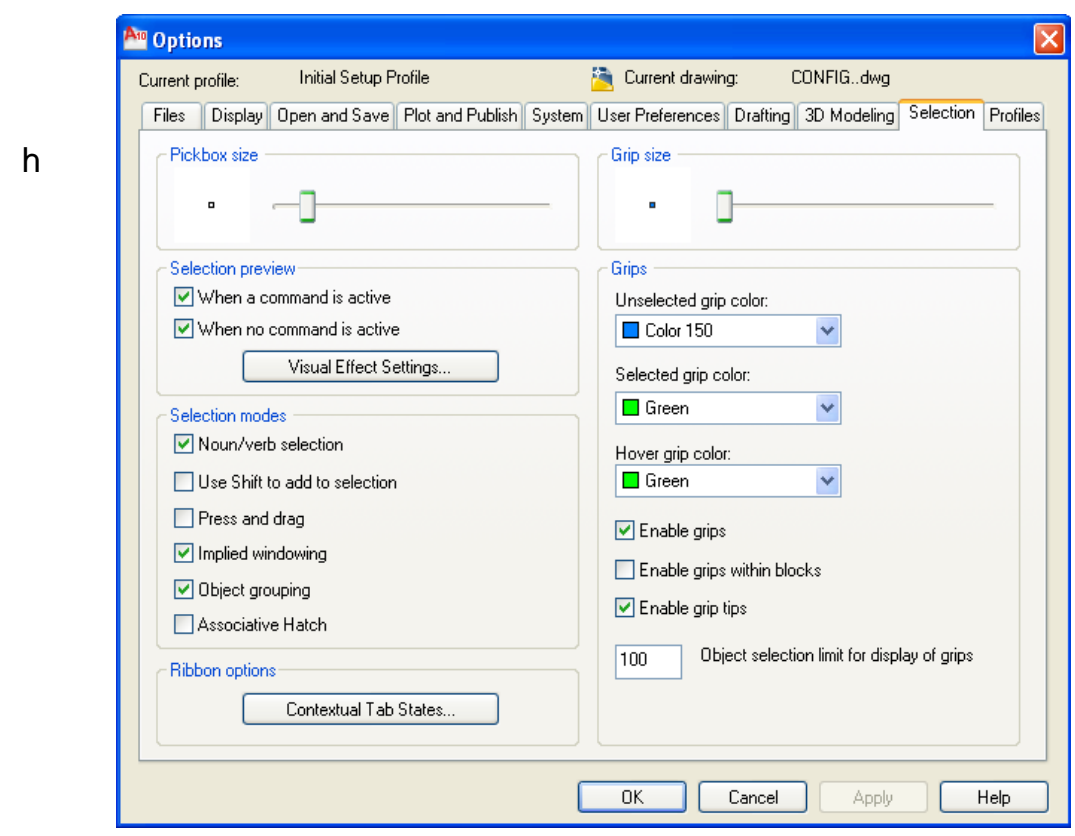

Figura 4.17 - Janelas de Opções - Setores ou campos de ajuste/configuração individualizada dos parâmetros funcionais requeridos à operacionalização dos desenhos (sequência de a a h)

A escala de medida foi previa e automaticamente ajustada por meio de configuração padrão, opcional e automática, do software AutoCAD ${ }^{\circledR}$. (figura 4.18)

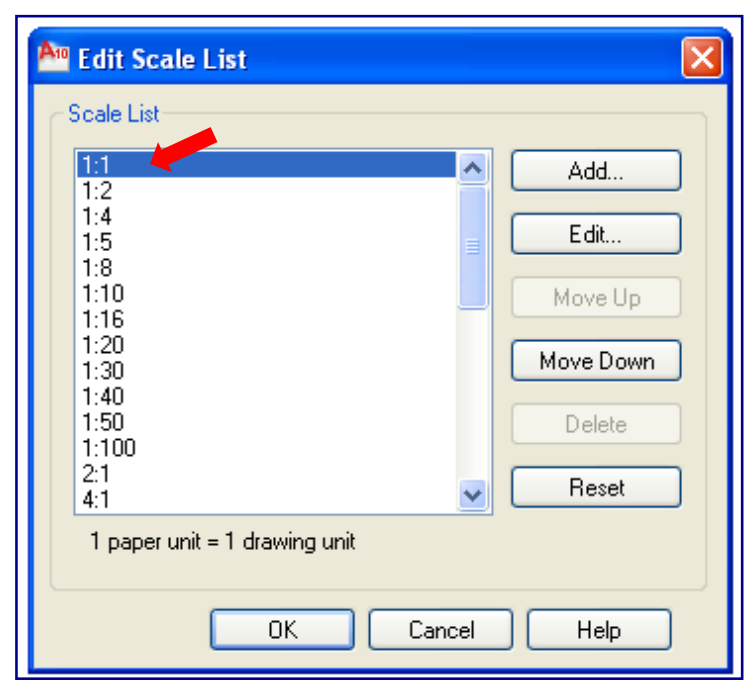

Figura 4.18 - Janela Lista de Edição de Escala - opções de configuração de escalas operacionais

A precisão padrão de medição foi ajustada em janela específica do programa AutoCAD ${ }^{\circledR}$, e para a escala do milímetro. (figura 4.19) 


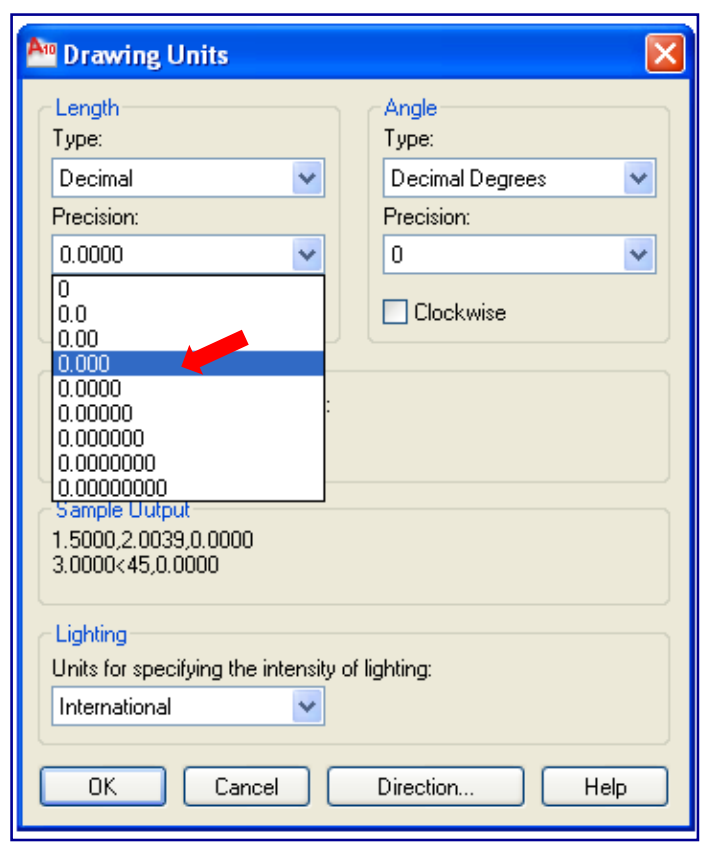

Figura 4.19 - Janela Unidades do Desenho - Opções de configuração do Sistema de Unidades, do tipo (decimal) e da precisão (centesimal) da escala operacional

\subsubsection{2 operacionalização básica}

A área gráfica do programa é o local onde serão visualizadas e utilizados todos os recursos computacionais, e permite operações conforme infinitas dimensões.

A área gráfica utilizada neste experimento corresponde ao espaço de modelação 2D (2D model space).

O cursor de tela (crosshair), o qual mostra a posição em que o operador se encontra na área gráfica, pode também assumir outras formas quando seleciona objetos. O cursor é o indicador posicional a partir do qual é possível a identificação dos pontos tomográficos.

Os comandos do programa podem ser efetuados a partir de cliques nas macros do menu da tela de trabalho, a partir da programação escrita, ou, ainda, a partir de macros de acesso rápido (atalhos). (figura 4.20) 


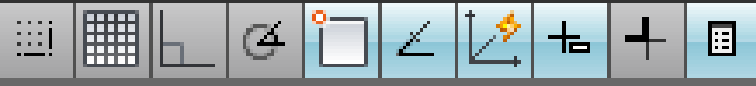

\section{MODEL 四国}

Figura 4.20 - Macros (AutoCAD ${ }^{\circledR}$ ) de comandos operacionais de acesso rápido

A regeneração do desenho (regen) é um dos muitos comandos do AutoCAD ${ }^{\circledR}$ acessíveis somente pelo teclado (caixa de programação), e com este mesmo descritor. É auto executável em algumas outras funções. Serve quando é notada alguma falha (desorganização) gráfica de visualização do desenho geométrico (desenho é a construção geométrica, e não a própria imagem tomográfica, a qual está em outra camada de trabalho - layer).

As "desorganizações" são ocorrência comum devido ao ritmo de funcionamento do programa. Então, o comando regen regenera integralmente o conteúdo gráfico da camada de trabalho, e o desenho passa a mostrar todo o seu conteúdo novamente na tela de visualização (Autodesk, 2009).

Esta função foi continuamente utilizada neste experimento, pois, embora as "desorganizações" não sejam capazes de afetar as dimensões originais dos desenhos, tampouco as da área de trabalho, julgou-se procedente ativar a função regen entre as transições de zoom de tela (ver adiante), como garantia de ótima visualização dos limites gráficos dos desenhos durante as medições.

\subsubsection{1 primitivas geométricas}

As primitivas geométricas são os elementos geométricos que compõem um desenho, ou seja, linhas, arcos, textos, círculos, polígonos, etc. Estes comandos podem ser utilizados a partir do menu DRAW. 


\title{
4.3.2.2.2 sequência inicial
}

Inicialmente, e a partir da abertura de novo arquivo de trabalho, etapa "um" (e1) , foram ajustados os seguintes setores (campos):

\author{
e1 - [CO]: file - new (novo arquivo); \\ e2 - [CO]: em preferences - options; \\ e3 - [CO]: em crosshair lines, ajustar para 1\% $\downarrow$; \\ e4 - [CO]: e4 - format - units - drawing units (insertion scale units $=\mathbf{m m}$ )
}

\subsubsection{Inserção da imagem tomográfica}

A inserção das imagens (JPEG) ocorreu após terem sido ajustadas as características necessárias à operacionalização dos elementos gráficos e textuais do próprio software $\left(A u t o C A D^{\circledR}\right)$ (figuras 4.21 e 4.22 ), sem que houvesse quaisquer prejuízos à qualidade da imagem tomográfica, e considerando as particularidades técnicas do método desenvolvido. ( [CO]: insert - attach - raster image ) 


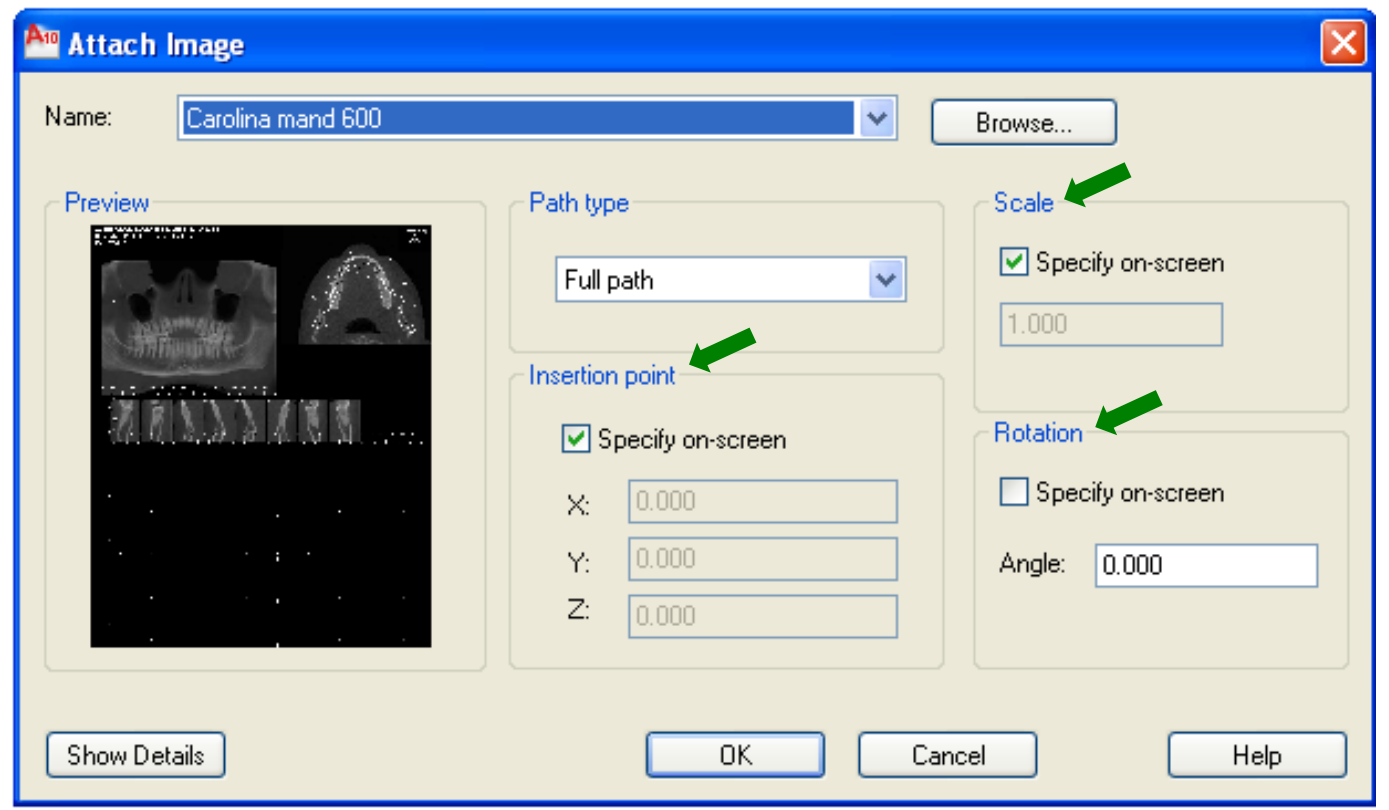

Figura 4.21 - Janela de inserção da imagem tomográfica - seleção do arquivo de imagem, padrões posicionais de inserção e escala
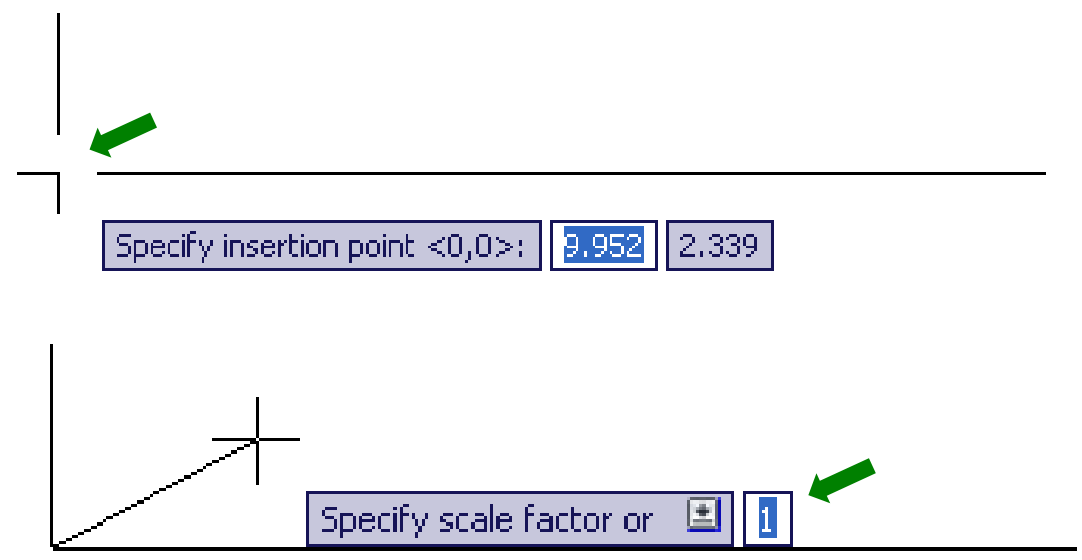

Figura 4.22 - Solicitação de informações de entrada da figura inserida. a) especificação do ponto de inserção na tela - model space; b) especificação da escala de inserção. Setas em cor verde

A imagens trans-axiais previamente salvas em arquivos com extensão JPEG, e convertidas automaticamente em suas escalas originais (de polegadas para milímetros), permaneceram em pastas externas ao programa AutoCAD ${ }^{\circledR}$. Esta providência garantiria que a imagem fosse importada (raster image) com seus padrões originais, e em escala do milímetro. 
As imagens em extensão JPEG, uma vez importadas para $\circ$ AutoCAD ${ }^{\circledR}$, foram qualitativamente comparadas àquelas dos arquivos JPEG originais, quando então pode ser confirmada a manutenção da qualidade em termos de visualização, inclusive após seguidos testes de ampliação (zoom) aleatória. Desse modo, e ao menos para a capacidade óptica habitual, não houve prejuízo associado à utilização das imagens em JPEG no programa AutoCAD ${ }^{\circledR}$.

Foi realizado, ainda, teste complementar (Equivalência Dimensional) para confirmação da exatidão original das imagens tomográficas após a transferência para o AutoCAD ${ }^{\circledR}$.

\subsubsection{Equivalência dimensional}

O teste de equivalência dimensional ocorreu a partir de comparação (linear, na escala do milímetro e com precisão centesimal de medida) entre as quantidades tomográficas originais, provenientes do registro definitivo ("régua tomográfica de referência") e as quantidades demarcadas pelas linhas-teste (AutoCAD ${ }^{\circledR}$ ) construídas a partir de ampliação prévia da imagem (padrão de 0.70). (figura 4.23)

Considerando as especificações técnicas do programa $A u t o C A D^{\circledR}$, as ampliações de tela não interferem na escala dimensional configurada (Autodesk, 2009). Esta condição (zoom) pode, eventualmente e dependendo dos objetivos da inspeção, estar associada a prejuízos de reconhecimento visual de certas características de interesse, mas essa eventual limitação constitui-se a partir do modo de obtenção original da imagem, e não é influenciada, no AutoCAD ${ }^{\circledR}$, pela ampliação de visualização (zoom).

A decisão pela ampliação (aproximação/zoom) de 0.70 foi em decorrência da necessidade (esperada) de serem ampliadas as imagens para a realização das medições, de tal modo que fosse maior que aquelas utilizadas pelos operadores, no sentido de gerar condições visuais (teste) supostamente mais extremas, visando o conhecimento do erro dimensional eventualmente associado aos limites de qualidade de visualização a partir de ampliações pré-estabelecidas.

Esta necessidade de ampliação das imagens (zoom) também haveria se o software nativo do iCAT ${ }^{\circledR}($ Xoran $)$, ou ainda qualquer outro software, fosse utilizado. 
As linhas-teste (AutoCAD ${ }^{\circledR}$ ) foram todas realizadas sobre uma das imagens (cortes) trans-axiais disponíveis, a qual fora aleatoriamente selecionada.

As medidas foram obtidas com dois intervalos de uma (01) semana, duas medidas em cada sessão, em locais diferentes da "régua tomográfica" daquele local em particular (da mesma imagem), e executado pelo operador principal (Op.0) ao início dos trabalhos com o programa AutoCAD ${ }^{\circledR}$.

Para a medição foi utilizado o recurso suplementar de linha ortogonal do AutoCAD ${ }^{\circledR}$ (comando: [CO]: ortogonal), de modo que foram intuitivamente identificados os centros transversais dos "travessões brancos verticais" da "régua tomográfica", e então demarcadas, horizontal e perpendicularmente àqueles "travessões", as linhas-teste de medida descritas. (figura 4.23)

Em seguida, as quatro linhas foram medidas (comando [CO]: dimension linear), utilizando-se como referências o início e o final das mesmas, e sempre com o auxílio do recurso AutoSnap $^{\circledR}$ - endpoint , a fim de garantir automação e ausência de erros de demarcação no processo de medição.

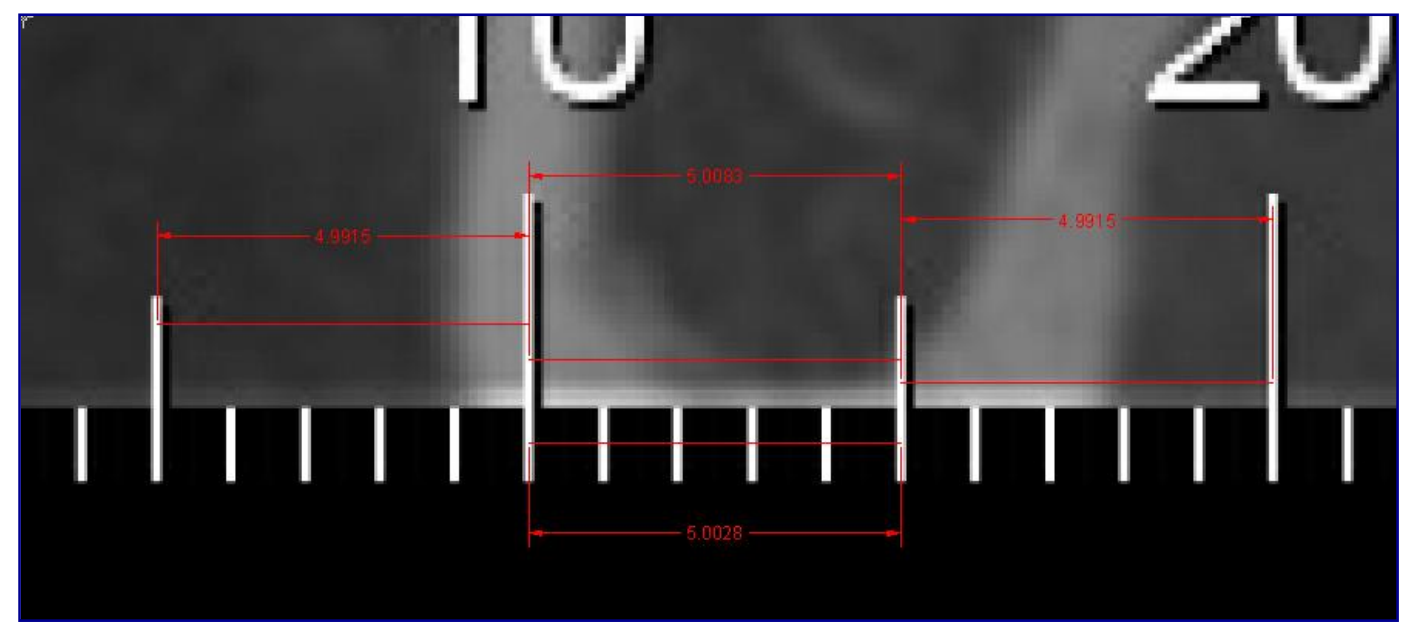

Figura 4.23 - "Régua tomográfica" ("travessões verticais de cor branca"), linhas-teste (linhas horizontais em cor vermelha) de correspondência dimensional e as cotas de medida, e mm, correspondentes (números)

A utilização de média aritmética simples $(\bar{x})(1)$, das quatro medidas $\left(T_{n}\right)$ das distâncias lineares ortogonalmente obtidas, foi considerada para avaliação da precisão de correspondência dimensional.

$$
\bar{x}=\frac{x_{1}+x_{2}+\ldots+x_{n}}{n}=\frac{1}{n} \sum_{i=1}^{n} x_{i}
$$


Foi também calculado o erro absoluto de medida (EA) - o erro absoluto de uma medida $\mathrm{M}(\mathrm{EAM})$ (2), é a diferença entre um valor $M$ absoluto considerado (em regra, o valor verdadeiro do mensurando é desconhecido), e aquele medido $\bar{M}$ experimentalmente (Vuolo, 1996).

$$
\mathrm{EAM}=|M-\bar{M}|
$$

Na presente investigação, após ter sido configurada a escala de trabalho (1:1) e ainda verificada a exatidão de transferência da imagem, a régua tomográfica da imagem do software (nativo) assumiu a função de indicador métrico do valor absoluto do mensurando tomográfico.

A tabela 4.1 apresenta os valores correspondentes às medições de equivalência dimensional realizados.

Tabela 4.1- Valores das quatro medições lineares (T1,T2,T3 e T4), em mm e de "mesmas" quantidades (M), para o teste de equivalência dimensional

\begin{tabular}{l|l}
\hline & M (mm) \\
\hline T1 & 4,991 \\
\hline T2 & 5,083 \\
\hline T3 & 4,991 \\
\hline T4 & 5,002 \\
\hline
\end{tabular}

A média $(\bar{x})$, ou valor mais provável entre as quatro medidas $\left(T_{n}\right)$, foi de $4,998 \mathrm{~mm}$. Considerando o valor absoluto considerado $(M=5,000 \mathrm{~mm})$, constatou-se que uma ampliação de 0.70 (mais que o dobro daquelas utilizadas como padrões durante o presente experimento, 0.23 e 0.30 - ver adiante) é capaz de gerar, dependendo do operador e considerando a identificação de referenciais tomográficos dimensionais bastante nítidos, um erro absoluto tomográfico (interno) 
associado (EA) de 0,002mm. Esta análise preliminar indicou que os erros associados aos modos de ampliação (zoom), descritos neste experimento, foram tecnicamente desprezíveis.

\subsubsection{Ampliação (Zoom)}

A ampliação da tela de trabalho - a partir da qual são definidos: campo de inspeção, registro das demarcações, construções geométricas, edição e, ainda, medições - representa um dos recursos mais importantes durante a obtenção de informações tomográficas, tanto as qualitativas quanto as quantitativas, haja vista que a utilização de imagens ampliadas pode tanto favorecer a inspeção de referenciais antes não detectados, como também, se excessiva for, prejudicar devido à progressiva incapacidade técnica de manutenção das qualidades de resolução original da imagem.

Essa possibilidade computacional, no $A u t o C A D^{\circledR}$, acabou por agregar versatilidade, estabilidade e precisão durante as funções de visualização, quer fosse de ampliação local pré-estabelecida, ou de ampliação livre, ou mesmo de ampliação geral, impostas pelo processo operacional.

Sendo assim, e com o intuito de favorecer o POP deste experimento, foram definidos:

- três modos pré-estabelecidos de ampliação local programada (zoom);

- um modo de ampliação local livre (zoom janela), e

- o modo padrão de ampliação geral (zoom extents).

Ampliação local programada

Foram três as pré-definições desse modo particular de zoom, e de acordo com o interesse operacional, a saber: 
- zoom 0.23 - ampliação (zoom) operacional padrão durante os registros de inspeção e identificação. (comando [CO]: $z \hookleftarrow 0.23 \hookleftarrow$ )

- zoom 0.30 - modo eventual de ampliação complementar, durante os registros de inspeção e identificação, em relação ao zoom 0.23. (comando [CO]: $z$ $0.30 \hookleftarrow$ )

- zoom 0.70 - zoom padrão durante as medições. Definido arbitrariamente de modo que fosse apropriado à visualização dos centros dos círculos (pontos), para confirmar a qualidade de localização automática da função AutoSnap ${ }^{\circledR}$. (comando [CO]: $\mathbf{z} \hookleftarrow 0.70 \hookleftarrow$ )

Ampliação local livre

- zoom janela - para correções geométricas e visualizações específicas, eventualmente necessárias. (comando [CO]: $z \hookleftarrow$ definição de janela do local de ampliação $\downarrow$ )

Ampliação Geral

- zoom extents - modo de visualização original, sem ampliação, de todos os componentes, geométricos e inseridos (raster image), presentes no espaço de modelamento. (comando [CO]: $\mathbf{z} \hookleftarrow \mathbf{e} \hookleftarrow$ ) 


\subsubsection{Camadas de trabalho (layers)}

O programa AutoCAD ${ }^{\circledR}$ propicia a criação de camadas de trabalho (layers), as quais podem ser convenientemente configuradas, desde os padrões de visualização e suas capacidades dimensionais, até os de edição, para gravações e impressão (figura 4.24).

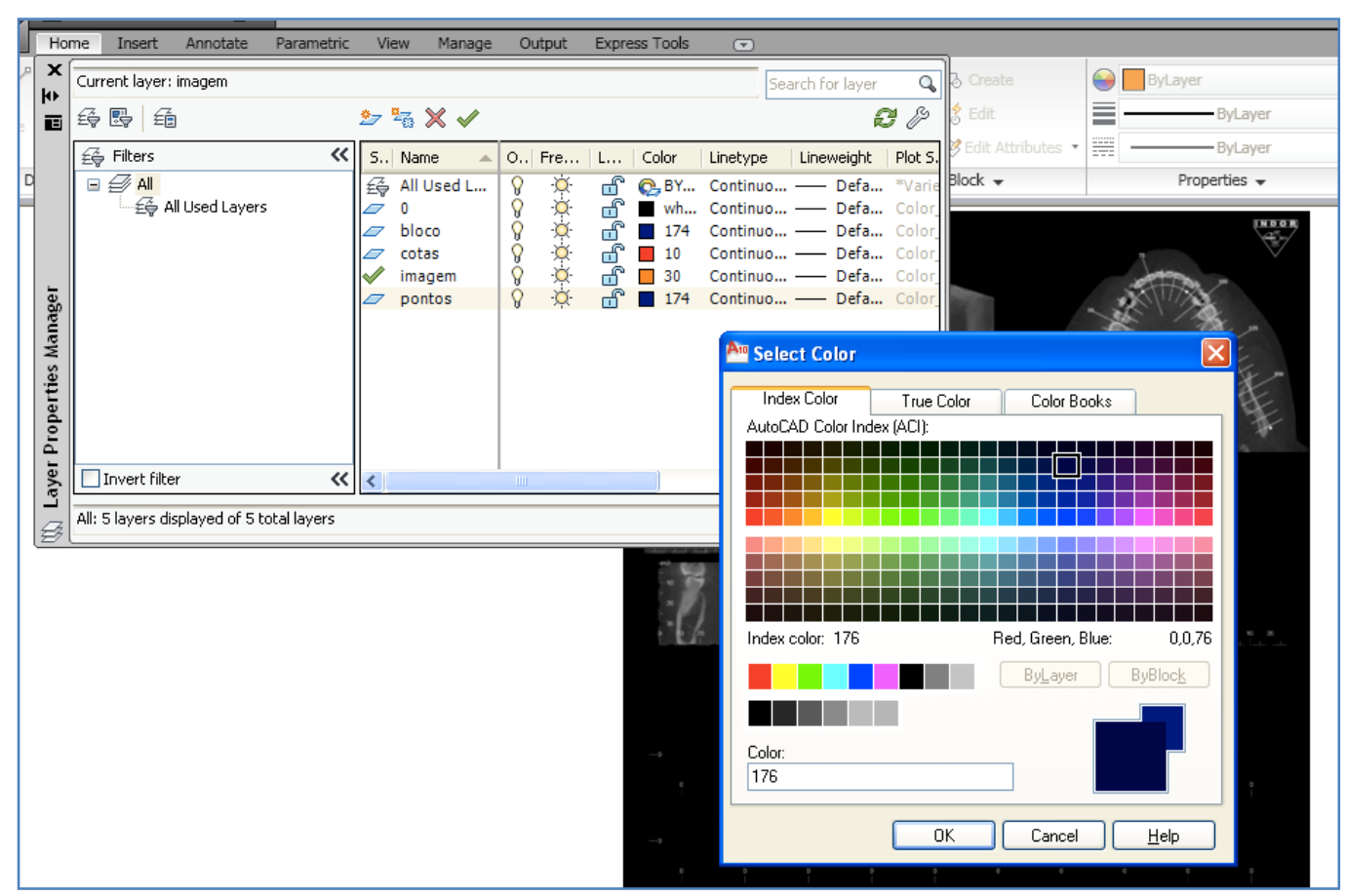

Figura 4.24 - Janela de edição de layers (camadas) de trabalho - opções de configuração: ordem, cor e condição

Para cumprir com os requerimentos desta pesquisa, foi necessária a utilização de apenas quatro (04) camadas (layers) de trabalho, denominadas, por conveniência, de: imagem (camada da imagem tomográfica); pontos (camada específica dos pontos, ou mini círculos, utilizados para a identificação dos reparos anatômicos/tomográficos); bloco (camada onde foram construídos os MGAs - ver adiante), e cotas (onde foram registrados os resultados das medições alinhadas, com precisão centesimal).

Para a realização dos testes, as camadas (layers) imagem, pontos e bloco foram sobrepostas, de modo que todos os elementos gráficos estivessem visíveis ao início dos procedimentos de inspeção visual. 


\subsubsection{Modelo Geométrico Auxiliar (MGA)}

Um modelo geométrico auxiliar (MGA), ou "template", fora especialmente desenvolvido com a finalidade de servir de referência geométrica local e objetiva durante a realização do experimento de registro (inspeção e identificação) e, por conseguinte, da medição das espessuras ósseas alveolares sugeridas.

A seguir serão descritos, justificados e ilustrados ${ }^{1}$ os constituintes gráficos do MGA (pontos anatômicos e linhas - linhas-base e linhas funcionais, e grandezas tomográficas) bem como o sumário da sequência operacional (Programa AutoCAD ${ }^{\circledR}$.

\subsubsection{1 pontos anatômicos e linhas}

- pontos anatômicos

Os pontos (figuras gráficas) do programa $A u t o C A D{ }^{\circledR}$, os quais foram utilizados pelos operadores como referências pontuais a serem posicionadas nos locais de interesse, ou limites entre estruturas óssea e dentária, foram virtualmente representados por círculos (figura 4.25, p. 147), construídos com raio de $0,10 \mathrm{~mm}$ (comando: [CO]: circle $\downarrow$ ), e de modo que os pontos de referência fossem diminutos o suficiente para não interferirem no processo de reconhecimento visual das dimensões e reparos anatômicos pretendidos, e também convenientemente delgados em suas bordas a fim de que fossem prontamente identificados. Contudo, ainda deveriam seguir proporcionalmente as ampliações padrões (zoom) do campo de inspeção (model space) sem que, com isso, interferissem no processo de inspeção visual.

\footnotetext{
1 As figuras do tópico 4.3.2.7 - MGA, servem apenas para ilustrar didaticamente a sequência metodológica de construção do MGA. Os desenhos foram realizados com recurso "polyline" do Programa AutoCAD ${ }^{\circledR}$, e não representam nem os limites reais entre tecidos representados (dentes e ossos), nem tampouco os tamanhos e proporções reais daqueles que foram utilizados durante a execução dos testes.
} 
A cor (preta) foi definida para que não houvesse interferência visual com os padrões de intervalos de cinza subjacentes e, ainda, para que fosse facilmente identificada, durante as medições, em contraste com o branco das estruturas de interesse.

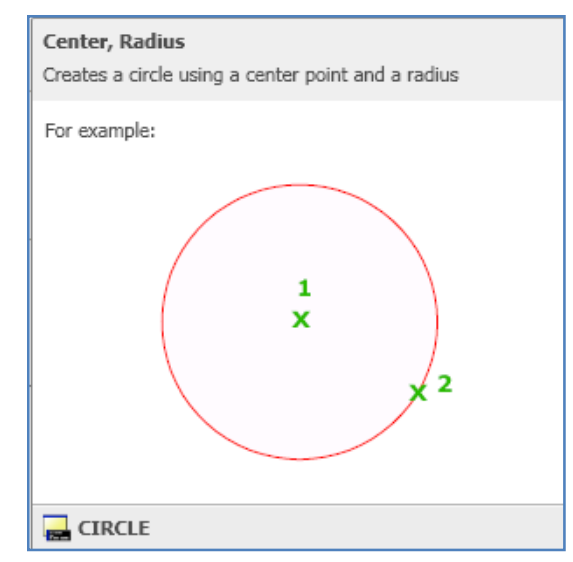

Figura 4.25 - Imagem (ampliada) das características geométricas do ponto de referência (círculo) utilizado para as definições. Cor e dimensões meramente ilustrativas

Os pontos anatômicos, determinados por meio de inspeção visual tomográfica direta dos locais correspondentes, compõem um dos principais fatores de teste deste experimento.

A qualidade final dos registros de inspeção e identificação, em termos de "poder de detecção anatômica" e a partir das imagens tomográficas geradas, é função direta tanto da capacidade de localização espacial dos pontos sugeridos (operador dependente - resolução espacial e detalhe de imagem, regularidade de contornos, contraste e familiarização com os modos operacionais), quanto dos conceitos anatômicos/tomográficos concebidos previamente pelos examinadores (competências próprias associadas ao conhecimento anatômico e experiência do operador; e competências recentes, associadas às instruções circunstanciais de padronização da informação, na tentativa de evitar juízos grosseiramente equivocados).

A seguir, serão descritos os pontos anatômicos selecionados (figuras 4.26 , 4.27, 4.28, 4.29 e 4.30): 
- JACr (junção amelo-cementária vestibular) - ponto, obtido a partir de inspeção visual direta da imagem tomográfica correspondente à junção amelocementária da face vestibular, de incisivos, caninos e molares. (figura 4.26)

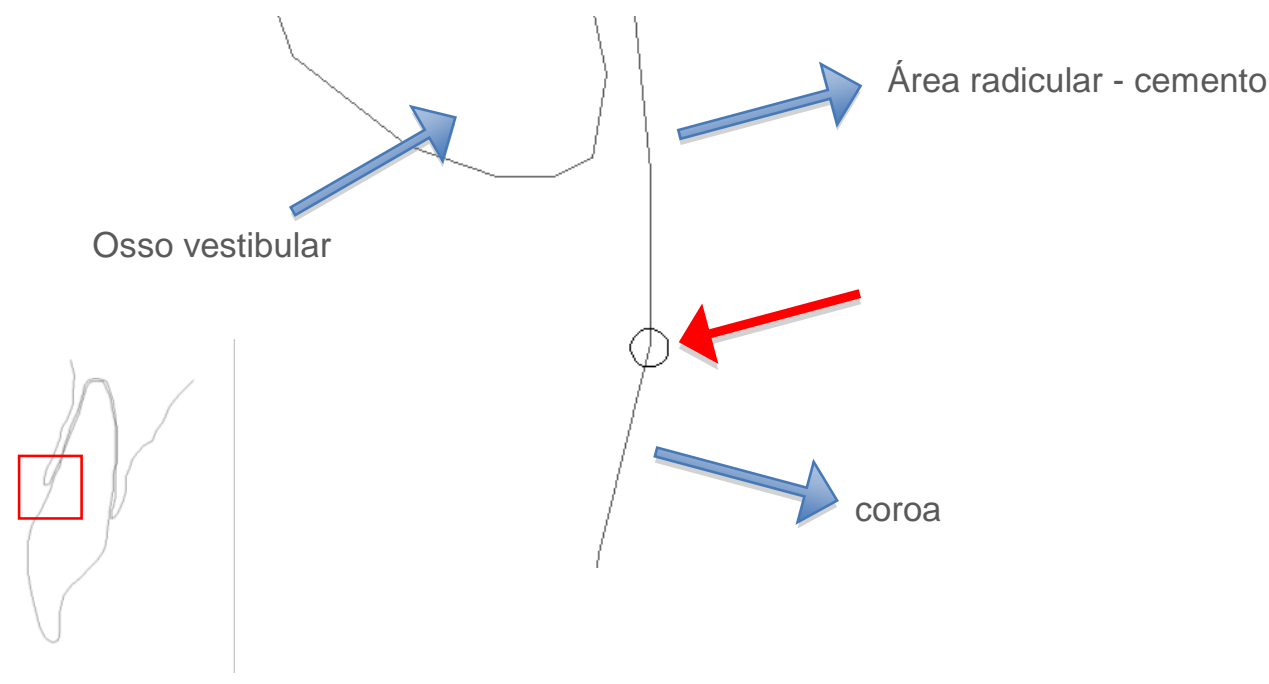

Figura 4.26 - Obtenção do ponto JACv. (seta vermelha)

- JACl/p (junção amelo-cementária lingual/palatina) - ponto, obtido a partir de inspeção visual direta da imagem tomográfica correspondente à junção amelocementária da face lingual ou palatina, de incisivos, caninos e molares. (figura 4.27)

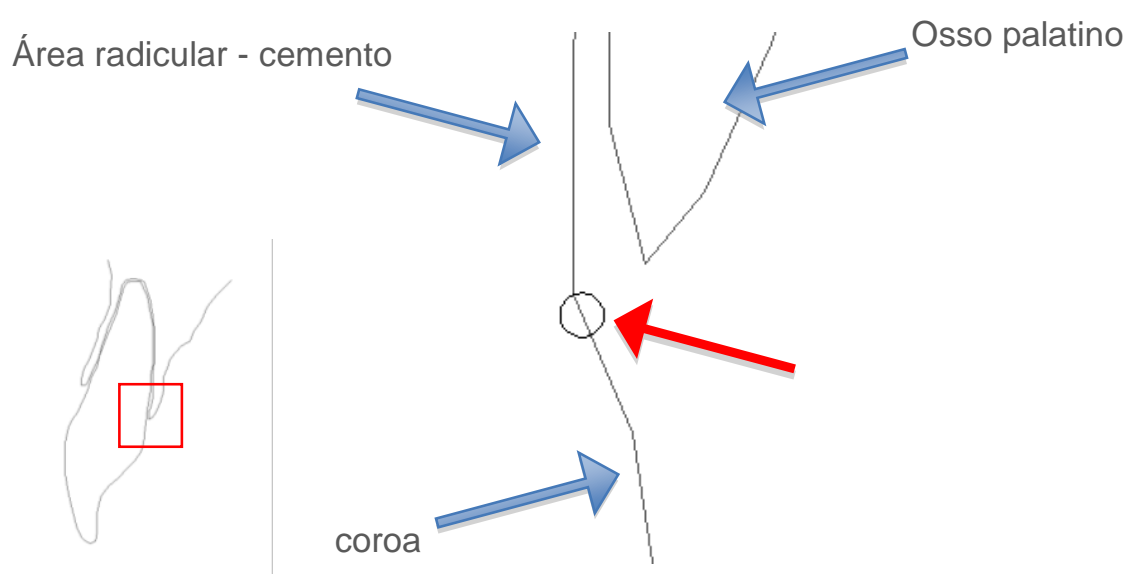

Figura 4.27 - Obtenção do ponto JAC l/p. (seta vermelha) 
- LA (limite apical) - ponto, obtido a partir de inspeção visual direta da imagem tomográfica correspondente ou ao limite apical da raiz dentária, ou ao forame apical, de incisivos, caninos e molares. (figura 4.28)

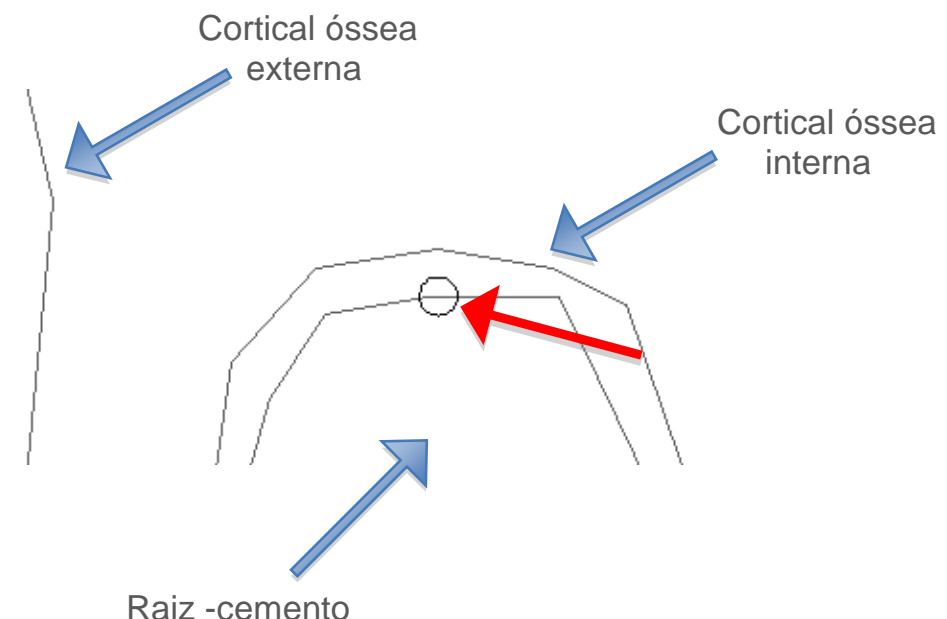

Figura 4.28 - Obtenção do ponto Limite Apical (LA). (seta vermelha)

No caso especial de ocorrência de duas ou mais imagens radiculares, em situação de acentuada divergência vestíbulo-lingual, sugere-se que seja identificado um "ponto LA geométrico" (LAG), correspondente ao local médio, por inspeção obtido, entre as raízes divergentes a fim de que os referenciais de auxílio do MGA possam ser obtidos de modo anatomicamente mais proporcional (figura 4.29).

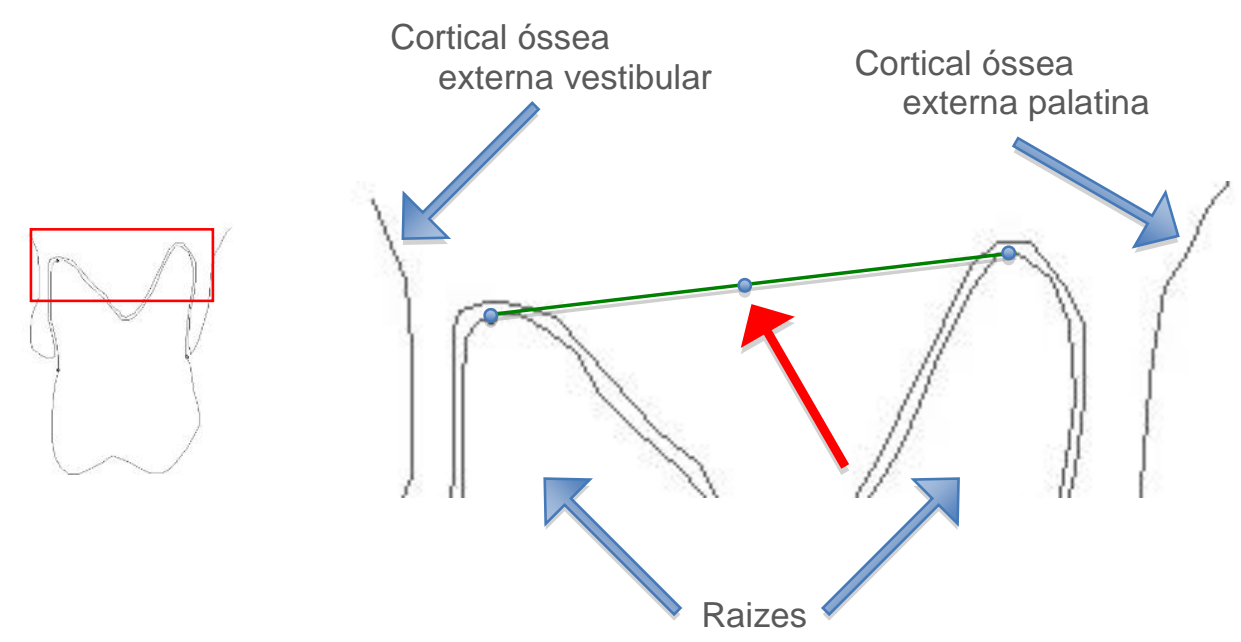

Figura 4.29 - Obtenção do ponto Limite Apical Geométrico (LAG). (seta vermelha) 


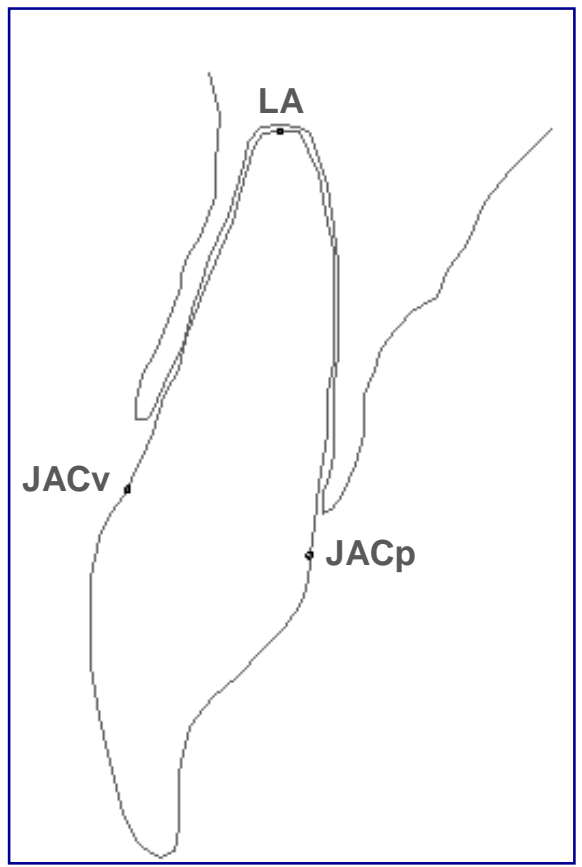

Figura 4.30 - Pontos anatômicos de referência: JACv; JACl/p e LA

- linhas

O MGA foi construído a partir de linhas (cor azul escuro e de espessura de plotagem de $0,05 \mathrm{~mm}$ ) definidas geometricamente de modo livre e ortogonal, e sempre com o auxílio da função AutoSnap ${ }^{\circledR}$, para a precisão de definição dos seus limites. (figura 4.31)

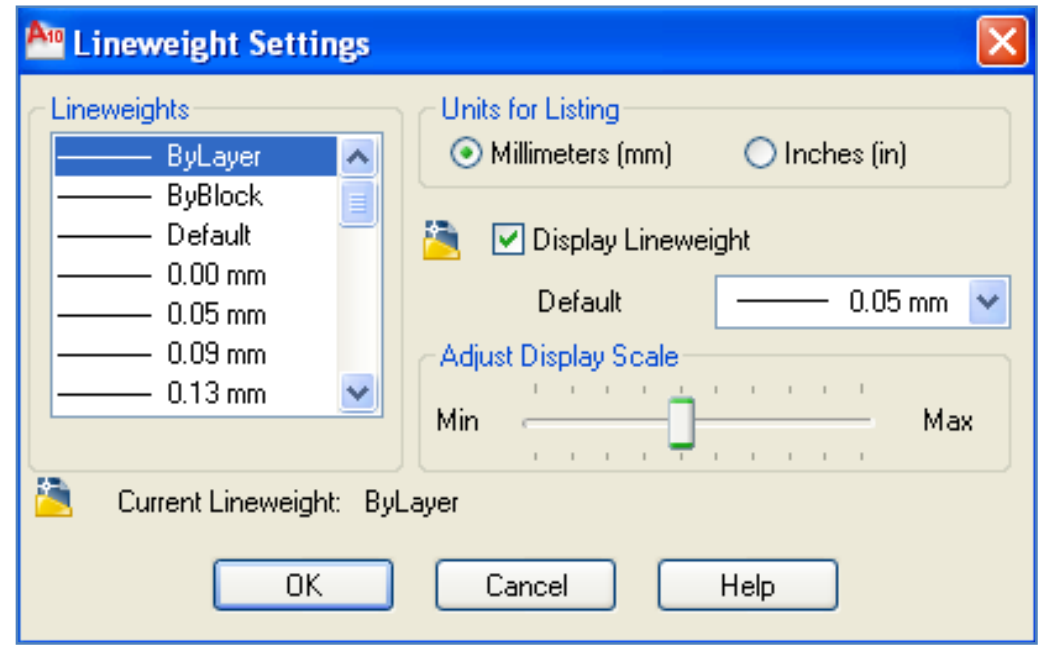

Figura 4.31 - Configuração da espessura das linhas geométricas do MGA 
Com vistas à tornar anatomicamente representativa a obtenção do modelo geométrico auxiliar (MGA), e já que a imagem tomográfica trans-axial oferece um padrão real (1:1) bidimensional, ponderou-se acerca da possibilidade de serem estabelecidos referenciais cartesianos para favorecer o controle durante a execução do Procedimento Operacional Padrão (POP). Assim, foi definida a criação e utilização de duas linhas-base de construção deste referencial geométrico, a partir das quais foram também propostas e aplicadas linhas geométricas auxiliares, ou linhas funcionais principais.

linhas-Base

As duas linhas-base foram determinadas com a finalidade de representar (geometricamente) dois limites bidimensionais possíveis e associados a cada dente em sua particularidade anatômica, sendo um em direção transversal, representado pela linha LBC (sentido vestíbulo-lingual), e outro em direção vertical, representado pela linha ERL (sentido cérvico-apical), permitindo, deste modo, a orientação de construção do MGA.

Antes da determinação da linha ERL, foi determinada uma linha de associação anatômica denominada de linha cervical (LC), a qual corresponde ao segmento de reta que une os pontos JACv e JACl/p.

Uma referência central de construção do MGA é o ponto $\mathbf{L C / 2}$. O referido ponto é geometricamente derivado e divide, exatamente em duas partes, a distância linear obtida com a linha LC. (figura 4.32)

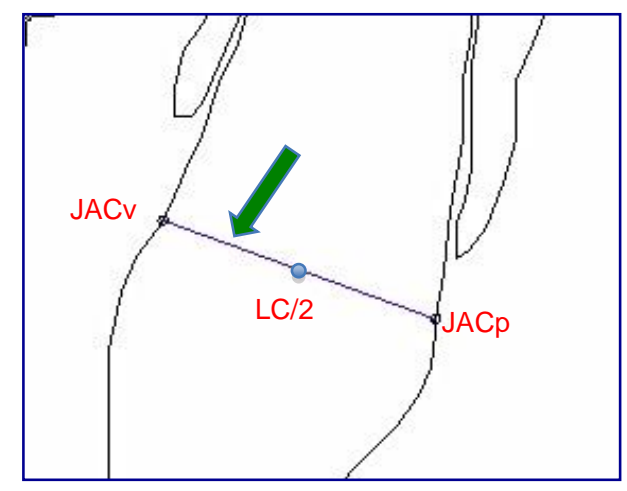

Figura 4.32 - Obtenção da linha cervical (LC) (seta verde) e do ponto LC/2 (em cor azul) 
Assim, LC/2 ("meio de LC") corresponde ao ponto geométrico derivado e obtido a partir de divisão automática da distância linear representada pela linha LC.

Após ter sido selecionado o ponto $\mathrm{LC} / 2$, procedeu-se, então, com a identificação da linha ERL, assim que:

- ERL (eixo radicular longitudinal) - corresponde ao segmento de reta que atravessa longitudinalmente a linha LC, à meia distância desta (ponto LC/2), e conforme limites: apical - ponto LA; e cervical - extensão coronária à distância média de $20 \mathrm{~mm}$ a partir do ponto de corte na linha LC (ponto LC/2). (figura 4.33)

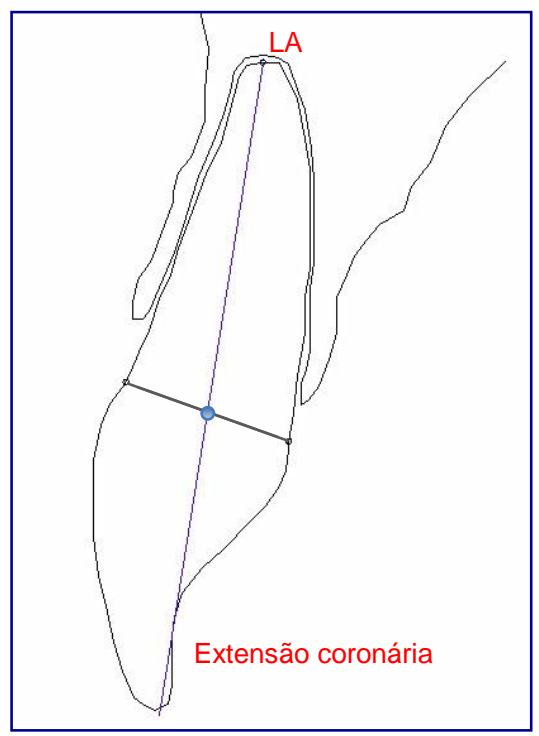

Figura 4.33 - Obtenção da Linha Eixo Radicular Longitudinal (ERL). (cor azul)

- LLA (linhas laterais de auxílio) - dois segmentos de reta, um vestibular (LLAv) e outro palatino/lingual (LLAp/I), inseridos lateral e paralelamente à linha ERL, conforme distância conveniente (dependente da anatomia local individual).

São cópias paralelas laterais à ERL, possuindo assim as mesmas dimensões e inclinação vestíbulo-lingual destas últimas. (figura 4.34) 


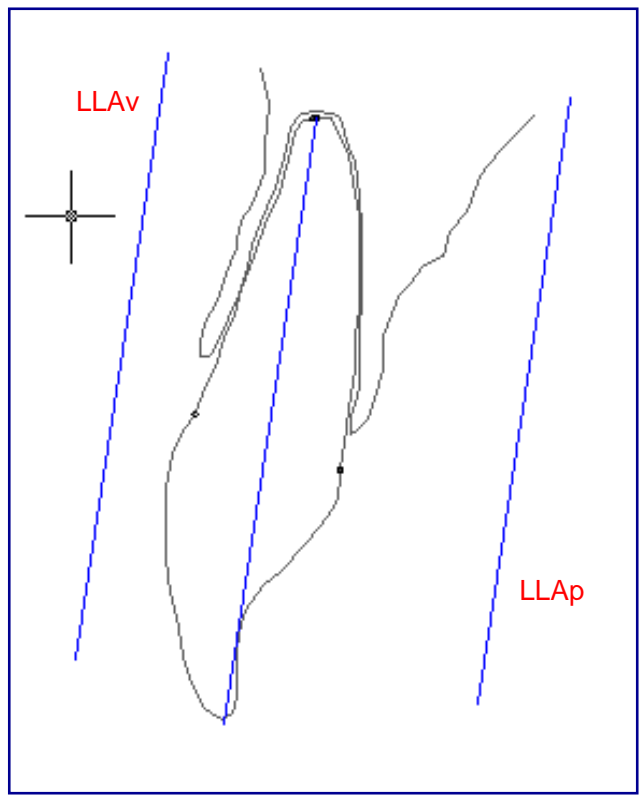

Figura 4.34 - Obtenção das Linhas Laterais de Auxílio (LLA)

- LBC (linha-base cervical) - segmento de reta que une ortogonalmente as linhas laterais de auxílio, vestibular e palatina/lingual (LLAv-LLAp/I), à linha ERL, passando pelo ponto LC/2. (figura 4.35)

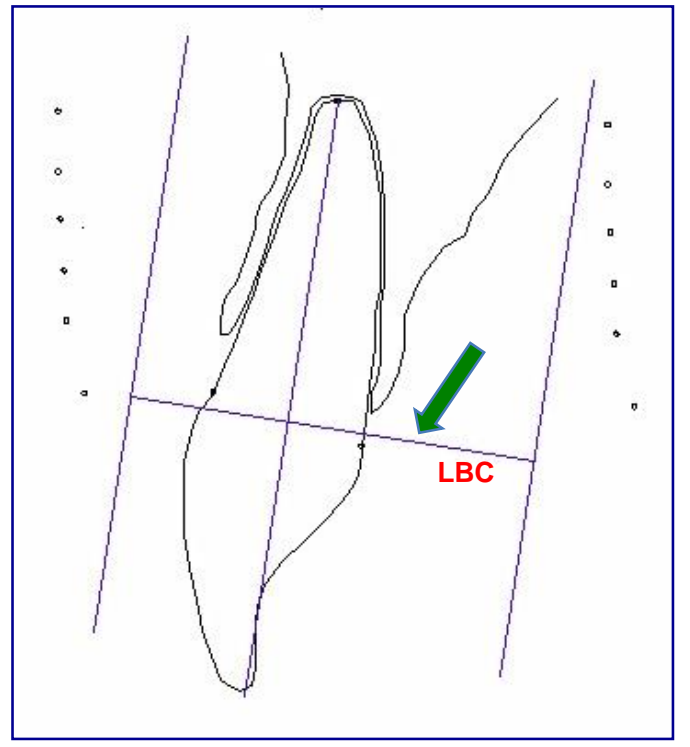

Figura 4.35 - Obtenção da Linha-Base Cervical (LBC). (seta verde) 
Linhas Funcionais - Principais

Devido ao fato de existirem, naturalmente, diferentes condições (anatômicas) dentárias relativas ao tipo, posição, e também a quantidades variáveis de osso circundante, optou-se por definir um padrão proporcional para a quantidade (níveis), de avaliações das espessuras ósseas alveolares. Destarte, se o dente fosse curto, em proporção seriam também automaticamente ajustadas as linhas ortogonais de referência aos níveis de espessura avaliados.

Assim, e para esta investigação, mediante ponderação prévia dos tamanhos radiculares (tomográficos) relativos, e ainda considerando o que seria um número adequado, tanto para as finalidades do experimento em termos de execução dos testes matemáticos/estatísticos, quanto para que não fossem excessivamente resumidas, nem tampouco exageradamente valorizadas as características próprias de cada unidade de observação (dente-alvo), foram definidos três (03) níveis de avaliação, ou seja, três qualidades geometricamente pré-definidas de espessuras ósseas alveolares (medida do comprimento radicular dividida por quatro), as quais acabam por associar as duas faces, vestibulares e linguais/palatinas, de cada dente considerado, seja ele maxilar ou mandibular, em um mesma e fixa direção de avaliação, gerando assim as seguintes referências (figura 4.36):

- L1 ("éle um") - linha, perpendicular às linhas LLAv e LLAp/l e paralela à LBC, que corresponde ao primeiro nível de avaliação das espessuras ósseas;

- L2 ("éle dois") - linha, perpendicular às linhas LLAv e LLAp/I e paralela à LBC, que corresponde ao segundo nível de avaliação das espessuras ósseas, e

- L3 ("éle três") - linha, perpendicular às linhas LLAv e LLAp/l e paralela à LBC, que corresponde ao terceiro e último nível de avaliação das espessuras ósseas propostas.

Assim, e como exemplo, se o comprimento radicular era de $21 \mathrm{~mm}$, então L1 estaria localizada, em sentido cérvico-apical, a uma distância de $5,25 \mathrm{~mm}$ do ponto 
LC/2; e L2, por sua vez, estaria à distância de $10,5 \mathrm{~mm}$ do ponto $\mathbf{L C} / \mathbf{2}$. Finalmente, a linha funcional principal L3 estaria à $15,75 \mathrm{~mm}$ daquele ponto inicial de referência.

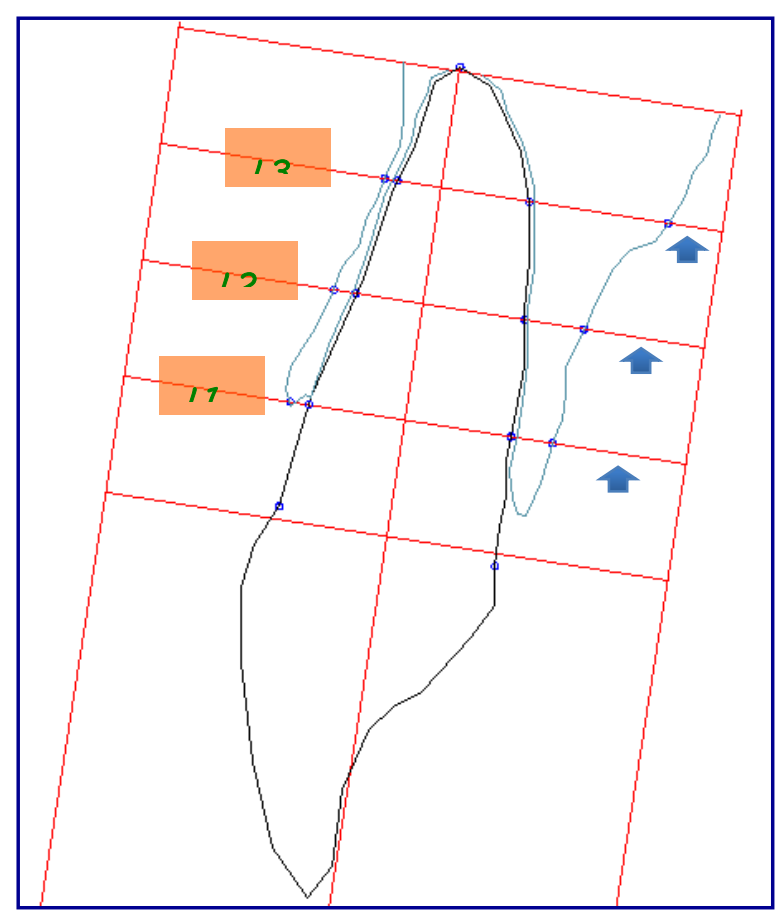

Figura 4.36 - Representação esquemática das linhas funcionais principais (L1, L2 e L3) (setas azuis)

\section{Pontos Funcionais}

São os pontos (ósseos e dentários) de demarcação tomográfica propriamente ditos (figura 4.37), a saber:

\section{- Ósseos}

- LOC v (limite ósseo cervical vestibular) - corresponde ao limite vestibular da imagem tomográfica (anatômica) do tecido ósseo alveolar, ao longo da L1 do MGA. Estabelece o limite horizontal, cervical e vestibular da imagem tomográfica do osso alveolar do dente considerado. 
- LOI v (limite ósseo intermédio vestibular) - corresponde ao limite vestibular da imagem tomográfica (anatômica) do tecido ósseo alveolar, ao longo da L2 do MGA. Estabelece o limite horizontal, intermediário e vestibular da imagem tomográfica do osso alveolar do dente considerado.

- LOA v (limite ósseo apical vestibular) - corresponde ao limite vestibular da imagem tomográfica (anatômica) do tecido ósseo alveolar, ao longo da L3 do MGA. Estabelece o limite horizontal, apical e vestibular da imagem tomográfica do osso alveolar do dente considerado.

- LOC I/p (limite ósseo cervical lingual/palatino) - corresponde ao limite lingual/palatino da imagem tomográfica (anatômica) do tecido ósseo alveolar, ao longo da L1 do MGA. Estabelece o limite horizontal, cervical e lingual/palatino da imagem tomográfica do osso alveolar do dente considerado.

- LOI I/p (limite ósseo intermédio lingual/palatino) - corresponde ao limite lingual/palatino da imagem tomográfica (anatômica) do tecido ósseo alveolar, ao longo da L2 do MGA. Estabelece o limite horizontal, intermediário e lingual/palatino da imagem tomográfica do osso alveolar do dente considerado.

- LOA I/p (limite ósseo apical lingual/palatino) - corresponde ao limite lingual/palatino da imagem tomográfica (anatômica) do tecido ósseo alveolar, ao longo da L3 do MGA. Estabelece o limite horizontal, apical e lingual/palatino da imagem tomográfica do osso alveolar do dente considerado.

- Dentários

- LDC v (limite dentário cervical vestibular) - corresponde ao limite vestibular da imagem tomográfica (anatômica) do tecido dentário radicular (cemento), ao longo da L1 do MGA. Estabelece o limite horizontal, cervical e vestibular da imagem tomográfica da raiz do dente considerado. 
- LDI v (limite dentário intermédio vestibular) - corresponde ao limite vestibular da imagem tomográfica (anatômica) do tecido dentário radicular (cemento), ao longo da L2 do MGA. Estabelece o limite horizontal, intermediário e vestibular da imagem tomográfica da raiz do dente considerado.

- LDA v (limite dentário apical vestibular) - corresponde ao limite vestibular da imagem tomográfica (anatômica) do tecido dentário radicular (cemento), ao longo da L3 do MGA. Estabelece o limite horizontal, apical e vestibular da imagem tomográfica da raiz do dente considerado.

- LDC I/p (limite dentário cervical lingual/palatino) - corresponde ao limite lingual/palatino da imagem tomográfica (anatômica) do tecido dentário radicular (cemento), ao longo da L1 do MGA. Estabelece o limite horizontal, cervical e lingual/palatino da imagem tomográfica da raiz do dente considerado.

- LDI I/p (limite dentário intermédio lingual/palatino) - corresponde ao limite lingual/palatino da imagem tomográfica (anatômica) do tecido dentário radicular (cemento), ao longo da L2 do MGA. Estabelece o limite horizontal, intermediário e lingual/palatino da imagem tomográfica da raiz do dente considerado.

- LDA I/p (limite dentário apical lingual/palatino) - corresponde ao limite lingual/palatino da imagem tomográfica (anatômica) do tecido dentário radicular (cemento), ao longo da L3 do MGA. Estabelece o limite horizontal, apical e lingual/palatino da imagem tomográfica da raiz do dente considerado. 


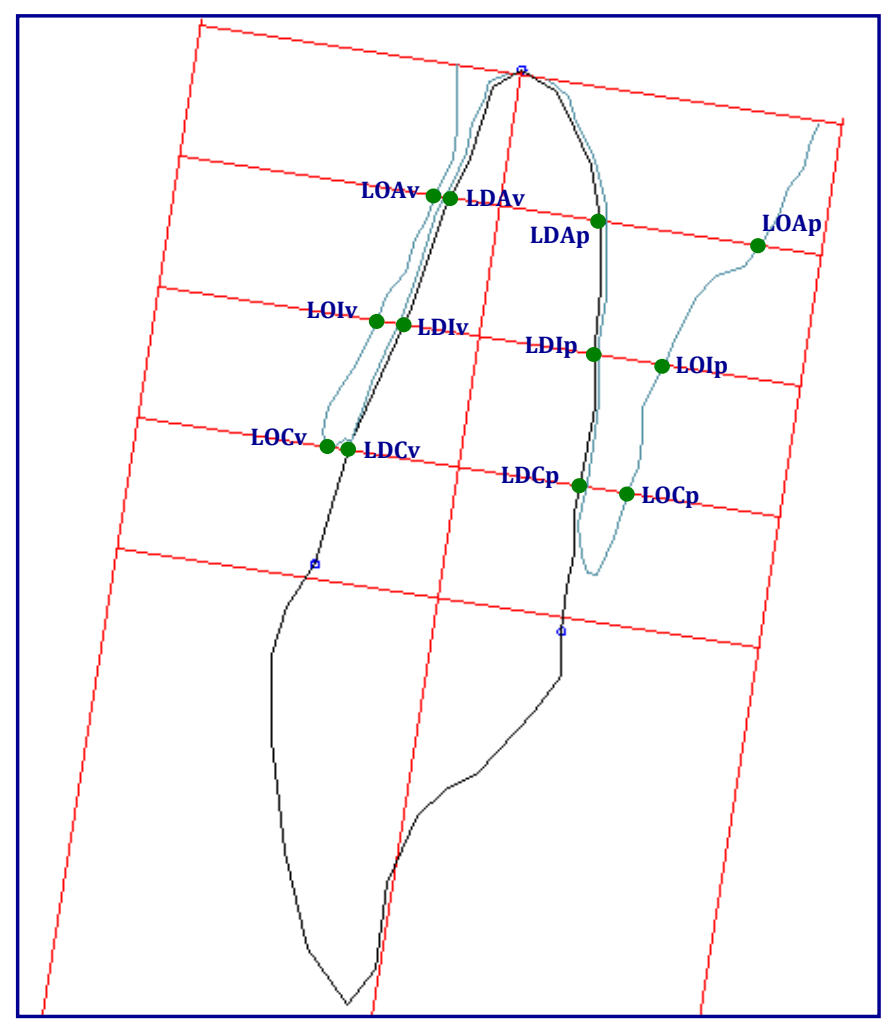

Figura 4.37 - Representação esquemática dos pontos funcionais, ósseos e dentários, preconizados a partir do MGA proposto (esferas verdes)

\section{Linhas Funcionais Derivadas}

São as linhas constituintes dos seis (06) tipos de medida propostos para a grandeza tomográfica avaliada (espessura óssea) (figura 4.38), a saber:

- LV1 (linha V1) - segmento de reta, da L1, que une os pontos LOCv e LDCv;

- LV2 (linha V2) - segmento de reta, da L2, que une os pontos LOIv e LDIv;

- LV3 (linha V3) - segmento de reta, da L3, que une os pontos LOAv e LDAv;

- LP/L1 (linha P/L1) - segmento de reta, da L1, que une os pontos LOCp/I e LDCp/I; 
- LP/L2 (linha P/L2) - segmento de reta, da L2, que une os pontos LOIp/I e LDIp/I;

- LP/L3 (linha P/L3) - segmento de reta, da L3, que une os pontos LOAp/I e LDAp/l.

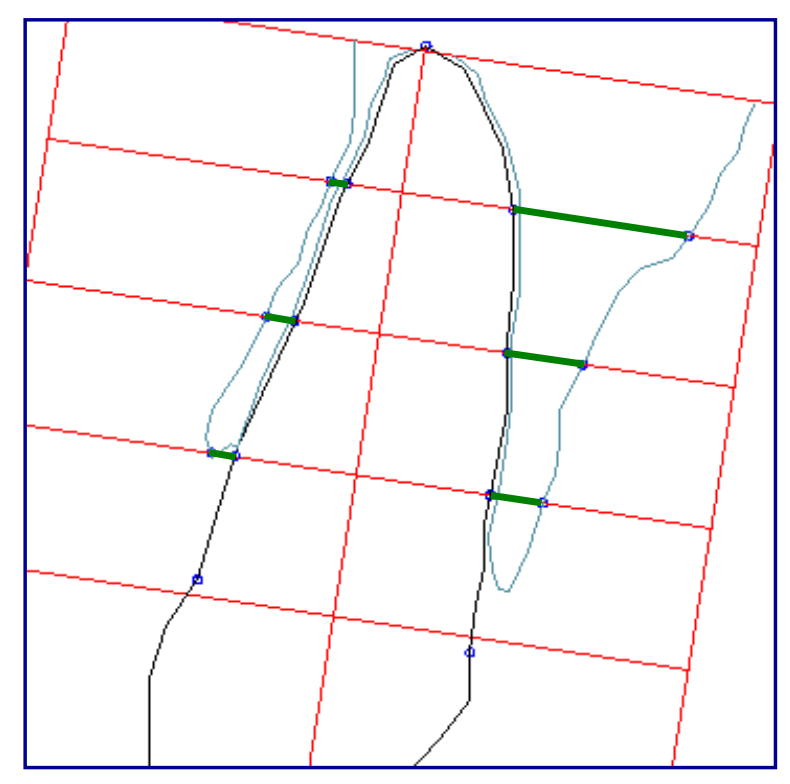

Figura 4.38 - Representação esquemática das linhas funcionais derivadas (linhas verdes)

\subsubsection{2 grandezas tomográficas}

O MGA foi construído de acordo com a orientação vestíbulo-lingual/palatina de cada dente, bem como em proporção direta ao comprimento vertical (cérvicoapical) de cada uma das raízes dos doze (12) dentes, seis (06) maxilares e seis (06) mandibulares, selecionados para constituir os cortes trans-axiais do experimento.

Optou-se pela definição um eixo longitudinal dentário (radicular) como parâmetro principal de informação da inclinação de toda a construção geométrica construída de linhas do MGA, haja vista que a adoção de referenciais independentes da inclinação radicular (dentária) poderiam sofrer influência tanto do modo de preparação pós-processamento do corte tomográfico trans-axial (oblíquo) a partir dos recursos de cada software selecionado, como, ainda, de movimentos da cabeça durante o posicionamento do indivíduo na cadeira do tomógrafo. 
Assim, e conforme os níveis pretendidos de avaliação já descritos, a grandeza selecionada foi a da espessura óssea alveolar, a qual foi considerada em três (03) níveis e seis (06) tipos ou modos de avaliação (figura 4.39), a saber:

- V1 (espessura óssea alveolar cervical vestibular) - é a medida, alinhada e em $\mathrm{mm}$, da linha V1;

- V2 (espessura óssea alveolar intermédia vestibular) - é a medida, alinhada e em $\mathrm{mm}$, da linha $\mathbf{V} \mathbf{2}$, e

- V3 (espessura óssea alveolar apical vestibular) - é a medida, alinhada e em $\mathrm{mm}$, da linha V3.

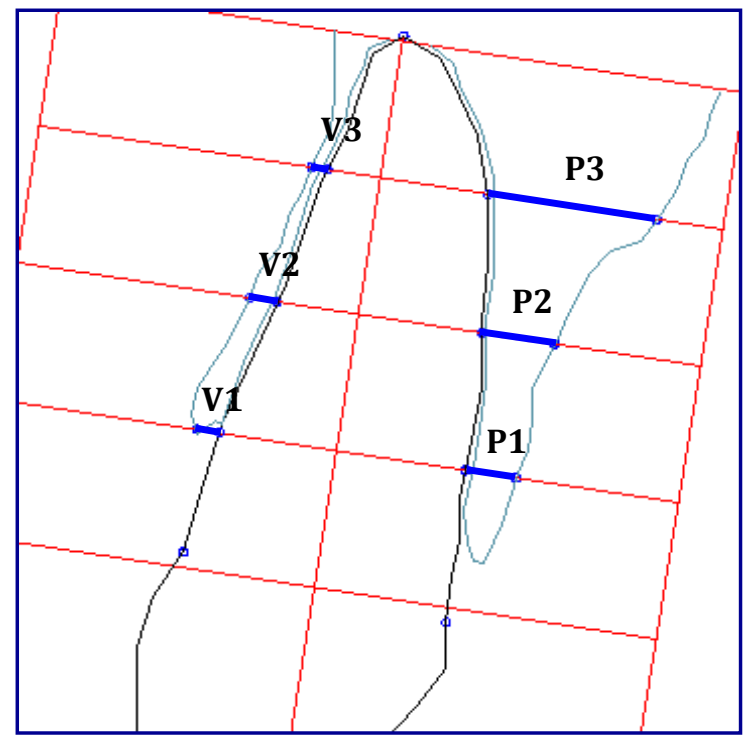

Figura 4.39 - $\begin{gathered}\text { Representação esquemática das espessuras ósseas } \\ \text { preconizadas }\end{gathered}$

- P/L1 (espessura óssea alveolar cervical palatina/lingual) - é a medida, alinhada e em mm, da linha P/L1;

- P/L2 (espessura óssea alveolar intermédia palatina/lingual) - é a medida, alinhada e em $\mathrm{mm}$, da linha $\mathbf{P} / \mathrm{L} 2$, e

- P/L3 (espessura óssea alveolar apical palatina/lingual) - é a medida, alinhada e em mm, da linha P/L3. 
Assim, foram definidas seis (06) medidas dessa grandeza em particular, para cada dente considerado, sendo três (03) em cada uma das duas faces (vestibular e lingual/palatina), e conforme os já descritos três (03) níveis de avaliação, consideradas a partir do corte trans-axial gerado.

Um total de trinta e seis (36) medidas foram obtidas para a maxila (dentes: incisivos centrais - 11 e 21 ; caninos - 13 e 23 e primeiros molares - 16 e 26), e outras trinta e seis (36) para a mandíbula (dentes: incisivos centrais - 31 e 41; caninos - 33 e 43 e primeiros molares - 36 e 46), totalizando setenta e duas (72) medidas realizadas por cada um dos operadores participantes, a partir da identificação, se houvesse osso local, de cento e quarenta e quatro (144) pontos tomográficos associados.

Cada dente, em sua particularidade anatômica (de contornos e posicional), recebeu seu próprio MGA, bem como a notação das (06) seis espessuras ósseas correspondentes, como, por exemplo:

- 23 V1 ("V1 do vinte e três") - corresponde ao valor de medida de V1 (espessura óssea alveolar vestibular cervical), considerando o dente canino superior esquerdo (figura 4.40);

- 36 L3 ("L3 do trinta e seis") - corresponde ao valor de medida de L3, considerando o dente primeiro molar inferior esquerdo, e

- 41 L2 ("L2 do quarenta e um") - corresponde ao valor de medida de L2, considerando o dente incisivo central inferior direito. 


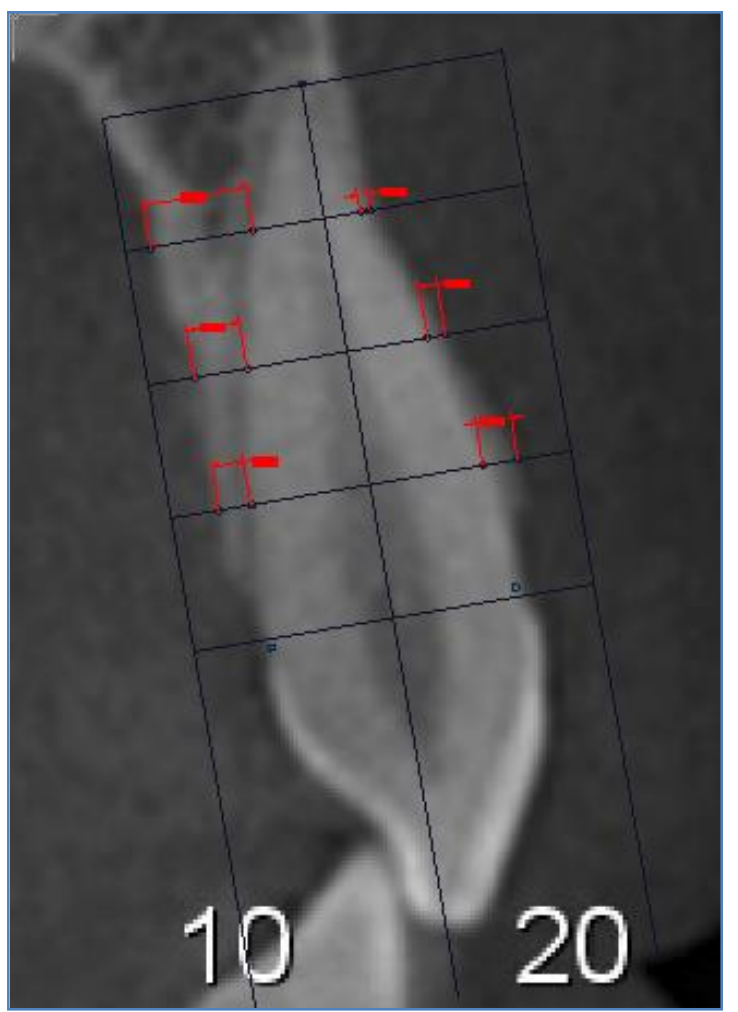

Figura 4.40 - Exemplo de visualização (dente 23) e aplicação real do MGA (linhas escuras) e das espessuras ósseas alveolares medidas por um dos operadores (linhas e números em cor vermelha)

4.3.2.4 Critério de Operacionalização - Inspeção e Identificação e Medição

4.3.2.4.1 inspeção e identificação

a) Automação de Ação

O programa AutoCAD ${ }^{\circledR}$, com vistas a propiciar padronização e precisão para a qualidade no processo de construção geométrica, representação gráfica e medição, oferece a possibilidade de serem automatizados alguns dos comandos de ação por meio da função AutoSnap ${ }^{\circledR}$ (Autodesk, 2009). (figura 4.41) 


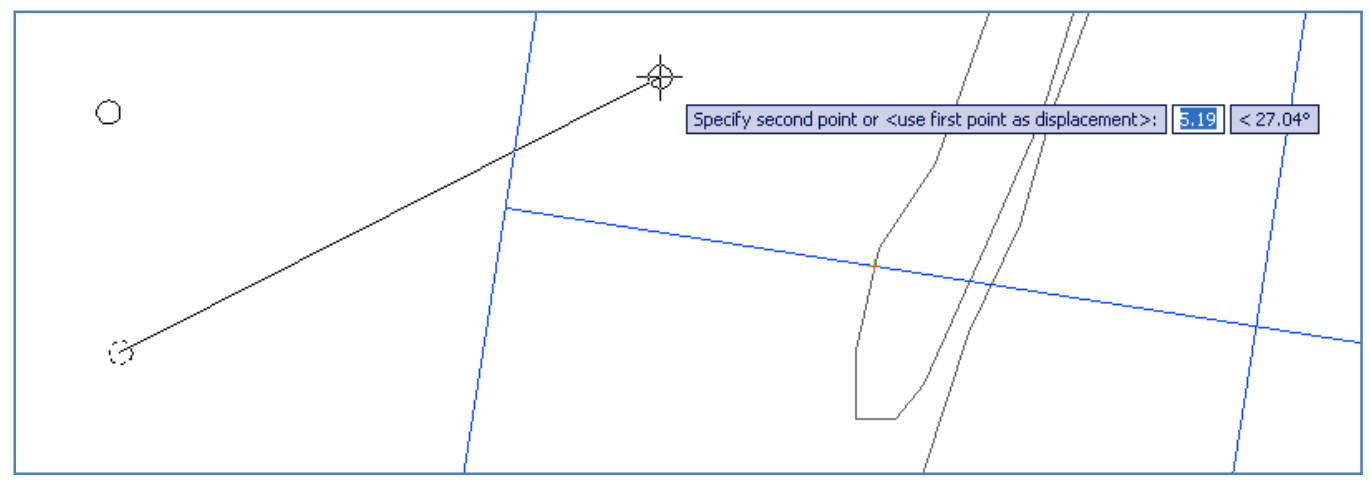

Figura 4.41 - Função de automação - precisão (absoluta) durante a identificação de referenciais geométricos

Essa condição, de fato, é capaz de garantir menor incidência de tendenciosidades em decorrência da própria automação, diminuindo a participação humana no processo, garantindo assim identificação geométrica computacional mais precisa.

A correta seleção das referências e figuras geométricas criadas, que, nesse caso, são aquelas que constituem o MGA, representa importante evento durante participação orientada do operador.

Portanto, o recurso AutoSnap ${ }^{\circledR}$ foi utilizado como auxiliar no processo de inspeção e identificação (registro).

A figura 4.42 ilustra a tela de utilização do comando AutoSnap $^{\circledR}$, com indicação visível da referência desejada, fosse ela: intersection, center, midpoint, apparent intersection, none, nearest, node, perpendicular ou mesmo endpoint.
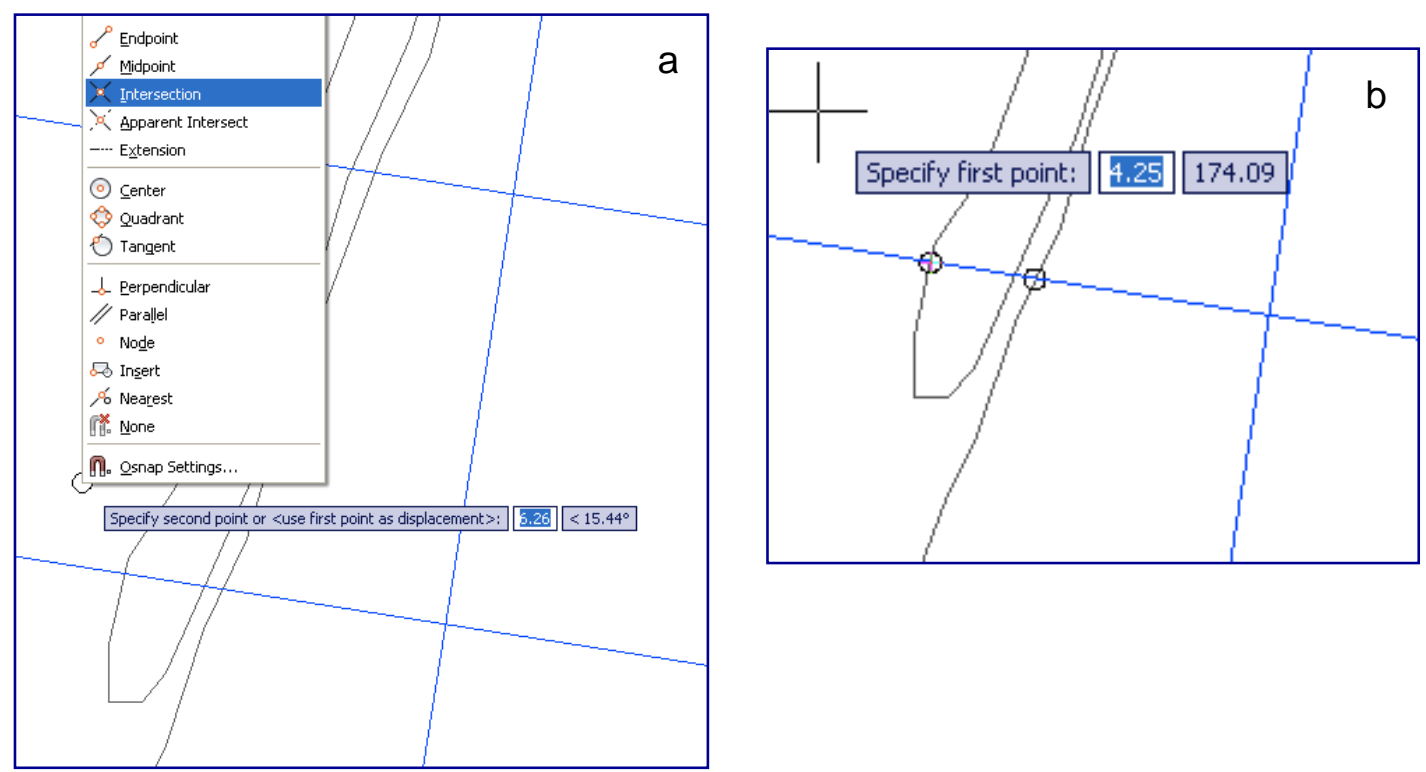

Figura 4.42 - a) visualização da função AutoSnap ${ }^{\circledR}$ para um comando “ímã" de precisão de identificação da intersecção; b) solicitação padrão para o posicionamento do cursor 
A sequência operacional de inspeção foi iniciada sempre pelo operador principal (Op.0), o qual foi o responsável pela definição das situações de automação no processo, e a partir dos seguintes comandos:

- Object Snap (AutoSnap ${ }^{\circledR}$ ) - center - para a localização automática dos centros geométricos dos pontos construídos (círculos) de demarcação, propiciando o início da possibilidade automação;

- Object Snap (AutoSnap ${ }^{\circledR}$ ) - nearest - selecionada a fim de que fosse propiciado o "efeito imã" de manutenção da orientação posicional de inspeção de cada operador sobre a linha horizontal correspondente ao nível de avaliação das espessuras ósseas. Com o auxílio deste recurso, é impossível que o operador identifique (pela confirmação de posicionamento espacial do ponto geométrico) limite ou ponto de intenção (tecidual), o qual não seja, obrigatoriamente, ao longo das linhas funcionais principais de avaliação (L1, L2 ou L3) (p. 145), ou seja, o erro vertical de precisão é igual a zero em todos os casos.

- Regen (comando [CO]: $\mathbf{z} \hookleftarrow \mathbf{e} \downarrow$ ) - utilizado para regularizar as relações entre desenhos geométricos, sem alterar suas dimensòes reais, contudo otimizando os padrões de suas visualizações.

- Zoom - para a transição entre ampliações de visualização na tela de trabalho (0.23 / 0.30 / 0.70; zoom janela e, ainda, zoom extents)

- Undo - para desfazer, quando necessário fosse, as opções do operador.

b) Ação Livre

A partir desta etapa o participante era liberado a agir livremente a fim de efetivar e qualificar o processo de inspeção, obtendo total controle de movimentos 
do cursor, em todos as direções e sentidos da tela de trabalho, a fim de que pudesse obter, no próprio cursor, tanto um recurso auxiliar durante a inspeção dos pontos de demarcação, quanto o conhecimento prático da sensibilidade de controle oferecido pelo mouse, e de como deveria aplicar o movimento "fino" até o local definitivo de demarcação, identificando cada ponto requerido com um único clique no botão esquerdo do mouse.

Essa condição permitiu ao operador a liberdade de observação, fazendo com que pudesse, calma e criteriosamente, ponderar acerca da qualidade dos reparos de interesse dispostos pela imagem tomográfica no local de inspeção indicado, sem ter de se preocupar com treinamentos prévios considerando o software utilizado.

A figura 4.43b (com ampliação padrão daquela utilizada pelos operadores durante os testes - zoom 0.23), apresenta referenciais visuais de alguns dos conceitos (comentados adiante) e interpretações associados à qualidade de inspeção e identificação tomográficas - dentes anteriores.

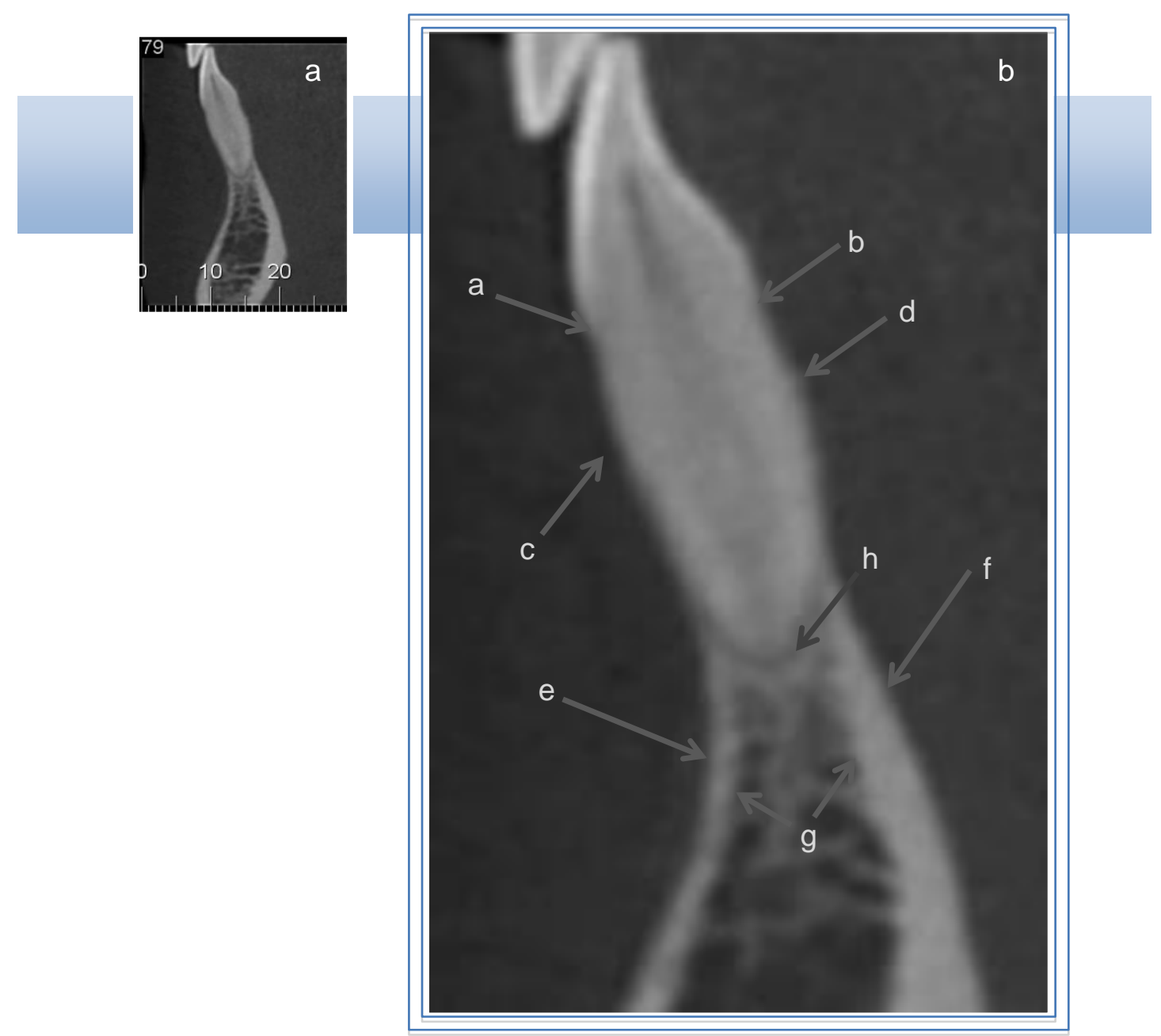

Figura 4.43 - a) dente 41 - visualização referencial ; b) visualização conforme ampliação (zoom) padrão de 0.23 . Setas identificadas indicam alguns dos locais associados à inspeção e identificação tomográficas 
Onde:

a - Indicação visual da junção amelo-cementária vestibular;

b - Indicação visual da junção amelo-cementária lingual;

c - Indicação visual de ausência de osso alveolar circundante.

Note-se que há um contínuo de imagem (faixa) hipodensa (escura) imediatamente lateral e vestibular ao padrão longitudinal homogêneo de densidade subjacente (espectro gradual de cinzas). Embora não possa ser confirmada idealmente uma linha de delimitação entre os tecidos, parece ser evidente a presença de uma dada continuidade qualitativa, tanto de densidade, quanto de regularidade de contorno neste local, o que poderia indicar tanto a densidade própria do cemento (e ausência de osso local), quanto uma derivada de condensação entre tecidos a partir de um resultado de atenuação ponderado entre: fina camada ou resquício de osso alveolar, ligamento periodontal e cemento.

O efeito de volume parcial (Loubele et al., 2006; Scarfe; Farman, 2008; Romans, 2011; Schulze et al., 2011; Sun et al., 2011; Timock et al., 2011; Tsutsumi et al., 2011) é capaz de gerar pixels de indefinição tomográfica, fazendo da identificação exata dos limites entre tecidos adjacentes uma tarefa tecnicamente improdutiva, haja vista a similaridade entre densidades, de tecidos bastante diminutos (com proximidade dimensional do tamanho do voxel/pixel) e, ainda, muito próximos entre si.

A referida faixa hipodensa (escura), de aspecto qualitativamente distinto entre os setores coronário (onde se apresenta mais intensa) e radicular, pode ser tanto o resultado da combinação de atenuação entre saliva e tecidos não mineralizados presentes no local, quanto algum efeito de beam hardening (interferência pela diferença de incidência dos feixes) associado à hiperdensidade do esmalte (logo acima) e/ou do próprio perfil cementário (subjacente);

d - Indicação de presença de resquício ósseo alveolar (tomográfico) circundante. 
Note-se a impossibilidade de diferenciação objetiva entre qualidades esperadas de uma maior quantidade de osso, devendo haver diferenciação entre osso cortical e trabecular. Condição compatível com maior grau dificuldade e incerteza de inspeção.

e - Indicação de osso alveolar circundante (cortical óssea vestibular). Note-se a possibilidade de diferenciação objetiva entre qualidades esperadas de uma maior quantidade de osso, havendo nítida diferenciação entre osso cortical e trabecular. Condição compatível com menor grau de dificuldade e de incerteza de inspeção e identificação.

f - Indicação de osso alveolar circundante (cortical óssea lingual). Note-se a possibilidade de diferenciação objetiva entre qualidades esperadas de uma maior quantidade de osso, havendo nítida diferenciação entre osso cortical e trabecular. Condição compatível com menor grau de dificuldade e de incerteza de inspeção e identificação.

g - Indicação dos limites das corticais ósseas internas (mediais), vestibular e lingual. Condição compatível com menor grau de dificuldade e de incerteza de inspeção e identificação.

h - indicação de espaço periodontal a partir da nítida hipodensidade adjacente às imagens de relativa maior densidade, tanto da cortical óssea interna, como do limite externo do cemento. 
A figura 4.44b (com ampliação padrão daquela utilizada pelos operadores durante os testes - zoom 0.23), apresenta referenciais visuais de alguns dos conceitos (comentados adiante) e interpretações associados à qualidade de inspeção e identificação tomográficas - dentes posteriores.

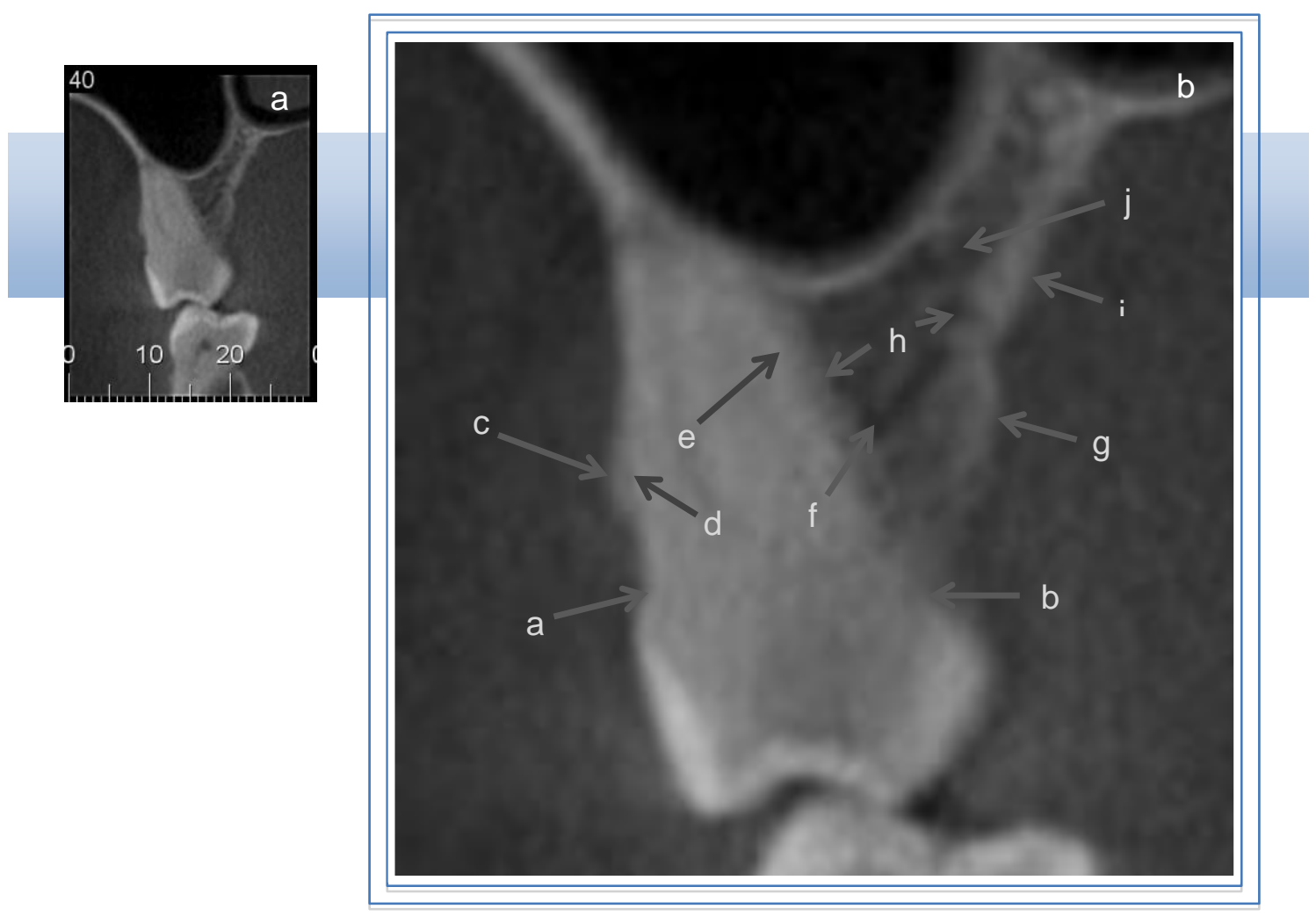

Figura 4.44 - a) dente 16 - visualização referencial ; b) visualização conforme ampliação (zoom) padrão de 0.23. Setas identificadas indicam alguns dos locais associados à inspeção e identificação tomográficas

Onde:

a - Indicação visual da junção amelo-cementária vestibular;

b - Indicação visual da junção amelo-cementária palatina;

C - imagem de densidade diversa daquela que delimita o cemento, indicando presença de osso. Embora apresente-se de modo diverso do exemplo apresentado pela figura 4.43 (p. 164), haja vista que alguma delimitação anatômica parece ser viável pela identificação de densidades distintas entre os tecidos, repete-se, neste caso, a impossibilidade de diferenciação objetiva (detalhe reduzido-reduzida 
resolução de baixo contraste) entre as qualidades ósseas esperadas. Osso cortical e trabecular parecem fazer parte de uma mesma densidade local. Esta condição pode ser resultante da presença de volumes teciduais realmente menores que a dimensão-limite do voxel/pixel, e/ou podem, ainda, estar muito próximos entre si (efeito de volume parcial). Condição também compatível com maior grau dificuldade e incerteza de inspeção.

d - imagem de regularidade e continuidade de contorno, vestibular, o qual parece delimitar densidade diferencial entre os tecidos locais - cemento e osso alveolar.

e - imagem de regularidade e continuidade de contorno, palatino, o qual parece delimitar densidade diferencial entre os tecidos locais - cemento.

f - indicação de espaço periodontal a partir da nítida hipodensidade adjacente às imagens de relativa maior densidade tanto da cortical óssea interna, como do limite externo do cemento.

g - imagem de regularidade e continuidade de contorno palatino (típico) radicular, por meio da densidade do cemento (forma de superfície radicular). Notese que, neste corte em particular, houve como que um "espectro" de projeção do contorno da raiz palatina do dente 16 , fazendo com que o contraste tenha sido, em parte, prejudicado, mas por condição de inclusão anatômica local.

h - imagem de regularidade e continuidade de contornos, vestibulares e palatinos, correspondentes às densidades da corticais ósseas palatinas, externa e interna respectivamente.

i - Indicação de osso alveolar circundante. Note-se a possibilidade de diferenciação objetiva entre qualidades esperadas de uma maior quantidade de osso, havendo nítida diferenciação entre osso cortical e trabecular. Condição compatível com menor grau de dificuldade e de incerteza de inspeção e identificação. 
j - Densidade intermediária, indicando típica qualidade visual tomográfica do osso alveolar da região posterior da maxila - trabecular.

Os operadores só utilizaram a direção vertical de inspeção, eventual e preliminarmente à demarcação final (identificação tomográfica) dos pontos ao longo das três linhas verticais de avaliação, quando houve a necessidade (circunstancial) de se avaliar a qualidade da regularidade longitudinal dos contornos tomográficos dos tecidos sob avaliação, como que se fosse este um artifício intuitivo e auxiliar ao acerto de localização dos pontos de interesse horizontais, os quais delimitam as distâncias ou espessuras ósseas analisadas.

Esta pode ser reconhecida como uma das vantagens de terem sido selecionados cortes trans-axiais diante da dificuldade de identificação dos limites entre os tecidos avaliados, já que o operador pode ter, na referida regularidade de continuidade longitudinal (direção vertical) e caso julgasse necessário a fim de tentar vencer a dificuldade local, noção eventualmente mais correta da melhor estimativa posicional horizontal naquelas situações em que a inspeção direta acabava por não oferecer qualidade favorável em termos de informação anatômica do local de interesse.

\subsubsection{3 medição}

$\mathrm{Na}$ camada (layer) denominada cotas, e então com ampliação de tela definida (zoom) em 1.30, foram medidas as distâncias entre os pontos demarcados pelos operadores participantes.

Ampliação de 0.70 foi utilizada para a verificação preliminar da qualidade de reconhecimento automático por meio da função AutoSnap ${ }^{\circledR}$.

A função dimension aligned (em home - annotation - aligned) (fig. 4.45) foi selecionada ao propósito de medição com liberdade de controle (não ortogonal), já que esta função é capaz de, livremente, determinar a medida linear entre dois pontos demarcados. A função de medida linear do AutoCAD ${ }^{\circledR}$ determina medidas com igual precisão e automação, só que considerando os referenciais ortogonais do 
software, o que prejudicaria a intenção de definição prévia do MGA. Desse modo, a função dimension aligned foi eleita à tarefa de medição. (comando: [CO]: dimaligned $\downarrow$ ou home - annotation - aligned)
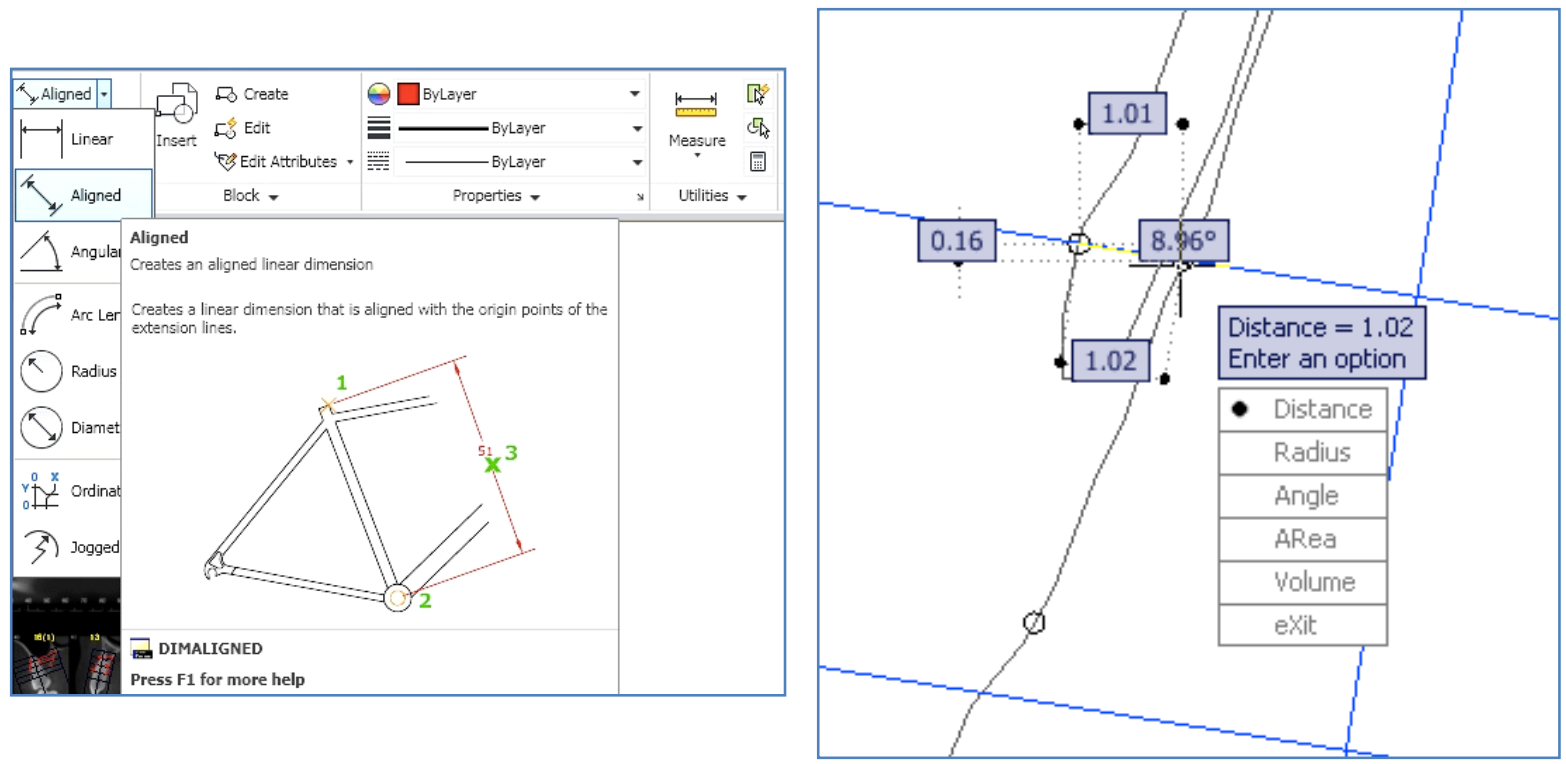

Figura 4.45 - a) exemplo função de medida dimension aligned ; b) visualização de opções de apresentação na tela de trabalho (model space)

Todas as medidas foram automaticamente (precisão computacional centesimal) registradas pelo operador principal (Op.0), e todos os referenciais geométricos, necessários à efetivação da precisão de ação do recurso AutoSnap ${ }^{\circledR}$, foram verificados, conforme descrição anterior, em sua qualidade antes de serem final e definitivamente registradas as respectivas medidas lineares das espessuras ósseas alveolares. (figura 4.46)

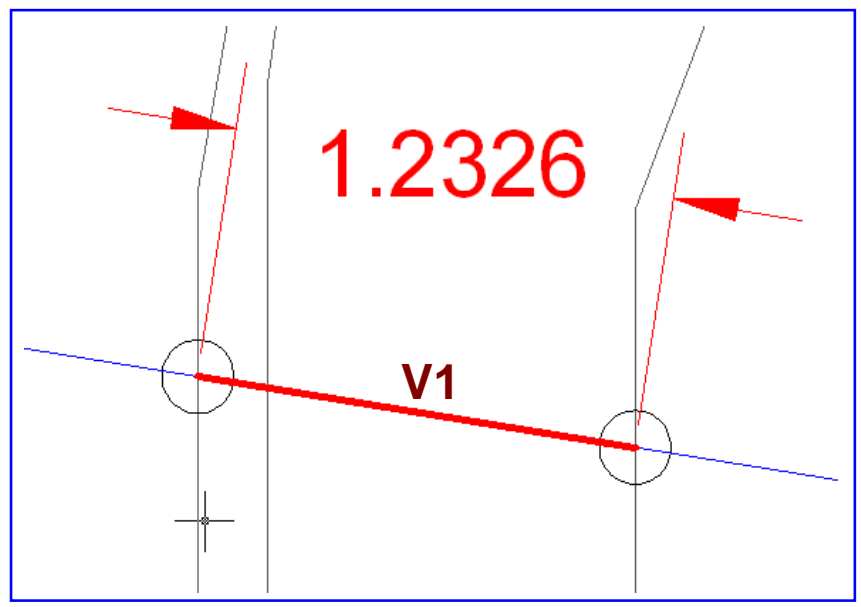

Figura 4.46 - representação esquemática (ampliada) da espessura óssea vestibular cervical (V1) e a medida linear (cota), em mm, associada 
Após o registro das medidas "alinhadas", as mesmas foram salvas em pastasarquivo (Excel-Microsoft ${ }^{\circledR}$ ) próprias e identificadas com o nome dos respectivos operadores, e, então, o arquivo $d w g$. foi finalizado, com isso salvando também o registro gráfico das medidas nas respectivas camadas de trabalho (cotas) (figuras 4.47 e 4.48 ) do programa AutoCAD ${ }^{\circledR}$.

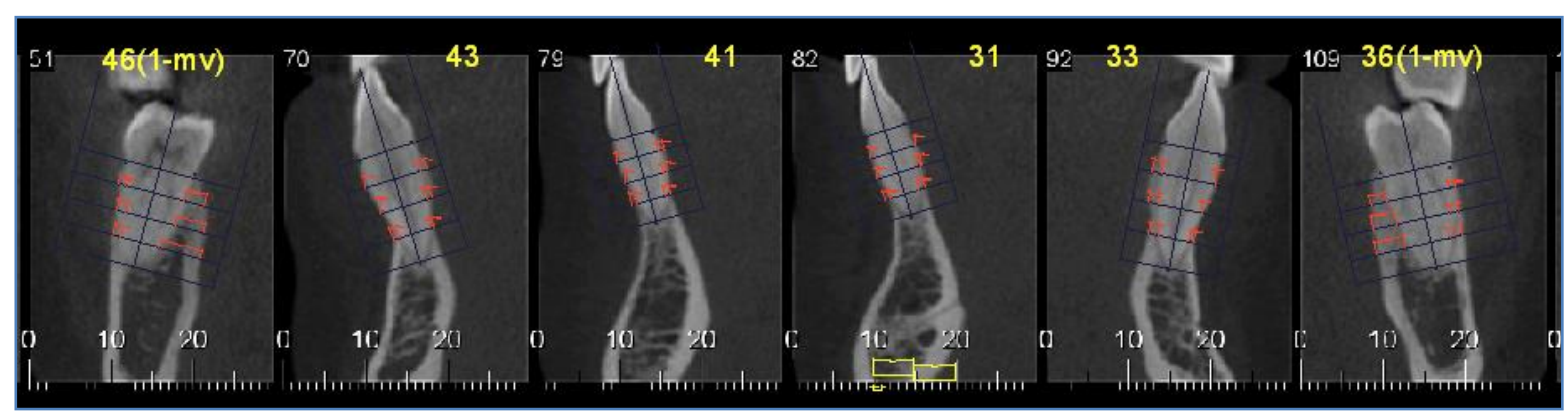

Figura 4.47 - a) visualização, conforme ampliação referencial, da sequência de MGAs aplicados individualmente às unidades de observação/medição (dentes) selecionadas para os testes no arco mandibular, com as respectivas cotas de medição, de um dos operadores

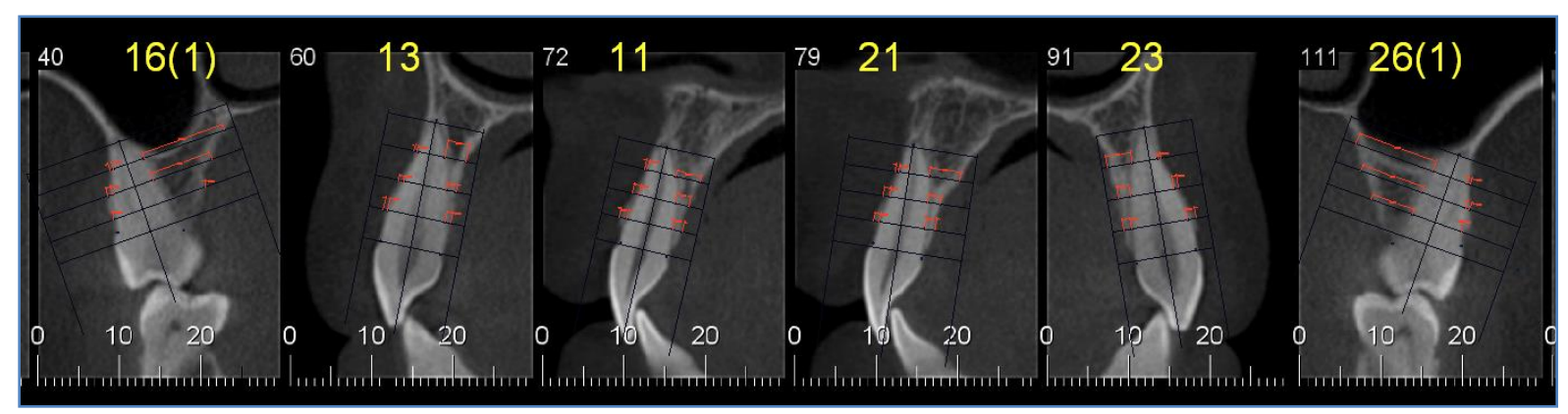

Figura 4.48 - a) visualização, conforme ampliação referencial, da sequência de MGAs aplicados individualmente às unidades de observação/medição (dentes) selecionadas para os testes no arco maxilar, com as respetivas cotas de medição, de um dos operadores 


\section{RESULTADOS}

"Se considerarmos uma lei particular qualquer, de antemão podemos estar certos de que ela só pode ser aproximativa. De fato, é deduzida de verificações experimentais, e essas verificações só eram e só poderiam ser aproximadas. Devemos sempre esperar que medidas mais precisas nos obriguem a acrescentar novos termos a nossas fórmulas"

HENRI POINCARÉ

O Valor da Ciência - VI. A ciência e a realidade. 5: Contingência e Determinismo 2000.

\subsection{MEDIÇÕES}

As tabelas, de 5.1 a 5.6 , apresentam os resultados de medidas obtidos pelo Operador Principal (Op.0) - nos três (03) tempos (I, II e III) de medição, para a maxila e mandíbula, respectivamente.

Tabela 5.1 - Medidas absolutas, sem aproximações e em milímetros, correspondentes à participação do Operador Principal (Op.0), em tempo I. Também relacionados estão: unidades de observação (dentes) e os três (03) níveis de avaliação (variáveis) das espessuras ósseas alveolares, vestibulares e palatinas, maxilares

\begin{tabular}{|c|c|c|c|c|c|c|}
\hline Dente/Variáveis & V1 & V2 & V3 & P1 & P2 & P3 \\
\hline 11 & 0,922 & 0,852 & 0,541 & 1,222 & 1,522 & 3,034 \\
\hline 13 & 0,436 & 0,407 & 0,358 & 0,001 & 1,163 & 2,588 \\
\hline 16 & 0 & 0,545 & 0,342 & 0 & 7,005 & 10,726 \\
\hline 21 & 0,811 & 0,642 & 0,386 & 1,097 & 1,601 & 3,886 \\
\hline 23 & 1,039 & 0,934 & 0,52 & 1,113 & 1,397 & 3,104 \\
\hline 26 & 0 & 0,954 & 0,844 & 5,253 & 7,724 & 10,617 \\
\hline
\end{tabular}

Tabela 5.2 - Medidas absolutas, sem aproximações e em milímetros, correspondentes à participação do Operador Principal (Op.0), em tempo II. Também relacionados estão: unidades de observação (dentes) e os três (03) níveis de avaliação (variáveis) das espessuras ósseas alveolares, vestibulares e palatinas, maxilares

\begin{tabular}{|c|c|c|c|c|c|c|}
\hline Dente/Variáveis & V1 & V2 & V3 & P1 & P2 & P3 \\
\hline 11 & 0,989 & 0,913 & 0,378 & 1,207 & 1,41 & 3,119 \\
\hline 13 & 0,563 & 0,513 & 0,291 & 0,651 & 1,163 & 2,46 \\
\hline 16 & 0 & 0,532 & 0,32 & 0 & 6,995 & 10,314 \\
\hline 21 & 0,838 & 0,749 & 0,493 & 1,069 & 1,552 & 3,65 \\
\hline 23 & 0,838 & 0,593 & 0,317 & 0,853 & 1,416 & 2,9 \\
\hline 26 & 0 & 0,56 & 0,335 & 5,393 & 7,797 & 10,474 \\
\hline
\end{tabular}

Tabela 5.3 - Medidas absolutas, sem aproximações e em milímetros, correspondentes à participação do Operador Principal (Op.0), em tempo III. Também relacionados estão: unidades de observação (dentes) e os três (03) níveis de avaliação (variáveis) das espessuras ósseas alveolares, vestibulares e palatinas, maxilares

\begin{tabular}{|c|c|c|c|c|c|c|}
\hline Dente/Variáveis & V1 & V2 & V3 & P1 & P2 & P3 \\
\hline 11 & 0,938 & 0,758 & 0,405 & 1,135 & 1,436 & 3,02 \\
\hline 13 & 0 & 0 & 0 & 0,728 & 1,385 & 2,559 \\
\hline 16 & 0 & 0,604 & 0,306 & 0 & 7,459 & 10,624 \\
\hline 21 & 0,97 & 0,692 & 0,392 & 1,08 & 1,498 & 3,778 \\
\hline 23 & 0,846 & 0,541 & 0,455 & 1,151 & 1,483 & 3,199 \\
\hline 26 & 0 & 0,491 & 0,209 & 5,417 & 7,575 & 10,379 \\
\hline
\end{tabular}


Tabela 5.4 - Medidas absolutas, sem aproximações e em milímetros, correspondentes à participação do Operador Principal (Op.0), em tempo I. Também relacionados estão: unidades de observação (dentes) e os três (03) níveis de avaliação (variáveis) das espessuras ósseas alveolares, vestibulares e linguais, mandibulares

\begin{tabular}{|c|c|c|c|c|c|c|}
\hline Dente/Variáveis & V1 & V2 & V3 & L1 & L2 & L3 \\
\hline 31 & 0 & 0 & 0,261 & 0 & 0,283 & 0,349 \\
\hline 33 & 0 & 0 & 0,552 & 1,163 & 1,143 & 1,163 \\
\hline 36 & 0,256 & 0,504 & 1,415 & 2 & 3,153 & 3,56 \\
\hline 41 & 0 & 0 & 0,291 & 0,367 & 0,267 & 0,394 \\
\hline 43 & 0 & 0 & 0,749 & 0,687 & 0,439 & 0,421 \\
\hline 46 & 0,576 & 0,515 & 0,719 & 2,442 & 3,556 & 4,923 \\
\hline
\end{tabular}

Tabela 5.5 - Medidas absolutas, sem aproximações e em milímetros, correspondentes à participação do Operador Principal (Op.0), em tempo II. Também relacionados estão: unidades de observação (dentes) e os três (03) níveis de avaliação (variáveis) das espessuras ósseas alveolares, vestibulares e linguais, mandibulares

\begin{tabular}{|c|c|c|c|c|c|c|}
\hline Dente/Variáveis & V1 & V2 & V3 & L1 & L2 & L3 \\
\hline 31 & 0 & 0 & 0,359 & 0,261 & 0,378 & 0,374 \\
\hline 33 & 0 & 0 & 0,494 & 1,143 & 1,309 & 1,269 \\
\hline 36 & 0,381 & 0,659 & 1,378 & 1,947 & 3,067 & 3,667 \\
\hline 41 & 0 & 0 & 0,325 & 0,481 & 0,299 & 0,373 \\
\hline 43 & 0 & 0 & 0,826 & 0,602 & 0,498 & 0,591 \\
\hline 46 & 0,76 & 0,568 & 0,875 & 2,614 & 3,642 & 5,218 \\
\hline
\end{tabular}

Tabela 5.6 - Medidas absolutas, sem aproximações e em milímetros, correspondentes à participação do Operador Principal (Op.0), em tempo III. Também relacionados estão: unidades de observação (dentes) e os três (03) níveis de avaliação (variáveis) das espessuras ósseas alveolares, vestibulares e linguais, mandibulares

\begin{tabular}{|c|c|c|c|c|c|c|}
\hline Dente/Variáveis & V1 & V2 & V3 & L1 & L2 & L3 \\
\hline 31 & 0,229 & 0,331 & 0,375 & 0,312 & 0,394 & 0,438 \\
\hline 33 & 0 & 0 & 0,564 & 1,148 & 1,185 & 1,162 \\
\hline 36 & 0,351 & 0,668 & 1,422 & 1,935 & 3,078 & 3,754 \\
\hline 41 & 0,194 & 0,186 & 0,386 & 0,304 & 0,451 & 0,539 \\
\hline 43 & 0 & 0 & 0,586 & 0,565 & 0,396 & 0,465 \\
\hline 46 & 0,454 & 0,33 & 0,796 & 2,564 & 3,731 & 5,116 \\
\hline
\end{tabular}

As tabelas, de 5.7 a 5.18 , apresentam os resultados de medida obtidos pelos demais participantes/operadores (Op.1, Op.2, Op.3, Op.4, Op.5 e Op.6), em um único tempo, para a maxila e mandíbula, respectivamente.

Tabela 5.7 - Medidas absolutas, sem aproximações e em milímetros, correspondentes à participação do Operador 1 (Op.1). Também relacionados estão: unidades de observação (dentes) e os três (03) níveis de avaliação (variáveis) das espessuras ósseas alveolares, vestibulares e palatinas, maxilares

\begin{tabular}{|c|c|c|c|c|c|c|}
\hline Dente/Variáveis & V1 & V2 & V3 & P1 & P2 & P3 \\
\hline 11 & 0,815 & 0,6 & 0,277 & 1,248 & 1,533 & 2,942 \\
\hline 13 & 0,318 & 0,398 & 0,417 & 0,513 & 1,115 & 2,56 \\
\hline 16 & 0 & 0,433 & 0,27 & 0 & 7,03 & 10,444 \\
\hline 21 & 0,755 & 0,589 & 0,308 & 1,021 & 1,53 & 3,999 \\
\hline 23 & 0,755 & 0,423 & 0,315 & 1,063 & 1,293 & 2,877 \\
\hline 26 & 0 & 0,472 & 0 & 5,144 & 7,85 & 10,234 \\
\hline
\end{tabular}


Tabela 5.8 - Medidas absolutas, sem aproximações e em milímetros, correspondentes à participação do Operador 1 (Op.1). Também relacionados estão: unidades de observação (dentes) e os três (03) níveis de avaliação (variáveis) das espessuras ósseas alveolares, vestibulares e linguais, mandibulares

\begin{tabular}{|c|c|c|c|c|c|c|}
\hline Dente/Variáveis & V1 & V2 & V3 & L1 & L2 & L3 \\
\hline $\mathbf{3 1}$ & 0 & 0 & 0 & 0 & 0,302 & 0,45 \\
$\mathbf{3 3}$ & 0 & 0 & 0,318 & 0,996 & 1,151 & 0,911 \\
$\mathbf{3 6}$ & 0,315 & 0,686 & 1,463 & 1,77 & 3,089 & 3,582 \\
$\mathbf{4 1}$ & 0 & 0 & 0,222 & 0 & 0 & 0,283 \\
$\mathbf{4 3}$ & 0 & 0 & 0,811 & 0,354 & 0,3 & 0,463 \\
\hline $\mathbf{4 6}$ & 0,595 & 0,49 & 0,764 & 2,531 & 3,585 & 4,62 \\
\hline
\end{tabular}

Tabela 5.9 - Medidas absolutas, sem aproximações e em milímetros, correspondentes à participação do Operador 2 (Op.2). Também relacionados estão: unidades de observação (dentes) e os três (03) níveis de avaliação (variáveis) das espessuras ósseas alveolares, vestibulares e palatinas, maxilares

\begin{tabular}{|c|c|c|c|c|c|c|}
\hline Dente/Variáveis & V1 & V2 & V3 & P1 & P2 & P3 \\
\hline 11 & 1,07 & 0,896 & 0,354 & 1,222 & 1,522 & 3,045 \\
\hline 13 & 0,474 & 0,707 & 0,514 & 0,765 & 1,386 & 2,617 \\
\hline 16 & 0 & 0,765 & 0,655 & 0 & 7,847 & 10,754 \\
\hline 21 & 0,958 & 0,633 & 0,405 & 1,195 & 1,579 & 3,874 \\
\hline 23 & 1,039 & 0,675 & 0,374 & 0,984 & 1,439 & 3,089 \\
\hline 26 & 0 & 0,985 & 0,991 & 5,553 & 8,036 & 10,389 \\
\hline
\end{tabular}

Tabela 5.10 - Medidas absolutas, sem aproximações e em milímetros, correspondentes à participação do Operador 2 (Op.2). Também relacionados estão: unidades de observação (dentes) e os três (03) níveis de avaliação (variáveis) das espessuras ósseas alveolares, vestibulares e linguais, mandibulares

\begin{tabular}{|c|c|c|c|c|c|c|}
\hline Dente/Variáveis & V1 & V2 & V3 & L1 & L2 & L3 \\
\hline 31 & 0 & 0 & 0,468 & 0 & 0 & 0,501 \\
\hline 33 & 0 & 0 & 0,436 & 1,105 & 1,134 & 1,027 \\
\hline 36 & 0,037 & 0,986 & 1,432 & 1,882 & 3,023 & 3,543 \\
\hline 41 & 0 & 0 & 0 & 0,815 & 0,489 & 0,592 \\
\hline 43 & 0 & 0 & 0,516 & 1,029 & 0,575 & 0,612 \\
\hline 46 & 0,863 & 0,901 & 1,031 & 2,35 & 3,454 & 4,594 \\
\hline
\end{tabular}

Tabela 5.11 - Medidas absolutas, sem aproximações e em milímetros, correspondentes à participação do Operador 3 (Op.3). Também relacionados estão: unidades de observação (dentes) e os três (03) níveis de avaliação (variáveis) das espessuras ósseas alveolares, vestibulares e palatinas, maxilares

\begin{tabular}{|c|c|c|c|c|c|c|}
\hline Dente/Variáveis & V1 & V2 & V3 & P1 & P2 & P3 \\
\hline 11 & 0,959 & 0,685 & 0,418 & 1,233 & 1,559 & 2,96 \\
\hline 13 & 0,601 & 0,669 & 0 & 0,785 & 1,28 & 2,54 \\
\hline 16 & 0 & 0,781 & 0,359 & 0 & 7,236 & 10,392 \\
\hline 21 & 0,699 & 0,684 & 0,371 & 1,06 & 1,593 & 4,025 \\
\hline 23 & 0,829 & 0,593 & 0,462 & 0,935 & 1,281 & 2,884 \\
\hline 26 & 0 & 1,123 & 0,841 & 5,203 & 7,395 & 10,61 \\
\hline
\end{tabular}

Tabela 5.12 - Medidas absolutas, sem aproximações e em milímetros, correspondentes à participação do Operador 3 (Op.3). Também relacionados estão: unidades de observação (dentes) e os três (03) níveis de avaliação (variáveis) das espessuras ósseas alveolares, vestibulares e linguais, mandibulares

\begin{tabular}{|c|c|c|c|c|c|c|}
\hline Dente/Variáveis & V1 & V2 & V3 & L1 & L2 & L3 \\
\hline 31 & 0 & 0 & 0,64 & 0 & 0,316 & 0,762 \\
\hline 33 & 0 & 0 & 0,552 & 1,023 & 1,051 & 0,968 \\
\hline 36 & 0,863 & 1,077 & 1,452 & 1,875 & 2,971 & 3,63 \\
\hline 41 & 0 & 0 & 0,59 & 0,772 & 0,521 & 0,685 \\
\hline 43 & 0 & 0 & 0,779 & 0,955 & 0,669 & 0,426 \\
\hline 46 & 0,84 & 1,057 & 0,958 & 2,4 & 3,572 & 5,11 \\
\hline
\end{tabular}


Tabela 5.13 - Medidas absolutas, sem aproximações e em milímetros, correspondentes à participação do Operador 4 (Op.4). Também relacionados estão: unidades de observação (dentes) e os três (03) níveis de avaliação (variáveis) das espessuras ósseas alveolares, vestibulares e palatinas, maxilares

\begin{tabular}{|c|c|c|c|c|c|c|}
\hline Dente/Variáveis & V1 & V2 & V3 & P1 & P2 & P3 \\
\hline $\mathbf{1 1}$ & 1,078 & 0,959 & 0,455 & 1,211 & 1,5 & 2,093 \\
$\mathbf{1 3}$ & 0,31 & 0,504 & 0,31 & 0,707 & 1,211 & 107 \\
$\mathbf{1 6}$ & 0 & 0,515 & 0,389 & 0 & 7,318 & 10,71 \\
$\mathbf{2 1}$ & 0,796 & 0,559 & 0,413 & 0,958 & 1,544 & 3,845 \\
$\mathbf{2 3}$ & 0,927 & 0,561 & 0,357 & 1,048 & 1,317 & 3,015 \\
$\mathbf{2 6}$ & 0 & 0,625 & 0,498 & 5,536 & 7,634 & 10,367 \\
\hline
\end{tabular}

Tabela 5.14 - Medidas absolutas, sem aproximações e em milímetros, correspondentes à participação do Operador 4 (Op.4). Também relacionados estão: unidades de observação (dentes) e os três (03) níveis de avaliação (variáveis) das espessuras ósseas alveolares, vestibulares e linguais, mandibulares

\begin{tabular}{|c|c|c|c|c|c|c|}
\hline Dente/Variáveis & V1 & V2 & V3 & L1 & L3 \\
\hline $\mathbf{3 1}$ & 0 & 0 & 0 & 0 & 0,345 & 0,421 \\
\hline $\mathbf{3 3}$ & 0 & 0 & 0,455 & 0,921 & 1,386 & 1,163 \\
$\mathbf{3 6}$ & 0,563 & 0,852 & 1,415 & 1,919 & 3,083 & 3,646 \\
$\mathbf{4 1}$ & 0 & 0 & 0,394 & 0,563 & 0,468 & 0,386 \\
$\mathbf{4 3}$ & 0 & 0 & 0,595 & 0,61 & 0,483 & 0,498 \\
\hline $\mathbf{4 6}$ & 0,442 & 0,407 & 1,019 & 2,566 & 3,547 & 4,747 \\
\hline
\end{tabular}

Tabela 5.15 - Medidas absolutas, sem aproximações e em milímetros, correspondentes à participação do Operador 5 (Op.5). Também relacionados estão: unidades de observação (dentes) e os três (03) níveis de avaliação (variáveis) das espessuras ósseas alveolares, vestibulares e palatinas, maxilares

\begin{tabular}{|c|c|c|c|c|c|c|}
\hline Dente/Variáveis & V1 & V2 & V3 & P1 & P2 & P3 \\
\hline 11 & 0,933 & 0,826 & 0,322 & 1,33 & 1,233 & 2,986 \\
\hline 13 & 0,31 & 0,397 & 0,195 & 0,707 & 1,018 & 2,375 \\
\hline 16 & 0,108 & 0,359 & 0,329 & 0 & 7,192 & 10,586 \\
\hline 21 & 0,738 & 0,439 & 0,11 & 0,982 & 1,552 & 3,624 \\
\hline 23 & 0,984 & 0,463 & 0,203 & 1,016 & 1,34 & 2,86 \\
\hline 26 & 0 & 0,671 & 0,329 & 4,957 & 7,209 & 10,211 \\
\hline
\end{tabular}

Tabela 5.16 - Medidas absolutas, sem aproximações e em milímetros, correspondentes à participação do Operador 5 (Op.5). Também relacionados estão: unidades de observação (dentes) e os três (03) níveis de avaliação (variáveis) das espessuras ósseas alveolares, vestibulares e linguais, mandibulares

\begin{tabular}{|c|c|c|c|c|c|c|}
\hline Dente/Variáveis & V1 & V2 & V3 & L1 & L2 & L3 \\
\hline 31 & 0 & 0 & 0,392 & 0,374 & 0,454 & 0,378 \\
\hline 33 & 0 & 0 & 0,339 & 1,163 & 1,25 & 1,211 \\
\hline 36 & 0,611 & 1,029 & 1,533 & 2,037 & 3,083 & 3,608 \\
\hline 41 & 0,224 & 0,299 & 0,394 & 0,42 & 0,133 & 0,516 \\
\hline 43 & 0 & 0 & 0,548 & 0,766 & 0,719 & 0,374 \\
\hline 46 & 0,732 & 0,407 & 0,958 & 2,267 & 3,633 & 4,665 \\
\hline
\end{tabular}

Tabela 5.17 - Medidas absolutas, sem aproximações e em milímetros, correspondentes à participação do Operador 6 (Op.6). Também relacionados estão: unidades de observação (dentes) e os três (03) níveis de avaliação (variáveis) das espessuras ósseas alveolares, vestibulares e palatinas, maxilares

\begin{tabular}{|c|c|c|c|c|c|c|}
\hline Dente/Variáveis & V1 & V2 & V3 & P1 & P2 & P3 \\
\hline 11 & 1,045 & 0,825 & 0,31 & 1,306 & 1,714 & 3,051 \\
\hline 13 & 0,517 & 0,728 & 0,398 & 0,716 & 1,233 & 2,689 \\
\hline 16 & 0 & 0,604 & 0,358 & 0 & 7,648 & 10,511 \\
\hline 21 & 0,706 & 0,787 & 0,405 & 1,211 & 1,566 & 3,878 \\
\hline 23 & 1,035 & 0,552 & 0,284 & 0,974 & 1,564 & 3,09 \\
\hline 26 & 0 & 0,511 & 0,455 & 5,34 & 7,954 & 10,016 \\
\hline
\end{tabular}


Tabela 5.18 - Medidas absolutas, sem aproximações e em milímetros, correspondentes à participação do Operador 6 (Op.6). Também relacionados estão: unidades de observação (dentes) e os três (03) níveis de avaliação (variáveis) das espessuras ósseas alveolares, vestibulares e linguais, mandibulares

\begin{tabular}{|c|c|c|c|c|c|c|}
\hline Dente/Variáveis & V1 & V2 & V3 & L2 & L3 \\
\hline 31 & 0 & 0 & 0,361 & 0,183 & 0,171 & 0,4 \\
\hline 33 & 0 & 0 & 0,551 & 1,103 & 1,174 & 1,092 \\
\hline $\mathbf{3 6}$ & 0,188 & 0,565 & 1,162 & 1,786 & 2,992 & 3,487 \\
$\mathbf{4 1}$ & 0 & 0,512 & 0,451 & 0,493 & 0,378 & 0,435 \\
$\mathbf{4 3}$ & 0 & 0 & 0,516 & 0,889 & 0,529 & 0,373 \\
\hline $\mathbf{4 6}$ & 0,624 & 0,829 & 0,856 & 2,441 & 3,544 & 4,925 \\
\hline
\end{tabular}

\subsection{ANÁLISE ESTATÍSTICA}

Para avaliação do erro associado ao método que se está propondo, foi utilizado o Modelo de Componentes de Variância, e foram consideradas como fontes de variação (fatores) as medidas efetuadas por um mesmo operador ou por diferentes operadores, a face (vestibular ou lingual/palatina) considerada, os locais (três níveis de espessura óssea alveolar) em cada uma das faces, e os diferentes dentes incluídos no estudo.

Esta análise foi realizada de forma separada para mandíbula e maxila. Os dados foram analisados em planilha $\operatorname{Exce}^{\circledR}{ }^{\circledR}$ (Microsoft $^{\circledR}$ ) e valores de $\mathrm{p}<0,05$ indicaram significância estatística.

Em Estatística, um Modelo de Efeitos Aleatórios, também denominado de Modelo de Componentes de Variância, é um tipo de Modelo Hierárquico Linear (MHL/HLM), o qual é uma forma de análise multinível.

A utilização dessa condição de análise pressupõe que o conjunto de dados sob análise consiste de uma dada hierarquia de diferentes populações, cujas diferenças estão relacionadas diretamente a esta hierarquia.

O método estatístico considerado, sendo um dos modos mais atuais para análise de variâncias com Coeficientes de Correlação Intraclasse (CCl) de vários grupos associados, determina uma estimativa de variabilidade da medida, considerando a repetição das medições dos operadores.

Desta forma, esta medida geral de confiabilidade entre repetições de um mesmo operador, com padrão intervalar de repetição, e de diversos (06) operadores considerando uma variável contínua e aqui representada pela distância linear entre 
pontos tomográficos (escala do milímetro), foi estimada de modo geral considerando o referido método particular de medição.

\subsubsection{Repetitividade de Medição, Repetibilidade de medidas e Condição de Repetitividade}

Para avaliação da repetitividade de medida das distâncias nos diferentes dentes e locais associados ao dente, foram realizadas três (03) medições pelo mesmo operador (Op.0). Estas avaliações foram feitas em seis (06) dentes da mandíbula e 6 dentes da maxila. A seguir, são apresentados os resultados obtidos da análise estatística.

\subsubsection{Mandíbula}

Na tabela 5.19 são apresentados os resultados de médias e desvios-padrões das três (03) repetições; para os três (03) níveis de espessura óssea alveolar, vestibulares e linguais, e para cada um dos dentes mandibulares considerados. São também apresentadas as médias relativas às medidas obtidas em cada face (vestibular e lingual) e em cada dente. 
Tabela 5.19 - Médias e desvios-padrões das três (03) repetições para os três (03) níveis de espessura óssea alveolar, vestibulares e palatinas/linguais, e para os seis (06) dentes mandibulares

\begin{tabular}{|c|c|c|c|c|c|c|c|c|}
\hline Dente & Face & Local & $\begin{array}{l}\text { Média das } 3 \\
\text { medidas }\end{array}$ & $\begin{array}{l}\text { DP das } \\
\text { medidas }\end{array}$ & 3 Média & $\mathrm{V} / \mathrm{L}$ & $\begin{array}{l}\text { Média } \\
\text { dente }\end{array}$ & do \\
\hline \multirow[t]{6}{*}{31} & Vest & V1 & 0,076 & 0,132 & & & & \\
\hline & & V2 & 0,110 & 0,191 & & & & \\
\hline & & V3 & 0,332 & 0,062 & 0,173 & & & \\
\hline & Ling & L1 & 0,191 & 0,167 & & & & \\
\hline & & L2 & 0,352 & 0,060 & & & & \\
\hline & & L3 & 0,387 & 0,046 & 0,310 & & 0,241 & \\
\hline \multirow[t]{6}{*}{33} & Vest & V1 & 0,000 & 0,000 & & & & \\
\hline & & V2 & 0,000 & 0,000 & & & & \\
\hline & & V3 & 0,537 & 0,037 & 0,179 & & & \\
\hline & Ling & L1 & 1,151 & 0,010 & & & & \\
\hline & & L2 & 1,212 & 0,086 & & & & \\
\hline & & L3 & 1,198 & 0,061 & 1,187 & & 0,683 & \\
\hline \multirow[t]{6}{*}{36} & Vest & V1 & 0,329 & 0,065 & & & & \\
\hline & & V2 & 0,610 & 0,092 & & & & \\
\hline & & V3 & 1,405 & 0,024 & 0,782 & & & \\
\hline & Ling & L1 & 1,961 & 0,035 & & & & \\
\hline & & L2 & 3,099 & 0,047 & & & & \\
\hline & & L3 & 3,660 & 0,097 & 2,907 & & 1,844 & \\
\hline \multirow[t]{6}{*}{41} & Vest & V1 & 0,065 & 0,112 & & & & \\
\hline & & V2 & 0,062 & 0,107 & & & & \\
\hline & & V3 & 0,334 & 0,048 & 0,154 & & & \\
\hline & Ling & L1 & 0,384 & 0,090 & & & & \\
\hline & & L2 & 0,339 & 0,098 & & & & \\
\hline & & L3 & 0,435 & 0,090 & 0,386 & & 0,270 & \\
\hline \multirow[t]{6}{*}{43} & Vest & V1 & 0,000 & 0,000 & & & & \\
\hline & & V2 & 0,000 & 0,000 & & & & \\
\hline & & V3 & 0,720 & 0,123 & 0,240 & & & \\
\hline & Ling & L1 & 0,618 & 0,063 & & & & \\
\hline & & L2 & 0,444 & 0,051 & & & & \\
\hline & & L3 & 0,492 & 0,088 & 0,518 & & 0,379 & \\
\hline \multirow[t]{6}{*}{46} & Vest & V1 & 0,597 & 0,154 & & & & \\
\hline & & V2 & 0,471 & 0,125 & & & & \\
\hline & & V3 & 0,797 & 0,078 & 0,621 & & & \\
\hline & Ling & L1 & 2,540 & 0,088 & & & & \\
\hline & & L2 & 3,643 & 0,088 & & & & \\
\hline & & L3 & 5,086 & 0,150 & 3,756 & & 2,189 & \\
\hline
\end{tabular}

Inicialmente, testou-se a hipótese nula $(H 0)$ de médias iguais nos seis (06) dentes, versus a hipótese alternativa $(H 1)$ de pelo menos um (01) dente com média diferente dos demais. $O$ resultado do teste estatístico levou à não rejeição da hipótese nula $(p=0,430)$, indicando não haver diferença significativa entre os dentes, em relação a esta medida.

Também foi testada a hipótese nula $(H 0)$ de médias iguais nas duas faces (vestibular e lingual), versus a hipótese alternativa $(H 1)$ de médias diferentes. $\mathrm{O}$ resultado do teste estatístico levou à rejeição da hipótese nula $(p<0,001)$, indicando haver diferença significativa entre as faces, em relação a esta medida.

Para avaliação dos fatores que influenciam a medida realizada, foram consideradas as fontes de variação relativas ao dente (1, 3 e 6), à face do continente 
ósseo das medidas, vestibular e lingual ( $\mathrm{V}$ e L ), ao nível de avaliação da espessura óssea alveolar (1- Cervical, 2- Intermédia e 3- Apical) e ao operador (Op.0). Esta última fonte corresponde ao erro intrínseco do método.

De modo geral, a medida de erro das repetições do operador (Op.0) em uma dada face, em um particular local (nível de espessura) e de um dente específico, correspondeu a $0,091 \mathrm{~mm}$. Esta fonte de variação (variabilidade do operador) representou $0,53 \%$ (ER) da variabilidade total. Já $77,40 \%$ da variabilidade total foi devida às variações entre faces (vestibular e lingual), considerando cada dente em particular. O percentual de variação devido aos níveis de avaliação das espessuras, nas faces vestibular e lingual (V1,V2, V3 e L1, L2 e L3), correspondeu a 16,13\%. O percentual relativo ao fator dentes correspondeu a $5,94 \%$ da variação total.

Pode-se concluir que grande parte da variabilidade total $(99,47 \%-0.994 \mathrm{CCl})$ foi devida aos fatores: dente, face e nível de avaliação da espessura óssea, variações estas reconhecidas como biológicas ou inerentes às características anatômicas/tomográficas do indivíduo. Apenas $0,53 \%$ foi devida ao operador, caracterizando, assim, grau significativo de consistência em termos de Condição de Repetitividade associada ao POP do método proposto, e para aplicações na mandíbula.

\subsubsection{Maxila}

$\mathrm{Na}$ tabela 5.20 são apresentados os resultados de médias e desvios-padrões das três (03) repetições; para os três (03) níveis de espessura óssea alveolar, vestibulares e palatinas, e para cada um dos dentes maxilares considerados. São, também, apresentadas as médias relativas às medidas obtidas em cada face (vestibular e palatina) e em cada dente. 
Tabela 5.20 - Médias e desvios-padrões das três (03) repetições para os três (03) níveis de espessura óssea alveolar, vestibulares e palatinas/linguais, e para os seis (06) dentes maxilares

\begin{tabular}{|c|c|c|c|c|c|c|c|}
\hline Dente & Face & Local & $\begin{array}{l}\text { Média das } 3 \\
\text { medidas }\end{array}$ & $\begin{array}{l}\text { DP das } \\
\text { medidas }\end{array}$ & 3 Média & V/P & $\begin{array}{ll}\begin{array}{l}\text { Média } \\
\text { dente }\end{array} & \text { do } \\
\end{array}$ \\
\hline \multirow[t]{6}{*}{11} & Vest & V1 & 0,950 & 0,035 & & & \\
\hline & & V2 & 0,841 & 0,078 & & & \\
\hline & & V3 & 0,441 & 0,087 & 0,744 & & \\
\hline & Palat & $\mathrm{P} 1$ & 1,188 & 0,047 & & & \\
\hline & & P2 & 1,456 & 0,059 & & & \\
\hline & & P3 & 3,058 & 0,054 & 1,901 & & 1,322 \\
\hline \multirow[t]{6}{*}{13} & Vest & V1 & 0,333 & 0,295 & & & \\
\hline & & V2 & 0,307 & 0,271 & & & \\
\hline & & V3 & 0,216 & 0,190 & 0,285 & & \\
\hline & Palat & P1 & 0,460 & 0,399 & & & \\
\hline & & P2 & 1,237 & 0,128 & & & \\
\hline & & P3 & 2,536 & 0,067 & 1,411 & & 0,848 \\
\hline \multirow[t]{6}{*}{16} & Vest & V1 & 0,000 & 0,000 & & & \\
\hline & & V2 & 0,560 & 0,038 & & & \\
\hline & & V3 & 0,323 & 0,018 & 0,294 & & \\
\hline & Palat & $\mathrm{P} 1$ & 0,000 & 0,000 & & & \\
\hline & & P2 & 7,153 & 0,265 & & & \\
\hline & & P3 & 10,555 & 0,215 & 5,903 & & 3,098 \\
\hline \multirow[t]{6}{*}{21} & Vest & V1 & 0,873 & 0,085 & & & \\
\hline & & V2 & 0,694 & 0,054 & & & \\
\hline & & V3 & 0,424 & 0,060 & 0,664 & & \\
\hline & Palat & P1 & 1,082 & 0,014 & & & \\
\hline & & P2 & 1,550 & 0,052 & & & \\
\hline & & P3 & 3,771 & 0,118 & 2,135 & & 1,399 \\
\hline \multirow[t]{6}{*}{23} & Vest & V1 & 0,908 & 0,114 & & & \\
\hline & & V2 & 0,689 & 0,213 & & & \\
\hline & & V3 & 0,431 & 0,104 & 0,676 & & \\
\hline & Palat & $\mathrm{P} 1$ & 1,039 & 0,162 & & & \\
\hline & & P2 & 1,432 & 0,045 & & & \\
\hline & & P3 & 3,068 & 0,153 & 1,846 & & 1,261 \\
\hline \multirow[t]{6}{*}{26} & Vest & V1 & 0,000 & 0,000 & & & \\
\hline & & V2 & 0,668 & 0,250 & & & \\
\hline & & V3 & 0,463 & 0,336 & 0,377 & & \\
\hline & Palat & $\mathrm{P} 1$ & 5,354 & 0,089 & & & \\
\hline & & P2 & 7,699 & 0,113 & & & \\
\hline & & $\mathrm{P} 3$ & 10,490 & 0,120 & 7,848 & & 4,112 \\
\hline
\end{tabular}

Inicialmente, testou-se a hipótese nula $(H 0)$ de médias iguais nos seis (06) dentes, versus a hipótese alternativa $(H 1)$ de pelo menos um (01) dente com média diferente dos demais. O resultado do teste estatístico levou à não rejeição da hipótese nula $(p=0,814)$, indicando não haver diferença significativa entre os dentes em relação a esta medida.

Também foi testada a hipótese nula de médias iguais nas duas faces (vestibular e palatina), versus a hipótese alternativa de médias diferentes. 0 resultado do teste estatístico levou à rejeição da hipótese nula $(p<0,001)$, indicando haver diferença significativa entre as faces, em relação a esta medida. 
Para avaliação dos fatores que influenciam a medida realizada, foram consideradas as fontes de variação relativas ao dente (1, 3 e 6), à face do continente das medidas, vestibular e palatina ( $V$ e $P$ ), ao nível de avaliação das espessuras alveolares (1-Cervical, 2- Intermédia e 3- Apical) e ao operador (Op.0). Esta última fonte corresponde ao erro intrínseco do método.

De modo geral, a medida de erro das repetições do operador (Op.0) em uma dada face, em um particular local (nível de espessura) e de um dente específico, correspondeu a $0,156 \mathrm{~mm}$. Esta fonte de variação (variabilidade do operador) representou 0,24\% (ER) da variabilidade total.

Já $65,71 \%$ da variabilidade total é devida a variações entre lados (vestibular e palatino) considerando cada dente em particular. O percentual de variação devido aos níveis de avaliação das espessuras nas faces vestibular e palatina (V1,V2, V3 e P1, P2 e P3) correspondeu a 34,05\%. Em função da elevada variabilidade entre lados, bem como entre locais (níveis) de cada face, a estimativa do percentual de variação devida a fator dentes foi igual a zero.

Pode-se concluir que significativa parte da variabilidade total (99,76\%- 0.997 CCI) foi devida aos fatores: dente, face e nível de avaliação das espessuras, variações estas reconhecidas como biológicas ou inerentes às características anatômicas/tomográficas do indivíduo. Apenas $0,24 \%$ foi devida à participação do operador, caracterizando, assim, significativo grau de consistência em termos de Condição de Repetitividade associada ao POP do método proposto, e para aplicações na maxila.

\subsubsection{Precisão de Medição, Reprodutibilidade de Medidas e Condição de Precisão Intermediária}

Para esta avaliação foram consideradas as medidas obtidas por sete (07) operadores independentes, sendo que um deles (Op. 0) foi aquele que fez as medições para avaliação da repetitividade de medida.

Para este operador (Op. 0), então, foi considerada a sua primeira medição (série de medidas) como referência proporcional à comparação com às séries dos 
demais operadores (Op.1, Op.2, Op.3.....pp.6), haja vista a necessidade de que as mesmas chances de acerto fossem contempladas.

Cada operador avaliou uma única vez os seis (06) dentes da mandíbula e os seis (6) dentes da maxila.

A seguir são apresentados os resultados obtidos da análise estatística.

5.2.2.1 Mandíbula

Na Tabela 5.21 são apresentados os resultados de médias e desvios-padrões das sete (07) repetições para os três (03) níveis de espessura óssea alveolar, vestibulares e linguais, e para cada um dos dentes mandibulares considerados. São, também, apresentadas as médias relativas às medidas obtidas em cada face (vestibular e lingual) e em cada dente. 
Tabela 5.21 - Médias e desvios-padrões das sete (07) repetições para os três (03) níveis de espessura óssea alveolar, vestibulares e palatinas/linguais, e para os seis (06) dentes mandibulares

\begin{tabular}{|c|c|c|c|c|c|c|c|}
\hline Dente & Face & Local & $\begin{array}{l}\text { Média das } 7 \\
\text { medidas }\end{array}$ & $\begin{array}{l}\text { DP das } \\
\text { medidas }\end{array}$ & 7 Média V/L & $\begin{array}{l}\text { Média } \\
\text { dente }\end{array}$ & do \\
\hline \multirow[t]{6}{*}{31} & Vest & V1 & 0,000 & 0,000 & & & \\
\hline & & V2 & 0,000 & 0,000 & & & \\
\hline & & V3 & 0,303 & 0,237 & 0,101 & & \\
\hline & Lingual & L1 & 0,080 & 0,147 & & & \\
\hline & & L2 & 0,267 & 0,145 & & & \\
\hline & & L3 & 0,466 & 0,140 & 0,271 & 0,186 & \\
\hline \multirow[t]{6}{*}{33} & Vest & V1 & 0,000 & 0,000 & & & \\
\hline & & V2 & 0,000 & 0,000 & & & \\
\hline & & V3 & 0,458 & 0,100 & 0,153 & & \\
\hline & Lingual & L1 & 1,068 & 0,091 & & & \\
\hline & & L2 & 1,184 & 0,107 & & & \\
\hline & & L3 & 1,076 & 0,112 & 1,109 & 0,631 & \\
\hline \multirow[t]{6}{*}{36} & Vest & V1 & 0,405 & 0,286 & & & \\
\hline & & V2 & 0,814 & 0,231 & & & \\
\hline & & V3 & 1,410 & 0,117 & 0,876 & & \\
\hline & Lingual & L1 & 1,896 & 0,100 & & & \\
\hline & & L2 & 3,056 & 0,064 & & & \\
\hline & & L3 & 3,579 & 0,055 & 2,844 & 1,860 & \\
\hline \multirow[t]{6}{*}{41} & Vest & V1 & 0,032 & 0,085 & & & \\
\hline & & V2 & 0,116 & 0,207 & & & \\
\hline & & V3 & 0,335 & 0,188 & 0,161 & & \\
\hline & Lingual & L1 & 0,490 & 0,274 & & & \\
\hline & & L2 & 0,322 & 0,198 & & & \\
\hline & & L3 & 0,470 & 0,137 & 0,427 & 0,294 & \\
\hline \multirow[t]{6}{*}{43} & Vest & V1 & 0,000 & 0,000 & & & \\
\hline & & $\mathrm{V} 2$ & 0,000 & 0,000 & & & \\
\hline & & V3 & 0,645 & 0,130 & 0,215 & & \\
\hline & Lingual & L1 & 0,756 & 0,231 & & & \\
\hline & & L2 & 0,531 & 0,142 & & & \\
\hline & & L3 & 0,452 & 0,083 & 0,580 & 0,397 & \\
\hline \multirow[t]{6}{*}{46} & Vest & V1 & 0,667 & 0,152 & & & \\
\hline & & V2 & 0,658 & 0,265 & & & \\
\hline & & V3 & 0,901 & 0,123 & 0,742 & & \\
\hline & Lingual & L1 & 2,428 & 0,102 & & & \\
\hline & & L2 & 3,556 & 0,054 & & & \\
\hline & & L3 & 4,798 & 0,193 & 3,594 & 2,168 & \\
\hline
\end{tabular}

Inicialmente, testou-se a hipótese nula $(H 0)$ de médias iguais nos seis (6) dentes, versus a hipótese alternativa $(H 1)$ de pelo menos um (01) dente com média diferente dos demais. $O$ resultado do teste estatístico levou à não rejeição da hipótese nula $(p=0,355)$, indicando não haver diferença significativa entre os dentes, em relação a esta medida.

Também foi testada a hipótese nula de médias iguais nas duas faces (vestibular e lingual), versus a hipótese alternativa de médias diferentes. O resultado do teste estatístico levou à rejeição da hipótese nula $(p<0,001)$, indicando haver diferença significativa entre as faces, em relação a esta medida. 
Para avaliação dos fatores que influenciam a medida realizada, foram consideradas as fontes de variação relativas ao dente, à face (vestibular ou lingual), ao nível de avaliação da espessura óssea em cada uma das faces (V1, V2, V3, e L1, L2, L3) e aos operadores (Op.0, Op1, Op.2, Op.3, Op.4, Op.5 e Op.6). Esta última fonte corresponde ao erro intrínseco do método.

De modo geral, a medida de erro das avaliações (repetições) dos operadores em uma dada face, em um particular local (nível de espessura) e de um dente específico, correspondeu a $0,149 \mathrm{~mm}$. Esta fonte de variação (variabilidade dos operadores) representou 1,52\% (ER) da variabilidade total. Já $69,53 \%$ (CCl) da variabilidade total foi devida às variações entre faces (vestibular e lingual), considerando cada dente em particular. O percentual de variação devido aos níveis de avaliação das espessuras, nas faces vestibular e lingual (V1, V2, V3 e L1, L2 e L3), correspondeu a $15,47 \%$. O percentual relativo ao fator dentes correspondeu a $13,48 \%$ da variação total.

Pode-se concluir que significativa parte da variabilidade total $(98,48 \%-0.998$ $\mathrm{CCl})$ foi devida aos fatores: dente, face e nível de avaliação das espessuras, variações estas reconhecidas como biológicas ou inerentes às características anatômicas/tomográficas do indivíduo. Apenas $1,52 \%$ foi devida à participação dos operadores, caracterizando, assim, significativo grau de consistência em termos de Condição de Precisão Intermediária ("Reprodutibilidade") associada ao método proposto, e para aplicações na mandíbula.

\subsubsection{Maxila}

Na Tabela 5.22 são apresentados os resultados de médias e desvios-padrões das sete (07) repetições para os três (03) níveis de espessura óssea alveolar, vestibulares e palatinas, e para cada um dos dentes maxilares considerados. São, também, apresentadas as médias relativas às medidas obtidas em cada face (vestibular e palatina) e em cada dente. 
Tabela 5.22 - Médias e desvios-padrões das sete (07) repetições para os três (03) níveis de espessura óssea alveolar, vestibulares e palatinas/linguais, e para os seis (06) dentes maxilares

\begin{tabular}{|c|c|c|c|c|c|c|c|}
\hline Dente & Face & Local & $\begin{array}{l}\text { Média das } 7 \\
\text { medidas }\end{array}$ & $\begin{array}{l}\text { DP das } \\
\text { medidas }\end{array}$ & Média V/P & $\begin{array}{l}\text { Média } \\
\text { dente }\end{array}$ & do \\
\hline \multirow[t]{6}{*}{11} & Vest & V1 & 0,975 & 0,096 & & & \\
\hline & & V2 & 0,806 & 0,123 & & & \\
\hline & & V3 & 0,382 & 0,094 & 0,721 & & \\
\hline & Palatino & P1 & 1,253 & 0,046 & & & \\
\hline & & P2 & 1,512 & 0,142 & & & \\
\hline & & P3 & 3,016 & 0,055 & 1,927 & 1,324 & \\
\hline \multirow[t]{6}{*}{13} & Vest & V1 & 0,424 & 0,115 & & & \\
\hline & & V2 & 0,544 & 0,152 & & & \\
\hline & & V3 & 0,313 & 0,169 & 0,427 & & \\
\hline & Palatino & P1 & 0,599 & 0,278 & & & \\
\hline & & P2 & 1,201 & 0,118 & & & \\
\hline & & P3 & 2,563 & 0,096 & 1,454 & 0,941 & \\
\hline \multirow[t]{6}{*}{16} & Vest & V1 & 0,015 & 0,041 & & & \\
\hline & & V2 & 0,572 & 0,158 & & & \\
\hline & & V3 & 0,386 & 0,124 & 0,324 & & \\
\hline & Palatino & P1 & 0,000 & 0,000 & & & \\
\hline & & P2 & 7,325 & 0,314 & & & \\
\hline & & P3 & 10,589 & 0,145 & 5,971 & 3,148 & \\
\hline \multirow[t]{6}{*}{21} & Vest & V1 & 0,780 & 0,089 & & & \\
\hline & & V2 & 0,619 & 0,108 & & & \\
\hline & & V3 & 0,343 & 0,109 & 0,581 & & \\
\hline & Palatino & P1 & 1,075 & 0,099 & & & \\
\hline & & P2 & 1,566 & 0,026 & & & \\
\hline & & P3 & 3,876 & 0,130 & 2,172 & 1,377 & \\
\hline \multirow[t]{6}{*}{23} & Vest & V1 & 0,944 & 0,11 & & & \\
\hline & & V2 & 0,600 & 0,169 & & & \\
\hline & & V3 & 0,359 & 0,107 & 0,634 & & \\
\hline & Palatino & P1 & 1,019 & 0,060 & & & \\
\hline & & P2 & 1,376 & 0,100 & & & \\
\hline & & P3 & 2,988 & 0,111 & 1,794 & 1,214 & \\
\hline \multirow[t]{6}{*}{26} & Vest & V1 & 0,000 & 0,000 & & & \\
\hline & & V2 & 0,763 & 0,255 & & & \\
\hline & & V3 & 0,565 & 0,348 & 0,443 & & \\
\hline & Palatino & P1 & 5,284 & 0,213 & & & \\
\hline & & P2 & 7,686 & 0,299 & & & \\
\hline & & P3 & 10,349 & 0,218 & 7,773 & 4,108 & \\
\hline
\end{tabular}

Inicialmente, testou-se a hipótese nula $(H 0)$ de médias iguais nos seis (6) dentes, versus a hipótese alternativa $(H 1)$ de pelo menos um $(01)$ dente com média diferente dos demais. O resultado do teste estatístico levou à não rejeição da hipótese nula $(\mathrm{p}=0,810)$, indicando não haver diferença significativa entre os dentes em relação a esta medida.

Também foi testada a hipótese nula $(H 0)$ de médias iguais nas duas faces (vestibular e palatina), versus a hipótese alternativa $(H 1)$ de médias diferentes. $O$ resultado do teste estatístico levou à rejeição da hipótese nula $(p<0,001)$, indicando haver diferença significativa entre as faces em relação a esta medida. 
Para avaliação dos fatores que influenciam a medida realizada, foram consideradas as fontes de variação relativas ao dente, à face (vestibular ou palatina), ao nível de avaliação da espessura óssea em cada uma das faces (V1, V2, V3, e P1, P2, P3) e aos operadores (Op.0, Op1, Op.2, Op.3, Op.4, Op.5 e Op.6). Esta última fonte corresponde ao erro intrínseco do método.

De modo geral, a medida de erro das avaliações (repetições) dos operadores em uma dada face, em um particular local (nível de espessura) e de um dente específico, correspondeu a $0,158 \mathrm{~mm}$. Esta fonte de variação (variabilidade dos operadores) representou $0,25 \%$ (ER) da variabilidade total. Já $65,14 \%$ (0.651-CCl) da variabilidade total foi devida às variações entre faces (vestibular e palatina) considerando cada dente em particular. O percentual de variação devido aos níveis de avaliação das espessuras, nas faces vestibular e palatina (V1, V2, V3 e P1, P2 e P3), correspondeu a $34,61 \%$. Em função da elevada variabilidade entre lados, bem como entre locais (níveis) de cada face, a estimativa do percentual de variação devida a fator dentes foi igual a zero.

Pode-se concluir que significativa parte da variabilidade total $(99,75 \%-0.997$ CCl) foi devida aos fatores: dente, face e nível de avaliação das espessuras, variações estas reconhecidas como biológicas ou inerentes às características anatômicas / tomográficas do indivíduo. Apenas $0,25 \%$ foi devida à participação dos operadores, caracterizando, assim, significativo grau de consistência em termos de Condição de Precisão Intermediária ("Reprodutibilidade") associada ao método proposto, e para aplicações na maxila. 


\section{DISCUSSÃo}

XIII. LOKAVAGGA

167. hīnam dhammam na seveyya

pamādena na samvase

micchāditthim na seveyya

na siyā lokavaddhano.
XIII. DO MUNDO

167. Que o homem não sirva aos fins indignos,

que ele não viva em remissão;

Que o homem não siga pontos de vista falsos,

que ele não seja do mundo a sustentação.

DHAMMAPADA - A senda da virtude

\subsection{TOMOGRAFIA VOLUMÉTRICA (FEIXE-CÔNICO) E APLICABILIDADE}

Atualmente diversas são as indicações e modos de avaliação tomográfica disponíveis para uso em Odontologia (Loubele et al., 2006; Scarfe; Farman, 2008; Suomalainen et al., 2007).

Considerando a tomografia volumétrica (TCFC), ainda podem ser inúmeras as finalidades de aplicação e interpretação (Brezniak et al., 2004; Özer, 2011; Shiratori et al., 2011). O sistema de obtenção tomográfica com feixe-cônico (TCFC) é capaz de oferecer meios confiáveis de avaliação local (Suomalainen et al., 2007; Baumgaertel; Hans, 2009), regional (Baumgaertel, 2011) e também da face como um todo, adequando-se às mais diversas situações e necessidades, sejam estas de estudos dirigidos ou mesmo diretamente associadas à aplicação clínica (Saddy, 2006; Brown et al., 2009; Kamburoglu et al., 2010; Almeida, 2011; Kapila et al., 2011; Vasconcelos et al., 2012).

Este recurso complementar de imagem tornou-se particularmente importante a partir dos avanços tecnológicos produzidos diante de algumas das condições limitantes associadas às técnicas radiográficas convencionais, como efeitos de distorção, ampliação, imprecisão e inexatidão (Chilvarquer et al., 2008), e fundamentalmente considerando a relação entre dose de radiação e qualidade superior de resultados (Loubele et al., 2006; Brown et al., 2009; Kapila et al., 2011), favorecendo tanto a eliminação de algumas destas condições limitantes, como também a minoração de outras tantas, além de, também, propiciar menor custo. 
Todas essas qualidades, naturalmente, implicadas na condição de maior precisão e exatidão gerais das informações tomográficas pretendidas (Scarfe; Farman, 2008).

Contudo, e embora os registros provenientes de tomografia volumétrica (TCFC) possam ser reconhecidos como exames bastante apropriados à detecção de detalhes anatômicos topográficos devido à qualidade das imagens geradas, bem como à versatilidade de utilização dos recursos computacionais associados aos diversos equipamentos de geração tomográfica (Ballrick et al., 2008; Kamburoglu et al., 2010; Leung et al., 2010; Razavi et al., 2010), os limites precisos e confiáveis de resultados quantitativos relativos às condições biológicas limítrofes, considerando a escala sub milimétrica, representam, ainda, um fator emergente e dependente de mais e melhores estudos para o conhecimento interpretativo, sugerindo, a partir do que pode ser verificado na literatura disponível, que ainda não foram completamente identificados, estimados e integralmente testados estes parâmetros.

Neste âmbito, um fator de notória relevância é a qualidade técnica do sistema tomográfico (TCFC) utilizado para a geração das imagens (Loubele et al.,2006; Patcas et al, 2012), já que as características industriais de funcionamento dos equipamentos tomográficos podem, com efeito, determinar um meio tecnicamente menos invasivo e relativamente mais confiável à obtenção daquelas informações complementares.

O valor final da decisão clínica, portanto, está associado ao reconhecimento do possível problema como sendo algo atípico e/ou anormal, e também à familiaridade do operador com o uso e indicação dos exames complementares disponíveis e específicos à elaboração do diagnóstico, os quais deveriam efetivamente "fazer a diferença" considerando a planificação do tratamento idealizado (Freitas, 1988; Mileman; van den Hout, 2009).

\subsection{CONDIÇÃO DE REPETITIVIDADE E CONDIÇÃO DE PRECISÃO INTERMEDIÁRIA}

O Vocabulário Internacional de Metrologia (VIM) estabelece normas internacionais e consensuais para a realização de experimentos metrológicos (Inmetro, 2009), registrando conceitos previamente discutidos e relativos às 
condições metodológicas necessárias à obtenção de qualidade nos processos de medição, tanto para a minimização e controle dos tipos de erro associado, sistemático e aleatório, como também para padronizar a terminologia, favorecendo assim melhor aproveitamento dos esforços destinados à pesquisa experimental.

Embora repetibilidade, repetitividade e reprodutibilidade sejam termos frequente e equivocadamente empregados como sinônimos, esta interpretação não foi mantida para a realização da presente investigação, haja vista a preferência pela utilização de critérios metrológicos objetivos, internacionalmente aceitos e reconhecidos.

Embora tenha sido constatada alguma distinção prática de aplicação das qualidades de repetitividade e reprodutibilidade (Brezniak et al., 2004; Suomalainen et al., 2007; Ballrick et al., 2008; Swasty et al., 2011), estas duas condições, verificou-se, não foram exploradas em detalhes quanto à variação dos resultados associados. A maioria dos estudos de confiabilidade combinaram esta qualidade de avaliação com a análise de exatidão entre métodos comparados. A maioria das avaliações de confiabilidade incluiu a participação de operadores "não principais" (variação inter-operadores), quando então foram discutidas as características relativas à qualidade dos resultados. Contudo, e considerando estes estudos, foi constatada discordância geral entre propostas de delineamentos experimentais quanto ao número de participantes, quanto aos modos de participação dos mesmos, associados às sequências operacionais e recursos e, ainda, quanto ao tipo de instrução contemplada para a realização dos testes de inspeção tomográfica.

Porém, quando ocorria de haver descrição metrologicamente mais favorável, então era o método de visualização das imagens tomográficas, e/ou de registro das referências pretendidas, e/ou, ainda e frequentemente, de medição das grandezas solicitadas que indicavam ausência proporcional de detalhamento metodológico, lacunas estas que, possivelmente, poderiam estar participando significativamente da formação dos gradientes de variação, naqueles estudos encontrados.

Quando uma dada condição de medição é constituída, seja ela de Repetitividade, de Precisão Intermediária ou de Reprodutibilidade, obriga-se, ao(s) responsável(is) pelo processo metrológico, a especificação de qual é, ou quais são as qualidades que pretendem ser testadas, bem como quais são os objetivos para que a análise geral da confiabilidade nos padrões de medição estabelecidos possa 
ser conduzida proporcionalmente (Inmetro, 2009), garantindo validade às diferenças estatisticamente verificadas (Wagner, 1973; Vuolo, 1996).

Embora os termos variação intra e inter-operadores tenham sido frequentemente utilizados durante a realização de testes com as mais variadas propostas e finalidades associadas ao conhecimento do erro aleatório, estes termos não foram incluídos em protocolos operacionais mais abrangentes e formais (POP) quanto à terminologia, classificação, descrição e importância para o processo de obtenção dos resultados experimentais.

A qualidade das estimativas lineares obtidas a partir dos experimentos tomográficos, os quais foram com equipamentos específicos, procedimentos de visualização, operacionalização e medição também específicos, está diretamente associada ao padrão de delineamento experimental, onde então condições de fragilidade metodológica devem ser idealmente consideradas, neutralizadas e/ou discutidas a fim de que o fenômeno medido seja, de fato, representado adequadamente (Hulley et al., 2008).

A rigor, embora tenha sido anunciada e considerando indicações normativas oficiais (Inmetro, 2009), bem como a associação entre softwares, equipamentos tomográficos, quantidade e qualidade de operadores e, ainda, métodos de medição, nenhum dos trabalhos testou verdadeiramente a Condição de Reprodutibilidade dos métodos selecionados para os registros de espessuras ósseas alveolares em escala sub milimétrica. Este fato, eventualmente, pode não acarretar prejuízos metodógicos, tampouco clínicos, desde que as quantidades associadas àqueles experimentos não sejam diretamente aplicadas clinicamente, nem tampouco consideradas como estimativas cientificamente confiáveis.

A Condição de Precisão Intermediária, que nos estudos foram parcialmente e sumariamente praticada como "reprodutibilidade metodológica" - "concordância entre operadores", "variação inter-operadores não significante" - também não foi formalmente detalhada e efetivamente testada, haja vista que não foram oferecidas descrições pormenorizadas das sequências e dos dados utilizados. Asssim sendo, os resultados, por estes estudos referidos, deveriam gerar interpretação de conteúdos meramente informativos, descritivos e aproximados nos casos de medidas quantitativas, considerando a qualidade da precisão e confiabilidade no(s) método(s) proposto(s). 
Usualmente, informações, as quais foram bastante variáveis quanto à origem e qualidade, foram oferecidas e comparadas como sendo indicadores (similares) da Condição de Repetitividade, ou seja, pode-se inferir que a maioria dos estudos compulsados realizou avaliações de repetitividade de medições, embora, como será comentado adiante, conforme qualidades distintas de entendimento e aplicação, que foram desde "médias aritméticas simples para redução do erro", até procedimentos realmente consistentes quanto à avaliação do erro promovido pelo operador principal. Sendo assim, verificou-se que vários estudos contemplaram, sim, a análise do erro aleatório, mas quando o fizeram, a mesma foi conduzida de modo desigual e comparativamente incompleto quando referenciada em parâmetros oficiais, e, ainda, não foram discutidas detalhadamente as prerrogativas metrológicas associadas à qualidade dos resultados das medições.

Não foram constatadas discussões específicas acerca das diferenças interpretativas, e sua importância, entre repetitividade (repetibilidade) de medição, Condição de Repetitividade, precisão intermediária de medição, Condição de Precisão Intermediária, reprodutibilidade de medição e Condição de Reprodutibilidade. Daí decorre que as referidas relações metrológicas não tem sido exploradas proporcionalmente em relação a referenciais de critérios oficiais estabelecidos, os quais estabeleceriam distinção funcional de aplicação destes termos quando fossem aplicados aos procedimentos técnicos de medição, comparação e, ainda, de verificação comparativa multicêntrica.

Portanto, mesmo tendo sido constatado o uso indiscriminado (variável) dos termos "repetitividade e reprodutibilidade", e considerando o sistema metrológico selecionado como referência durante o presente delineamento experimental, de fato não foram obtidos, com este estudo, valores estritos de reprodutibilidade de medição, nem foi testada, por conseguinte, a condição de reprodutibilidade do método (Inmetro, 2009) (grifos do autor).

Assim, diante da classificação metrológica considerada e em observância às características do delineamento deste experimento, os fatores associados à confiabilidade metodológica observados nesta avaliação foram: condição de repetitividade e condição de precisão intermediária (Inmetro, 2009) (grifos do autor).

Portanto, e embora os resultados do presente experimento, em termos de confiabilidade interna e "mista", tenham sido bastante satisfatórios e promissores, se 
for considerado o rigor metrológico adotado, e é o que se está sugerindo, não parece correto afirmar que foi verificada e atestada (senso estrito) a reprodutibilidade do método em sua forma mais integral e abrangente. Com isso, é sugerida certa cautela quanto à aplicação inferencial das qualidades aqui testadas e verificadas (condição de repetitividade e condição de precisão intermediária) como se fossem, estas, similares à qualidade de reprodutibilidade (condição de reprodutibilidade) do método, haja vista que o POP aqui desenvolvido não foi testado com instrumentos de medição distintos, em diversos centros e com número e qualidade diferentes de participantes em relação, necessariamente, a esta proposta original, a fim de que fossem conhecidas as características inerentes à validação consensual do referido método.

O objetivo principal deste experimento foi determinar o poder de utilidade, em termos de qualidade de precisão e análise global de confiabilidade, de um modo próprio de análise osteométrica (Proposição, p. 108). Contudo, e a fim de que fosse favorecida a comparabilidade metodológica, uma vez observada a distinção metodológica, os resultados aqui obtidos foram associados a discussões relativas à qualidade técnica dos equipamentos, instrumentos, participações dos operadores, métodos de registro (inspeção e identificação) e, essencialmente, de medição tomográfica sub milimétrica, existentes na iteratura especializada.

Isto posto, e visando favorecer a comparabilidade metodológica, foram considerados os valores numéricos e interpretações publicados nos demais estudos lá referidos como "repetibilidade e reprodutibilidade", para a análise das condições de variação intra e inter-operadores respectivamente, embora sejam estas, em senso estrito, e conforme o que já foi descrito, condições metrológicas funcionalmente distintas (Inmetro, 2009) daquelas encontradas na literatura especializada.

As diferenças, no caso da presente investigação, podem estar associadas tanto à quantidade de operadores participantes, como também às condições de execução "externa" do Procedimento Operacional Padrão (POP) definido e testado quanto à condição de repetitividade associada às medições sugeridas.

Assim, considerando a presente investigação e os resultados obtidos associados à variação durante o processo de medição, aqui referidos como sendo de repetitividade de medição (variação intra-operador associada a uma dada Condição de Repetitividade) e de precisão intermediária de medição (variação inter- 
operadores associada a uma dada Condição de Precisão Intermediária), foram geradas evidências para que fosse possível a avaliação acerca da confiabilidade metodológica associada tanto à referida Condição de Repetitividade (consistência metodológica "interna"), quanto à referida Condição de Precisão Intermediária (consistência metodológica "mista"), respectivamente. Qualidades estas que, combinadas, determinam a confiabilidade geral do método que se está propondo.

É opinião desse autor, corroborando a indicação oficial proposta pelo VIM que, para que a Condição de Reprodutibilidade do método fosse estritamente testada, então mais operadores (sob condições distintas e/ou com diferentes sistemas de medição) deveriam testar um mesmo Procedimento Operacional Padrão (POP), o qual, naturalmente, deve ter sido previamente definido e testado em sua confiabilidade (Inmetro, 2009).

Um exemplo possível desta situação (teste da condição de reprodutibilidade) seria a realização de testes de medição sob condições locais diversas daquelas originalmente concebidas, com outros softwares (os quais deveriam possuir capacidades computacionais supostamente similares de registro e precisão de medição), com a participação de diversos operadores diferentes, a partir de mesmas instruções operacionais (Apêndice B - PPO, p. 235) e todos eles medindo as mesmas unidades de observação/medição, a partir da sequência de um dado POP previamente definido e atestado em sua confiabilidade. Desta forma, poder-se-ia inferir acerca da reprodutibilidade metodológica do POP especificamente desenvolvido e dado à execução de medições das quantidades ósseas pretendidas.

A preferência pela utilização destes critérios metrológicos partiu de certas dificuldades verificadas durante análise dos trabalhos publicados e, a partir destes, da realização da Fase // da presente investigação (Método, p. 116; Apêndice D, Nota Técnica - Fase II, p. 244). Dificuldades essas relativas ao entendimento de quais seriam os limites de delineamento mais adequados e favoráveis à análise da qualidade de participação dos erros incidentes, bem como quais seriam as possibilidades de comparação e de aplicabilidade inferencial decorrentes da determinação daqueles limites de delineamento.

Infelizmente não foi encontrado estudo em que estas condições tenham sido formalmente reconhecidas e aplicadas.

Até o presente, nenhum estudo testou Procedimentos Operacionais Padrões (POP) detalhados à situações distintas e controladas para cada uma das ações 
computacioais e suas justificativas, e com mais de três (03) operadores, para a obtenção sistemática de espessuras ósseas alveolares tomográficas, maxilares e mandibulares; mesmo porque também não foi encontrada evidência de que algum(ns) dos métodos utilizados tenham sido previamente testados para 0 conhecimento preliminar dos intervalos de erro associados, antes de serem aplicados a estudos de exatidão (acurácia).

Isto não significa que sequências não tenham sido propostas (Baumgaertel; Hans, 2009; Baumgaertel, 2011; Naitoh et al., 2011; Shiratori et al., 2011; Sun et al., 2011; Timock et al., 2011; Patcas et al., 2012; Vasconcelos et al., 2012), e que alguns estudos não tenham utilizado mais de três (03) operadores (Brezniak et al., 2004 - 06 examinadores; Ballrick et al., 2008 - 30 examinadores; Noujeim et al., 2009 - 10 examinadores; Razavi et al., 2010 - 10 examinadores), ou, ainda, que algumas grandezas não tenham sido descritas e comentadas no interesse de favorecer o processo de inspeção e identificação (Sherrad et al., 2010; Timock et al., 2011; Patcas et al., 2012)

Intui-se, talvez, que esta seja uma das causas principais da pouca ênfase conferida à discussão da influência do delineamento experimental, em seus critérios formais de registro e medição, nos padrões de aplicabilidade inferencial pretendidos com os sistemas de TCFC para obtenção de informações quantitativas confiáveis.

Estudos tem registrado e discutido resultados de quantificação de espessuras ósseas alveolares (Almeida, 2011; Suomalainen et al., 2007; Baumgaertel; Hans, 2009; Razavi et al., 2010; Januário et al., 2011; Naitoh et al., 2011; Swasty et al., 2011). No entanto, muitas das referências analisadas neste contexto foram de trabalhos descritivos retrospectivos (Almeida, 2011; Nowzari et al., 2010; Baumgaertel, 2011; Farnsworth et al., 2011; Januário et al., 2011; Swasty et al., 2011), com amostras de conveniência e, ainda, com métodos de medição pouco ou mesmo insuficientemente descritos, para os quais os procedimentos de medição tenham sido previamente testados e conhecidos em suas características e limitações, o que inclui, idealmente e também para o conhecimento da variação envolvida (Inmetro, 2009), a avaliação do erro associado à participação de vários operadores e conforme protocolos de registro tomográfico detalhadamente descritos (fatores estes relevantes quando o interesse é avaliar a participação do erro aleatório e o grau de influência que este pode exercer sobre a qualidade de aplicabilidade inferencial das estimativas obtidas). Quanto maior for o erro 
desconhecido associado aos processos de obtenção de quantidades numéricas, maiores serão as limitações impostas à qualidade de extrapolação dos resultados (Vuolo, 1996; Hulley et al., 2008).

\subsection{EXATIDÃO E PRECISÃO}

A validação do método de análise tomográfica, considerando finalidades específicas de identificação das condições atípicas, anormais e/ou patológicas, depende da utilização de uma referência-padrão confiável, seja esta absoluta (padrão-ouro) (Saddy, 2006) ou mesmo considerada como sendo a melhor estimativa possível disponível (padrão-ouro convencionado), qualitativa e/ou quantitativa, do mensurando em questão (Ballrick et al., 2008; Mileman; van den Hout, 2009; Leung et al., 2010). Entretanto, e a não ser que as informações de exatidão tomográfica sejam provenientes de análise computacional direta (gráficos MTF, como um exemplo), sem a participação humana no processo de registro e medição de quantidades comparadas conforme dois ou mais métodos em condições de teste (Loubele et al., 2006), todo o conhecimento (maioria na literatura) dos valores de aplicabilidade dos intervalos de exatidão tomográfica, depende da participação humana e, a partir disso, todo o processo acaba sendo essencialmente dependente desta classe de variação, bem como dos métodos de registro (inspeção e identificação) e dos recursos de medição selecionados, os quais deveriam ser previamente testados e conhecidos em suas vantagens e desvantagens operacionais, antes de serem prontamente utilizados como se fossem recursos confiáveis à aplicação específica durante testes de validação tomográfica (exatidão).

Embora já tenha sido considerado o valor tomográfico de $0,2 \mathrm{~mm}$ como sendo clinicamente significante (Sherrard et al., 2010), o de 0,1 mm como clinicamente não significante (Ballrick et al., 2008), e também o limite tomográfico de $0,7 \mathrm{~mm}$ como um valor de erro supostamente reconhecido como clinicamente aceitável (Loubele et al., 2006), outros estudos devem confirmar estas interpretações, especialmente quando associadas à variação durante a realização de testes de precisão entre dimensões diminutas sob comparação e, fundamentalmente, a partir de vários operadores pois, mesmo assim, dissenso poderá persistir entre autores acerca da qualidade e 
quantidade de variação, as quais seriam consideradas clinicamente desprezíveis, e para a diversidade de aplicações pretendidas.

Dada a escala considerada à avaliação tomográfica dos reparos anatômicos de interesse, bem como os recursos computacionais e suas capacidades técnicas de gerar informação, um dos fatores que mereceu especial atenção durante a análise dos resultados obtidos foi o modo de interpretação dos valores numéricos de variação associados à qualidade de inspeção visual dos operadores.

Isto posto, e considerando os tecidos biológicos reais, os quais são fonte das dimensões quantitativas estudadas, pergunta-se:

As diferenças quantitativas entre os tecidos avaliados (nesta escala e proximidade), podem, com efeito, ser tomograficamente detectadas em indivíduos vivos com confiabilidade de resultados, e conforme o material e método definidos para a geração das imagens do presente experimento?

A resposta a esta questão depende essencialmente de três fatores principais:

a) o sistema e equipamento utilizados à geração de qualidade das imagens tomográficas;

b) o(s) programa(s) computacional(is) (software) utilizado(s) para a visualização, registro (de inspeção e identificação) dos referenciais de interesse e medição das distâncias pretendidas, bem como o método utilizado, e

c) o "fator operador-dependente", ou seja, o modo pelo qual vários operadores concordam entre si com a obtenção de resultados suficientemente precisos de medidas tomográficas sub milimétricas.

Estes fatores serão discutidos a seguir.

a) Qualidade de Imagem 
Estudos demonstraram graus relativos de aplicabilidade associada aos resultados de interpretação das capacidades tomográficas (Kamburoglu et al., 2010; Leung et al., 2010; Razavi et al., 2010; Özer, 2011; Shiratori et al., 2011; Tsutsumi et al., 2011; Kajan; Toramsari, 2012; Patcas et al., 2012; Vasconcelos et al., 2012). Contudo, a capacidade tomográfica de reproduzir características específicas dos objetos reais, depende diretamente da qualidade dos resultados de exatidão, tanto aqueles obtidos a partir de delineamentos específicos considerando o uso de fantomas, quanto aqueles obtidos a partir de gráficos MTF, onde as capacidades internas dos sistemas são analisadas a partir da relação de utilização do tamanho dos objetos reais (Loubele et al., 2006; Scarfe; Farman, 2008; Strateman et al., 2008; Romans, 2011).

Foi registrado que aumento do tempo de exposição, associado à seleção de voxel de menor tamanho pode, técnica e efetivamente, gerar melhores padrões de resolução espacial (detalhe) para as imagens tomográficas volumétricas (TCFC) (Ballrick et al., 2008; Naitoh et al., 2011). Contudo, e embora os estudos discordantes desta possibilidade (Sun et al., 2011; Sherrard et al., 2010), e ainda aqueles em que somente um ou outro tamanho de voxel foi utilizado (Almeida et al., 2011 - voxel de 0,4mm; Baumgaertel, 2011 - voxel de 0,29mm; Farnsworth et al., 2011 - voxel de 0,39mm) não tenham oferecido protocolos rígidos de delineamento metrológico, nem associado parâmetros de aquisição ajustados proporcionalmente como o foram para a realização do presente experimento, é possível que essa opção técnica, realmente e pela maior chance de participação de ruído de imagem, como também do efeito de volume parcial, possa ser, eventualmente, equivalente em termos de exatidão comparada aos protocolos de aquisição com maiores tamanhos de voxel. Embora não tenha sido o objetivo da presente investigação, epecula-se, comparativamente e considerando como sendo constante a qualidade técnica/industrial do tomógrafo, a possibilidade de que quantidade maior de miliamperagem $(37,7 \mathrm{~mA})$, utilizada como um dos parâmetros definidos neste experimento, além do voxel de $0,25 \mathrm{~mm}$ e tempo de $26,9 \mathrm{~s}$, sejam os principais fatores responsáveis pela qualidade de detalhe obtida durante a realização dos testes deste experimento, o que provavelmente influenciou positivamente a facilidade de inspeção registrada pelos operadores, gerando intervalos de erro menos significativos, corroborando o que foi verificado por Shiratori et al. (2011), os quais utilizaram protocolo de aquisição semelhante ao selecionado para este estudo, 
com modelo Classic de tomógrafo $\left(\mathrm{iCAT}^{\circledR}\right.$ ), mas com maiores tempo de aquisição e quantidade de corrente, (40s e 46,72mA, respectivamente), resultando em condições bastante favoráveis de inspeção tomográfica com resolução de voxel $0,25 \mathrm{~mm}$.

Nesse sentido, as características técnicas associadas aos limites de resolução espacial gerados pelo sistema de TCFC necessitam ser consideradas. E, de fato, o foram a partir de estudos de validação tomográfica (Brezniak et al., 2004; Lascala et al., 2004; Ballrick et al., 2008; Suomalainen et al., 2008; Leung et al., 2010; Patcas et al., 2012).

Contudo, mesmo esses estudos diferiram em sua indicação metodológica, fosse por diferenças entre sistemas e equipamentos, fosse pela magnitude das dimensões estudadas ou, ainda e também, pelas diversas fontes de padrões-ouro utilizados à condução dos experimentos de comparação entre métodos.

b) Programa Computacional (software) e Método

\section{- Programa Computacional}

Além da qualidade dos resultados obtidos a partir da capacidade operacional disponibilizada pelo programa AutoCAD $2011^{\circledR}$, foram também descritas e justificadas algumas das características computacionais mais utilizadas durante 0 experimento (Método, p. 116; Apêndice D - Nota Técnica - Fase II, p. 244), garantindo, assim, a utilização de um programa computacional confiável para a realização dos testes de inspeção e identificação (registros) tomográficas.

Infelizmente não foram registradas discussões técnicas específicas, as quais permitissem a comparabilidade analítica das condições sistemáticas intrínsecas inerentes aos programas computacionais utilizados, e associadas à qualidade de operacionalização (modos de visualização para pesquisa, preparação dos recursos de registro - inspeção e identificação, e de medição tomográfica) oferecida pelos mesmos, de modo que a discussão deste tópico requer melhor quantidade e qualidade de informações associadas. 
- Método

Devido ao fato de ter sido constatada considerável variação metodológica inerente aos modos de operacionalização das imagens tomográficas, e para as mais variadas propostas, então a discussão acerca das vantagens e desvantagens, bem como das expectativas relacionadas aos resultados daquele(s) que poderia $(\mathrm{m})$ ser considerado(s) como representativo(s) de um dado sistema "ideal" de registro de inspeção e identificação tomográficos e, fundamentalmente, de medição de números e tipos variáveis de espessuras ósseas alveolares, vestibulares e linguais / palatinas, maxilares e mandibulares, torna-se por demais limitada considerando estas condições, e esta pode ser entendida como a principal justificativa para a presente proposta metodológica.

Destaque-se que apenas três (03) estudos (Sherrard et al., 2010; Swasty et al., 2011; Timock et al., 2011) combinaram descrições mais detalhadas do padrão de operacionalização tomográfica concomitantes à proposta de referenciais geométricos locais específicos e auxiliares à obtenção das medidas tomográficas, embora tenham sido constatadas, em ambos, diferenças metodológicas associadas especialmente a limitações operacionais inerentes aos softwares e ao modo pelo qual os mesmos foram aplicados.

Nestes trabalhos, o número máximo de operadores "externos" participantes foi igual a dois (02).

c) Fator operador-dependente

O erro aleatório, associado à precisão dos resultados (concordância entre resultados casuais - distribuição probabilística), o qual corresponde a um dos erros de medição (Vuolo, 1996; Inmetro, 2009) e, ainda, contribui à determinação da confiabilidade metodológica geral e específica, depende do estudo planejado de uma dada série de repetições para que, seguindo a Teoria do Limite Central (Teoria da Probabilidade), haja a possibilidade de que este tipo de erro, com mesma 
probabilidade de que seja positivo ou negativo, se distribua normalmente após inúmeras repetições, e acabe ou se aproximando ou mesmo se anulando em zero.

Tal é o erro estatístico (aleatório), causado por eventos casuais, os quais representam um dos objetos de estudo quando são utilizados diversos operadores durante um experimento associado à verificação do "comportamento" de variável quantitativa. Assim, a participação humana durante os procedimentos de inspeção tomográfica determina, sempre, efeitos gerais e específicos associados a estes erros (variações) (Mileman; van den Hout, 2009). Contudo, para Timock et al. (2011), os quais criticaram haver poucos estudos com a participação de diversos operadores para o conhecimento da variação de medições tomográficas e, ainda, que a adoção de protocolos mais bem definidos podem realmente oferecer parâmetros de medidas mais confiáveis, resolveram que a participação de apenas dois (02) operadores já teria sido suficiente para o conhecimento da confiabilidade do método, embora não tenham justificado suas opiniões, as quais, curiosamente, se distanciam do padrão usual de entendimento de como se distribuem os erros aleatórios (probabilísticos) e, por conseguinte, como deveriam ser entendidas as decisões de delineamento experimental (Vuolo, 1996; Inmetro, 2009).

Um dos pré-requisitos para a possibilidade de inferência metodológica é o correto conhecimento de como se apresentam os padrões de variação (erro) casual. Não parece ser possível testar graus "cada vez mais externos" (e provavelmente mais variáveis) de validação (confiabilidade), ou de universalidade, sem que as condições de variação ditas "mais internas", e naturalmente já testadas, sejam conhecidas em suas características, tanto as favoráveis como as desfavoráveis.

Um dos efeitos gerais verificados na presente investigação, e com significativa qualidade atestada por meio de critérios matemáticos (estatísticos), foi, dada a participação mínima de variação aleatória, o elevado grau de concordância (equivalentes $\mathrm{CCl}$ acima de 0.9 ) entre os sete (07) operadores em "acertar" (precisão) referenciais anatômicos supostamente entendidos e praticados por todos os examinadores como sendo realmente verdadeiros (fidedignos), a partir das congruências intuídas entre "aquilo que é, aquilo que pode ser e aquilo que não é compativel com as noções individuais do que seria o real anatômico". Outros estudos, embora totalmente distintos em termos metodológicos e de finalidades de aplicação, também obtiveram resultados consistentes associados às análises de participação do erro aleatório (Suomalainen et al., 2007; Damstra et al., 2010; 
Farnsworth et al., 2011; Özer, 2011; SUN et al., 2011; Swasty et al., 2011; Timock et al., 2011; Tomasi et al., 2011; Patcas et al., 2012).

Na presente investigação, os examinadores avaliaram vários (144) e mesmos locais tomográficos, de modo individual, intervalar e independente, a partir de breve instrução técnica preliminar e de treinamento supervisionado de até trinta (30) minutos, gerando, cada um deles, o total de setenta e duas (72) medidas lineares milimétricas (variação sub milimétrica). Os resultados foram bastante consistentes para a análise geral de confiabilidade metodológica (Resultados - Análise Estatística, p. 176), e esse foi o objetivo principal desta investigação.

Diversamente de Leung et al. (2010), que relataram ter havido a necessidade de realização de ajustes de correção linear devido ao conhecimento prévio de subestimação padrão (erro sistemático) de medição, equivalente ao tamanho do voxel $(0,38 \mathrm{~mm})$ utilizado, e inerente ao próprio software selecionado (Accurex $\left.{ }^{\circledR}\right)$, 0 programa aqui utilizado $\left(A u t o C A D^{\circledR}\right)$ - e conforme a constatação de não haver erro (sistemático) associado ao recurso de medição do mesmo (Método, p. 116), haja vista que as medidas não foram obtidas por meio de automação computacional de detecção eletrônica dos padrões de cinza em suas diferenças, mas sim por operadores solicitados - não precisou de quaisquer ajustes pós-processamento para compensações da escala original derivada do tomógrafo (iCAT ${ }^{\circledR}$ ).

Embora não tenha sido o objetivo experimental deste trabalho, um dos efeitos específicos e diretamente associados à relevante à discussão relativa aos limites de aplicabilidade inferencial clínica confiável, dos resultados aqui registrados, é a capacidade de serem tomograficamente informadas, aos operadores, as características verdadeiras (reais) relativas aos tecidos observados. Assim, e para adiantar o esclarecimento desta questão, é preciso recorrer aos intervalos de erro associados à exatidão de medida (acurácia) disponíveis na literatura.

Foi constatado dissenso entre os diversos autores quanto à possibilidade de identificação qualitativa confiável da presença ou ausência de osso alveolar por meio de TCFC (estudos qualitativos, de avaliação dicotômica) (Sun et al., 2011; Patcas e al., 2012). Deste modo, destaca-se que aquela qualidade, que os operadores da presente investigação avaliaram (qualitativamente) como sendo compatível com ausência de osso ("osso igual a zero"), pode ter sido, eventualmente, um juízo falso (falso-positivo) de avaliação, e até mesmo este mesmo erro pode ter sido cometido quando da identificação de quantidades ósseas ou muito diminutas, ou obtidas a 
partir de referenciais tomográficos incertos ou dados à baixa objetividade de identificação, gerando toda sorte de falsos-positivos e falsos-negativos para a identificação fidedigna dos limites entre aqueles tecidos, considerando a informação quantitativa como objetivo da avaliação interpessoal pretendida.

Por essa razão é que se está sugerindo que os valores de erro associados à precisão (intervalos de erro) dos métodos de registro e medição tomográfica, sejam conhecidos previamente à utilização dos mesmos em experimentos de exatidão (com padrões-ouro). Assim, e diversamente do que se tem verificado a partir da análise da literatura, poder-se-ia computar os intervalos de erro aleatório (precisão), já conhecidos, àqueles intervalos de erro sistemático obtidos por meio dos experimentos de exatidão (acurácia) associados a valores de medida sub milimétricos. Esta providência, parece a esse autor, poderia propiciar meios consideravelmente mais uniformes e favoráveis à aplicação científica experimental.

Se é requerido o conhecimento quantitativo de um dado fenômeno biológico, então é fundamental que os modos e meios de medição elegíveis ao delineamento experimental sejam aqueles em que já tenha sido constatada a menor, e controlável, participação de erro total.

De um modo ou de outro, e considerando os resultados disponibilizados pelos outros autores, parece lícito sugerir que sejam concebidos certos intervalos de significância clínica.

Embora possa haver dissenso quanto à qualidade da capacidade de reprodução do real (exatidão) pelos exames de tomografia volumétrica (TCFC) (Sherrard et al., 2010; Patcas et al., 2012; Timock et al., 2011; Loubele et al., 2006), a literatura compulsada também apresenta considerável variabilidade metodológica experimental (Lascala et al., 2004; Damstra et al., 2010; Leung et al., 2010; Vasconcelos et al., 2012). Assim, entre cortes trans-axiais e medidas tomográficas (TCFC) sobre o volume (3D), a decisão de presença ou ausência de osso (informação qualitativa, dicotômica) pode ser parcialmente resolvida por alguns pesquisadores (Leung et al., 2010; Sun et al., 2011; Patcas et al., 2012), indicando que, em cinquenta por cento $(50 \%)$ das vezes, haveria superestimação dos defeitos ósseos simulados de fenestrações e/ou deiscências, e, ainda, que em todas as vezes que for detectada condição de normalidade quanto à presença de osso, esta provavelmente seria diretamente constatada. Contudo, a significância clínica destes resultados ainda depende de livre interpretação, considerando sua relativa validade. 
Portanto, são exigidas outras investigações para melhor esclarecimento destas condições limítrofes. Neste contexto, Leung et al. (2010) concluíram que há limitações sistemáticas entre os delineamentos compulsados, os quais possivelmente poderiam interferir em algum aspecto dos resultados, e que as medidas em TCFC não são tão exatas quanto aquelas obtidas diretamente. As principais diferenças, acrescentaram, seriam devidas às limitações de resolução espacial das imagens de TCFC.

Enquanto que a perda de detalhe relativo aos contornos pode, de fato, influenciar na qualidade dos níveis de exatidão pretendidos, esta variável, além de outras macroscopicamente consideradas na presente investigação, não foram capazes de influenciar negativamente os resultados de precisão a partir do método proposto (Resultados, p.173), já que, a partir das evidências registradas, não foram constatadas inconsistências metodológicas de participação dos examinadores (Apêndice E - Nota Técnica - Fase III, p. 247), sendo que todos concordaram com o que seriam os padrões de aparência relativos aos perfis tomográficos (bidimensionais) representativos do tecido ósseo alveolar e do cemento.

Contudo, quatro condições, aquém da participação do operador, se fazem presentes e podem acarretar prejuízo à capacidade de exatidão final inerente às imagens tomográficas: a) efeito de volume parcial - onde há ponderação computacional entre padrões de cinza de estruturas menores que o tamanho de voxel selecionado, fazendo da detecção tomográfica do referido objeto uma ação tecnicamente impossível; b) resolução de alto contraste, ou quando duas estruturas verdadeiramente separadas entre si podem, de fato, ser reconhecidas tomograficamente como entidades distintas; c) incapacidade de resolução espacial devido à probabilidade de representação inexata do objeto em relação posicional à matriz de pixels (Teorema da Amostragem de NYQUIST), indicando que, no mínimo, o pixel deveria ter metade da dimensão do objeto a ser resolvido, e d) limitações associadas a detectabilidade de contraste (resolução de baixo contraste), quando objetos muito próximos e com pouca diferença entre suas densidades são representados como uma só estrutura (Kapila et al., 2011; Romans, 2011; Timock et al., 2011).

Portanto, estas quatro condições parecem ser as principais responsáveis pelas limitações associadas à exatidão das imagens produzidas pelos sistemas de TCFC e, a partir disto, devem impor sérias restrições às intenções de aplicação 
associadas tanto aos padrões qualitativos muito específicos e diminutos ("há ou não há osso circundante?"), quanto aos quantitativos pretendidos, em mesma proporção de escala.

Assim sendo, sugere-se que melhores demarcações (uniformidade) destas limitações sejam obtidas por meio de delineamentos experimentais mais concisos, controlados e precisos para as respectivas demandas.

A partir desta discussão, e quando consideradas as características do tecido ósseo, aqui representado por meio de distâncias lineares locais específicas denominadas de espessuras ósseas alveolares, constatou-se a impossibilidade de serem obtidos valores precisos consensuais de correspondência de exatidão, sugerindo que apenas estimativas de intervalos lineares destes possam ser apresentadas. Resta saber, com isso, quais seriam os intervalos de medida mais prováveis e representativos.

\subsection{MEDIÇÃO - ANÁLISE E INTERPRETAÇÃO DO ERRO}

A medição é um modo de se obter informação quantitativa. Assim, existem dois modos possíveis de avaliação quantitativa, e geralmente estão direta ou indiretamente associadas, um modo corresponde à medição direta, a partir da qual são obtidos os valores ou parâmetros denominados padrões-ouro de um dado mensurando, sejam eles absolutos (Saddy, 2006), ou mesmo convencionados (melhor estimativa), e o outro modo corresponde à medição indireta que, no presente experimento, foi representado pelas medições tomográficas (TCFC).

Medir diretamente cada espessura óssea alveolar atualmente é possível por meio de estudos realizados com material ex-vivo. Contudo, a aplicabilidade inferencial de tais resultados é questionável (Leung et al., 2010), embora necessária, pois sem estes referenciais não seria possível obter estimativas confiáveis de erro relativo e absoluto.

Métodos de medição foram informalmente propostos durante a realização de estudos radiográficos/tomográficos, muitos dos quais combinando convenientemente softwares agregados ao próprio sistema de aquisição tomográfica, para operacionalização-padrão das imagens (Leung et al., 2010; Shiratori et al., 2011; 
Sun et al., 2011; Patcas et al., 2012; Timock et al., 2011), considerados como modos ou protocolos-padrão de obtenção tomográfica. Outros, ainda, conferiram atenção principal aos resultados da análise de geração de exatidão (acurácia) de alguns sistemas, num todo considerados, sem que houvesse descrição integral, quer fosse do protocolo de participação dos operadores, ou mesmo dos resultados de confiabilidade, prévia e devidamente testada, associada às etapas do procedimento de medição, considerando as condições de registro (inspeção e identificação) e medição propriamente dita (Sun et al., 2011; Timock et al., 2011)

Entretanto, a maioria dos experimentos compulsados foi conduzida com vistas a identificar a qualidade de participação do erro associado à condição tomográfica per se, fosse ela a partir de TC médica convencional (Loubele et al., 2006; Saddy, 2006) ou mesmo de TCFC (Kamburoglu et al., 2010; Ballrick et al., 2008), relacionando tanto variáveis qualitativas (Leung et al., 2010; Umetsubo, 2011), como também quantitativas (Honda et al., 2004; Sherrard et al., 2010; Ballrick et al., 2008), em estudos ex vivo (Lascala et al., 2004; Patcas et al., 2012) e in vivo (Almeida, 2011).

Embora seja possível converter os dados quantitativos obtidos em qualitativos ordinais (categoriais) com vistas à aplicação de avaliação de coeficientes de concordância inter-examinadores (Sim; Wright, 2005; Sun et al., 2011), esse recurso, se resolveu, faria com que o poder de confiabilidade final fosse prejudicado se comparado àquele proveniente da utilização de outros métodos convencionalmente aplicados às distribuições essencialmente quantitativas, como Análise de Variância (ANOVA) e, para esta finalidade epecífica, modos de interpretação de Coeficientes de Correlação Intraclasse (CCI), considerando as finalidades pretendidas de detecção do erro ou variação, em um dado modelo de variâncias.

\subsection{MÉTODO}

Cortes tomográficos trans-axiais foram a opção prevalente nos estudos de avaliação das espessuras ósseas alveolares, fossem a partir de propostas para avaliações tomográficas diversas (Nowzari et al., 2010; Sherrard et al., 2010), ou 
para detecção de osso com a finalidade de aplicação de implantes dentários (Razavi et al., 2010; Naitoh et al., 2011), ou mesmo para seleção de locais de fixação de miniimplantes (Baumgaertel, 2011; Farnsworth et al., 2011) e, ainda, para experimentos de exatidão (acurácia) tomográfica onde as medidas foram comparadas com medidas reais de cortes histológicos similares (Sun et al., 2011; Patcas et al., 2012; Vasconcelos et al., 2012). Verificou-se, deste modo, indicação favorável de utilização desta modalidade derivada de imagens volumétricas, especialmente considerando avaliações ósseas de defeitos periodontais específicos (Sun et al., 2011; Timock et al., 2011; Patcas et al., 2012), sejam elas quantitativas (principalmente) ou qualitativas.

O intervalo temporal entre sessões, definido para as avaliações-teste intraoperador no presente experimento (Apêndice B, PPO, p. 235), foi de uma (01) semana entre as sessões, e foi observado conforme prática usual presente na literatura (Strateman et al., 2008; Sherrard et al., 2010; Sun et al., 2011).

Embora os estudos de confiabilidade avaliados tenham utilizado recursos tomográficos atuais e fidedignos quanto à qualidade das imagens geradas (Sherrard et al., 2010; Timock et al., 2011; Patcas et al., 2012; Honda et al., 2004; Almeida, 2011; Vasconcelos et al., 2012), pode-se afirmar que, em sua maioria, esses estudos não foram de confiabilidade de reprodutibilidade metodológica em senso estrito, haja vista a diversidade presente de delineamentos e propostas metodológicas, onde não foram descritos formalmente os critérios de delineamento experimental, nem e as respectivas justificativas de influência nos resultados de aplicação inferencial (Lascala et al., 2004; Nowzari et al., 2010).

A partir disto, constatou-se que não tem sido devidamente valorizadas as características metodológicas funcionais, conforme hierarquia esperada de aplicações e com o propósito de serem uniformizados os delineamentos, para que fosse conhecido o comportamento estatístico dos intervalos de erro, quando estes deveriam ser submetidos a condições-teste diversas daquelas originalmente concebidas.

É compreensível que houvesse escassez de informações acerca destas condições, ou pressupostos metodológicos, já que os programas computacionais mais frequentemente utilizados para os testes publicados foram softwares de aplicação comercial mais genérica e, portanto, mais variável, haja vista que os mesmos não foram especificamente desenvolvidos para a realização de pesquisas 
de confiabilidade em seus termos metrologicamente mais abrangentes, reprodutíveis e confiáveis.

Estudos foram realizados com a intenção de oferecer valor de confiabilidade metodológica. Porém, poucos foram os que ofereceram registro formal dos critérios operacionais utilizados à obtenção das medidas ósseas lineares sub milimétricas comparadas.

Poucos foram os estudos em que o procedimento operacional de visualização tomográfica, registro (inspeção e identificação) e medição (critério integral de medição) foi descrito considerando a importância do detalhamento metodológico descrito (Sherrard et al., 2010; Timock et al., 2011; Razavi et al., 2010; Swasty et al., 2011).

Erros de repetitividade e reprodutibilidade do método compõem o gradiente de erro aleatório (casual) no processo de obtenção e utilização da quantificação numérica (Slezák; Waczulíková, 2011; Inmetro, 2009), e uma de suas funções é delimitar a precisão final do método que está sendo testado (Vuolo, 1996).

Assim, verificou-se, a partir dos estudos revistos, que a utilização de três ou mais operadores participantes, bem como de programas computacionais (softwares) os quais fossem previamente atestados em sua confiabilidade metodológica (e isso inclui todas as etapas e justificativas metrológicas nos casos de avaliações quantitativas), não foi respeitada como um fator de relevância à concretização dos objetivos propostos. Assim sendo, é imperativo que seja salientada a importância do reconhecimento das possíveis fontes de erro, ainda mais sendo a dimensão sub milimétrica aquela sob análise. Discretas variações metodológicas, não previstas e/ou não consideradas durante a análise de confiabilidade dos métodos de registro e medição podem, com efeito, determinar confusão acerca da precisão nestes processos e, com isso, comprometer tanto a sua confiabilidade, quanto os resultados das estimativas de exatidão (acurácia).

A maioria dos estudos compulsados combinou, em um só experimento, a execução de testes de confiabilidade (precisão) e de validação (exatidão), porém utilizando métodos de medida circunstancialmente criados, e quase ou totalmente dependentes dos recursos de operacionalização e medição oferecidos pelos próprios programas de visualização tomográfica selecionados (Lascala et al., 2004; Suomalainen et al., 2007; Leung et al., 2010; Razavi et al., 2010; Sherrard et al., 2010; Sun et al., 2011; Timock et al., 2011; Patcas et al., 2012), portanto sem 
conhecimento prévio do erro incidente associado especificamente aos fatores: método de visualização, método de registro de inspeção anatômica e, também, e não menos importante, método de medição.

Essa condição, por si só, já é suficiente para a ocorrência de viés de seleção de recursos (Hulley, 2008). A questão do por que, quando, como e onde este viés pode trazer eventuais consequências desfavoráveis à confiabilidade final dos resultados, intencionalmente gerados às possibilidades de aplicação clínica, é condição que os experimentos deveriam explorar melhor e responder, preferencialmente não durante ou após os experimentos, mas sim, e naturalmente, antes do início dos mesmos.

É opinião desse autor que essa possibilidade pode, eventualmente, agregar erros durante a realização e interpretação de medidas, haja vista que, se os testes de confiabilidade (precisão) não forem favoráveis durante o próprio procedimento, perder-se-ão, em parte ou integralmente, os efeitos de controle operacional relativos à qualidade então obtida tanto da utilização dos equipamentos, como também dos esforços das medições diretas realizadas requeridas aos estudos de exatidão (acurácia).

Parece lícito supor, a fim de que sejam adequada e eficientemente testados certos valores de medida bastante diminutos, associados à exatidão e seu valor de aplicabilidade inferencial clínica, que os recursos de medição sejam antes testados em sua eficiência específica, ou seja, em sua confiabilidade metodológica. A partir do conhecimento dos valores associados ao erro e às incertezas de medida, poderiam ser definidos, então, delineamentos experimentais apropriados às limitações conhecidas destes recursos.

Assim, é lançada a questão: o que é possível medir (e como?) indiretamente (tomograficamente), com necessárias confiabilidade (precisão) e validade (exatidão), considerando o valor de relevância clínica pretendido?

É opinião desse autor, que até que sejam conhecidos os intervalos de erro clinica e consensualmente aceitos para a série de situações clínicas exigidas, que no caso da presente investigação é representada pela condição óssea alveolar por meio de distâncias tomográficas (de resolução sub milimétrica), que não sejam prontamente inferidos, como se fossem consensualmente representativos, certos valores lineares obtidos a partir de experimentos em que a participação do erro 
aleatório, combinada à interpretação do(s) sistemático(s) associado(s) aos métodos e equipamentos, não tenham sido rigorosamente consideradas.

Percebe-se, de modo geral e a partir das características descritas e discutidas nos trabalhos avaliados, que o rigor metodológico de hierarquia entre modalidades de estudo não está sendo observado quanto ao rigor metrológico de delineamento experimental, haja vista a carência de uniformidade metodológica para os mesmos interesses ou finalidades de aquisição de informação.

Estudos de confiabilidade devem avaliar precisão metodológica. Estudos de validação devem avaliar exatidão (acurácia). Em senso estrito não é possível testar níveis de exatidão se os recursos e/ou instrumentos de medição selecionados à tarefa ainda não puderam ser adequadamente testados. Assim, curiosamente e de modo inverso daquele esperado, surge a demanda por definições metodológicas as quais sejam reprodutíveis, confiáveis e facilmente aplicáveis enquanto métodos científicos de registro (inspeção e identificação) e medição tomográfica.

A partir disso, nenhum dos trabalhos compulsados de exatidão (acurácia) apresentou referência prévia de publicação, ou mesmo descrita no próprio estudo, de valores (fossem eles absolutos ou relativos) dos intervalos de erro associados aos métodos de medição empregados. Essa condição, por si só, só aumenta a confusão do entendimento quanto às reais condições de aplicabilidade das técnicas, equipamentos, métodos e resultados de pesquisas prévias.

A exemplo, o trabalho de Sun et al. (2011) combinou a avaliação intra e interoperadores de modo distinto daquela definida por Patcas et al. (2012), as quais foram, também, bastante diversas daquelas proposta por Razavi et al. (2010) e Leung et al. (2010).

Ainda em Sun et al. (2011), e também em Timock et al. (2011), onde o delineamento metodológico foi pouco valorizado para a participação dos operadores "externos", ou mesmo sem a inclusão destes (Sun et al., 2011 - dois examinadores; Timock et al., 2011 - apenas um operador), foi afirmada "confiabilidade" do método utilizado, porém não foram descritos os critérios específicos de obtenção das medições, nem mesmo as condições de participação dos operadores. Entretanto, e mesmo assim, indicaram vantagens na utilização de voxel de $0,25 \mathrm{~mm}$, contudo também afirmaram não haver diferenças entre a seleção de voxel 0,25mm e 0,4mm para a obtenção de medidas ósseas alveolares, especulando o fato de poder ter 
havido, ainda, algum viés associado ao método de inspeção tomográfica, embora essa condição não tenha sido por eles melhor explorada.

Enquanto Sun et al. (2011) registraram subestimação tomográfica linear do padrão-ouro (ex vivo - porcos) quando a dimensão de medida estudada se aproximava do valor limite do voxel $(0,4 \mathrm{~mm})$, e, ainda, que quando esta se afastava deste referencial, havia superestimação de perdas ósseas verticais lineares, Timock et al. (2011) constataram não haver nem subestimação, nem superestimação significante do padrão-ouro (ex vivo - cadáveres humanos preservados), registrando diferença absoluta de $0,30 \mathrm{~mm}$ para as alturas ósseas e de $0,13 \mathrm{~mm}$ para as espessuras, embora tenham verificado maior confiabilidade de detecção das alturas do que das espessuras ósseas alveolares.

Patcas et al. (2012), diversamente destes, obtiveram valores absolutos de exatidão bastante representativos (entre $-0,13 \mathrm{~mm}$ e $+0,13 \mathrm{~mm}$ ), porém com variação significante de concordância $(2,1 \mathrm{~mm})$, a qual foi dependente, afirmaram, tanto do tipo de medida como da resolução espacial considerada. Destaque-se que os referidos autores anunciaram a intenção de resolver deficiências de delineamentos experimentais prévios. Entretanto, utilizaram somente um (01) operador para as análises, voxels de equipamentos diferentes em via de comparação direta, repetindo apenas uma vez as medidas e, ainda, que com procedimentos de medição os quais não foram detalhadamente descritos e explorados.

Já para Razavi et al. (2010), que descreveram com maior riqueza de detalhe os critérios adotados à obtenção das medidas, e, ainda, consideraram a participação de dez (10) examinadores para obter os parâmetros de confiabilidade metodológica associada ao erro aleatório, as medidas de exatidão das corticais ósseas (ex vivo costelas bovinas), bastante delgadas, com voxel de $0,125 \mathrm{~mm}$ do sistema Accuitomo $^{\circledR}$, foram mais confiáveis que aquelas obtidas com voxel de $0,3 \mathrm{~mm}$ do sistema $\operatorname{iCAT} N \mathrm{G}^{\circledR}$, embora a dose de radiação tenha sido maior com o sistema Accuitomo $^{\circledR}$. Concluíram estes autores que ambos os sistemas tomográficos subestimaram as medidas de espessura óssea (medidas maiores tiveram erros associados menores), e superestimaram as medidas de altura selecionadas.

Portanto, e a partir destes poucos exemplos, parece lícito afirmar que há considerável variabilidade metodológica experimental, fato este que, provavelmente, determina a inconsistência metrológica verificada e associada aos critérios metodológicos preliminares de visualização, registro e medição tomográfica. 


\subsection{INFORMAÇÃO DA IMAGEM TOMOGRÁFICA}

Se a condição tomográfica limitante de ocorrência do efeito de volume parcial, a partir da qual se concebe que as densidades semelhantes de objetos reais e diminutos, e muito próximos espacialmente, acabam sendo ponderadas em médias de cinza para um mesmo pixel, fazendo da deteç̧ão visual (inspeção e identificação) um procedimento tecnicamente improdutivo (Scarfe; Farman, 2008; Sun et al., 2011), então essa dificuldade, além de outras mais, deveriam, é opinião desse autor, ser consideradas previamente ao delineamento experimental, selecionando meios e recursos de medição confiáveis, já testados em sua metodologia aplicada e que possam servir às finalidades propostas de análise.

A partir disto, parece lícito afirmar que esforços, investimentos e qualidade agregados acabam sendo sub valorizados, mal aplicados e interpretados.

Esta limitação, talvez, represente um dos fatores causais centrais da ausência percebida de detalhamento exploratório relativo aos recursos dos softwares comercialmente disponíveis, bem como da qualidade das informações técnicas oferecidas aos operadores, ainda mais considerando que esta modalidade específica de avaliação tomográfica, objetivando a identificação de dimensões sub milimétricas, ao menos ainda, permanece como sendo um procedimento bastante operador-dependente.

Estudos tomográficos (TCFC) de exatidão (acurácia) relataram intervalos variáveis de erro associados à aplicação inferencial das distâncias ósseas locais estudadas (Patcas et al., 2012; Leung et al., 2010; Timock et al., 2011; SUN et al., 2011; Ravazi et al., 2010; Swasty et al., 2011), as quais foram avaliadas conforme a aplicação de protocolos de aquisição tomográfica distintos (quilovoltagem, miliamperagem, tempo de exposição e resolução do tamanho de voxel), com cortes de análise diferentes, modos de visualização específica distintos e, essencialmente, com procedimentos de medição parcialmente descritos.

Este somatório de variação, eventualmente e considerando as finalidades de aplicação inferencial, pode ser proporcionalmente muito maior que algumas das 
diminutas médias (sub milimétricas) obtidas de alguns experimentos (Patcas et al., 2012).

Surpreendentemente, e provavelmente devido à frequente variação metodológica observada na literatura (Nowzari et al., 2010; Leung et al., 2010), incluindo combinações de equipamentos diferentes, com softwares agregados (nativos) e genéricos (Razavi et al., 2010), oferecendo diversas capacidades operacionais e, ainda, com participação humana bastante variável (Suomalainen et al., 2007; Ballrick et al., 2008), não foi possível obter um padrão médio aparente e suficientemente confiável às aplicações generalizadas de um dado intervalo linear de erro, mostrando, desse modo, que as estimativas prováveis de exatidão, relativas às espessuras ósseas alveolares, devem ser consideradas com cautela e associando, sempre, as fontes de erro individualmente estabelecidas.

\subsection{ANÁLISE POR CRITÉRIOS MATEMÁTICOS (ESTATÍSTICA)}

Na presente investigação, a condição de normalidade de distribuição não foi objeto principal de avaliação. Para que fosse incluída, deveria ser efetuada considerando as repetições independentes, observando cada combinação de dente em particular, a face e o(s) nível(is) de espessura pretendido(s). Assim, o número de casos seria três (3) ou sete (7), para a repetitividade e "reprodutibilidade".

Entretanto, o Modelo de Análise de Variância utilizado nesta investigação é suficientemente robusto para desvios da condição de normalidade.

Para propósitos complementares de estudo, e em termos de direcionamento analítico para uma dada avaliação quantitativa mais específica, e de eventuais diferenças entre determinadas condições, como, por exemplo, se um particular dente, ou ainda de grupos de dentes, participaram de modo metodologicamente distinto dos demais, então a análise do erro do método poder ser estabelecida no âmbito desta(s) especificação(ões) particular(es). Contudo, deve ser considerado que será uma nova interpretação a partir dos resultados. (grifo nosso)

O objetivo da presente análise não foi o de comparar grupos específicos. Assim, os testes de hipóteses foram realizados apenas com o intuito principal de 
fornecer subsídios para as participações de cada fonte de variação no gradiente de variabilidade total.

Quando o teste indicou a rejeição da hipótese nula, de igualdade para as duas faces consideradas, este resultado acabou por justificar o significativo percentual de variabilidade total, explicada pela diferença (anatômica) entre faces avaliadas, fator este considerado como constante diante dos objetivos especificamente testados e considerando o POP estabelecido para método que está sendo proposto.

A maioria dos estudos compulsados desenvolveu, para a avaliação da qualidade em termos de confiabilidade metodológica, análise estatística a partir do cálculo de Coeficientes de Correlação Intraclasse $(\mathrm{CCl})$, os quais relacionam a intensidade de variância a partir de grupos comparados de medidas.

Coeficientes de concordância eventualmente foram preferidos (Özer, 2011 Kappa; Swasty et al., 2011 - de Lin) quando da utilização de dados na forma de variável categorial, com vistas à avaliação dicotômica (qualitativa).

Para cumprir com a análise estatística (por critérios matemáticos) dos dados obtidos na presente investigação, foi, também, definida preferência pelo cálculo de Coeficientes de Correlação Intraclasse (CCI). Contudo, dada a qualidade de aleatorização e organização do delineamento definidos previamente ao início da pesquisa, e considerando as várias classes (grupos) geradas pelo experimento em termos de níveis ou graus de associação entre as mesmas, bem como o volume de dados disponibilizados, a Análise de Componentes de Variância (Modelo Hierárquico Multinível) foi selecionada à obtenção do conhecimento das intensidades de variação, considerando tanto a precisão de medição associada à repetitividade de medição (para a Condição de Repetitividade - qualidade abrangente da variação intra-operador), quanto a precisão de medição associada à precisão intermediária de medição (para a Condição de Precisão Intermediária - qualidade abrangente da variação inter-operadores), associadas ao método e com a participação sistemática dos examinadores participantes considerando cada grupo de medidas resultante (Resultados - Análise Estatística, p. 177).

Como o presente estudo não pretendeu testar exatidão (acurácia), então, como modo de discutir acerca das possibilidades de aplicabilidade inferencial da qualidade aqui obtida, sugere-se, naturalmente, que sejam consideradas as 
estimativas lineares oferecidas pelos estudos/experimentos em que essa qualidade foi avaliada.

Para tanto, recomenda-se a seleção daqueles estudos em que os métodos foram os mais proporcionais àquele utilizado pela presente investigação (POP), e ainda considerando os intervalos de erro associados.

Seja de confiabilidade ou mesmo de validação, verificou-se a ocorrência de resultados anunciados com parâmetros variáveis de confiabilidade, onde os procedimentos operacionais associados à obtenção das medidas não foram, em sua maioria, descritos em detalhe.

Entretanto, e naqueles em que o POP foi mais bem detalhado e considerado como fonte possível de variação, os resultados indicam, mesmo com variações metodológicas evidentes, que é possível obter estimativas lineares relativamente precisas e exatas para algumas medidas ósseas específicas (Ballrick et al., 2008; Razavi et al., 2010; Timock et al., 2011; Swasty et al., 2011).

Esta discussão é importante para a prática inferencial em termos de extrapolação clínica dos resultados obtidos neste trabalho. Pois, embora não se tenha pretendido avaliar/testar a exatidão (acurácia) de medida, é lícito afirmar que há total possibilidade de serem extrapolados os dados obtidos, uma vez que o protocolo de aquisição tomográfica, aqui definido e também testado em certos parâmetros, já foi descrito em outros estudos e essencialmente testado em seus valores de estimativa de exatidão linear, a partir de material obtido de humanos vivos (Almeida, 2011; Özer, 2011; Shiratori et al., 2011; Sun et al., 2011; Timock et al., 2011; Umetsubo, 2011; Vasconcelos et al., 2012).

Essa é uma das razões pelas quais se está sugerindo que o Procedimento Operacional Padrão (POP), resultante desta proposta metodológica, pode ser utilizado com segurança como uma das fontes de padrão-ouro convencionado (tomográfico), desde que observados os valores e estimativas registradas pela presente investigação.

A fim de que essa condição fosse previamente testada, e com o intuito de saber se as eventuais inconsistências dimensionais seriam provocadas apenas por intermédio da influência humana (erro aleatório), e diante de condições de visualização supostamente mais críticas (zoom) em relação à definição dos detalhes de imagem (pós-processamento e já na área de trabalho do AutoCAD ${ }^{\circledR}$ ), foi definida ampliação padrão-teste, com zoom de 0.70, valor este que foi maior que o dobro da 
maior ampliação padrão utilizada (0.30) (Apêndice B - PPO, p. 235) pelos examinadores durante os registros (inspeção e identificação) tomográficos definitivos. Esta condição demonstra que mesmo dobrando a proporção de ampliação, quando então as imagens "hiperdensas" dos travessões verticais ("régua referencial tomográfica") perderam parte de sua qualidade relativa ao detalhe, ainda assim as condições resultantes propiciaram o registro de imprecisão de medida tão diminuta quanto 0,01mm (EA).

Em decorrência desse resultado, o valor do erro absoluto (EA) calculado, em relação à correspondência entre imagens de softwares, não foi computado como variável neste estudo. Além de que, esse cálculo, mesmo que fosse hipoteticamente significativo, só serviria para testar a qualidade do valor quantitativo tomográfico do mensurando em relação a um dado padrão-ouro correspondente, que não foi e nem poderia ser o caso da presente investigação.

Assim, e então conhecido "erro tomográfico absoluto", bem como sua eventual participação no processo de medição, foi descartada a influência sistemática para ocorrência de erro entre escalas dos softwares considerados (Método, p. 116), mantendo assim a indicação do fabricante, de exatidão (acurácia) com proporção de 1:1 (Material, p. 114).

Embora sejam propagadas e relativamente conhecidas as vantagens práticas de utilização dos softwares associados industrialmente aos sistemas de aquisição de imagens (tomógrafo), bem como de programas computacionais independentes disponíveis para atender às inúmeras demandas profissionais, todos os softwares utilizados na Fase /I da presente investigação não ofereciam, à época em que os mesmos foram utilizados e subjetivamente testados, os recursos operacionais necessários à obtenção do controle operacional exigido à realização do presente experimento associado (Apêndice D - Nota Técnica - Fase II, p. 244).

A presente investigação, a partir da proposta metodológica descrita, testada e confirmada em seus objetivos, sugere a utilização de um modelo de Procedimento Operacional Padrão (POP), o qual é capaz de oferecer meios reprodutíveis e cientificamente confiáveis à avaliação quantitativa de espessuras ósseas alveolares, vestibulares e palatinas/linguais, maxilares e mandibulares, e conforme modo particular de avaliação incluindo um Modelo Geométrico Auxiliar (MGA), o qual é capaz de contemplar, de modo padronizado e para análises subsequentes, tanto a dimensão de cada dente considerado (vestíbulo-lingual), quanto a orientação 
espacial dos mesmos (inclinação vestíbulo-lingual/palatina), considerando que são, os dois, referenciais-base interdependentes, tanto na construção geométrica do MGA, quanto, naturalmente, na própria constituição anatômica (individual).

Portanto assume-se, com a presente proposta metodológica, a possibilidade de relacionar a característica anatômica individual de cada dente, maxilar ou mandibular, com a distribuição quantitativa linear de suas espessuras ósseas alveolares correspondentes, vestibulares e/ou linguais/palatinas, de modo preciso e confiável, propiciando a exclusão de possíveis fontes de erro, como:

a) posição da cabeça durante a aquisição tomográfica;

b) magnificação estatisticamente significante de imagem e distorções, sistemáticas e aleatórias, associadas às limitações produzidas pela técnica de obtenção radiográfica convencional;

c) limitações sistemáticas (variáveis de acordo com o nível de precisão e exatidão requeridos) decorrentes da utilização de cortes tomográficos axiais para avaliação de níveis (verticais) de espessura óssea alveolar (devido à espessura do corte original - nativo, considerando a direção de avaliação linear sub milimétrica);

d) ineficácia de precisão devido à incapacidade técnica de geração do controle metodológico exigido à sequência de testes, especificamente considerados aos locais de interesse desse experimento, osso alveolar e as respectivas dimensões (sub milimétricas) envolvidas. Esta variável, em particular, inclui as etapas computacionais de visualização das imagens, registro (inspeção e identificação) dos referenciais pretendidos e, finalmente, o procedimento de medição propriamente dito.

Para que sejam conhecidos os eventuais prejuízos decorrentes da ação ortodôntica associada à seleção e utilização de diversas formas e tamanhos de arco, bem como da expressão combinada destes com as prescrições straight-wire (SW) disponíveis, faz-se necessário o conhecimento dos padrões qualitativos (Goldman; 
Cohen, 1958; Baumgaertel, 2011; Sun et al., 2011; Patcas et al., 2012) e quantitativos ósseos correspondentes (Suomalainen et al., 2007; Damstra et al., 2010; Farnsworth et al., 2011; Özer, 2011; SUN et al., 2011; Swasty et al., 2011; Timock et al., 2011; Tomasi et al., 2011; Patcas et al., 2012). Portanto, conhecer o modo de reação do tecido ósseo diante dos inúmeros efeitos da aplicação de força ortodôntica é imprescindível à correta definição do diagnóstico e tratamento especializados (Palomo et al., 2008).

Sendo assim, é essencial que seja considerada a confiabilidade nos meios e métodos de obtenção daquelas informações, haja vista que a não confiabilidade pode, com efeito, propiciar ações baseadas em coincidência/acaso, ou, ainda e pior que isso, favorecer o surgimento de feitos clínicos deletérios inesperados.

Dentre as várias fontes de informação tomográfica quantitativa disponíveis, e relativas à condição óssea dento-alveolar, as mais confiáveis são aquelas provenientes de estudos comparativos onde foram utilizadas técnicas capazes de gerar reproduções virtuais do real (modelos) com erro absoluto (exatidão) tão diminuto quanto 0,001 mm (Saddy, 2006; Loubele et al., 2006). Contudo, e como foi constatado a partir da análise da literatura especializada, os estudos apresentaram resultados variáveis e a partir de condições metodológicas também bastante variáveis, e ainda, considerando que os próprios padrões-ouro podem ser questionados quanto à sua utilidade inferencial clínica (Mileman; van den Hout, 2009).

Se, de um ponto de vista, a variedade metodológica constatada pode eventualmente favorecer o benefício da livre escolha profissional diante das possibilidades tecnológicas disponíveis, por outro, e com efeito, pode também confundir e gerar pouca prospecção de real evolução de aplicabilidade estatisticamente confiável, haja vista a necessidade de serem obtidos parâmetros metrológicos reprodutíveis, apropriados e que possam conduzir às melhores informações do modo mais rápido possível, e menos custoso em um sistema ideal.

Destarte, e considerando a frequência de variações encontradas na literatura compulsada, a obtenção de estimativas lineares médias (exatidão sub milimétrica), para as espessuras ósseas vestibulares e palatinas/linguais, obtidas de cortes tomográficos TCFC trans-axiais, pode ser considerada apenas a partir de um dado intervalo de significância clínica inferencial, uma vez que a resolução espacial geométrica das reconstruções volumétricas difere de equipamento para 
equipamento e de software para software, considerando tanto os padrões físicos de aquisição, como também os algoritmos de pós-processamento.

O referido intervalo de significância clínica inferencial, seria um dependente tanto da exatidão linear tomográfica média, consensualmente estabelecida, quanto da precisão do método de registro e medição e, fundamentalmente, das necessidades práticas de aplicação das informações quantitativas específicas do(s) mensurando(s) considerado (s). Esses três fatores, é opinião desse autor, compõem o campo de análise necessário às decisões clínicas e aplicação inferencial dos resultados provenientes dos trabalhos de pesquisa.

A partir das informações disponíveis, pode-se afirmar que há, em média e de modo geral, discreta subestimação de medidas tomográficas lineares produzidas a partir do sistema de TCFC (Lascala et al., 2004; Razavi et al., 2010; Sun et al., 2011).

Contudo, é essencial informar que não há registro de um dado padrão consensual para a direção e magnitude dos intervalos de inexatidão publicados. Esta condição, ora de superestimação, ora de subestimação linear, tanto para distâncias tomográficas horizontais, quanto para as verticais, e considerando a ampla variação metodológica verificada (entre equipamentos, softwares e métodos de operacionalização e medição), em todos os níveis hierárquicos dos delineamentos experimentais tomográficos analisados, provavelmente determina a ocorrência de heterogeneidade, a qual representa o efeito geral de participação de inúmeros vieses de pesquisa (Hulley et al., 2008).

Sendo assim, e considerando o POP estabelecido a partir da presente investigação, verificou-se que dimensões reais menores que $0,25 \mathrm{~mm}$ (correspondente ao tamanho do voxel/pixel) utilizado - mesmo tendo sido verificados (Resultados, p. 172) valores de erros relativos (ER) bastante favoráveis (ER / intraoperador: 0,53\% / mandíbula e 0,24\% / maxila; ER / Inter-operadores: 1,52\% / mandíbula e 0,25\% / maxila), o que se traduz em precisão (excelente) de detecção tomográfica - não seriam efetivamente detectáveis a partir do sistema tomográfico utilizado em decorrência do limite máximo de resolução espacial do sistema de geração de imagens (Romans, 2011; Loubele et al., 2006; Scarfe; Farman, 2008; Schulze et al., 2011).

Considerando a relação geral e variável de subestimação tomográfica linear (ora de subestimação e, ora, de superestimação, como se fosse um erro aleatório 
quando, de fato, deveria ser sistemático), bem como a participação dos quatro fatores de inexatidão já comentados, e, ainda, a informação dos intervalos de variação relativos à precisão obtidos nesta pesquisa, medidas reais, as quais estejam localizadas no intervalo de 0,25 a $0,5 / 0,6 \mathrm{~mm}$, podem ser tomograficamente detectáveis, porém com confiabilidade crítica.

Medidas reais maiores que 0,5 / 0,6mm, novamente considerando a relação geral e variável de subestimação tomográfica linear (Lascala et al., 2004; Sun et al., 2011; Razavi et al., 2010) e eventualmente de superestimação dependendo da dimensão estudada (Sun et al., 2011, Leung et al., 2010; Tsutsumi et al., 2011), bem como os erros relativos (ER) obtidos no presente experimento, podem ser confiavelmente estimadas tomograficamente desde que observados os critérios e limitações associados ao POP definido no presente trabalho.

Assume-se, com isso, que medidas tomográficas de humanos vivos, a partir dos intervalos de erro verificados com este experimento e cada vez maiores que o intervalo quantitativo de 0,5/0,6mm, possam ser realmente estimadas com excelente confiabilidade a partir do POP estabelecido. Contudo, e naturalmente, o valor final de precisão obtida com este experimento só deverá ser efetivamente considerado em sua relevância clínica quando o mesmo estiver diretamente implicado com as necessidades de precisão e exatidão de medida exigidas por aqueles contextos (ponderar a condição do clinicamente significante).

Entretanto, e considerando a finalidade de pesquisa experimental, o referido método possui ampla possibilidade de ser aproveitado em sua relevância.

Para aqueles locais, nesse experimento, onde foram constatadas (convencionadas) ausências de osso alveolar (exemplos: V1 e V2 dos dentes 31 e 33), e sempre considerando a espessura de corte nativo do equipamento como uma das limitações à inferência qualitativa de fenestrações e/ou deiscências (Patcas et al., 2012), então parece correto afirmar a tendência de que, provavelmente, não haja osso naqueles locais avaliados ou, se houver, deve ser uma camada tão fina e irregular que, em termos de prática ortodôntica, teriam, as duas possibilidades, igual importância quanto à adoção de providências preventivas associadas à exploração dos limites ósseos alveolares correspondentes.

A identificação de ausência óssea, por parte dos operadores, segue um critério único e qualitativo (dicotômico) em razão da percepção visual de diferenças entre densidades das partes ósseas e do cemento correspondente. Como a intenção 
deste estudo não foi testar experimentalmente a qualidade de dois ou mais métodos (sistemas) de representação do real (exatidão), nem tampouco a sensibilidade e/ou a especificidade de tipos de defeitos ósseos simulados ou naturalmente presentes, então, e com isso, fica estabelecida a limitação inferencial quanto à fidelidade de representação do que seriam as estruturas ósseas reais relacionadas aos extremos de detecção tomográfica dicotômica, além das dimensões reais dos objetos avaliados. Sendo assim, afirmações categóricas não são possíveis nessa ordem de interesse.

Esta seria, então, a qualidade final do intervalo de significância clínica inferencial sugerido.

A exemplo, e lembrando que a avaliação inter-examinadores gerou valores associados ao erro relativo (ER) proporcionalmente maiores que aqueles obtidos da avaliação intra-operador (Resultados, p. 173), segue-se que:

a) se for considerado o valor médio obtido para a espessura vestibular intermédia do dente 36 ("V2 do 36"), que foi de 0,81mm (Resultados, p. 173), ignorando a discreta subestimação tomográfica geral e conforme a utilização dos referenciais obtidos desta investigação (de variação inter-operadores), então, tem-se que a estimativa linear para a medida selecionada será de:

$0,81 \mathrm{~mm} \times 1,52 \%$ (ER da classe), ou

$=0,81 \mathrm{~mm}( \pm 0,01 \mathrm{~mm}), \mathrm{e}$

b) se for considerado o valor médio obtido para a espessura vestibular intermédia do dente 16 ("V2 do 16"), que foi de 0,57mm (Resultados, p. 173), ignorando a discreta subestimação tomográfica geral e conforme a utilização dos referenciais obtidos desta investigação (de variação inter-operadores), então, tem-se que a estimativa linear para a medida selecionada será de:

$0,57 \mathrm{~mm} \times 0,25 \%$ (ER da classe), ou

$=0,57 \mathrm{~mm}( \pm 0,001 \mathrm{~mm})$.

Conhecidas as qualidades técnicas e operacionais associadas aos sistemas de TCFC, bem como sendo conhecidos os intervalos de variação (erro e incerteza de medida) associados à precisão de detecção tomográfica de espessuras ósseas 
alveolares, vestibulares e palatinas/linguais, maxilares e mandibulares, a partir do método proposto e ainda considerando a utilização de padrão de testes representativo (modelo humano), sugere-se:

- que o POP (Procedimento Operacional Padrão), aqui definido em sua proposta e justificativas, e para a obtenção dos resultados pretendidos por esta pesquisa, possa ser utilizado como método de obtenção de padrõesouro convencionados (tomográficos) para espessuras ósseas alveolares, com vistas à agregar qualidade metodológica aos processos de medição, comparação e interpretação tomográfica com os sistemas de TCFC, e

- que o MGA (Modelo Geométrico Auxiliar), aqui definido e proposto experimentalmente com vistas a atender a execução dos referidos testes, também possa ser utilizado como parte integrante e metodologicamente efetiva do POP desenvolvido, garantindo assim a geração de padrões de precisão e confiabilidade conhecidos, estatisticamente significativos e clinicamente bastante favoráveis, e não somente aplicáveis às espessuras ósseas alveolares, mas, eventualmente e também, às distâncias verticais (alturas) como possibilidades complementares de avaliação quantitativa angular local, provavelmente com similares condições de controle, embora esta condição ainda necessite ser testada. 


\section{CONCLUSÃO}

[...] Imagine uma cena em um espaço bidimensional: um homem reclinado em um banco, por exemplo. Atrás do banco há uma árvore. Agora imagine o homem indo do banco até uma pedra, do outro lado da árvore. Ele só pode alcançar a pedra passando pela frente ou por trás da árvore. O que é impossível no espaço bidimensional. Ele só chegará à pedra se fizer uma excursão à terceira dimensão. Imagine agora outro homem sentado no banco. Como foi que ele chegou lá? Como dois corpos não podem ocupar o mesmo lugar ao mesmo tempo, ele só pode ter chegado lá antes ou depois que o primeiro homem saiu. Em outras palavras, ele deve ter se movido no tempo. O tempo é a quarta dimensão.

ALBERT EINSTEIN 1929.

Conforme os critérios estabelecidos pelo POP deste experimento, e considerando a qualidade de informação obtida a partir de análise crítica da literatura especializada compulsada, conclui-se que:

- Os resultados, considerando a Condição de Repetitividade, indicaram significativa confiabilidade geral no método proposto, com apenas $0,24 \%$ da variabilidade maxilar total, e mandibular total de $0,53 \%$, atribuíveis a um único operador, e com valores expressivos relativos às incertezas de medida maxilares $(0,156 \mathrm{~mm})$ e mandibulares $(0,091 \mathrm{~mm})$, atestando, desse modo, a significativa consistência interna (repetitividade) do método proposto.

- Os testes da Condição de Precisão Intermediária também indicaram significativa confiabilidade geral no método proposto, com apenas 1,52\% da variabilidade total mandibular, e total maxilar de 0,25\%, atribuíveis à participação de diversos operadores (07), e com valores também expressivos relativos às incertezas de medida mandibulares $(0,149 \mathrm{~mm}) \mathrm{e}$ maxilares $(0,158 \mathrm{~mm})$, desse modo atestando significativa condição final de precisão intermediária ("reprodutibilidade").

- O programa AutoCAD ${ }^{\circledR}$, a partir de suas características originalmente concebidas de precisão, padronização, e também de versatilidade operacional considerando a construção de desenhos geométricos, propicia 
a livre definição de inúmeras possibilidades em termos de métodos e protocolos técnicos padronizados, os quais podem servir, com efeito, às mais diversas finalidades de experimentação científica.

- O Programa AutoCAD ${ }^{\circledR}$ provou ser um recurso bastante versátil e metodologicamente confiável. Contudo, o referido programa computacional requer significativa (atual) memória de trabalho para o desenvolvimento pleno de todas as suas capacidades, dada a ampla diversidade operacional disponível, incluindo padrões de operacionalização em três dimensões (3D). Acredita-se que os recursos utilizados para este experimento sejam possivelmente reprodutíveis em outra configuraçãobase de software, a qual possa garantir a mesma eficiência geral e específica, só que com menores: custo agregado e utilização de memória, embora esta seja apenas uma das conjecturas resultantes deste experimento, mas com ampla possibilidade de ser testada e desenvolvida.

- A participação de operadores qualificados, adequadamente instruídos, minimamente treinados e incluídos em um Procedimento Operacional Padrão, prévia e integralmente descrito, com suas participações associadas ao tipo metodológico considerado, podem resultar em níveis de controle operacional bastante favoráveis à execução de testes metrológicos. Contudo, e embora as condições produzidas para a presente análise tenham sido propositadamente aproximadas ao máximo da realidade e da rotina profissional, são estas, ainda, condições-teste controladas, para as quais as eventuais diferenças devem ser consideradas se houver interesse em comparações com situações de aplicabilidade de rotina, conforme o que fora verificado durante a presente investigação.

- A utilização de imagens provenientes de tomógrafo iCAT ${ }^{\circledR}$, conforme os parâmetros definidos nessa investigação, e com indicação de resolução de voxel de 0,25mm, em humanos vivos e a partir de cortes trans-axiais sistematicamente operacionalizados com auxílio do programa computacional AutoCAD ${ }^{\circledR}$, é capaz de propiciar a geração de condições 
metodológicas suficientemente favoráveis à obtenção de mapeamento ósseo quantitativo linear, em escala sub milimétrica, de espessuras ósseas alveolares, vestibulares e/ou palatinas/linguais, tanto para a maxila quanto para a mandíbula.

- A partir das evidências obtidas da análise do erro, bem como da avaliação das condições associadas ao delineamento experimental descrito, foi atestada plena confiabilidade ao método de obtenção de espessuras ósseas alveolares tomográficas proposto, com o qual foram, também, definidos tanto um Procedimento Operacional Padrão (POP), o qual incluiu a definição de um Protocolo de Participação do Operador (PPO), quanto a utilização de um recurso próprio de auxílio computacional ao registro (inspeção e identificação) e medição, denominado Modelo Geométrico Auxiliar (MGA). O método desenvolvido, provou-se, é cientificamente confiável, versátil e especialmente interessante à realização de análises tomográficas osteométricas em condições de variações sub milimétricas.

- Outros estudos são sugeridos no sentido de se obter melhor esclarecimento acerca da participação dos diversos tipos de erro (sistemáticos e aleatórios) associados aos sistemas de obtenção, visualização, registro e medição de imagens tomográficas volumétricas disponíveis atualmente, haja vista a significativa variação metodológica verificada, o que vem a dificultar tanto o entendimento das limitações inerentes, tornando limitada a realização de Revisões Sistemáticas e de Meta-Análises, como também, e naturalmente, a possibilidade de aplicação clínica inferencial de medidas de espessuras ósseas em escala sub milimétrica. 


\section{REFERÊNCIAS 2}

Almeida CP. Influência da base craniana sobre as dimensões transversais das bases apicais e dos arcos dentários [dissertação]. São Paulo, Universidade de São Paulo, Faculdade de Odontologia; 2011.

Autodesk $^{\circledR}$. Learning AutoCAD ${ }^{\circledR} 2010$ / Autodesk Official Training Guide - Essentials. [place unknown]: Autodesk Certification Preparation, 2009. 001B1 - 050000 CM10A

Ballrick JW, Palomo JM, Ruch E, et al. Image distortion and spacial resolution of a commercially available cone-beam computed tomography machine. Am J Othod Dentofacial Orthop. 2008 Oct;134(4):572-82.

Baumgaertel S. Cortical bone thickness and bone depth of the posterior palatal alveolar process for mini-implant insertion in adults. Am J Orthod Dentofacial Orthop. 2011 Dec;140(6):806-11.

Baumgaertel S, Hans MG. Buccal cortical bone thickness for mini-implant placement. Am J Orthod Dentofacial Orthop. 2009 Aug;136(6):230-5.

Brezniak N, Goren S, Zoizner R, et al. The accuracy of the cementoenamel junction identification on periapical films. Angle Orthod. 2004 Aug;74(4):496-500.

Brown AA, Scarfe WC, Scheetz JP, et al. Linear accuracy of cone beam CT derived 3D images. Angle Orthod. 2009 Jan;79(1):150-7.

Carranza F, Newman M, Takei H. The tooth-supporting structures. Clinical Periodontology. 9th ed. Philadelphia: W. B. Saunders; 2002.

Chilvarquer I, Hayek JE, Azevedo B. Tomografia: seus avanços e aplicações na Odontologia. Rev ABRO. 2008;9(1):3-9.

Damstra J, Fourie Z, Huddleston Slater JJ, et al. Accuracy of linear measurements from cone-beam computed tomography-derived surface models of different voxel sizes. Am J Orthod Dentofacial Orthop 2010 Jan;137(1):16.e1-6, discussion 16-7.

\footnotetext{
${ }^{2}$ De acordo com estilo Vancouver.
} 
Farnsworth D, Rossouw PE, Ceen RF, et al. Cortical bone thickness at common miniscrew implant placement sites. Am J Orthod Dentofacial Orthop 2011 Apr;139(4):495-503.

Freitas A, Rosa JE, Souza IF. Radiologia odontológica. 2ª ed. São Paulo: Artes Médicas; 1988. $612 \mathrm{p}$.

Goldman HM, Cohen DW. The infrabony pocket: classification and treatment. J Periodontol 1958 Oct;29(4):272-9.

Honda K, Arai Y, Kashima M, et al. Evaluation of the usefulness of the limited conebeam CT (3DX) in the assessment of the thickness of the roof of the glenoid fossa of the temporomandibular joint. Dentomaxillofacial Radiol 2004 Nov;33(6):391-5.

Hulley SB, Cummings SR, Browner WS, et al. Delineando a pesquisa clínica - uma abordagem epidemiológica. Porto Alegre: Artmed; 2008. 384 p.

Inmetro - Instituto Nacional de Metrologia, Normalização e Qualidade Industrial. Vocabulário Internacional de Metrologia: conceitos fundamentais e gerais e termos associados (VIM2008). 1를 ed. Rio de Janeiro; 2009.

Januário AL, Duarte WR, Barriviera $\mathrm{M}$, et al. Dimension of the facial bone wall in the anterior maxilla: a cone-beam computed tomography study. Clin Oral Implants Res 2011 Oct;22(10):1168-71.

Kajan ZD, Taromsari M. Value of cone beam CT in detection of dental root fractures. Dentomaxillofacial Radiol 2012 Jan;41(1):3-10.

Kamburoglu K, Kiliç C, Ozen T, et al. Accuracy of chemically created periapical lesion measurements using limited cone beam computed tomography. Dentomaxillofacial Radiol 2010 Feb;39(2):95-9.

Kameoka S, Kuroki Y, Honda K, et al. Diagnostic accuracy of microcomputed tomography for osseous abnormalities in the rat temporomandibular joint condyle. Dentomaxillofacial Radiol 2009 Oct;38(7):465-9.

Kapila S, Conley RS, Harrell JW. The current status of cone beam computed tomography imaging in orthodontics. Dentomaxillofacial Radiol 2011 Jan;40(1):2434. 
Lascala CA, Panella J, Marques M. Analysis of the accuracy of linear measurements obtained by cone beam computed tomography (CBCT-NewTom). Dentomaxillofacial Radiol 2004 Sep;33(5):291-4.

Leung CC, Palomo L, Griffith R, et al. Accuracy and reliability of cone-beam computed tomography for measuring alveolar bone height and detecting bony dehiscences and fenestrations. Am J Orthod Dentofacial Orthop 2012 Apr;32(4 Suppl):S109-19.

Loubele M, Maes F, Schutyser F, et al. Assessment of bone segmentation quality of cone-beam CT versus multislice spiral CT: a pilot study. Oral Surg Oral Med Oral Pathol Oral Radiol Endod 2006 Aug;102(2):225-34.

Mileman P, Van den Hout WB. Evidence-based diagnosis and clinical decision making. Dentomaxillofacial Radiology 2009 Jan;38(1):1-10.

Misch KA, Yi ES, Sarment DP. Accuracy of cone beam computed tomography for periodontal defect measurements. J Peridontol 2006 Jul;77(7):1261-6.

Mol A. Imaging methods in periodontology. Periodontol 2000. 2004;34:34-48.

Naitoh M, Hayashi $\mathrm{H}$, Tsukamoto $\mathrm{N}$, et al. Labial bone assessment surrounding dental implant using cone-beam computed tomography: an in vitro study. Clin Oral Implants Res 2011 Aug;1-5. doi: 10.1111/j.1600-0501.2011.02249.x.

Noujeim M, Prihoda T, Langlais R, et al. Evaluation high-resolution cone beam computed tomography in the detection of simulated interradicular bone lesions. Dentomaxillofacial Radiol 2009 Mar;38(3):156-62.

Nowzari $\mathrm{H}$, Molayem $\mathrm{S}$, Chiu $\mathrm{CH}$, et al. Cone beam computed tomographic measurement of maxillary central incisors to determine prevalence of facial alveolar bone width $\geq 2 \mathrm{~mm}$ cid_287. Clin Implant Dent Relat Res 2010 May. doi: 10.1111/j.1708-8208.2010.00287.x.

Özer SY. Detection of vertical root fractures by using cone beam computed tomography with variable voxel sizes in an in vitro model. J Endod 2011 Jan;37(1):75-9.

Palomo L, Palomo JM, Bissada NF. Salient periodontal issues for the modern 
biologic orthodontist. Seminn Orthod 2008 Dec;14(4):229-45.

Patcas R, Müller L, Ullrich $\mathrm{O}$, et al. Accuracy of cone-beam computed tomography at different resolutions assessed on the bony covering of the mandibular anterior teeth. Am J Orthod Dentofacial Orthop 2012 Jan;141(1): 41-50.

Razavi T, Palmer RM, Davies J, et al. Accuracy of measuring the cortical bone thickness adjacent to dental implants using cone beam computed tomography. Clin Oral Implants Res 2010 Jul;21(7):718-25.

Romans L. CT Image Quality [5 out. 2011]. Disponível em: http://www.cewebsource.com

Saddy MS. Estudo comparativo entre a tomografia computadorizada e a tomografia volumétrica na confecção de modelos de prototipagem [tese de doutorado]. São Paulo: Universidade de São Paulo, Faculdade de Odontologia; 2006.

Scarfe WC, Farman AG. What is cone-beam CT and how does it work? Dent Clin North Am 2008 Oct;52(4):707-30.

Schulze R, Heil U, Gross D, et al. Artefacts in CBCT: a review. Dentomaxillofacial Radiol 2011 Jul;40(5):265-73.

Sherrard JF, Rossouw PE, Benson BW, et al. Accuracy and reliability of tooth and root lengths measured on cone-beam computed tomographs. Am J Orthod Dentofacial Orthop 2010 Apr;137(4 Suppl):s100-8.

Shiratori LN, Marotti J, Yamanouchi J, et al. Measurement of buccal bone volume of dental implants by means of cone-beam computed tomography. Clinical Oral Implants Res 2011 Jun. doi: 10.1111/j.1600-0501.2011.02207.x.

Sim J, Wright CC. The kappa statistic in reliability studies: use, interpretation, and sample size requirements. Phys Ther 2005 Mar;85(3):257-68.

Slezák P, Waczulíková I. Reproducibility and Repeatability. Physiol Res 2011;60(1):203-5.

Stratemann SA, Huang JC, Maki K, et al. Comparison of cone beam computed tomography imaging with physical measures. Dentomaxillofacial Radiol 2008 
Feb;37(2):80-93.

Sun Z, Smith T, Kortam S, et al. Effect of bone thickness on alveolar bone-height measurements from cone-beam computed tomography images. Am J Orthod Dentofacial Orthop 2011 Feb;139(2):e117-27.

Suomalainen A, Smith T, Kortam S, et al. Dosimetry and image quality of four dental cone beam computed tomography scanners compared with multislice computed tomography scanners. Dentomaxillofacial Radiol 2009 Sep;38(6):367-78.

Suomalainen AK, Salo A, Robinson S, et al. The 3DX multi image micro-CT device in clinical dental practice. Dentomaxillofacial Radiol 2007 Feb;36(2):80-5.

Suomalainen A, Vehmas T, Kortesniemi M, et al. Accuracy of linear measurements using dental cone beam and conventional multislice computed tomography. Dentomaxillofacial Radiol 2008 Jan;37(1):10-7.

Swasty D, Lee J, Huang JC, et al. Cross-sectional human mandibular morphology as assessed in vivo by cone-beam computed tomography in patients with different vertical facial dimensions. Am J Orthod Dentofacial Orthop 2011 Apr;139(4 Suppl):e377-89.

Timock AM, Cook V, McDonald T, et al. Accuracy and reliability of buccal bone height and thickness measurements from cone-beam computed tomography imaging. Am J Orthod Dentofacial Orthop 2011 Nov;140(5):734-44.

Tomasi C, Bressan E, Corazza B, et al. Reliability and reproducibility of linear mandible measurements with the use of a cone-beam computed tomography and two object inclinations. Dentomaxillofacial Radiol 2011 May;40(4):224-50. doi: 10.1259/dmfr/1742330.

Tsutsumi K, Chikui T, Okamura K, et al. Accuracy of linear measurement and the measurement limits of thin objects with cone beam computed tomography: effects of measurement directions and of phantom locations in the fields of view. Int $\mathrm{J}$ Oral Maxillofacial Implants 2011 Jan-Feb;26(1):91-100.

Umetsubo OS. Tomografia computadorizada por feixe cônico para detecção de lesões incipientes de furca simuladas em mandíbulas suínas maceradas [dissertação]. São Paulo: Universidade de São Paulo, Faculdade de Odontologia; 2011. 
Vasconcelos KF, Evangelista KM, Rodrigues CD, et al. Detection of periodontal bone loss using cone beam CT and intraoral radiography. Dentomaxillofacial Radiol 2012 Jan;41(4):64-9.

Vuolo JH. Fundamentos da teoria de erros. $2^{\mathrm{a}}$ ed. São Paulo: Edgard Blücher; 1996.

Wagner AG. The meaning of statistics in dental literature. J Prost Dent 1973; 30(4): 446-53.

Zanet TG. Sistema de apoio à decisão diagnóstica baseado em características radiográficas [tese doutorado]. 2009. São Paulo: Universidade de São Paulo, Faculdade de Odontologia; 2009. 


\author{
UNIVERSIDADE DE SAO PAULO \\ FACULDADE DE ODONTOLOGIA \\ PROGRAMA DE PÓS-GRADUAÇAO EM ODONTOLOGIA \\ DEPARTAMENTO DE ORTODONTIA E OONTOPEDIATRIA
}

\title{
Termo de Consentimento Livre e Esclarecido (TCLE)
}

Titulo do projeto: Análise tomográfica quantitativa linear de espessuras ósseas dentoalveolares com vistas ao diagnóstico em Ortodontia - Proposta de Método

Pesquisadores responsáveis: Prof. Dr. Jorge Abrão - Professor Associado do Departamento de Ortodontia e Odontopediatria da FOUSP / Orientador da pesquisa ; CD. Siddhartha Uhrigshardt Silva - Doutorando em Ortodontia pela FOUSP / Responsável pela pesquisa

Instituição / Departamento: FOUSP/ Ortodontia e Odontopediatria

Telefone para contato: (0xx11) 3091-7812- falar com Viviane ou Édina

Local da coleta de dados: FOUSP / Clínica de Ortodontia e INDOR/FUNDECTO (Av. Lineu Prestes 2227, 05508-000 São Paulo/SP).

\section{Prezado Senhor(a):}

- Você esta sendo convidado(a) a participar desta pesquisa de modo totalmente voluntário.

- Antes de concordar em participar desta pesquisa, é muito importante que você compreenda as informações e instruções contidas neste documento.

- Os pesquisadores deverão responder todas as suas dúvidas antes de você se decidir a participar. 
- Você tem o direito de desistir de participar da pesquisa em qualquer momento da sequência de sua realização, sem nenhuma penalidade e sem perder os benefícios aos quais tenha direito.

Objetivo do estudo: Pretende-se avaliar a viabilidade prática de serem obtidas algumas medidas ósseas tomográficas, denominadas de espessuras ósseas alveolares, maxilares e mandibulares, com a finalidade de testar cientificamente se as mesmas podem ser confiáveis para a utilização durante a elaboração do diagnóstico e tratamento ortodônticos.

Procedimentos: Sua participação nesta pesquisa consistirá em ser submetido a um (01) exame de tomografia computadorizada de feixe cônico (cone beam), sem uso de contraste, para posterior análise e realização do experimento-pesquisa.

Riscos e Desconfortos: A dose de radiação do exame tomográfico / aparelho de cone beam varia de 40 a $50 \mu \mathrm{Sv}$, sendo similar a de um exame periapical completo, ou seja, de 14 radiografias periapicais, cuja variação e de 33 a $84 \mu$ Sv. No momento da realização da tomada radiográfica, todas as normas, atualmente consideradas e relacionadas à proteção biológica, serão prontamente adotadas conforme o protocolo selecionado.

Tempo: O tempo de duração do procedimento a que será submetido será de aproximadamente trinta (30) segundos, sendo necessária a sua permanência nas dependências do local de realização do exame (INDOR), caso haja necessidade de preenchimento de fichas e outras necessidades. A realização do seu exame será em uma única sessão.

Benefícios: A partir da realização do exame, serão avaliadas e diagnosticadas eventuais condições morfológicas e/ou patológicas atípicas e relevantes quanto ao prejuízo à saúde dos tecidos revelados pelo exame específico de tomografia computadorizada (de feixecônico). Estas características do diagnóstico, caso sejam encontradas, serão devidamente descritas, explicadas e consideradas no interesse do seu caso. Os registros tomográficos, ainda, fornecerão dados para a obtenção de maior conhecimento sobre o tema abordado, favorecendo sobremaneira e agregando valor aos processos de investigação e pesquisa científica associados ao tema.

Ajuda de Custos: Caso julgue necessário, as despesas de transporte decorrentes da sua participação nessa pesquisa poderão ser compensadas pelo pesquisador responsável. 
Sigilo: O exame realizado será arquivado e integrado ao Acervo de Documentações do Departamento de Ortodontia e Odontopediatria da Faculdade de Odontologia da Universidade de São Paulo. As informações obtidas serão utilizadas para produção cientifica, podendo servir para a realização de teses, dissertações, monografias, artigos em periódicos e apresentações em Congressos. Os dados relativos à sua pessoa serão preservados com garantia de sigilo e respeitados considerando os preceitos da moral e ética.

Se houver dúvidas sobre a ética da pesquisa entre em contato com o Comitê de Ética em Pesquisa da Faculdade de Odontologia (Av. Lineu Prestes 2227, 05508-000 São Paulo ou pelo e-mail cepfo@usp.br).

Declaro que discuti com o aluno de Pós-Graduação (Doutorado) Siddhartha Uhrigshardt Silva sobre a minha decisão em participar dessa pesquisa. Ficaram claros, para mim, quais serão os propósitos do estudo, os procedimentos necessários à sua realização, os desconfortos e riscos, as garantias de confidencialidade e de permanentes esclarecimentos. Ficou claro, também, que minha participação é isenta de despesas. Sendo assim, concordo em participar voluntariamente deste estudo e poderei retirar o meu consentimento em qualquer momento, antes ou durante o mesmo, sem penalidades, ou prejuízo, ou ainda perda de quaisquer benefícios que possa eu ter adquirido.

Sendo assim, declaro, também, que estou assinando e recebendo uma cópia assinada deste termo.

Nome:

$R G$ :

Data:

Telefone:

Assinatura:

Siddhartha U. Silva - Pesquisador responsável (orientando) - CPF: 026.091.059-75

Contato: (0xx11) 3091-7812 / Endereço eletrônico: sus@usp.br

Jorge Abrão - Orientador da pesquisa - CPF: 530-562-648-04

Contato: (0xx11) 3091-7812 / Endereço eletrônico: jabrao@usp.br 
APÊNDICE B - Protocolo de Participação do Operador (PPO)

Com vistas a favorecer o controle e reprodutibilidade do sistema de observação previamente delineado, foram definidas e registradas ações técnicas, gerais e específicas, considerando a participação dos examinadores durante a ações de inspeção e identificação. A saber:

\section{Gerais}

1.1 - Cada operador foi inicialmente instruído acerca dos requerimentos necessários à realização das sequências-teste. Todas as instruções de participação foram previamente padronizadas e então apresentadas, verbal e visualmente (com auxílio de programa de apresentação de slides), para cada operador, e durante tempo médio de duração de vinte (20) minutos. Após a apresentação, todos os operadores foram indagados sobre eventuais dúvidas remanescentes, as quais seriam solucionadas antes do início dos testes;

1.2 - Todos os participantes (incluindo o operador principal), antes de iniciarem o treinamento prévio (tempo limite definido em até 30 minutos) com algumas imagens isoladas da sequência definitiva, foram submetidos a teste preliminar de acuidade visual a partir do Programa (aplicativo-“app") "Senses - What U See” (Baltronic ${ }^{\circledR}$-Multimedia Systems Department - Gdänsk University of Technology) a fim de que fosse conhecida a capacidade de cada operador em diferenciar graus variados de contraste de cinza. O teste foi realizado com a sala mantida em mesmas condições (controle de luminosidade - escura) daquelas que seriam utilizadas, em seguida, para a sequência dos registros definitivos. O Programa foi aplicado em dispositivo móvel com tela de 9,7 pol. (iPad, Machintosh ${ }^{\circledR}$, EUA), e foram seguidas as recomendações originais dos desenvolvedores para a realização dos testes. Dois resultados são possíveis com o referido teste: suficiente ou insuficiente. Caso fosse constatada insuficiência após a realização do teste, o participante seria convidado a repetilo. O limite de "duas insuficiências seguidas" foi adotado como critério adicional de exclusão do participante. Embora o referido teste não seja, em si, um teste oftalmológico oficial, os fabricantes indicam sua validade para resultados positivos. Havendo repetidas respostas negativas, então seria necessária a realização de teste oftalmológico oficial. 


\section{Específicas - Inspeção e Identificação}

\subsection{Preparo do local}

Os testes foram realizados em três ambientes distintos, de acordo com a disponibilidade do operador e com as necessidades requeridas pelo POP definido. A intensidade da luz presente nos ambientes foi controlada para que houvesse pouca luminosidade (escura), principalmente nas proximidades de onde estava o computador.

\subsection{Recursos computacionais - Ajuste de monitor e Mouse}

A tela (monitor) do computador (MacBook Air) utilizado para a realização dos testes, no tocante à inclinação vertical da mesma, foi definida individualmente por cada operador em sua preferência de conforto. Assim também foi com a posição lateral do mouse. A fim de que fosse mantido o conforto visual de acomodação, foi estabelecida distância mínima de vinte e cinco (25) centímetros, dos olhos até a tela de inspeção. O computador permaneceu, durante todos os procedimentos, conectado à fonte de alimentação de energia de modo que fosse obtido o melhor aproveitamento do rendimento luminoso. A intensidade de brilho da tela foi mantida constante. $O$ mouse $\left(\right.$ Microsoft ${ }^{\circledR}$-wireless) foi previamente configurado para a máxima sensibilidade de movimento, suas pilhas eram novas e o MousePad foi, naquele instante, fixado à bancada de trabalho por meio de adesivo industrialmente incorporado à face inferior do mesmo. Os operadores foram instruídos a manter a atenção para que o mouse permanecesse sobre a superfície do MousePad durante a sua utilização.

\subsection{Preparo o operador}

Desde a realização dos testes preliminares até a finalização de cada registro-teste, os operadores foram diretamente supervisionados pelo operador principal (Op.0). Não houve comunicação entre os operadores acerca de quaisquer imagens ou resultados gerados, e durante a realização dos procedimentos os operadores foram instruídos a desligar seus telefones celulares. Assim, não foram permitidas interrupções durante os procedimentos. Os 
operadores foram instruídos a permanecer sentados confortavelmente durante todo o procedimento.

\subsection{Preparo dos arquivos}

Um arquivo padrão inicial foi totalmente configurado em conformidade com as definições metodológicas descritas (Método - Programa AutoCAD ${ }^{\circledR}$, p. 131). A partir deste, foram então replicados sete (07) arquivos, um para cada um dos operadores participantes. O acesso dos arquivos foi imediato e deu-se após terem sido apresentadas as características operacionais do experimento aos operadores.

\subsection{Aleatoriedade da sequência de inspeção visual}

Devido à possibilidade de ocorrência de vieses de seleção (preferências individuais associadas às sequências e aos tipos de imagens), foram, antes do início dos testes e por cada operador, sorteadas (sorteio simples) as respectivas sequências de inspeção, a partir do total de doze (12) dentes, resultando em um sorteio de seis (06) dentes para a sequência maxilar, e outro de seis (06) dentes para a sequência mandibular. Uma vez tendo sido iniciada a sequência de registros, e considerando novamente o viés de seleção, as faces de orientação consideradas, vestibular e palatina/lingual, foram intercaladas em cada novo dente avaliado para resolver a aplicação dos pontos. Ficou a critério do operador a decisão de qual seria a sequência de seleção e demarcação dos pontos, em uma mesma face, para os níveis de espessura (1, 2 ou 3 ) estabelecidos.

\subsection{Inspeção e Identificação}

As ações operacionais de inspeção e identificação tomográfica foram instruídas a partir da sequência descrita no POP definido para esta investigação (Método / POP, p. 131). 


\subsection{Tempo e Intervalos}

Não foi estabelecido limite de tempo para a obtenção dos resultados, nem tampouco foram considerados objetivamente (análise) os tempos de participação de cada examinador. Contudo, e apenas como informação descritiva adicional, cada operador foi cronometrado em sua participação a fim de que fosse obtida, ao final, média geral para os resultados na maxila e na mandíbula (Apêndice E- Nota Técnica Fase III, p. 247).

Foram também instituídos intervalos de descanso, com mínimo de cinco (5) e máximo de dez (10) minutos, executados a cada três dentes operacionalizados, totalizando quatro (4) intervalos, arquivos maxila e mandíbula, durante a realização de toda a sequência. Durante os intervalos, os operadores foram instruídos a alongar o corpo e desviar seus olhares da tela. Caso houvesse necessidade, e/ou a pedido do participante, o tempo poderia eventualmente ser estendido. 
APÊNDICE C - Nota Técnica - Fase I

\section{A - Testes Preliminares com Softwares}

Com o intuito de obter conhecimento prévio da qualidade e real possibilidade de serem estabelecidos padrões metodológicos apropriados, associados à precisão e reprodutibilidade, foram, considerando os objetivos do presente experimento, subjetivamente testados alguns programas computacionais comercialmente disponíveis para a operacionalização de arquivos DICOM. Estes programas foram utilizados nas dependências tanto do Departamento de Ortodontia e Odontopediatria da FOUSP, como do INDOR/FUNDECTO, pelo operador principal deste estudo (Op. 0), de modo independente, autorizado e a partir de imagens dos respectivos Acervos de Documentação Tomográfica.

Inúmeras são possibilidades de aplicação anunciadas pelos fabricantes dos softwares destinados ao registro, análise e auxílio à interpretação tomográfica, seja ela qualitativa (observação) ou mesmo quantitativa (medição). Entre elas estão as avaliações clínicas para diagnóstico, planificação e controle terapêuticos e, eventualmente, para prognósticos; as aplicações acadêmicas - como fonte de conhecimento anatômico descritivo e topográfico, e, ainda, as aplicações científicas experimentais.

Os testes realizados foram especialmente conduzidos para o conhecimento da qualidade preliminar dos seguintes recursos ou funções:

Ampliação (zoom) padrão - era possível estabelecer padrões definidos pelo operador de ampliação de visualização das imagens, sem que estas distorcessem ou mesmo perdessem a proporção das medidas realizadas?

Operacionalização para experimentos científicos - era possível o controle total e livre do operador quanto às figuras geométricas e outros elementos gráficos auxiliares com precisão sub milimétrica reconhecida? Era possível operar em camadas (layers) no sentido de sobrepor inúmeras análises em um mesmo corte tomográfico?

Medição - o procedimento de medição podia ser livremente ajustado para as necessidades metodológicas (metrológicas) do experimento?

Considerando os quesitos supra citados, e de um modo geral, nenhum dos programas inicialmente consultados (NemoChep3 $D^{\circledR}$ e NemoScan ${ }^{\circledast}$ - Software Nemotec S.L.- The

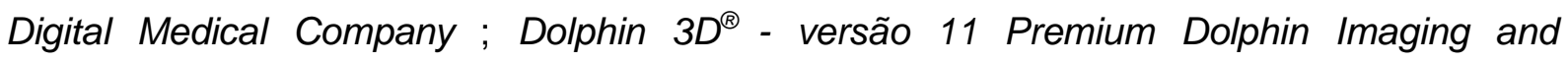


Management Solutions, Chatsworth, CA, EUA; InVivoDental 4.0 $0^{\circledR}$ Anatomage Inc. San Jose, CA, e iCAT Xoran $^{\circledR}$ - versão 3.1.62) foi capaz oferecer o conjunto de recursos necessários à execução dos testes propostos com a presente investigação.

Não foram constatadas, à época da realização desta fase do estudo (I), definições e/ou instruções oficiais as quais fossem referenciadas em documentos de experimentação científica prévia, relatando intervalos de precisão e/ou de exatidão associados aos resultados de medição oferecidos pelos recursos de cada software em sua particularidade operacional/comercial, e a partir da visualização direta de cada um dos modos de observação conjugados pelos próprios sistemas TCFC, fossem estes obtidos de cortes tomográficos 2D (planares) específicos das reformatações volumétricas ou, ainda, de avaliação direta do volume (3D) considerado.

Deste modo, as decisões baseadas nas informações quantitativas obtidas daqueles softwares acabavam por depender, quase que totalmente e nos casos de valores obtidos em menor escala, da participação indesejável de condições não testadas associadas à incerteza de medida, além, é claro, da experiência, capacidade e conhecimento individuais prévios do operador, o que torna o processo bastante "operador-dependente" e, com isso, mais sujeito à participação de erros. $E$ já que estes erros não são amplamente conhecidos e poderiam ser potencialmente desfavoráveis à comparabilidade dos resultados das medições (vieses), optou-se pela utilização de outro(s) software(s) para a operacionalização dos registros tomográficos, o(s) qual(is) fosse $(\mathrm{m})$ capaz(es) de reunir as qualidades técnicas ora citadas.

É opinião desse autor, desde que sejam respeitados certos limites intuitivos de aplicação científica diante da ausência de informações objetivas e uniformes relativas à confiabilidade nos processos de registro e medição associados àqueles softwares, que algumas das propostas, anunciadas comercialmente por aqueles fabricantes, possam ser efetivamente empreendidas, mas que deveriam, sempre, estar em proporção direta e justificada com a qualidade das evidências disponíveis, geradas por meio de expedientes próprios e há muito já conhecidos de experimentação científica.

A seguir são apresentadas as principais condições não-conformes, ou seja, as principais fontes de insegurança metodológica (variação durante padronização e controle operacional e tendências-vieses às limitações metrológicas), distribuídas entre os quatro programas inicialmente consultados, e observadas durante a Fase I deste experimento, a saber:

a) incapacidade do cursor de medida em propiciar visualização direta de reparos anatômicos bastante diminutos durante a inspeção tomográfica específica (testes), em 
decorrência do seu tamanho, cor e formato, considerando as coordenadas posicionais associadas aos modos de ampliação (zoom);

b) incapacidade de serem obtidas ampliações (zoom) das imagens para visualização conforme valores numéricos específicos de controle; os quais fossem definidos pelo próprio operador/pesquisador, e não sujeitos às determinações pré-estabelecidas pelos recursos dos softwares;

c) incapacidade de serem desenvolvidos "templates" de auxílio geométrico à realização das medições, os quais sejam livres, ou seja, totalmente controláveis pelo operador /pesquisador em suas formas, características e posições;

d) impossibilidade de serem operacionalizadas imagens tomográficas em outros formatos de arquivo que não aqueles em formato DICOM (à exceção do iCAT Xoran ${ }^{\circledR}$, para arquivos xoran), fazendo com que a interface de uso seja limitada diante de situações em que, por razões técnicas associadas à necessidade de obtenção de qualidade dos cortes tomográficos e para finalidades específicas (o caso desse estudo), esses outros formatos sejam necessários.

e) Incapacidade de oferecer automação de alguns dos processos específicos dependentes das preferências do pesquisador (melhor controle), tanto durante os eventos relativos à inspeção e identificação dos pontos de referência, quanto durante a medição linear de distâncias em escala de resolução sub milimétrica.

Em algumas situações, e isto já havia sido constatado pelo operador principal (Op.0) previamente à realização dos testes, a imagem tomográfica disponível em um dado local de interesse não correspondia à conceituação descrita (Método, p. 116) dos pontos que deveriam ser identificados. Essa condição, naturalmente, já era esperada, haja vista que a conceituação proposta representa uma situação anatômica idealizada, baseada em modelos conceituais de anatomia "real". Portanto, tanto para a experiência conceitual do operador principal, quanto para aquela dos outros operadores, em relação aos padrões de reconhecimento das representações tomográficas dos tecidos envolvidos durante os registros-teste, é considerada variável. Sendo assim, as instruções técnicas preliminares, as quais foram oferecidas aos examinadores, tinham apenas a finalidade de influenciar, de modo variável, alertando para algumas das dificuldades mais frequentes associadas à inspeção tomográfica. 
Se não havia quantidade óssea circunjacente aos locais de demarcação, ou, ainda, se a imagem local inspecionada não correspondia àquela de maior densidade, esperada para as corticais ósseas, ou mesmo dos limites de superfície associados ao cemento, então, embora essa condição pudesse eventualmente mudar a conceituação dos pontos, não mudou sua interpretação de aplicação, uma vez que o que se buscava era a noção representativa dos limites anatômicos entre os tecidos.

Esta variável foi incluída nos registros de inspeção e identificação, e sua análise foi integral (Resultados, p. 173).

\section{B - Seleção do sistema e parâmetros de aquisição tomográfica}

1- $i C A T^{\circledR}$ - o tomógrafo $\mathrm{iCAT}^{\circledR}$ foi selecionado devido à sua representatividade em termos de frequência de aplicações e qualidade dos resultados a ele atribuídos na literatura especializada.

2- FOV - Buscou-se selecionar um dado campo de visão (FOV) o qual fosse capaz de propiciar a avaliação tanto dos dentes maxilares quanto dos mandibulares em uma mesma aquisição. Com isso, houve a intenção de não fosse muito diferente daqueles utilizados pela maioria dos protocolos disponíveis na literatura, a fim de que fosse beneficiada a comparabilidade metodológica. Desse modo, e em obediência aos limites de configuração / resolução do equipamento ( iCAT $^{\circledR}$ ) foi determina a relação final entre tamanho de voxel, matriz e FOV, e foi o FOV de $13 \mathrm{~cm}$ aquele selecionado para este experimento.

3- Resolução de voxel de $0,25 \mathrm{~mm}$ - Diante da condição de incerteza relativa à variação de participação dos operadores, bem como dos vieses associados ao padrão de delineamento do presente experimento, e ainda considerando a escala de medida (sub milimétrica) das distâncias pretendidas, foi pensada a possibilidade de ser utilizado o melhor padrão de resolução espacial possível.

Assim, foram prévia e subjetivamente testadas as seguintes resoluções de voxel: $0,125 \mathrm{~mm}, 0,25 \mathrm{~mm}, 0,3 \mathrm{~mm}$ e $0,4 \mathrm{~mm}$. A opção que melhor reproduziu imagens com qualidade de detalhe relativa aos contornos ósseos de cortes trans-axiais (oblíquos/coronais), conforme protocolos similares de obtenção, mesmo tomógrafo (iCAT ${ }^{\circledR}$ ), porém provenientes de indivíduos distintos e para diversas finalidades, foi a de $0,25 \mathrm{~mm}$ (tamanho de voxel/pixel).

Todos os testes subjetivos de qualidade de reprodução de detalhes foram realizados nas dependências do INDOR/FUNDECTO, conforme operacionalização tomográfica 
especializada do Dr. Tiago Zanet, e a partir da estação de trabalho (workstation) com o software nativo de visualização do próprio sistema iCAT ${ }^{\circledR}$ (iCAT® Xoran / iCAT® Vision). Entretanto, naquele momento não foram concomitantemente testados os recursos de medida e de operacionalização do referido software. Esta providência foi testada previamente e com seleção casual de alguns arquivos de imagem tomográfica dos Acervos de Documentação Radiológica, do INDOR e do Departamento de Ortodontia e Odontopediatria da FOUSP.

Assim, e a partir de avaliação preliminar destes arquivos tomográficos pertencentes aos referidos Acervos de Documentações, foi definida a utilização de resolução de voxel de $0,25 \mathrm{~mm}$ para a realização do presente experimento.

No Apêndice D (Nota Técnica - Fase II, p.244) estão registrados os comentários associados aos fatores necessários à obtenção de condições mais apropriadas e favoráveis ao método de registro (inspeção e identificação) e medição estabelecido nesta proposta, com vistas à obtenção de espessuras ósseas alveolares, vestibulares e palatinas/linguais, maxilares e mandibulares. 
APÊNDICE D - Nota Técnica - Fase II

A seguir serão descritas e comentadas algumas das características técnicas favoráveis obtidas com a utilização do programa AutoCAD ${ }^{\circledR}$.

a) Cursor

O cursor de tela (model space crosshair) pode ser ajustado conforme as mais variadas necessidades operacionais. Para este experimento, ajustes na forma, tamanho, cor, e, ainda, na espessura das linhas constituintes foram definidos com a finalidade de propiciar condições mais favoráveis durante os registros de inspeção visual e identificação manual dos pontos tomográficos estabelecidos. Assim, a intenção foi de que a suavidade de movimento do cursor, determinada pela sensibilidade de movimento do mouse, fosse valorizada com a possibilidade efetiva de certas condições visuais, as quais não fossem capazes de interferir no reconhecimento anatômico das estruturas de interesse.

Percebeu-se, em outros programas, que essa versatilidade, quando existia, era bastante limitada, fazendo com que, em alguns casos e pelo tamanho, cor, espessura e forma dos cursores, muitos reparos anatômicos diminutos fossem parcial ou totalmente sobrepostos pelos referidos cursores, prejudicando a visualização dos limites locais de interesse à inspeção.

Além das características estruturais descritas para o cursor (utilizado com o programa AutoCAD ${ }^{\circledR}$, uma função opcional específica foi aproveitada. A precisão dos desenhos geométricos e a qualidade métrica das medições pretendidas foram especialmente garantidas e facilitadas a partir do recurso AutoSnap ${ }^{\circledR}$. Assim, por meio desta função computacional de automação durante o reconhecimento posicional de elementos gráficos presentes (ímã), os referenciais geométricos selecionados, desenhados sobre a figura tomográfica importada (raster image), foram associados automaticamente por essa função do programa, e de modo independente do zoom de tela aplicado, ou mesmo do tipo de relação métrica pretendida considerando os pontos, linhas e distâncias (grandezas) estabelecidas.

b) Camadas de trabalho (layers) 
As camadas de trabalho são possibilidades gráficas de serem estabelecidos desenhos sobrepostos entre si, ou, como foi o caso do presente delineamento, sobre imagens tomográficas agregadas ao arquivo principal (dwg.).

Os desenhos podem ser definidos sob variados graus de dimensão, escala e, ainda, conforme necessidades diversas de demarcação e medição. Linhas construídas em sequência de diminutos segmentos de reta, conforme orientações não retilíneas, podem formar curvas (polyline / spline) com níveis de resolução bastante regulares e suficientemente representativas de uma dada uniformidade de contorno anatômico pretendido, embora esta função não tenha sido utilizada nesta pesquisa.

Esta possibilidade operacional (layers) permite relacionar todos os desenhos, com cores e características geométricas eventualmente diversas, salvá-los em mesmo arquivo e, fundamentalmente, relacionar suas dimensões sob diversos modos de interesse (diversas análises) e para muitas das inúmeras características geométricas representadas com precisão definida e reproduzível, além de gerar seletividade de observação e impressão.

c) Interface intuitiva

Muitos dos comandos utilizados podem também ser definidos a partir da utilização de algumas das funções macro do programa, com mesma qualidade e, eventualmente, com maior facilidade.

d) Operacionalidade

- Controle total dos elementos gráficos (linhas e figuras geométricas), inclusive texto e números, com pronto e efetivo controle também dos modos de ampliação para a visualização específica dos limites, contornos e posições de todos os objetos incluídos na tela de trabalho, individual ou coletivamente considerados;

- Automação participativa durante a inspeção e identificação dos pontos tomográficos, bem como durante os procedimentos de medição, sejam estes lineares ou angulares, propiciando níveis bastante favoráveis de controle operacional durante o 
delineamento experimental e medição das grandezas selecionadas, especialmente considerando a aplicabilidade científica, e

- Estabilidade durante e após a importação de imagens JPEG por meio da função [CO]: insert $\downarrow$ raster image $\downarrow$ ), além de arquivamento padrão, compartilhamento e, ainda, possibilidade de visualização e edição (limitada) dos arquivos a partir de aplicativos compatíveis com sistema iOS Machintosh ${ }^{\circledR}$ ("apps"), a exemplo daquele que fora utilizado neste experimento (AutoCAD Viewer WS ${ }^{\circledR}$-2011). 


\section{APÊNDICE E - Nota Técnica - Fase III}

1- A partir da realização dos testes preliminares de acuidade visual (Programa -aplicativo"Senses - What U See"), foram registradas duas insuficiências, as quais foram para operadores distintos e, ainda, as duas ocorreram após a primeira tentativa-teste. Entretanto, foi registrada suficiência após terem sido conduzidas as segundas tentativas para aqueles operadores. Desse modo, todos os participantes foram aprovados e liberados à seguir com os testes de registro tomográfico propriamente ditos;

2- Todos os operadores optaram pela utilização do mouse à direita (de quem opera) do computador. Assim, todas as ações foram determinadas pela mão direita;

3- Não houve a necessidade de se estender intervalos, ou mesmo de utilizar, mediante solicitação, intervalos adicionais;

4- O quadro a seguir apresenta a sequência do sorteio simples realizado para a definição da sequência operacional em relação aos dentes, maxilares e mandibulares respectivamente:

\begin{tabular}{|c|c|}
\hline Operador & Dentes/Sequência \\
\hline $0(I)$ & $16,13,23,26,21,11$ e $31,41,33,36,43,46$. \\
\hline $0(I I)$ & $21,23,26,11,13,16$ e $43,41,46,31,36,33$. \\
\hline $0(I I I)$ & $13,26,11,16,21,23$ e $33,41,31,43,46,36$. \\
\hline 1 & $11,16,21,23,13,26$ e $36,43,33,31,46,41$. \\
\hline 2 & $21,26,11,23,13,16$ e $43,41,33,46,36,31$. \\
\hline 3 & $11,21,16,26,13,23$ e $46,31,33,36,43,41$. \\
\hline 4 & $11,23,26,21,13,16$ e $46,31,33,36,43,41$. \\
\hline 5 & $13,21,11,23,16,26$ e $43,33,41,46,31,36$. \\
\hline 6 & $21,26,11,13,16,23$ e $43,41,46,31,36,33$. \\
\hline
\end{tabular}

Quadro E.1 - Operadores e respectivas sequências aleatórias de operacionalização dos registros (cortes/dentes). 
5- As informações a seguir foram incluídas com finalidade descritiva e, sendo assim, não foram consideradas à análise eventual de parâmetros associados à eficiência geral de participação dos operadores.

6- Os quadros, de E.2 a E.10, relacionam os tempos de duração dos procedimentos de inspeção tomográfica (dentes considerados individualmente e médias de cada arco) referentes a cada um dos sete (07) operadores participantes.

\begin{tabular}{|c|c|c|c|}
\hline \multicolumn{5}{|c|}{ Operador 0 (I) } \\
\hline Dente & Tempo (min.) & Dente & Tempo (min.) \\
\hline 16 & 03,32 & 36 & 02,08 \\
\hline 13 & 03,53 & 33 & 03,57 \\
\hline 11 & 04,23 & 31 & 03,12 \\
\hline 21 & 08,15 & 41 & 01,56 \\
\hline 23 & 03,41 & 43 & 02,32 \\
\hline 26 & 05,29 & 46 & 03,45 \\
\hline total & $\mathbf{2 7 , 9 3}$ & total & $\mathbf{1 6 , 1 0}$ \\
\hline
\end{tabular}

Quadro E.2 - Duração (em minutos) do registro de inspeção e identificação para o Operador 0 (tempo I).

\begin{tabular}{|c|c|c|c|}
\hline \multicolumn{5}{|c|}{ Operador 0 (II) } \\
\hline Dente & Tempo (min.) & Dente & Tempo (min.) \\
\hline 16 & 04,03 & 36 & 02,30 \\
\hline 13 & 05,45 & 33 & 03,09 \\
\hline 11 & 04,13 & 31 & 01,45 \\
\hline 21 & 09,18 & 41 & 03,40 \\
\hline 23 & 05,50 & 43 & 04,33 \\
\hline 26 & $\mathbf{0 6 , 4 1}$ & 46 & $\mathbf{1 7 , 8 2}$ \\
\hline total & $\mathbf{3 4 , 7 0}$ & total & \\
\hline
\end{tabular}

Quadro E.3 - Duração (em minutos) do registro de inspeção e identificação para o Operador 0 (tempo II). 


\begin{tabular}{|c|c|c|c|}
\hline \multicolumn{5}{|c|}{ Operador 0 (III) } \\
\hline Dente & Tempo (min.) & Dente & Tempo (min.) \\
\hline 16 & 03,19 & 36 & 02,40 \\
\hline 13 & 03,27 & 33 & 04,07 \\
\hline 11 & 04,25 & 31 & 03,00 \\
\hline 21 & 06,24 & 41 & 02,15 \\
\hline 23 & 03,43 & 43 & 03,30 \\
\hline 26 & 05,10 & 46 & 05,40 \\
\hline total & $\mathbf{2 5 , 4 8}$ & total & $\mathbf{2 0 , 3 2}$ \\
\hline
\end{tabular}

Quadro E.4 - Duração (em minutos) do registro de inspeção e identificação para o Operador 0 (tempo III).

\begin{tabular}{|c|c|c|c|}
\hline \multicolumn{5}{|c|}{ Operador 1 } \\
\hline Dente & Tempo (min.) & Dente & Tempo (min.) \\
\hline 16 & 05,21 & 36 & 05,03 \\
\hline 13 & 04,46 & 33 & 03,43 \\
\hline 11 & 10,13 & 31 & 04,11 \\
\hline 21 & 04,46 & 41 & 03,43 \\
\hline 23 & 05,40 & 43 & 03,48 \\
\hline 26 & 07,36 & 46 & 04,57 \\
\hline total & $\mathbf{3 7 , 0 2}$ & total & $\mathbf{2 4 , 0 5}$ \\
\hline
\end{tabular}

Quadro E.5 - Duração (em minutos) do registro de inspeção e identificação para o Operador 1.

\begin{tabular}{|c|c|c|c|}
\hline \multicolumn{5}{|c|}{ Operador 2 } \\
\hline Dente & Tempo (min.) & Dente & Tempo (min.) \\
\hline 16 & 04,36 & 36 & 04,30 \\
\hline 13 & 04,60 & 33 & 03,40 \\
\hline 11 & 05,02 & 31 & 02,58 \\
\hline 21 & 11,36 & 41 & 04,50 \\
\hline 23 & 04,37 & 43 & 03,44 \\
\hline 26 & 07,04 & 46 & 04,53 \\
\hline total & $\mathbf{3 6 , 7 5}$ & total & $\mathbf{2 2 , 7 5}$ \\
\hline
\end{tabular}

Quadro E.6 - Duração (em minutos) do registro de inspeção e identificação para o Operador 2. 


\begin{tabular}{|c|c|c|c|}
\hline \multicolumn{5}{|c|}{ Operador 3 } \\
\hline Dente & Tempo (min.) & Dente & Tempo (min.) \\
\hline 16 & 06,52 & 36 & 04,36 \\
\hline 13 & 06,47 & 33 & 06,29 \\
\hline 11 & 04,53 & 31 & 08,24 \\
\hline 21 & 05,10 & 41 & 03,43 \\
\hline 23 & 04,28 & 43 & 03,58 \\
\hline 26 & 07,32 & 46 & 06,18 \\
\hline total & $\mathbf{3 4 , 2 2}$ & total & $\mathbf{3 2 , 0 8}$ \\
\hline
\end{tabular}

Quadro E.7 - Duração (em minutos) do registro de inspeção e identificação para o Operador 3.

\begin{tabular}{|c|c|c|c|}
\hline \multicolumn{5}{|c|}{ Operador 4 } \\
\hline Dente & Tempo (min.) & Dente & Tempo (min.) \\
\hline 16 & 05,23 & 36 & 05,27 \\
\hline 13 & 05,46 & 33 & 05,00 \\
\hline 11 & 05,05 & 31 & 04,14 \\
\hline 21 & 05,00 & 41 & 03,53 \\
\hline 23 & 06,11 & 43 & 04,45 \\
\hline 26 & 05,18 & 46 & 07,43 \\
\hline total & $\mathbf{3 2 , 0 3}$ & total & $\mathbf{2 9 , 8 2}$ \\
\hline
\end{tabular}

Quadro E.8 - Duração (em minutos) do registro de inspeção e identificação para o Operador 4.

\begin{tabular}{|c|c|c|c|}
\hline \multicolumn{5}{|c|}{ Operador 5 } \\
\hline Dente & Tempo (min.) & Dente & Tempo (min.) \\
\hline 16 & 01,37 & 36 & 03,58 \\
\hline 13 & 05,20 & 33 & 03,14 \\
\hline 11 & 04,15 & 31 & 03,39 \\
\hline 21 & 04,13 & 41 & 04,46 \\
\hline 23 & 04,45 & 43 & 04,00 \\
\hline 26 & 03,46 & 46 & 04,18 \\
\hline total & $\mathbf{2 2 , 7 6}$ & total & $\mathbf{2 2 , 7 5}$ \\
\hline
\end{tabular}

Quadro E.9 - Duração (em minutos) do registro de inspeção e identificação para o Operador 5. 


\begin{tabular}{|c|c|c|c|}
\hline \multicolumn{5}{|c|}{ Operador 6 } \\
\hline Dente & Tempo (min.) & Dente & Tempo (min.) \\
\hline 16 & 05,04 & 36 & 06,11 \\
\hline 13 & 04,33 & 33 & 03,59 \\
\hline 11 & 03,17 & 31 & 04,12 \\
\hline 21 & 07,37 & 41 & 06,56 \\
\hline 23 & 05,20 & 43 & 04,30 \\
\hline 26 & 05,09 & 46 & 05,06 \\
\hline total & $\mathbf{3 0 , 2 0}$ & total & $\mathbf{2 9 , 7 4}$ \\
\hline
\end{tabular}

Quadro E.10 - Duração (em minutos) do registro de inspeção e identificação para o Operador 6.

\section{Descrição}

a) A média de duração da sequência operacional (para o registro tomográfico), na maxila, foi de 31,23 minutos;

b) A média de duração da sequência operacional (para o registro tomográfico), na mandíbula, foi de 24,33 minutos;

c) O dente maxilar avaliado com maior tempo de registro foi o incisivo central superior esquerdo (21), com 11,36 min.;

d) $\mathrm{O}$ dente mandibular avaliado com maior tempo de registro foi o incisivo central inferior esquerdo (31), com 08,24 min.;

e) Para a maxila, a maior média de duração registrada foi para o dente 21 (7,17 min.), e a menor, para o dente 23 (5,08 $\mathrm{min}$.);

f) Para a mandíbula, a maior média de duração registrada foi para o dente 46 (5,01 min.), e a menor, para o dente 41 (3,45 min.). 
6- Não foram constatadas inconsistências operacionais durante a realização dos testes, nem tampouco observadas situações de incerteza considerada atípica quanto ao reconhecimento anatômico das estruturas de interesse;

7- Foram observados, pelo Op.0 (principal), modos de interpretação tomográfica distintos a partir de comentários pessoais dos demais operadores durante a realização das inspeções e demarcações (identificação tomográfica propriamente dita) das referências anatômicas sobre as imagens de TCFC. Considerando os seis operadores selecionados, foram registradas oito (08) ocorrências de dúvida associadas ao procedimento de inspeção. Destas, seis (06) foram dúvidas gerais, associadas aos padrões de sequência operacional e lembretes da instrução prévia; e duas (02) foram relacionadas à noção da qualidade de alguns limites anatômicos tomográficos. Para todas as ocorrências, a participação do operador principal foi a de propiciar eventual esclarecimento imediato acerca da condição de incerteza, porém com isenção de influência quanto à qualidade de demarcação (identificação) final. Percebeu-se, em alguns desses casos, que a incerteza alegada parecia ter persistido. Entretanto, nesses casos, não houve revisão do procedimento, a não ser quando o operador solicitava explicitamente a revisão da identificação do ponto em questão. Quando essa ocorria, então todos os comandos de automação preliminares, e sob responsabilidade do operador principal, eram repetidos possibilitando ao operador (externo) nova tentativa de demarcação. Com isso, foi registrada média de cinco (05) solicitações de revisão de identificação por operador, a partir das quais os respectivos operadores acabaram por definir certeza final de identificação. Não foram registradas dúvidas adicionais e relativas à qualidade específica do método de registro e medição aplicado. 
APÊNDICE F - Declaração do pesquisador

Além da propriedade intelectual associada ao método desenvolvido em todas as suas características estruturais e funcionais de aplicabilidade, declaro, para as finalidades éticas e legais, que não houve e não há quaisquer vínculos de interesse econômico associados aos materiais utilizados neste experimento.

O software AutoCAD ${ }^{\circledR}$ foi adquirido com licença (compartilhada), e o Viewer (AutoCAD $W S^{\circledR}-$ Machintosh $^{\circledR}$ ) com licença própria (Siddhartha US).

O custo financeiro do registro tomográfico utilizado foi pago pelo próprio pesquisador.

À exceção da licença compartilhada do software AutoCAD ${ }^{\circledR}$, não foram doados nem emprestados materiais os quais pudessem ter sido utilizados nesta pesquisa.

Portanto, e embora haja a intenção, a partir das informações obtidas com a presente investigação e considerando o método proposto, de desenvolvimento, pelo autor deste trabalho, de software específico de aplicação científica (metrologia aplicada à tomografia computadorizada), este experimento foi desenvolvido de modo comercialmente independente e com finalidade estritamente científica. 
ANEXO A - VIM Definições

À exceção das ocasiões em que foi indicado no texto, todos os grifos são originais do autor, e não nossos.

\section{$1.3(1.2)$}

\section{sistema de grandezas}

\section{system of quantities \\ système de grandeurs \\ sistema de magnitudes}

Conjunto de grandezas associado a um conjunto de relações não contraditórias entre estas grandezas.

NOTA Grandezas ordinais, tais como dureza Rockwell C, geralmente não são consideradas como pertencentes a um sistema de grandezas porque estão relacionadas a outras grandezas somente através de relações empíricas.

\section{$1.16(1.12)$}

\section{Sistema Internacional de Unidades}

SI

International System of Units ; SI Système international d'unités ; SI

Sistema internacional de Unidades ; Sistema SI ; SI

Sistema de unidades, baseado no Sistema Internacional de Grandezas, incluindo os nomes e os símbolos das unidades e uma série de prefixos com seus nomes e símbolos, em conjunto com regras de utilização, adotado pela Conferência Geral de Pesos e Medidas (CGPM).

NOTA $10 \mathrm{SI}$ é baseado nas sete grandezas de base do ISQ. Os nomes e os símbolos das unidades de base estão contidos no quadro abaixo.

\begin{tabular}{|l|l|c|}
\hline \multicolumn{1}{|c|}{ Grandeza de base } & \multicolumn{2}{c|}{ Unidade de base } \\
\hline \multicolumn{1}{|c|}{ Nome } & Nome & Símbolo \\
\hline comprimento & metro & $\mathrm{m}$ \\
\hline massa & quilograma & $\mathrm{kg}$ \\
\hline tempo & segundo & $\mathrm{s}$ \\
\hline corrente elétrica & ampere & $\mathrm{A}$ \\
\hline temperatura termodinâmica & kelvin & $\mathrm{K}$ \\
\hline quantidade de substância & mol & $\mathrm{mol}$ \\
\hline intensidade luminosa & candela & $\mathrm{cd}$ \\
\hline
\end{tabular}


NOTA 2 As unidades de base e as unidades derivadas coerentes do SI formam um conjunto coerente, denominado "conjunto de unidades SI coerentes".

NOTA 3 Para uma descrição e uma explicação completas do Sistema Internacional de Unidades, ver a edição corrente do documento do SI publicado pelo Bureau International des Poids et Mesures (BIPM), disponível na página da internet do BIPM.

NOTA 4 Quando da álgebra das grandezas, a grandeza "número de entidades" é frequentemente considerada uma grandeza de base com a unidade de base igual a um, símbolo 1.

NOTA 5 Os prefixos SI para os múltiplos e submúltiplos das unidades são:

\begin{tabular}{|c|c|c|}
\hline \multirow{2}{*}{ Fator } & \multicolumn{2}{|c|}{ Prefixo } \\
\cline { 2 - 3 } & Nome & Símbolo \\
\hline $10^{24}$ & yotta & $\mathrm{Y}$ \\
\hline $10^{21}$ & zetta & $\mathrm{Z}$ \\
\hline $10^{18}$ & exa & $\mathrm{E}$ \\
\hline $10^{15}$ & peta & $\mathrm{P}$ \\
\hline $10^{12}$ & tera & $\mathrm{T}$ \\
\hline $10^{9}$ & giga & $\mathrm{G}$ \\
\hline $10^{6}$ & mega & $\mathrm{M}$ \\
\hline $10^{3}$ & quilo & $\mathrm{k}$ \\
\hline $10^{2}$ & hecto & $\mathrm{h}$ \\
\hline $10^{1}$ & deca & $\mathrm{da}$ \\
\hline $10^{-1}$ & deci & $\mathrm{d}$ \\
\hline $10^{-2}$ & centi & $\mathrm{C}$ \\
\hline $10^{-3}$ & mili & $\mathrm{m}$ \\
\hline $10^{-6}$ & micro & \\
\hline $10^{-9}$ & nano & $\mathrm{n}$ \\
\hline $10^{-12}$ & pico & $\mathrm{p}$ \\
\hline $10^{-15}$ & femto & $\mathrm{f}$ \\
\hline $10^{-18}$ & atto & $\mathrm{a}$ \\
\hline $10^{-21}$ & zepto & $\mathrm{z}$ \\
\hline $10^{-24}$ & yocto & $\mathrm{y}$ \\
\hline
\end{tabular}

$1.18(1.17)$

submúltiplo de uma unidade

submultiple of a unit sous-multiple d'une unité submúltiplo de una unidad

Unidade de medida obtida pela divisão de uma dada unidade de medida por um inteiro maior que um. 
EXEMPLO 10 milímetro é um submúltiplo decimal do metro.

EXEMPLO 2 Para um ângulo plano, o segundo é um submúltiplo não-decimal do minuto.

NOTA Os prefixos do SI para submúltiplos decimais das unidades de base e das unidades derivadas do SI são dados na Nota 5 de 1.16.

\author{
$1.19(1.18)$ \\ valor de uma grandeza \\ valor \\ quantity value; value of a quantity value \\ valeur d'une grandeur ; valeur \\ valor de una magnitud ; valor
}

Conjunto, formado por um número e por uma referência, que constitui a expressão quantitativa de uma grandeza.

EXEMPLO 1 Comprimento de uma determinada haste: $5,34 \mathrm{~m}$ ou $534 \mathrm{~cm}$

1.30

propriedade qualitativa

nominal property; propriété qualitative; attribut; propiedad cualitativa; cualidad

Propriedade de um fenômeno, corpo ou substância, a qual não pode ser expressa quantitativamente.

EXEMPLO 1 Sexo de um ser humano.

EXEMPLO 2 Cor de uma amostra de tinta.

EXEMPLO 3 Cor de "spot test" em química. EXEMPLO 4 Código ISO de país com duas letras.

EXEMPLO 5 Sequência de aminoácidos em um polipeptídeo.

NOTA 1 Uma propriedade qualitativa tem um valor que pode ser expresso em palavras, por meio de códigos alfanuméricos ou por outros meios.

NOTA 2 O valor de uma propriedade qualitativa não deve ser confundido com o valor nominal de uma grandeza.

\title{
2 Medição
}

$2.1(2.1)$

medição

measurement mesurage; mesure medición; medida 
Processo de obtenção experimental de um ou mais valores que podem ser, razoavelmente, atribuídos a uma grandeza.

NOTA 1 A medição não se aplica a propriedades qualitativas.

NOTA 2 A medição implica na comparação de grandezas e engloba contagem de entidades.

NOTA 3 A medição pressupõe uma descrição da grandeza que seja compatível com o uso pretendido de um resultado de medição, de um procedimento de medição e de um sistema de medição calibrado que opera de acordo com um procedimento de medição especificado, incluindo as condições de medição.

\section{$2.2(2.2)$}

metrologia

metrology; métrologie; metrología

Ciência da medição e suas aplicações.

NOTA A metrologia engloba todos os aspectos teóricos e práticos da medição, qualquer que seja a incerteza de medição e o campo de aplicação.

\section{$2.3(2.6)$}

mensurando

measurand; mesurande; mensurando

Grandeza que se pretende medir.

NOTA 1 A especificação de um mensurando requer o conhecimento do tipo de grandeza, a descrição do estado do fenômeno, do corpo ou da substância da qual a grandeza é uma propriedade, incluindo qualquer componente relevante e as entidades químicas envolvidas.

NOTA $2 \mathrm{Na} 2^{a}$ edição brasileira do VIM, o mensurando é definido como a "grandeza específica submetida à medição" e na IEC 60050-300:2001 é definido como a "grandeza submetida à medição".

NOTA 3 A medição, incluindo o sistema de medição e as condições sob as quais ela é realizada, pode modificar o fenômeno, o corpo ou a substância, de modo que a grandeza que está sendo medida pode diferir do mensurando como ele foi definido. Neste caso, é necessária uma correção adequada.

\section{EXEMPLO 1}

A diferença de potencial entre os terminais de uma bateria pode diminuir quando na realização da medição é utilizado um voltímetro com uma condutância interna significativa. A diferença de potencial em circuito aberto pode ser calculada a partir das resistências internas da bateria e do voltímetro.

\section{EXEMPLO 2}


O comprimento de uma haste de aço em equilíbrio com a temperatura ambiente de $23 \mathrm{C}$ será diferente do comprimento à temperatura especificada de $20 \mathrm{C}$. Neste caso, é necessária uma correção.

NOTA 4 Em química, "analito", ou o nome de uma substância ou de um composto, são termos utilizados algumas vezes para "mensurando". Tal uso é incorreto porque esses termos não se referem a grandezas.

\section{$2.4(2.3)$}

\section{princípio de medição}

measurement principle; principle of measurement; principe de mesure principio de medida

Fenômeno que serve como base para uma medição.

\section{EXEMPLO 1}

Efeito termoelétrico aplicado à medição de temperatura.

\section{EXEMPLO 2}

Absorção de energia aplicada à medição da concentração em quantidade de substância.

\section{EXEMPLO 3}

Redução da concentração de glicose no sangue de um coelho em jejum aplicada à medição da concentração de insulina em uma preparação.

NOTA O fenômeno pode ser de natureza física, química ou biológica.

$2.5(2.4)$

\section{método de medição}

measurement method; method of measurement; méthode de mesure método de medida

Descrição genérica da organização lógica de operações utilizadas na realização de uma medição.

NOTA Métodos de medição podem ser qualificados de vários modos, como:

- método de medição por substituição;

- método de medição diferencial, e

- método de medição "de zero";

ou

- método de medição direto, $\mathrm{e}$

- método de medição

indireto. Ver IEC 60050-

300:2001. 
$2.6(2.5)$

procedimento de medição

measurement procedure; procédure de mesure; procédure opératoire; procedimiento de medida

Descrição detalhada de uma medição de acordo com um ou mais princípios de medição e com um dado método de medição, baseada em um modelo de medição e incluindo todo cálculo destinado

à obtenção de um resultado de medição.

NOTA 1 Um procedimento de medição é geralmente documentado em detalhes suficientes para permitir que um operador realize uma medição.

NOTA 2 Um procedimento de medição pode incluir uma declaração referente à incerteza alvo.

NOTA 3 Um procedimento de medição é algumas vezes chamado em inglês standard operating procedure, abreviado como SOP. O termo usado em português é "procedimento operacional padrão", abreviado como POP. (grifo nosso)

\section{7}

procedimento de medição de referência

reference measurement procedure; procédure de mesure de référence; procédure opératoire de référence; procedimiento de medida de referencia

Procedimento de medição considerado capaz de fornecer resultados de medição adequados para a avaliação da veracidade de valores medidos obtidos a partir de outros procedimentos de medição para grandezas de mesmo tipo, em calibração ou em caracterização de materiais de referência.

\section{8}

procedimento de medição primário

procedimento de referência primário ; procedimento de medição de referência primário

primary reference measurement procedure; primary reference procedure procédure de mesure primaire; procédure opératoire primaire procedimiento de medida primario; procedimiento primario

Procedimento de medição de referência utilizado para obter um resultado de medição sem relação com um padrão de uma grandeza de mesmo tipo.

EXEMPLO O volume de água de uma pipeta de $5 \mathrm{ml}$ a $20 \mathrm{C}$ é medido através da pesagem da água vertida da pipeta em um béquer, levando-se em conta a massa total do béquer e da água menos a massa do béquer vazio, corrigindo-se a diferença de massa para a temperatura real da água, por intermédio da massa específica.

NOTA 1 O Comitê Consultivo de Quantidade de Substância - Metrologia em Química (CCQM) utiliza para este conceito o termo "método de medição primário". 


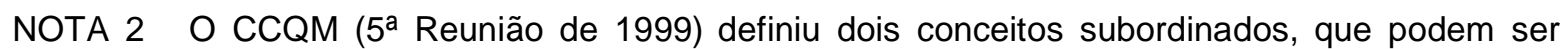
denominados "procedimento de medição primário direto" e "procedimento de medição primário de razão".

$2.9(3.1)$

resultado de medição

measurement result; result of measurement résultat de mesure; résultat d'un mesurage resultado de medida; resultado de una medición

Conjunto de valores atribuídos a um mensurando, completado por todas as outras informações pertinentes disponíveis.

NOTA 1 Um resultado de medição geralmente contém "informação pertinente" sobre o conjunto de valores, alguns dos quais podem ser mais representativos do mensurando do que outros. Isto pode ser expresso na forma de uma função de densidade de probabilidade (FDP).

NOTA 2 Um resultado de medição é geralmente expresso por um único valor medido e uma incerteza de medição. Caso a incerteza de medição seja considerada desprezível para alguma finalidade, o resultado de medição pode ser expresso como um único valor medido. Em muitas áreas, esta é a maneira mais comum de expressar um resultado de medição.

NOTA 3 Na literatura tradicional e na edição brasileira anterior do VIM, o resultado de medição era definido como um valor atribuído a um mensurando obtido por medição, que poderia ser representado por uma indicação, ou um resultado não corrigido, ou um resultado corrigido, de acordo com o contexto.

\subsection{0}

\section{valor medido}

measured quantity value; measured value of a quantity measured value; valeur mesurée; valor medido de una magnitud; valor medido

Valor de uma grandeza que representa um resultado de medição.

NOTA 1 Para uma medição envolvendo indicações repetidas, cada indicação pode ser utilizada para fornecer um valor medido correspondente. Este conjunto de valores medidos individuais pode ser utilizado para calcular um valor medido resultante, como uma média ou uma mediana, geralmente com uma menor incerteza de medição associada.

NOTA 2 Quando o intervalo de valores verdadeiros tidos como representativos do mensurando é pequena em relação à incerteza de medição, um valor medido pode ser considerado uma estimativa de um valor verdadeiro essencialmente único, sendo frequentemente uma média ou uma mediana de valores medidos individuais, obtidos através de medições repetidas.

NOTA 3 Nos casos em que o intervalo dos valores verdadeiros, tidos como representativos do mensurando, não é pequena em relação à incerteza de medição, um valor medido é 
frequentemente uma estimativa de uma média ou de uma mediana do conjunto de valores verdadeiros.

NOTA 4 No GUM, os termos "resultado de medição" e "estimativa do valor do mensurando" ou apenas "estimativa do mensurando" são utilizados para "valor medido".

\section{$2.11(1.19)$}

valor verdadeiro

valor verdadeiro de uma grandeza

true quantity value; true value of a quantity; true value; valeur vraie; valeur vraie d'une grandeur; valor verdadero de una magnitud; valor verdadero

Valor de uma grandeza compatível com a definição da grandeza.

NOTA $1 \mathrm{Na}$ Abordagem de Erro para descrever as medições, o valor verdadeiro é considerado único e, na prática, impossível de ser conhecido. A Abordagem de Incerteza consiste no reconhecimento de que, devido à quantidade intrinsecamente incompleta de detalhes na definição de uma grandeza, não existe um valor verdadeiro único, mas um conjunto de valores verdadeiros consistentes com a definição. Entretanto, este conjunto de valores é, em princípio e na prática, impossível de ser conhecido. Outras abordagens evitam completamente o conceito de valor verdadeiro e avaliam a validade dos resultados de medição com auxílio do conceito de compatibilidade metrológica.

NOTA 2 No caso particular de uma constante fundamental, considera-se que a grandeza tenha um valor verdadeiro único.

NOTA 3 Quando a incerteza definicional, associada ao mensurando, é considerada desprezível em comparação com os outros componentes da incerteza de medição, pode-se considerar que o mensurando possui um valor verdadeiro "essencialmente único". Esta é a abordagem adotada pelo GUM e documentos associados, onde a palavra "verdadeiro" é considerada redundante.

\subsection{2}

valor convencional

valor convencional de uma grandeza

conventional quantity value; conventional value of a quantity; conventional value; valeur conventionnelle; valeur conventionnelle d'une grandeur; valor convencional de una magnitud; valor convencional

Valor atribuído a uma grandeza por um acordo, para um dado propósito.

NOTA 10 termo "valor verdadeiro convencional" é algumas vezes utilizado para este conceito, porém seu uso é desaconselhado.

NOTA 2 Um valor convencional é algumas vezes uma estimativa de um valor verdadeiro.

NOTA 3 Geralmente considera-se que um valor convencional está associado a uma incerteza de medição convenientemente baixa, que pode ser nula.

EXEMPLO 1 Valor convencional da aceleração da gravidade, $g_{\mathrm{n}}=9,80665 \mathrm{~m} \cdot \mathrm{s}^{2}$ 
$2.13(3.5)$

\section{exatidão de medição}

exatidão ; acurácia

measurement accuracy; accuracy of measurement; accuracy; exactitude de mesure; exactitude; exactitud de medida; exactitud

Grau de concordância entre um valor medido e um valor verdadeiro de um mensurando.

NOTA 1 A "exatidão de medição" não é uma grandeza e não the é atribuído um valor numérico. Uma medição é dita mais exata quando é caracterizada por um erro de medição menor.

NOTA 2 O termo "exatidão de medição" não deve ser utilizado no lugar de veracidade, assim como o termo precisão de medição não deve ser utilizado para expressar "exatidão de medição", o qual, entretanto, está relacionado a ambos os conceitos.

NOTA 3 A "exatidão de medição" é algumas vezes entendida como o grau de concordância entre valores medidos que são atribuídos ao mensurando.

\subsection{4}

veracidade

veracidade de medição

measurement trueness; trueness of measurement; trueness; justesse de mesure; justesse; veracidad de medida; veracidad

Grau de concordância entre a média de um número infinito de valores medidos repetidos e um valor de referência.

NOTA 1 A veracidade não é uma grandeza e, portanto, não pode ser expressa numericamente. Porém, a norma ISO 5725 apresenta medidas para o grau de concordância.

NOTA 2 A veracidade está inversamente relacionada ao erro sistemático, porém não está relacionada ao erro aleatório.

NOTA 3 Não se deve utilizar o termo exatidão de medição no lugar de "veracidade" e vice-versa.

\subsection{5}

precisão de medição

precisão ; fidelidade

measurement precision; precision fidélité de mesure; fidélité precisión de medida; precisión

Grau de concordância entre indicações ou valores medidos, obtidos por medições repetidas, no mesmo objeto ou em objetos similares, sob condições especificadas. 
NOTA $1 \mathrm{~A}$ precisão de medição é geralmente expressa numericamente por indicadores de incerteza tais como: dispersão, desvio-padrão, variância ou coeficiente de variação, sob condições de medição especificadas.

NOTA 2 As "condições especificadas" podem ser, por exemplo, condições de repetitividade, condições de precisão intermediária ou condições de reprodutibilidade (ver ISO 5725-3: 1994).

NOTA 3 A precisão de medição é utilizada para definir a repetitividade de medição, a precisão intermediária de medição e a reprodutibilidade de medição.

NOTA 4 O termo "precisão de medição" é algumas vezes utilizado, erroneamente, para designar a exatidão de medição.

$2.16(3.10)$

erro de medição

erro

measurement error; error of measurement; error; erreur de mesure; erreur; error de medida; error

Diferença entre o valor medido de uma grandeza e um valor de referência.

NOTA 1 O conceito de "erro de medição" pode ser utilizado:

a) quando existe um único valor de referência, o que ocorre se uma calibração for realizada por meio de um padrão com um valor medido cuja incerteza de medição é desprezível, ou se um valor convencional for fornecido. Nestes casos, o erro de medição é conhecido.

b) caso se suponha que um mensurando é representado por um único valor verdadeiro ou um conjunto de valores verdadeiros de amplitude desprezível. Neste caso, o erro de medição é desconhecido.

NOTA 2 Não se deve confundir erro de medição com erro de produção ou erro humano.

\section{$2.17(3.14)$}

erro sistemático

systematic measurement error; systematic error of measurement; systematic error; erreur systématique; error sistemático de medida; error sistemático

Componente do erro de medição que, em medições repetidas, permanece constante ou varia de maneira previsível.

NOTA 1 Um valor de referência para um erro sistemático é um valor verdadeiro, ou um valor medido de um padrão com incerteza de medição desprezível, ou um valor convencional.

NOTA 2 O erro sistemático e suas causas podem ser conhecidos ou desconhecidos. Pode-se aplicar uma correção para compensar um erro sistemático conhecido.

NOTA 3 O erro sistemático é igual à diferença entre o erro de medição e o erro aleatório. 


\subsection{8 tendência}

measurement bias; bias; biais de mesure; biais; erreur de justesse; sesgo de medida; sesgo

Estimativa de um erro sistemático.

$2.19(3.13)$

erro aleatório

random measurement error; random error of measurement; random error; erreur aléatoire; error aleatorio de medida; error aleatorio

Componente do erro de medição que, em medições repetidas, varia de maneira imprevisível.

NOTA 1 O valor de referência para um erro aleatório é a média que resultaria de um número infinito de medições repetidas do mesmo mensurando.

NOTA 2 Os erros aleatórios de um conjunto de medições repetidas formam uma distribuição que pode ser resumida por sua esperança matemática ou valor esperado, o qual é geralmente assumido como sendo zero, e por sua variância.

NOTA 3 O erro aleatório é igual à diferença entre o erro de medição e o erro sistemático.

\section{$2.20(3.6$, NOTAS 1 e 2$)$}

condição de repetitividade

repeatability condition of measurement; repeatability condition; condition de répétabilité; condición de repetibilidad de una medición; condición de repetibilidad

Condição de medição num conjunto de condições, as quais compreendem o mesmo procedimento de medição, os mesmos operadores, o mesmo sistema de medição, as mesmas condições de operação e o mesmo local, assim como medições repetidas no mesmo objeto ou em objetos similares durante um curto período de tempo.

NOTA 1 Uma condição de medição é uma condição de repetitividade apenas com respeito a um conjunto especificado de condições de repetitividade.

NOTA 2 Em química, o termo "condição de precisão intrasserial" é algumas vezes utilizado para designar este conceito.

$2.21(3.6)$

repetitividade de medição

repetitividade; measurement repeatability; repeatability répétabilité de mesure; répétabilité repetibilidad de medida; repetibilidad 
Precisão de medição sob um conjunto de condições de repetitividade.

\subsection{2}

condição de precisão intermediária

condição de fidelidade intermediária

intermediate precision condition of measurement; intermediate precision condition; condition de fidélité intermédiaire

condición de precisión intermedia de una medición; condición de precisión intermedia

Condição de medição num conjunto de condições, as quais compreendem o mesmo procedimento de medição, o mesmo local e medições repetidas no mesmo objeto ou em objetos similares, ao longo de um período extenso de tempo, mas pode incluir outras condições que envolvam mudanças.

NOTA 1 As condições que podem variar compreendem novas calibrações, padrões, operadores e sistemas de medição.

NOTA 2 É conveniente que uma especificação referente às condições contenha, na medida do possível, as condições que mudaram e aquelas que não.

NOTA 3 Em química, o termo "condição de precisão interserial" é algumas vezes utilizado para designar este conceito.

\subsection{3}

precisão intermediária de medição

precisão intermediária; fidelidade intermediária intermediate measurement precision; intermediate precision fidélité intermédiaire de mesure; fidélité intermédiaire precisión intermedia de medida; precisión intermedia

Precisão de medição sob um conjunto de condições de precisão intermediária.

NOTA Os termos estatísticos pertinentes são apresentados na ISO 5725-3: 1994.

\subsection{4 (3.7, Nota 2)}

condição de reprodutibilidade

reproducibility condition of measurement; reproducibility condition; condition de reproductibilité; condición de reproducibilidad de una medición; condición de reproducibilidad

Condição de medição num conjunto de condições, as quais compreendem diferentes locais, diferentes operadores, diferentes sistemas de medição e medições repetidas no mesmo objeto ou em objetos similares.

NOTA 1 Os diferentes sistemas de medição podem utilizar procedimentos de medição diferentes. 
NOTA $2 \mathrm{Na}$ medida do possível, é conveniente que sejam especificadas as condições que mudaram

e aquelas que não.

\section{$2.25(3.7)$}

reprodutibilidade de medição

reprodutibilidade; measurement reproducibility; reproducibility reproductibilité de mesure; reproductibilité reproducibilidad de medida; reproducibilidad

Precisão de medição conforme um conjunto de condições de reprodutibilidade.

NOTA Os termos estatísticos pertinentes são apresentados na ISO 5725-1:1994 e na ISO 57252:1994.

$2.26(3.9)$

incerteza de medição

incerteza

measurement uncertainty; uncertainty measurement; uncertainty; incertitude de mesure; incertitude; incertidumbre de medida; incertidumbre

Parâmetro não negativo que caracteriza a dispersão dos valores atribuídos a um mensurando, com base nas informações utilizadas.

NOTA 1 A incerteza de medição compreende componentes provenientes de efeitos sistemáticos, tais como componentes associadas a correções e valores atribuídos a padrões, assim como a incerteza definicional. Algumas vezes não são corrigidos efeitos sistemáticos estimados; em vez disso são incorporadas componentes de incerteza de medição associadas.

NOTA 2 O parâmetro pode ser, por exemplo, um desvio padrão denominado incerteza padrão (ou um de seus múltiplos) ou a metade de um intervalo tendo uma probabilidade de abrangência determinada.

NOTA 3 A incerteza de medição geralmente engloba muitas componentes. Algumas delas podem ser estimadas por uma avaliação do Tipo A da incerteza de medição, a partir da distribuição estatística dos valores provenientes de séries de medições e podem ser caracterizadas por desvios-padrão. As outras componentes, as quais podem ser estimadas por uma avaliação do Tipo B da incerteza de medição, podem também ser caracterizadas por desvios padrão estimados a partir de funções de densidade de probabilidade baseadas na experiência ou em outras informações.

NOTA 4 Geralmente para um dado conjunto de informações, subentende-se que a incerteza de medição está associada a um determinado valor atribuído ao mensurando. Uma modificação deste valor resulta numa modificação da incerteza associada.

\subsection{7}

incerteza definicional 
definitional uncertainty incertitude définitionnelle; incertidumbre debida a la definición; incertidumbre intrínseca

Componente da incerteza de medição que resulta da quantidade finita de detalhes na definição de um mensurando.

NOTA 1 A incerteza definicional é a incerteza mínima que se pode obter, na prática, em qualquer medição de um dado mensurando.

NOTA 2 Qualquer modificação nos detalhes descritivos conduz a uma outra incerteza definicional.

NOTA 3 No Guia ISO/IEC 98-3:2008, D.3.4, e na IEC 60359 o conceito "incerteza definicional" é denominado "incerteza intrínseca".

\subsection{8}

avaliação do Tipo A da incerteza de medição avaliação do Tipo A

Type $A$ evaluation of measurement uncertainty; Type $A$ evaluation; évaluation de type $A$ de l'incertitude; évaluation de type A; evaluación tipo $A$ de la incertidumbre de medida; evaluación tipo $A$

Avaliação de uma componente da incerteza de medição por uma análise estatística dos valores medidos, obtidos sob condições definidas de medição.

NOTA 1 Para diversos tipos de condições de medição, ver condição de repetitividade, condição de precisão intermediária e condição de reprodutibilidade.

NOTA 2 Ver, por exemplo, o Guia ISO/IEC 98-3 para informações sobre análise estatística.

NOTA 3 Ver também o Guia ISO/IEC 98-3:2008, 2.3.2, a ISO 5725, a ISO 13528, a ISO/TS 21748 e a

ISO 21749.

2.29

avaliação do Tipo B da incerteza de medição

avaliação do Tipo B

Type $B$ evaluation of measurement uncertainty; Type $B$ evaluation; évaluation de type $B$ de l'incertitude; évaluation de type $B$; evaluación tipo $B$ de la incertidumbre de medida; evaluación tipo $B$

Avaliação de uma componente da incerteza de medição determinada por meios diferentes daquele adotado para a avaliação do Tipo $\mathbf{A}$ da incerteza de medição.

\section{EXEMPLOS:}

Avaliação baseada na informação:

-associada a valores publicados por autoridade competente,

-associada ao valor de um material de referência certificado, 
-obtida a partir de um certificado de calibração,

-relativa à deriva,

- obtida a partir da classe de exatidão de um instrumento de medição verificado,

-obtida a partir de limites baseados na experiência pessoal. NOTA Ver também o Guia ISO/IEC 98-3: 2008, 2.3.3.

\subsection{0}

incerteza padrão

standard measurement uncertainty; standard uncertainty of measurement; standard uncertainty; incertitude-type; incertidumbre típica de medida; incertidumbre estándar de medida; incertidumbre típica; incertidumbre estándar

Incerteza de medição expressa na forma de um desvio-padrão. 
Com base em parecer de relator, o Comitê de Ética em Pesquisa APROVOU ○ protocolo de pesquisa "Análise tomográfica quantilativa linear das espessuras ósseas dento alveolares com visłas ao diagnóstico em Ortodontia - Proposta de Méłodo", de responsabilidade do pesquisador Siddhartha Uhrigshardt Silva, sob orientação do Prof. Dr. Jorge Abrão.

Tendo em vista a legislação vigente, devem ser encaminhados a este Comitê relatórios anuais referentes ao andamento da pesquisa e ao término cópia do trabalho em "cd". Qualquer emenda do projeto original deve ser apresentada a este CEP para apreciação, de forma clara e sucinta, identificando a parte do protocolo a ser modificada e suas justificativas.

São Paulo, 13 de dezembro de 2011.

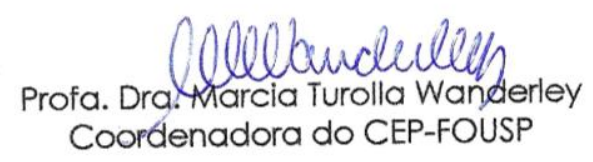

